\title{
Aldo Tonso
}

\section{MONITORAMENTO E OPERAÇÃo DE CULTIVOS DE}

\section{Células Animais em Sistemas de Perfusão}

Tese apresentada à Escola Politécnica da

Universidade de São Paulo para obtenção do título de Doutor em Engenharia

São Paulo

2000 


\section{Aldo Tonso}

\section{Monitoramento e Operação de Cultivos de}

\section{Células Animais em Sistemas de Perfusão}

Tese apresentada à Escola Politécnica da Universidade de São Paulo para obtenção do título de Doutor em Engenharia

Área de concentração:

Engenharia Química

Orientador:

Prof. Dr. Willibaldo Schmidell Netto

São Paulo

2000 


\section{FICHA CATALOGRÁFICA}

Tonso, Aldo

Monitoramento e operação de cultivos de células animais em sistemas de perfusão. São Paulo, 2000.

$109 p$.

Tese (Doutorado) - Escola Politécnica da Universidade de São Paulo. Departamento de Engenharia Química.

1. Processos fermentativos - Monitoramento 2. Células animais I. Universidade de São Paulo. Escola Politécnica. Departamento de Engenharia Química II. t. 
a três gerações:

mãe, esposa e bebê 


\section{AGRADECIMENTOS}

Sem dúvida, os anos nos quais esta tese foi realizada foram muito intensos. Na minha vida, muitas mudanças aconteceram, e queria agradecer por viver.

Agradeço antes de mais nada à minha mãe, tão presente durante toda minha vida como ainda é nos momentos importantes.

Pela concretização do trabalho, gostaria de agradecer:

- ao Willi, por sempre ser mais que o orientador, o amigo do trabalho que admiro

- ao Konstantin e Cary, pela oportunidade oferecida, e pelas excelentes discussões que tivemos durante mais de dois anos, que muito me serviram para amadurecer como profissional

- aos amigos da Bayer, que além de colaborarem com o trabalho, tornaram esse período mais agradável, em especial ao Achim, Rüdi, Eva e Reddy

Mas além dos que ajudaram diretamente, quero agradecer àqueles que fazem a vida feliz, e trazem assim prazer ao trabalho:

- a Carmen, razão de sorrir (ainda mais agora barriguda)

- a meu pai, que além de aprender a superar uma fase, é tão presente e carinhoso

- a meu irmão, que mesmo à distância sempre está por perto participando

- aos amigos do trabalho, que fazem o dia profissional valer a pena: Cândida, Beatriz, Elisete, D.Terezinha, Beth, Bonomi, Barral, os amigos do B20, além de Olivo e Andy, que mesmo não estando aqui estão presentes

- e a todos aqueles que gostam de dar um sorriso 


\section{ÍNDICE}

LISTA DE SÍMBOLOS …………………………………………………………… i

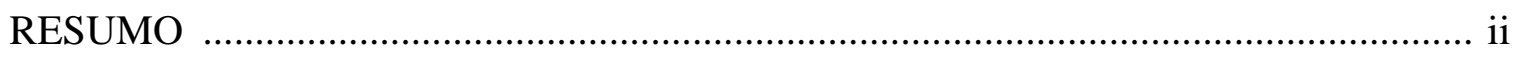

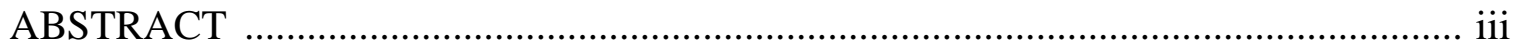

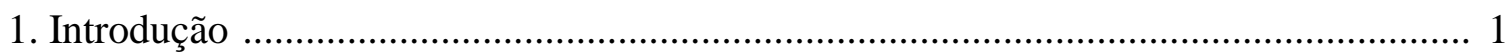

2. Revisão Bibliográfica ....................................................................................... 4

2.1 Cultura de células animais ................................................................................ 4

2.1.1 Diferenças biológicas e consequências para a engenharia ……………………….... 4

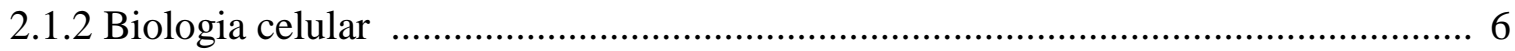

2.1.3 Vantagens de cultivos com células animais ............................................................ 7

2.2 Processos de cultivo ........................................................................................... 8

2.3 Sistemas de transferência de oxigênio .................................................................... 10

2.4 Monitoramento de processos fermentativos ……………..................................... 12

2.4.1 Concentração celular ................................................................................... 13

2.4.2 Oxigênio dissolvido ...................................................................................... 14

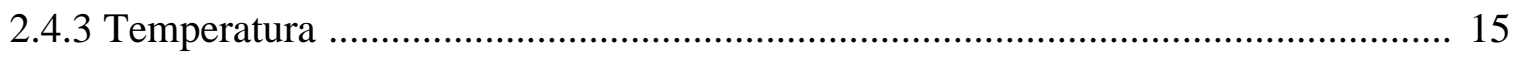

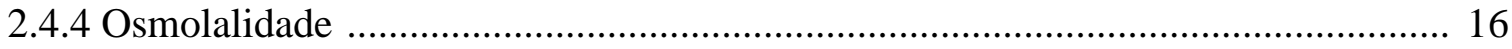

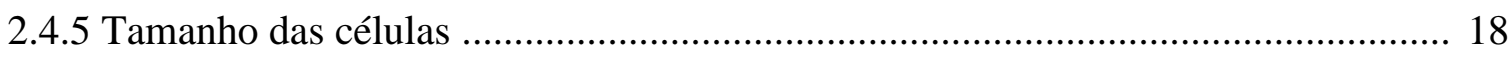

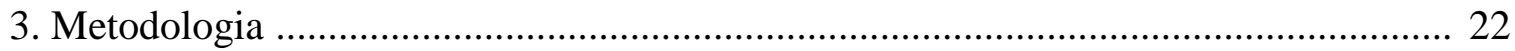

3.1 Meio de Cultura e Células Utilizadas ...................................................................... 22

3.2 Fermentador e Sistemas de Controle .............................................................. 24

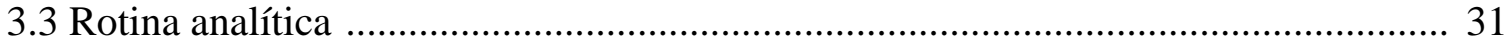

3.4 Distribuição de tamanho da célula e concentração celular via Lasentec FBRM ....... 38

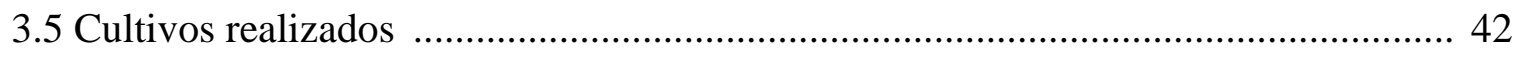

4. Resultados e Discussão ......................................................................................... 43

4.1 Processo de Perfusão .......................................................................................... 43

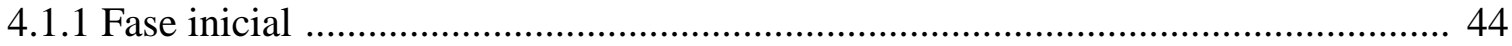

4.1.2 Fase em Perfusão ..................................................................................... 49

4.1.3 Variáveis de processo / Memorial de cálculo ......................................................... 55

4.2 Sistema de transferência de oxigênio por difusão em membrana de silicone ............ 57

4.2.1 Ensaio E3 - Influência de oxigênio dissolvido na produção de rFVIII por BHK ... 69

4.2.2 Ensaio E4 - Influência da temperatura na produção de rFVIII por BHK ............... 75 
4.3 Monitoramento do Processo - Osmolalidade em cultivos de células animais 84

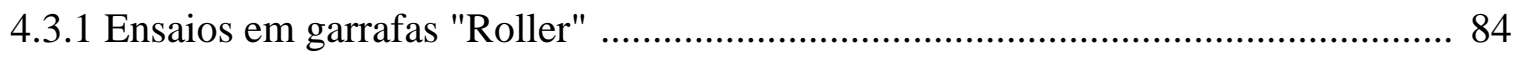

4.3.2 Ensaio E5 - Influência da osmolalidade na produção de anti-TNF por hibridoma 87

4.3.3 Ensaio E6 - Avaliação da sonda Lasentec ......................................................... 96

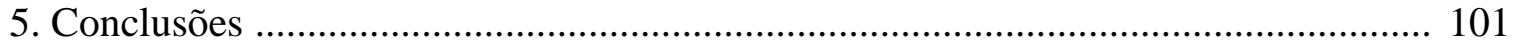

Referências Bibliográficas ........................................................................................ 104

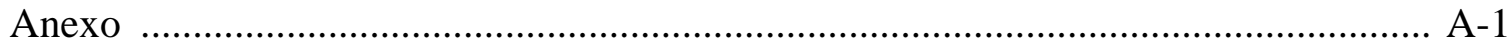




\section{LISTA DE SÍMBOLOS}

\begin{tabular}{|c|c|c|}
\hline abrev. & nome & unidade \\
\hline$\mu$ & velocidade específica de crescimento & $\mathrm{dia}^{-1}$ \\
\hline$\mu_{\text {Glic }}$ & velocidade específica de consumo de glicose & $\mathrm{pmol} / \mathrm{cel} / \mathrm{dia}$ \\
\hline$\mu_{\mathrm{Gln}}$ & velocidade específica de consumo de glutamina & $\mathrm{pmol} / \mathrm{cel} / \mathrm{dia}$ \\
\hline$\mu_{\mathrm{P}}$ & velocidade específica de produção & $\mu \mathrm{UA} / \mathrm{cel} / \mathrm{dia}$ \\
\hline biovol & biovolume das células & $\mu \mathrm{L} / \mathrm{mL}$ \\
\hline $\mathrm{D}$ & vazão específica de alimentação & $\mathrm{dia}^{-1}$ \\
\hline DO & densidade ótica & - \\
\hline Glic & concentração de glicose & $\mathrm{mM}$ \\
\hline Glic $_{\mathrm{a}}$ & concentração de glicose na alimentação & $\mathrm{mM}$ \\
\hline Gln & concentração de glutamina & $\mathrm{mM}$ \\
\hline $\operatorname{Gln}_{\mathrm{a}}$ & concentração de glutamina na alimentação & $\mathrm{mM}$ \\
\hline $\mathrm{i}$ & número da amostra & - \\
\hline $\mathrm{K}_{\mathrm{L}} \mathrm{a}$ & coeficiente de transferência de oxigênio & $h^{-1}$ \\
\hline OD & oxigênio dissolvido (\% da saturação com ar) & $\%$ \\
\hline OUR & velocidade de consumo de oxigênio & $\mathrm{mg} /(\mathrm{L} . \mathrm{h})$ \\
\hline $\mathrm{P}$ & concentração do produto (UA=unidades arbitrárias) & $\mathrm{UA} / \mathrm{mL}$ \\
\hline $\mathrm{p}_{\mathrm{CO} 2}$ & pressão parcial de $\mathrm{CO} 2$ na amostra & $\mathrm{mmHg}$ \\
\hline $\mathrm{P}_{\mathrm{e}}$ & pressão na entrada do tubo de silicone & atm \\
\hline $\mathrm{P}_{\mathrm{f}}$ & pressão na cabeça do biorreator & atm \\
\hline $\mathrm{pH}$ & $\mathrm{pH}$ & - \\
\hline $\mathrm{P}_{\mathrm{m}}$ & pressão média no tubo de silicone & atm \\
\hline $\mathrm{p}_{\mathrm{O} 2}$ & pressão parcial de $\mathrm{O} 2$ & $\mathrm{mmHg}$ \\
\hline $\mathrm{P}_{\mathrm{s}}$ & pressão na saída do tubo de silicone & atm \\
\hline $\mathrm{Q}_{\mathrm{B}}$ & vazão de base $(\mathrm{NaOH})$ & $\mathrm{L} / \mathrm{dia}$ \\
\hline $\mathrm{Q}_{\mathrm{e}}$ & vazão total de entrada no tubo de silicone & $\mathrm{L} / \mathrm{min}$ \\
\hline $\mathrm{Q}_{\mathrm{eAr}}$ & vazão de entrada de ar & $\mathrm{L} / \mathrm{min}$ \\
\hline $\mathrm{Q}_{\mathrm{eCO} 2}$ & vazão de entrada de gás carbônico & $\mathrm{L} / \mathrm{min}$ \\
\hline $\mathrm{Q}_{\mathrm{eN} 2}$ & vazão de entrada de nitrogênio & $\mathrm{L} / \mathrm{min}$ \\
\hline $\mathrm{Q}_{\mathrm{eO} 2}$ & vazão de entrada de oxigênio & $\mathrm{L} / \mathrm{min}$ \\
\hline $\mathrm{Q}_{\mathrm{L}}$ & vazão de líquidos & $\mathrm{L} / \mathrm{dia}$ \\
\hline $\mathrm{Q}_{\mathrm{O} 2}$ & velocidade específica de respiração & atm.mL/h \\
\hline $\mathrm{Q}_{\mathrm{P}}$ & vazão de retirada de produto & L/dia \\
\hline $\mathrm{Q}_{\mathrm{Pu}}$ & vazão de purga & $\mathrm{L} / \mathrm{dia}$ \\
\hline $\mathrm{Q}_{\mathrm{R}}$ & vazão de recirculação & $\mathrm{L} / \mathrm{dia}$ \\
\hline $\mathrm{T}$ & temperatura & ${ }^{\circ} \mathrm{C}$ \\
\hline $\mathrm{t}$ & tempo de cultivo & dia \\
\hline V & volume de reação & $\mathrm{L}$ \\
\hline VEP & velocidade específica de perfusão & $\mathrm{nL} / \mathrm{cel} / \mathrm{dia}$ \\
\hline viab & viabilidade (\% viáveis dividido por total) & $\%$ \\
\hline $\mathrm{X}$ & concentração celular (viáveis) & $\mathrm{E} 6 \mathrm{cel} / \mathrm{mL}$ \\
\hline $\mathrm{X}_{\mathrm{C}}$ & concentração celular total via Casy & $\mathrm{E} 6 \mathrm{cel} / \mathrm{mL}$ \\
\hline $\mathrm{X}_{\mathrm{L}}$ & contagem de cordas via Lasentec & - \\
\hline $\mathrm{X}_{\mathrm{P}}$ & concentração celular total no produto & $\mathrm{E} 6 \mathrm{cel} / \mathrm{mL}$ \\
\hline $\mathrm{X}_{\mathrm{ref}}$ & concentração celular total de referência & $\mathrm{E} 6 \mathrm{cel} / \mathrm{mL}$ \\
\hline$X_{t}$ & concentração celular total (viáveis + não-viáveis) & $\mathrm{E} 6 \mathrm{cel} / \mathrm{mL}$ \\
\hline
\end{tabular}




\section{RESUMO}

Os processos biotecnológicos com células animais tem despertado interesse crescente devido à sua capacidade de sintetizar moléculas complexas de altíssimo valor agregado, mesmo exigindo condições especiais de cultivo. Torna-se portanto fundamental o correto monitoramento de tais processos, para se manter seus parâmetros dentro de limites desejados.

O objetivo deste trabalho foi efetuar cultivos de células animais em processo de perfusão, aos quais se acoplavam sistemas de monitoramento visando melhor controle, de modo a contribuir para o aumento da produtividade.

Realizaram-se ensaios com células BHK e hibridoma em biorreator de $12 \mathrm{~L}$ em alta densidade celular (20E6 cel/mL), para produção de fator de coagulação FVIII e anticorpo anti-TNF. O processo de perfusão foi analisado, buscando-se melhoria em seu controle através da correta estimativa da concentração celular. O sistema de transferência de oxigênio através de membranas de silicone foi estudado, tendo-se elaborado uma simplificação para a estimativa da velocidade de consumo de oxigênio, baseando-a na pressão média da membrana de silicone, e tendo-se determinado a influência da concentração de oxigênio no crescimento e na produção e seu valor limitante (entre 5 e 10\%).

Por fim, estudou-se o efeito da osmolalidade do meio no processo, tanto com relação ao crescimento e consumo de substratos, como na produtividade. Observou-se o aumento do tamanho da célula com o aumento da osmolalidade (até $470 \mathrm{mmol} / \mathrm{kg}$ ) e como este fato influencia o cálculo da velocidade específica de produção. Tentou-se sem sucesso fazer um monitoramento "on-line" deste aumento de tamanho, com o uso da sonda Lasentec FBRM. No entanto esta se mostrou capaz de estimar a concentração celular.

O trabalho demonstra a importância de se efetuar um adequado monitoramento do processo para garantir a correta operação, em especial em cultivos com células animais em perfusão. 


\begin{abstract}
Animal cell culture technology has become apparent, due to its capacity to synthesize highly valuable complex molecules, even requiring special attention. In this scenario, adequate process monitoring becomes essential to keep its parameters well controlled.

The aim of this work is to perform perfusion cultures with animal cells, and couple them to monitoring systems, in order to improve the efficiency of the control and consequently productivity.

Runs were realized with BHK and hibridoma cells in a 12-L bioreactor at high cell density (20E6 cel/mL), to produce clotting factor FVIII and antibody anti-TNF. The perfusion process was analyzed, to enhance its control through reliable cell density estimate. Oxygen transfer system through silicone tubing was studied, resulting in a simple way to estimate oxygen uptake rate and establishing the influence of oxygen partial pressure in the growth and production.

At last, medium osmolality effect was investigated related to growth, substrate consumption, and productivity. Cell enlargement was observed at higher osmolalities (till $470 \mathrm{mmol} / \mathrm{kg}$ ) and its results over the specific production rate were analyzed. The cell size change was measured off-line. Lasentec FBRM probe could not follow the size change, but showed capable to estimate cell density

This work makes evident the importance in having adequate monitoring systems, in order to assure correct process operation, and specially cell culture perfusion processes.
\end{abstract}




\section{INTRODUÇÃO}

O presente trabalho foi desenvolvido experimentalmente no Laboratório de Desenvolvimento de Fermentações da Bayer Corp., Berkeley, Estados Unidos, na forma de um Doutorado Sanduíche. Deste fato resultam algumas peculiaridades que serão abordadas aqui na introdução, antes mesmo da definição dos objetivos específicos.

Usualmente tem-se empregado o termo doutorado sanduíche para denominar programas de doutoramento onde toda ou uma parcela da coleta de dados é realizada numa instituição que não aquela onde o candidato está inscrito. Cabe ressaltar que normalmente os doutoramentos sanduíche são realizados em conjunto com outra Universidade, porém, neste caso, a parte experimental foi realizada nos laboratórios de pesquisa de uma empresa.

O grupo transnacional Bayer, de origem alemã, é bem conhecido no mercado brasileiro, seja no segmento farmacêutico como no químico. Trata-se de uma empresa com faturamento anual superior a 32 bilhões de dólares, operando em 150 países com cerca de 144 mil empregados. Nos Estados Unidos a Bayer Corp. está presente em mais de 50 locais. Particularmente a unidade de Berkeley, na Califórnia, onde foram investidos mais de 100 milhões de dólares, é responsável pela produção de Kogenate, fator de coagulação VIII, para tratamento de hemofilia, cujas vendas em 1997 em todo mundo atingiram a marca de US\$ 330 milhões. Trata-se, para a Bayer americana, do seu primeiro produto biotecnológico, por empregar células geneticamente modificadas para a produção de uma proteína heteróloga. Kogenate é basicamente a única droga em produção no momento na planta de Berkeley, porém outras estão sendo desenvolvidas, ou em diferentes fases de avaliação na Food and Drug Administration (FDA) dos Estados Unidos. 
A unidade da Bayer em Berkeley é dividida em vários departamentos, além da parte administrativa e dos setores de garantia de qualidade e validação. O Departamento de Ciências de Processo é dividido em: Bioquímica, Biologia Celular e Molecular, Tecnologia de Processo e GMP (Good Manufacturing Process). Dentro do grupo de Tecnologia de Processo encontra-se o Laboratório de Desenvolvimento de Fermentações, com atuação destacada na pesquisa em fermentações com células animais e composto por cerca de 30 pesquisadores e técnicos. O Dr. Konstantin B. Konstantinov lidera este laboratório desde 1994, tendo também assumido a direção de Tecnologia de Processo em 1998. Ele se especializou ao longo de sua formação acadêmica em monitoramento e controle de processos fermentativos, tendo publicado amplamente na área ao longo dos últimos anos, inclusive após ingresso na Bayer.

A tecnologia de cultivo de células animais vem sendo utilizada há muito tempo, especialmente na produção de vacinas humanas e veterinárias, no entanto é mais recente seu emprego na indústria farmacêutica para a produção de proteínas terapêuticas, como é o caso da produção de ativador de plasminogênio tecidual (tPA) em tanques com 12000L utilizando células CHO (POLASTRI, 1997).

O uso de bactérias recombinantes como E.coli para produção de insulina humana e hormônio de crescimento humano conduziu a um otimismo crescente, como se todas as proteínas terapêuticas pudessem ser produzidas deste modo.

Certamente para a produção de proteínas simples e pequenas, microrganismos se apresentam como candidatos mais viáveis. Porém, no momento não podem ser empregados para a produção de proteínas grandes e complexas, como enzimas, eritropoetina, fator VIII, tPA, ou ainda anticorpos monoclonais. Microrganismos não possuem a complexa maquinaria biossíntética para realizar modificações pós- 
traducionais, como encontradas em células animais. Proteínas animais produzidas por bactérias frequentemente são desnaturadas ou perdem a configuração tridimensional apropriada (WIRTH; HAUSER, 1993). As proteínas animais de interesse farmacêutico são usualmente glicosiladas e contém ainda fosforilações e carboxilações, modificações importantes ou fundamentais para a correta atividade biológica da proteína.

Como contrapartida, processos com células animais requerem uma série de cuidados extras, em relação aos cultivos tradicionais com microrganismos.

Um dos cuidados refere-se à fragilidade das células à aeração por sistemas tradicionais de aspersão. Para contornar este problema, desenvolveu-se um sistema específico para cultivos em células animais: a aeração por membrana de silicone.

Outra limitação do cultivo com células animais decorre de sua velocidade de crescimento muito baixa, diminuindo-se assim sua produtividade em processos descontínuos, descontínuos-alimentados ou contínuos. Nesta direção, se aperfeiçoou o processo contínuo com retenção de células, que também é conhecido como perfusão.

Também devido a essas características específicas do cultivo com células animais, tornou-se necessário o desenvolvimento de sistemas de monitoramento adequados e de controle eficiente do processo.

Aproveitando-se da experiência do Dr. Konstantinov, além da disponibilidade de equipamentos em seu laboratório, este trabalho teve como objetivo realizar processos de cultivo de células animais em sistemas de perfusão, aos quais se acoplavam sistemas de monitoramento visando melhor controle, de modo a contribuir para o aumento da produtividade. 


\section{REVISÃO BIBLIOGRÁFICA}

O presente trabalho enfoca principalmente o monitoramento e operação de processos fermentativos, sendo este tópico, portanto, abordado aqui na revisão bibliográfica.

No entanto, por utilizar sistemas com células animais, e considerando a tradição da engenharia bioquímica no cultivo de microrganismos, a revisão inclui uma comparação entre cultivos com células animais e microbianas, enfocando as diferenças para a engenharia.

\subsection{Cultura de células animais}

As células de organismos superiores, tanto as de vegetais como as de animais (entre as quais as de mamíferos e de insetos), apresentam uma série de diferenças em comparação com as células microbianas.

\subsubsection{Diferenças biológicas e consequências para a engenharia}

Enquanto as células de microrganismos estão adaptadas ao crescimento independente, embora formando muitas vezes agregados, as células de seres superiores encontram-se diferenciadas, cada uma com uma função específica dentro do organismo. Durante a fase embrionária, estas células passam por uma série de transformações, de modo que cada célula adulta está diferenciada para exercer uma função, fazendo parte de um tecido ou órgão. Apesar de pertencerem todas à mesma espécie, e conterem exatamente o mesmo material genético, cada célula é capaz de sintetizar diferentes compostos que por sua vez poderão ser utilizados por células em outro órgão. 
Deste fato decorre a interdependência entre as células, que gera como consequência, uma série de limitações não encontradas em organismos microbianos. Por exemplo, uma bactéria é capaz de metabolizar várias fontes de carbono oferecidas, sintetizando vários compostos necessários ao seu crescimento. Desta forma, pode crescer em meios bastante simples, constituídos por uma fonte de carbono, uma de nitrogênio, alguns sais e alguma fonte de micronutrientes, como extrato de levedura.

Já uma célula animal está adaptada a crescer em um organismo que, através da corrente sanguínea, lhe proverá todos os nutrientes necessários. Outras partes do organismo serão responsáveis pela digestão do alimento ingerido e sua transformação em intermediários do metabolismo. Deste fato, conclui-se que ao se tentar crescer células animais in vitro (em biorreator), o meio de cultura oferecido deve ser extremamente complexo, contendo todos os aminoácidos, vários sais minerais, vitaminas, ácidos graxos e glicose, suprindo todos os ingredientes que normalmente o sangue supriria (WOLFE, 1993). Este meio pode ser dividido em duas partes: uma composta pelos nutrientes que efetivamente serão consumidos pelas células, e outra por aquilo que não será consumido, em sua maioria componentes inorgânicos, que servirão para ajustar a osmolalidade, prover tamponamento e promover forças iônicas adequadas (GAMBHIR et al., 1999). Outra característica de cultivos com células animais é a necessidade de duas fontes de carbono: glicose e glutamina, que é metabolizada em glutamato e alfa-cetoglutarato, entrando no ciclo de ácidos tricarboxílicos (VRIEZEN et al., 1997). No metabolismo destas fontes de carbono, praticamente toda glicose é convertida em lactato e toda glutamina em amônio. As relações entre lactato produzido por glicose consumida e de amônio produzido por glutamina consumida representam importantes parâmetros de acompanhamento do processo, fornecendo indícios do fluxo 
metabólico interno da célula a cada momento do cultivo (ZENG et al., 1998; OZTURK et al, 1997).

Semelhantemente, do ponto de vista de resistência ao estresse imposto em um biorreator, as células animais se apresentam muito mais frágeis que as microbianas, devido à falta de uma membrana celular rígida (SAMBANIS; HU, 1993). Desta forma, a frequência de agitação de centenas de rotações por minuto (típica em biorreatores de bancada com microrganismos) torna-se inibitória ao crescimento de células animais e, portanto o desenvolvimento de formas alternativas de agitação e aeração passa a ser objeto de estudo de engenharia. No caso de crescimento de células suspensas em reatores agitados e aerados por aspersão, PAPOUTSAKIS (1991) determinou que o maior dano é devido à quebra das bolhas de ar na superfície do líquido e à velocidade de drenagem do filme líquido em torno da interface gás-líquido. Várias tentativas de contornar este problema são frequentemente citadas na literatura (WU; GOOSEN, 1994;

FENGE et al., 1993; LAKHOTIA et al., 1993). A utilização de sistema de aeração sem a formação de bolhas é uma forma de se evitar este dano.

\subsubsection{Biologia celular}

Além das diferenças já apontadas, as células animais precisam passar por transformações para poderem ser utilizadas em processos industriais. Enquanto células microbianas podem se reproduzir ilimitadamente, células retiradas de tecidos (primárias) podem ser sub-cultivadas (passando a se chamarem normais) por um número finito de divisões, tipicamente em torno de 50 (BUTLER, 1991). Após este período, as células normais entram em processo de envelhecimento e morte programada (apoptose). Algumas células ocasionalmente podem perder esta limitação, dando origem 
a células transformadas ou linhagens contínuas, através de processo espontâneo ou através de carcinogênese. As células utilizadas em processos biotecnológicos são todas células transformadas, onde não há mais a limitação do número de divisões possível. Entre as linhagens mais comuns, pode-se citar: BHK (Baby Hamster Kidney), CHO (Chinese Hamster Ovary), Vero e hibridomas (KELLEY et al., 1993).

Outra característica das células animais é que, mesmo em condições otimizadas, apresentam velocidade específica de crescimento muito baixa, entre 0,01 e $0,05 \mathrm{~h}^{-1}$, muito menor que a apresentada geralmente pelos microrganismos, o que tende a encarecer o processo industrial (BAILEY; OLLIS, 1986; BUTLER, 1991).

\subsubsection{Vantagens de cultivos com células animais}

Em contrapartida às dificuldades apresentadas acima, no cultivo de células animais (meio de cultura complexo, fragilidade mecânica, baixa velocidade de crescimento e necessidade de desenvolvimento de linhagens contínuas), sua utilização permite a síntese de produtos que, por meio de microrganismos, não seria possível, ou cujo custo tornaria a produção inviável. Para exercerem funções terapêuticas, muitas proteínas necessitam passar por uma série de modificações pós-traducionais, que os microrganismos não são capazes de realizar, como glicosilação, fosforilação, sialização, carboxilação, amidação, acetilação, sulfatação e formação de ligações de enxofre (MAINS et al., 1987). Destas, a glicosilação é a modificação mais importante, de modo que já se estuda a clonagem das enzimas glicosiltransferases (JENKINS et al., 1996).

É o caso, por exemplo, do fator de coagulação VIII (FVIII), cuja falta é responsável pela doença hemofilia (incapacidade de coagulação do sangue). Trata-se de uma molécula muito grande $(265 \mathrm{kDa}$, formada a partir de 186.000 pares de bases, ou 
cerca de um milésimo do cromossomo X), altamente glicosilada (HIRONAKA et al., 1993), cuja síntese através de microrganismos nunca foi possível. Através da clonagem do cDNA para FVIII e sua expressão em células BHK-21 (Baby Hamster Kidney), é possível a produção industrial desse fármaco (CHAN, 1994).

Por outro lado, o desenvolvimento da tecnologia de produção de anticorpos monoclonais (MAb), através do cultivo de hibridomas, tornou possível seu uso para diagnóstico em larga escala e encontra cada vez mais aplicações terapêuticas (BLANCH; CLARK, 1997). Hibridomas resultam da fusão de células de linfócito B (capazes da produção de MAb, porém com duração de vida finita) com células de mieloma (que, por serem tumorgênicas, crescem indefinidamente). Hibridomas têm sido utilizados para a produção de anticorpos monoclonais para diagnóstico humano e, mais recentemente, para terapia humana (LINDL, 1996). Atualmente consegue-se produzir hibridomas capazes de secretar até 100pg de anticorpo por célula por dia. Em um processo descontínuo, atingindo 1E6 cél/mL, pode-se assim obter até 100mg/L (BIBILA et al., 1995).

\subsection{Processos de cultivo}

Semelhantemente a cultivos microbianos, há várias tipos de biorreatores para processos com células animais. A primeira classificação decorre do fato das células estarem suspensas ou imobilizadas. Células animais podem ser dependentes de ancoramento, necessitando assim de um suporte físico para crescerem, como por exemplo microcarregadores ou garrafas "Roller". Outra forma de se manter as células imobilizadas é através de fibras ocas ("hollow fiber") (HANDA-CORRIGAN, 1991). 
Para cultivos com células suspensas, utiliza-se principalmente biorreatores tipo tanque agitado, com ou sem algum sistema de separação de células, e em vários casos colunas de bolhas e reatores "air-lift". (SAMBANIS; HU, 1993).

Células animais crescem em velocidade muito baixa, e muitas vezes secretam produto mesmo sem estarem em fase de crescimento. Por esse motivo, os processos que incluem algum tipo de separação de células permitem manter o maior número possível de células produtoras dentro do reator, conseguindo-se assim aumento de produtividade. Usualmente os processos contínuos que se utilizam de algum sistema para separação de células são chamados de perfusão, sendo o sistema empregado no presente trabalho. ZHANG et al. (1998) utilizaram um filtro ultra-sônico da Applikon (Schiedam, Holanda) como sistema de separação de células de inseto Spodoptera frugiperda Sf9. A fonte de ultra-som gera uma região de ressonância intermitente, na linha de retirada de caldo, aprisionando as células com determinado tamanho. Com isso, conseguiram atingir concentração celular superior a 30E6 células/mL, mantendo a viabilidade superior a $90 \%$.

Em uma comparação entre processos contínuos e descontínuos para células animais, GRIFFITHS (1992) salientou que os cultivos contínuos são amplamente utilizados para a produção de produtos em pequenas quantidades (como anticorpos monoclonais e proteínas para serem submetidas a testes em humanos), empregando-se muitas vezes sistemas com fibra oca ou cartuchos cerâmicos Opticell. No entanto, para a produção em larga escala, é ainda mais comum o uso de sistemas com baixa concentração celular em processos descontínuos ou descontínuos alimentados, devido à sua simplicidade de operação, confiabilidade e, inclusive, tradição. 
Também segundo OZTURK (1996), os sistemas em perfusão com altas concentrações celulares atingem alta produtividade, porém são muito difíceis de projetar e operar, pois requerem controle contínuo da vazão de perfusão com base na estimativa da concentração celular. Além disso, podem sofrer falta de homogeneidade devido à agitação insuficiente e aumento da agregação das células, causando limitação nutricional a uma parcela das células.

KONSTANTINOV et al. (1996) sugerem um sistema de controle integrado de bioprocessos, baseado na medida em tempo real (na realidade, a cada hora) da concentração de glicose e lactato, em um modo de operação chamado nutristato ou auxostato de glicose. Utilizando células $\mathrm{CHO}$, mantém um cultivo em perfusão por 70 dias, com a concentração de glicose controlada ao longo de diferentes fases, atingindo concentração celular de 40E6 cél/mL.

\subsection{Sistemas de transferência de oxigênio}

Em cultivos aeróbicos de células microbianas e de organismos superiores, o oxigênio pode ser considerado como um nutriente do meio de cultura. A solubilidade do oxigênio em água é muito baixa, sendo ainda ligeiramente reduzida em meios de cultura $\left(6,5 \mathrm{mg} / \mathrm{L}\right.$, a $37^{\circ} \mathrm{C}$ e pressão parcial de oxigênio de 0,21 bar, segundo HENZLER; KAULING, 1993). Devido à esta baixa solubilidade, não pode ser fornecido como os demais nutrientes junto ao meio em quantidade suficiente para todo o cultivo e necessita ser constantemente suprido ao meio líquido, compensando o consumo pelas células para a respiração.

As formas de transferência de oxigênio ao meio em cultivos com células animais não diferem muito dos cultivos microbianos. Porém, devido à baixa velocidade de 
crescimento e, consequentemente, de respiração das células animais, nos cultivos aerados com aspersão em baixas concentrações celulares, a transferência não costuma ser limitante. Valores típicos da velocidade específica de respiração situam-se entre 1 e $24 \mu \mathrm{g}$ de oxigênio por $10^{6}$ células por hora, segundo AUNINS; HENZLER (1993); e entre 2 e $13 \mu \mathrm{g}$ de oxigênio por $10^{6}$ células por hora, segundo RUFFIEUX et al. (1998). Considerando a dificuldade de medida destes valores por serem muito pequenos, SINGH (1996) desenvolveu um método para estimativa da velocidade de consumo de oxigênio baseado na análise do sinal da sonda de oxigênio dissolvido em resposta a um pulso de ar ou oxigênio injetado no reator.

Apesar de eficiente, a transferência de oxigênio através da aspersão direta não é recomendável em vários cultivos com células animais, conforme visto no item 2.1.1. Convém ressaltar porém, que há ainda muitas dúvidas na literatura se é realmente elevado o dano causado pelas bolhas às células animais (MICHAELS et al., 1996). ZHANG et al. (1993) compararam crescimento de um hibridoma e produção de anticorpo monoclonal em um sistema que permitia a aeração de três formas distintas: aspersão, microaspersão (bolhas com diâmetro de cerca de $80 \mu \mathrm{m}$ ) e tubulação de silicone. Obtiveram melhor produtividade e crescimento nos sistemas com aspersão, utilizando Pluronic F-68 como aditivo para proteção ao estresse mecânico. Em sistema com leito fluidizado, REITER et al. (1992) utilizaram com sucesso um microaspersor de metal para a aeração do cultivo em escala de $80 \mathrm{~L}$.

Para os casos em que é crítico o dano às células causado pela ruptura das bolhas, recomenda-se a utilização de membranas de silicone para a transferência de oxigênio, conforme se observa em vários trabalhos na literatura (CASEY et al., 1999; 
KANOKWAREE; DORAN, 1998; EMERY et al., 1995; MOREIRA et al., 1995; JAEGER; KOBOLD, 1995).

\subsection{Monitoramento de processos fermentativos}

Através do desenvolvimento de diferentes técnicas, a capacidade de se observar um processo em biorreator tem evoluído muito nos últimos anos. Do ponto de vista de análise de amostras ("off-line", portanto), muitas metodologias (entre elas, cromatografia, eletroforese e imunoensaios) estão disponíveis no sentido de se quantificar uma grande variedade de metabólitos celulares, sem estarem restritas apenas à fonte de carbono, produto e biomassa.

Quando possível, a observação do cultivo "on-line" (isto é, no próprio biorreator, sem a necessidade de amostragem) traz uma série de vantagens. A simples ação da retirada de amostra muitas vezes prejudica o processo, por exemplo devido à diminuição de volume de reação, em casos de pequenos reatores. Além disso, a utilização dos resultados de uma análise para fins de controle depende da sua disponibilidade em tempo real. O desenvolvimento de novas ferramentas de análise "on-line", como determinação da concentração de substrato e produtos inibitórios permite o melhor controle do processo, aumentando a produtividade (OZTURK et al., 1997; KONSTANTINOV, 1996; KONSTANTINOV et al., 1996). Idealmente, se deseja também o monitoramento "on-line" da concentração de produto, objetivo final do processo fermentativo. OZTURK et al. (1995) desenvolveram um sistema que permite a aquisição em tempo real da concentração de um anticorpo monoclonal produzido por um hibridoma murino A10G10. Utilizaram um cromatógrafo HPLC automatizado, que injeta a cada 50 minutos amostras de $200 \mu \mathrm{L}$ em uma pequena coluna de afinidade 
porosa com tempo de retenção de $2,5 \mathrm{~min}$, permitindo a determinação da concentração de anticorpo, que foi comparável àquela determinada "off-line" através de ELISA ou método nefelométrico.

Muitas são as variáveis que afetam o crescimento e produção em processos fermentativos. Neste trabalho, serão estudadas as influências de: oxigênio dissolvido, temperatura, osmolalidade e, indiretamente, tamanho da célula.

\subsubsection{Concentração celular}

Certamente a concentração celular é a variável mais importante em todo processo fermentativo, pois dela depende a estimativa das velocidades específicas de crescimento, consumo de substrato e produção.

Segundo KONSTANTINOV et al. (1994), há várias técnicas sendo desenvolvidas atualmente para o acompanhamento da concentração celular (X) em um cultivo com células animais em suspensão, sendo classificadas em:

a) medidas diretas da concentração: densitometria de ressonância acústica, espectroscopia magnética nuclear em tempo real, condutividade, capacitância, fluorescência, medida da luz absorvida ou espalhada e análise de imagens

b) medidas indiretas: estimativas baseadas na velocidade de respiração, de produção de gás carbônico e de produção de ATP

A técnica mais empregada é o emprego de um turbidímetro, que fornece a densidade ótica (DO) como base para estimativa de X, aproveitando-se do fato que os meios de cultura são geralmente límpidos e as células crescem geralmente isoladas uma das outras. Há modelos de equipamentos que se utilizam da luz transmitida, luz espalhada e sistema misto (WU et al., 1994). Previamente, ou ainda durante o processo, 
deve-se proceder uma calibração, que permita transformar o valor de DO em concentração celular. Tal calibração pode ser desde um simples fator DO/X, como uma equação de reta (com dois parâmetros, portanto) ou polinomial. KONSTANTINOV et al. (1992) obtiveram uma excelente correlação polinomial de terceiro grau da concentração de hibridoma AFP-27 em função da densidade ótica, utilizando-se de uma sonda laser de alta sensibilidade. Neste trabalho, mostra-se a importância do processo de filtragem dos dados, para o cálculo em tempo real da velocidade específica de crescimento.

\subsubsection{Oxigênio dissolvido}

Como visto no item 2.3, a manutenção da concentração de oxigênio dissolvido no caldo de cultivo é fundamental para o crescimento de células animais, devido ao seu metabolismo aeróbico. A concentração de oxigênio dissolvido no líquido é portanto uma variável a ser acompanhada e, se possível, controlada numa faixa adequada, pois tanto valores em excesso como em falta acarretam perda de produtividade (KONZ et al., 1998).

Vários trabalhos foram publicados estudando os efeitos da concentração de oxigênio dissolvido em diferentes sistemas de cultivo com células animais (LIM et al., 1999; HEIDEMANN et al., 1998; JAN et al., 1997; OZTURK; PALSSON, 1990; MILLER et al., 1987). Sem entrar na discussão específica de cada um, o que se observa de modo geral é que em concentrações extremas, próximas de $0 \%$ e 100\%, o crescimento e produção são prejudicados, porém existe um ampla faixa de concentrações nas quais os parâmetros do cultivo são pouco influenciados pela concentração de oxigênio. Segundo KILBURN (1991), a maioria das células animais in 
vivo estão expostas a concentrações de oxigênio entre 3 e $20 \%$ da saturação, lembrando ainda que a concentração de oxigênio no sangue arterial é da ordem de $63 \%$ e no venoso, $25 \%$.

OZTURK; PALSSON (1990), estudando hibridomas submetidos a concentrações de oxigênio entre 0 e $100 \%$ da saturação com ar, observaram ainda que as células apresentavam maior viabilidade quando submetidas a baixas concentrações de oxigênio e que abaixo de $1 \%$ havia um significativo aumento nas velocidades específicas de consumo de glicose e glutamina e diminuição da velocidade específica de respiração.

Em contrapartida, estudando células de inseto, que apresentam elevada velocidade específica de respiração $\left(25 \mu \mathrm{g}\right.$ de oxigênio por $10^{6}$ células por hora), TATICEK; SHULER (1997) obtiveram aumento na produtividade ao aumentar a fração de oxigênio no gás de aeração de $21 \%$ para $80 \%$.

JORJANI; OZTURK (1999) estudaram a velocidade específica de respiração de três linhagens (BHK, CHO e hibridoma) em diferentes concentrações celulares de 1 a 20E6 cél/mL, não verificando sua influência na respiração. Observaram também que a velocidade específica de respiração diminui cerca de $10 \%$ a cada ${ }^{\circ} \mathrm{C}$ diminuído na temperatura a qual as células estão submetidas $\left(\right.$ de $37^{\circ} \mathrm{C}$ a $\left.6^{\circ} \mathrm{C}\right)$.

\subsubsection{Temperatura}

Da mesma forma que nos cultivos com microrganismos, a temperatura exerce grande influência no crescimento de células animais. WEIDEMANN et al. (1994) mostraram que células aderentes recombinantes BHK21, produtoras de antitrombina III, crescidas em processos descontínuo e descontínuo repetido, diminuem suas velocidades 
específicas de crescimento, de consumo de glicose e de produção de lactato quando cultivadas em temperaturas menores. No intervalo estudado $\left(30\right.$ a $\left.37^{\circ} \mathrm{C}\right)$, a produtividade e a máxima concentração celular aparentemente não foram afetadas. Outro trabalho (CHUPPA et al., 1996), utilizando a mesma linhagem BHK empregada no presente trabalho, porém em outro meio de cultura, mostrou que o crescimento celular e a produção de rFVIII são maximizados na faixa de 34 a $37^{\circ} \mathrm{C}$, sendo $37^{\circ} \mathrm{C}$ a temperatura ótima para crescimento e $34^{\circ} \mathrm{C}$ a temperatura ótima para produção. Como conclusão desta análise, para cultivos em perfusão, recomenda-se manter $37^{\circ}$ durante a fase de aumento de concentração celular e $34^{\circ} \mathrm{C}$ durante todo o processo de produção. Observou-se ainda, que em temperaturas mais baixas, a velocidade específica de respiração $\left(\mathrm{Q}_{\mathrm{O} 2}\right)$ diminuía, facilitando assim a transferência de oxigênio nesta situação.

\subsubsection{Osmolalidade}

A osmolalidade ou pressão osmótica do meio de cultivo é outra variável com grande influência no processo fermentativo, especialmente em cultivos com células de mamíferos (OZTURK; PALSSON, 1991). Osmolalidade pode ser definida como a molalidade (expressa em moles por kilograma de solvente) numa solução ideal de uma substância que não forma íons, que apresenta a mesma pressão osmótica da solução em questão. Sendo a osmolalidade de soro $290 \mathrm{mmol} / \mathrm{kg}$, os meios de cultura são formulados normalmente para apresentar valores entre 280 e $330 \mathrm{mmol} / \mathrm{kg}$. A utilização de meios com valores superiores a $400 \mathrm{mmol} / \mathrm{kg}$ costuma resultar em forte estresse osmótico para as células, sendo recomendável nessa situação a adição de algum osmoprotetor, como a betaína. Betaína é uma dentre várias substâncias consideradas como osmólito orgânico compatível, pois atua nos animais como parte de um sistema de 
acumulação controlada de compostos que permitem às células manter sua osmolalidade intracelular sem interferir na concentração de eletrólitos intracelulares (GARCIAPEREZ; BURG, 1991)

Para evitar níveis muito altos de osmolalidade em ensaios descontínuos alimentados de longa duração, RU; LEE (1998) se utilizaram de um artifício. Prepararam o meio inicial com baixa osmolalidade $(223 \mathrm{mmol} / \mathrm{kg})$, obtendo assim um prolongamento do ensaio devido a um aumento no número de pulsos de alimentação sem se atingir níveis letais de osmolalidade, e uma aumento de 1,5 vezes na concentração de anticorpo ao final do cultivo.

OYAAS et al. (1994) estudaram o crescimento em poços de $16 \mathrm{~mm}$, de um hibridoma murino 6H11, capaz de produzir anticorpos anti-TNF recombinante, sob diferentes osmolalidades, através da adição ao meio fisiológico (osmolalidade de $330 \mathrm{mmol} / \mathrm{kg}$ ) de $\mathrm{NaCl}$ ou de sacarose, atingindo $627 \mathrm{mmol} / \mathrm{kg}$, com a ajuda da adição de $15 \mathrm{mM}$ de betaína. Obtiveram um significativo aumento na velocidade específica de produção do anticorpo, chegando a 2,6 vezes em relação ao meio fisiológico, além de aumentos na velocidade específica de consumo de glicose. Nos valores mais elevados, a velocidade específica de crescimento caiu para um terço daquela em meio fisiológico.

Expostas a meio de cultura com valores de osmolalidade superior ao normal, as células tendem a diminuir seu tamanho nas primeiras horas, segundo a equação 2.1 de Boyle-vant Hoff (LUCKE; McCUTCHEON, 1932).

$$
P(V-b)=P_{0}\left(V_{0}-b\right)=\text { constante }
$$

onde $\mathrm{P}_{0}$ e $\mathrm{V}_{\mathrm{o}}$ são a pressão osmótica e o volume celular nas condições fisiológicas e $\mathrm{P}$ e V são a pressão osmótica e o volume celular a uma determinada osmolalidade e b o volume hipotético da célula sem solvente. 
No entanto, com células em crescimento (após se adaptarem à condição de hiperosmolalidade) observa-se um aumento do diâmetro, atingindo valores maiores que em situação normal, por razões ainda não completamente esclarecidas (OZTURK; PALSSON, 1991).

Devido a esse fenômeno de atraso na resposta à osmolalidade, diversos autores sugerem o aumento gradual na osmolalidade do meio, evitando provocar maior estresse às células. LIN et al. (1999), na produção de anticorpo monoclonal pelo hibridoma AFP27, testaram aumentar a osmolalidade em degraus, variando de um ensaio a outro a velocidade de aumento da osmolalidade, ou em outras palavras, em quantas horas levaram para atingir a osmolalidade final $(400 \mathrm{mmol} / \mathrm{kg})$. Quanto mais rápida esta mudança, menor a velocidade específica de crescimento. Cultivos em alta osmolalidade apresentaram velocidade específica de produção menor do que aqueles que atingiram tal osmolalidade em variações lentas.

De modo semelhante, CHERLET; MARC (1999) propõem o uso de cultivos contínuos para efetuar um aumento gradual na osmolalidade do meio e com isso evitar o estresse hiperosmótico. No entanto, diminuíram com isso a velocidade específica de produção. Segundo eles, as altas osmolalidades estimulariam o aparecimento de células não-produtoras, porém seus dados não são conclusivos.

Outro uso do controle da osmolalidade é apresentado por ROGNONI et al. (1999). O aumento da osmolalidade e do $\mathrm{pH}$ do cultivo permitiu uma redução no grau de agregação dos anticorpos produzidos, facilitando desta forma as etapas de recuperação e purificação. 


\subsubsection{Tamanho das células}

Como visto no item anterior, a variação da osmolalidade do meio resulta em variação do tamanho celular. Este fato passa a ser relevante tendo em vista que se pode considerar a concentração celular em função de seu número por volume, ou de seu volume ocupado, por volume de caldo. Em cultivos microbianos se expressa normalmente a concentração celular em massa de células secas por volume de caldo. Considerando uma porcentagem constante de água na célula, e tendo em vista que sua densidade é sempre muito próxima a da água, o uso de uma forma de cálculo de concentração celular ou outra leva a resultados diferentes, nos casos em que as células aumentam de tamanho.

A forma mais comum de se obter uma distribuição de tamanho de células é o emprego de aparelhos como o contador Coulter (OEHLER et al., 1996), que utiliza vários capilares, ou o CASY 1 TTC, que dispõe de apenas um capilar e uma curva de calibração previamente aferida (SEEWOSTER; LEHMANN, 1997).

Com o uso da citometria de fluxo (SEN et al., 1989), consegue-se obter uma distribuição de volume das células, além de uma estimativa de sua viabilidade, dependendo do corante empregado. O método baseia-se em iluminar um fluxo fino de amostra diluída, de modo que somente uma célula por vez intercepte o feixe luminoso. A medida da luz espalhada, assim como da fluorescência produzida, permite a obtenção de uma série de dados, que podem ser correlacionados com tamanho. Aparelho semelhante a este é o FACS, ou separador de células ativadas por fluorescência (RAMIREZ; MUTHARASAN, 1990). Através dele, pode-se determinar não só a distribuição do volume ds células, como determinar em que fase do ciclo de crescimento elas se encontram $\left(\mathrm{G}_{1}, \mathrm{~S}, \mathrm{G}_{2}\right.$ e $\left.\mathrm{M}\right)$. 
Outra forma de se determinar uma distribuição do tamanho das células é através da análise de várias imagens obtidas em um microscópio. Programas de computador estão cada vez mais adaptados para o processamento de imagens, permitindo que, após a aplicação de uma sequência de funções matemáticas, se determine parâmetros como distribuição de tamanho, grau de agregação, etc... A limitação desse procedimento é a necessidade de se preparar várias lâminas com amostras de cultivo, o que além de tedioso, causa variabilidade de operador a operador.

Como forma de contornar este problema, SUHR et al. (1995) desenvolveram um sistema para caracterização de células, baseado em um microscópio de fluorescência inserido através de uma porta padrão (diâmetro: $25 \mathrm{~mm}$ ) no biorreator. A amostra era iluminada por um pulso de curta duração (3ns) de laser de nitrogênio (comprimento de onda: $337 \mathrm{~nm}$ ) e sua emissão com comprimento de onda 450nm era coletada para análise. Um programa de computador calculava automaticamente a concentração e a área média da célula segmentada, a cada poucos segundos. O sistema foi utilizado com células de levedura e apresentou uma excelente correlação quanto à estimativa da concentração celular. Com relação ao tamanho, os autores relatam que a variação da área calculada ao longo do cultivo é compatível com o esperado através da simples visualização de amostras no monitor.

Por fim, uma outra alternativa para a estimativa da distribuição de tamanho de células é emprego da sonda Lasentec FBRM (Focused Beam Reflectance Measurement). Esta sonda tem sido empregada com muito sucesso no monitoramento de processos de cristalização e polimerização na indústria química, onde se deseja simplesmente acompanhar em tempo real variações no processo, e não é necessária uma medida real da distribuição de tamanho (RICHMOND et al., 1998; PHILLIPS; WALLING, 1998; 
REDMAN et al., 1997). Baseia-se na medida do tempo de duração da reflexão de um feixe de luz laser altamente focalizado, que incide em velocidade sobre a amostra a ser analisada. Esta técnica tem como desvantagem o fato dela fornecer uma distribuição de cordas, e não de diâmetros, que seria o desejado. A conversão da distribuição de cordas em distribuição de diâmetros não é uma tarefa fácil, sendo objeto de estudo de diferentes trabalhos (SIMMONS et al., 1999, LIU et al., 1996). Segundo MONNIER et al. (1996), a sonda requer uma série de condições para operar eficientemente, como por exemplo, grande número de medidas, rigidez na posição focal, calibração caso a caso da relação entre partículas medidas e real concentração na amostra. 


\section{METODOLOGIA}

\subsection{Meio de Cultura e Células Utilizadas}

As linhagens celulares utilizadas são linhagens hospedeiras comuns de coleções de culturas, alteradas geneticamente para permitir a expressão de uma proteína heteróloga (codificação não existente no genoma original).

Para a produção do anticorpo anti-TNF (fator de necrose tumoral), foi utilizado um hibridoma murino A10G10 desenvolvido nos laboratórios da Bayer, em Berkeley. A linhagem A10G10 foi obtida da fusão de um mieloma (célula cancerígena com duração infinita) com um linfócito capaz de exprimir o IgG anti-TNF, um anticorpo que se liga especificamente ao sítio de ligação do receptor de TNF na superfície da célula humana (MILES, 1993).

Para a produção do fator VIII de coagulação recombinante (conhecido como rFVIII), utilizou-se uma linhagem celular comprada de outra empresa de biotecnologia (Genentech, South San Francisco, CA, EUA) (GENENTECH, 1985). Tal célula foi construída a partir de uma linhagem bastante utilizada (BHK-21 ou Baby Hamster Kidney), através da co-transfecção de dois plasmídeos, um dos quais com a sequência do FVIII. Após a transfecção, foram selecionados os resistentes a neomicina e o número de cópias do plasmídeo foi amplificado através de seleção sequencial em metotrexato, atingindo cerca de 150 cópias por célula. Posteriormente, foi determinado que uma cópia do plasmídeo encontra-se integrada ao genoma (CHAN; LEMBACH, 1991).

Os meios de cultura empregados em todos os ensaios aqui apresentados, foram baseados na mistura dos meios DMEM e F12 em partes iguais (Tabela 3.1). Tal mistura, usualmente utilizada em cultivo de células (BUTLER, 1991), passou em cada caso (hibridoma e BHK) por pequenas modificações. 
Tabela 3.1 - Composição da mistura dos meios de cultura F12 e DMEM

\begin{tabular}{|c|c|c|c|}
\hline \multirow{2}{*}{ Componente } & \multirow{2}{*}{$\begin{array}{c}\text { Peso Molecular } \\
\text { g/mol }\end{array}$} & \multicolumn{2}{|c|}{ mistura de F12 e DMEM } \\
\hline & & g/L & $\mathbf{m M}$ \\
\hline \multicolumn{4}{|l|}{ Sais } \\
\hline $\mathrm{KCl}$ & 75 & $3.1 \mathrm{E}-1$ & $4.2 \mathrm{E}+0$ \\
\hline MgSO4 (anidro) & 120 & $8.4 \mathrm{E}-2$ & $7.0 \mathrm{E}-1$ \\
\hline $\mathrm{NaCl}$ & 58 & $7.0 \mathrm{E}+0$ & $1.2 \mathrm{E}+2$ \\
\hline $\mathrm{NaH} 2 \mathrm{PO} 4 . \mathrm{H} 2 \mathrm{O}$ & 138 & $6.2 \mathrm{E}-2$ & $4.5 \mathrm{E}-1$ \\
\hline Na2HPO4 (anidro) & 142 & $7.1 \mathrm{E}-2$ & $5.0 \mathrm{E}-1$ \\
\hline $\mathrm{CuSO} 4.5 \mathrm{H} 2 \mathrm{O}$ & 250 & $1.3 \mathrm{E}-6$ & $5.0 \mathrm{E}-6$ \\
\hline FeSO4.7H2O & 278 & $4.2 \mathrm{E}-4$ & $1.5 \mathrm{E}-3$ \\
\hline $\mathrm{ZnSO} 4.7 \mathrm{H} 2 \mathrm{O}$ & 288 & $4.3 \mathrm{E}-4$ & $1.5 \mathrm{E}-3$ \\
\hline $\mathrm{Fe}(\mathrm{NO} 3) 3.9 \mathrm{H} 2 \mathrm{O}$ & 404 & $5.1 \mathrm{E}-5$ & $1.3 \mathrm{E}-4$ \\
\hline $\mathrm{CaCl} 2$ (anidro) & 111 & $1.2 \mathrm{E}-1$ & $1.1 \mathrm{E}+0$ \\
\hline $\mathrm{NaHCO} 3$ & 84 & $2.4 \mathrm{E}+0$ & $2.9 \mathrm{E}+1$ \\
\hline \multicolumn{4}{|l|}{ L-Aminoácidos } \\
\hline L-Alanina & 89 & $4.5 \mathrm{E}-3$ & $5.0 \mathrm{E}-2$ \\
\hline L-Arginina $\mathrm{HCl}$ & 211 & $1.5 \mathrm{E}-1$ & $7.0 \mathrm{E}-1$ \\
\hline L-Asparagina $\mathrm{H} 2 \mathrm{O}$ & 150 & $7.5 \mathrm{E}-3$ & $5.0 \mathrm{E}-2$ \\
\hline L-Ácido Aspartico & 133 & $6.7 \mathrm{E}-3$ & $5.0 \mathrm{E}-2$ \\
\hline L-Cisteína HCl H2O & 157 & $1.6 \mathrm{E}-2$ & $1.0 \mathrm{E}-1$ \\
\hline L-Cistina $2 \mathrm{HCl}$ & 313 & $3.1 \mathrm{E}-2$ & $1.0 \mathrm{E}-1$ \\
\hline L-Ácido Glutâmico & 147 & $7.4 \mathrm{E}-3$ & $5.0 \mathrm{E}-2$ \\
\hline L-Glutamina & 146 & $3.7 \mathrm{E}-1$ & $2.5 \mathrm{E}+0$ \\
\hline L-Histidina $\mathrm{HCl} \mathrm{H} 2 \mathrm{O}$ & 209 & $3.1 \mathrm{E}-2$ & $1.5 \mathrm{E}-1$ \\
\hline L-Isoleucina & 131 & $7.2 \mathrm{E}-2$ & $5.5 \mathrm{E}-1$ \\
\hline L-Leucina & 131 & $5.9 \mathrm{E}-2$ & $4.5 \mathrm{E}-1$ \\
\hline L-Lisina $\mathrm{HCl}$ & 183 & $9.2 \mathrm{E}-2$ & $5.0 \mathrm{E}-1$ \\
\hline L-Metionina & 149 & $1.7 \mathrm{E}-2$ & $1.2 \mathrm{E}-1$ \\
\hline L-Fenilalanina & 165 & $3.5 \mathrm{E}-2$ & $2.2 \mathrm{E}-1$ \\
\hline L-Prolina & 115 & $1.7 \mathrm{E}-3$ & $1.5 \mathrm{E}-2$ \\
\hline L-Serina & 105 & $2.6 \mathrm{E}-2$ & $2.5 \mathrm{E}-1$ \\
\hline L-Treonina & 119 & $5.4 \mathrm{E}-2$ & $4.5 \mathrm{E}-1$ \\
\hline L-Triptofano & 204 & $9.2 \mathrm{E}-3$ & $4.5 \mathrm{E}-2$ \\
\hline L-Tirosina $2 \mathrm{Na} 2 \mathrm{H} 2 \mathrm{O}$ & 250 & $5.4 \mathrm{E}-2$ & $2.2 \mathrm{E}-1$ \\
\hline L-Valina & 117 & $5.3 \mathrm{E}-2$ & $4.5 \mathrm{E}-1$ \\
\hline L-Glicina & 75 & $1.9 \mathrm{E}-2$ & $2.5 \mathrm{E}-1$ \\
\hline \multicolumn{4}{|l|}{ Outros } \\
\hline Cloreto de Colina & 140 & $2.0 \mathrm{E}-3$ & $1.4 \mathrm{E}-2$ \\
\hline D-Ca-Pantotenato & 476 & $4.3 \mathrm{E}-3$ & $9.0 \mathrm{E}-3$ \\
\hline Ácido Fólico & 441 & $2.7 \mathrm{E}-3$ & $6.1 \mathrm{E}-3$ \\
\hline Hipoxantina de Sódio & 159 & $2.4 \mathrm{E}-3$ & $1.5 \mathrm{E}-2$ \\
\hline Inositol & 180 & $1.3 \mathrm{E}-2$ & $6.9 \mathrm{E}-2$ \\
\hline Piridoxina $\mathrm{HCl}$ & 206 & $3.1 \mathrm{E}-5$ & $1.5 \mathrm{E}-4$ \\
\hline Riboflavina & 376 & $2.3 \mathrm{E}-4$ & $6.0 \mathrm{E}-4$ \\
\hline Tiamina $\mathrm{HCl}$ & 337 & $1.7 \mathrm{E}-4$ & $5.0 \mathrm{E}-4$ \\
\hline Timidina & 242 & $1.8 \mathrm{E}-3$ & $7.5 \mathrm{E}-3$ \\
\hline Vitamina B-12 & 1355 & $6.8 \mathrm{E}-4$ & $5.0 \mathrm{E}-4$ \\
\hline Piridoxal $\mathrm{HCl}$ & 204 & $2.0 \mathrm{E}-3$ & $9.8 \mathrm{E}-3$ \\
\hline Putrescina $2 \mathrm{HCl}$ & 161 & $8.1 \mathrm{E}-5$ & $5.0 \mathrm{E}-4$ \\
\hline Nicotinamida & 122 & $2.0 \mathrm{E}-3$ & $1.7 \mathrm{E}-2$ \\
\hline Glicose & 180 & $3.2 \mathrm{E}+0$ & $1.8 \mathrm{E}+1$ \\
\hline Piruvato de Sódio & 110 & $1.1 \mathrm{E}-1$ & $1.0 \mathrm{E}+0$ \\
\hline Vermelho Fenol Sódio & 376 & $4.1 \mathrm{E}-3$ & $1.1 \mathrm{E}-2$ \\
\hline Ácido Linoleico & 280 & $4.2 \mathrm{E}-5$ & $1.5 \mathrm{E}-4$ \\
\hline Ácido Lipóico & 206 & $1.0 \mathrm{E}-4$ & $5.0 \mathrm{E}-4$ \\
\hline
\end{tabular}




\subsection{Fermentador e Sistemas de Controle}

Empregou-se um sistema de fermentação misto, composto de dorna de 15L (12L útil) da Applikon (Schiedam, Holanda) e uma unidade de controle da B.Braun (Melsungen, Alemanha) (Figura 3.1). A dorna, autoclavável, com camisa de água no fundo (de aço inox) e lateral de vidro boro-silicato, é provida de 5 portas laterais DN25 (Ingold $25 \mathrm{~mm}$ ) e, na cabeça, 6 de $27 \mathrm{~mm}, 2$ de $12 \mathrm{~mm}$ e 10 de $10 \mathrm{~mm}$, para diferentes eletrodos ( $\mathrm{pH}$, oxigênio dissolvido, pressão, temperatura, nível). A agitação é feita através de dois impelidores no eixo, sendo um padrão tipo hélice, na ponta inferior do eixo, e outro para promover a melhor homogeneidade em torno da gaiola de silicone, construído na Bayer. Este impelidor pode ser descrito como duas turbinas tipo lâminas planas, conectadas por placas semelhantes a chicanas. Os impelidores estão presos a um eixo com acoplamento magnético ao motor. É ainda provida de certas adaptações para permitir a aeração através de tubulação de silicone. Considerando-se que os objetivos deste trabalho incluem o desenvolvimento das técnicas de operação do sistema de perfusão e do sistema de transferência de oxigênio e, para evitar a repetição de boa parte das informações referentes a estes sistemas, eles serão descritos conjuntamente com sua utilização no capítulo de Resultados e Discussão. 


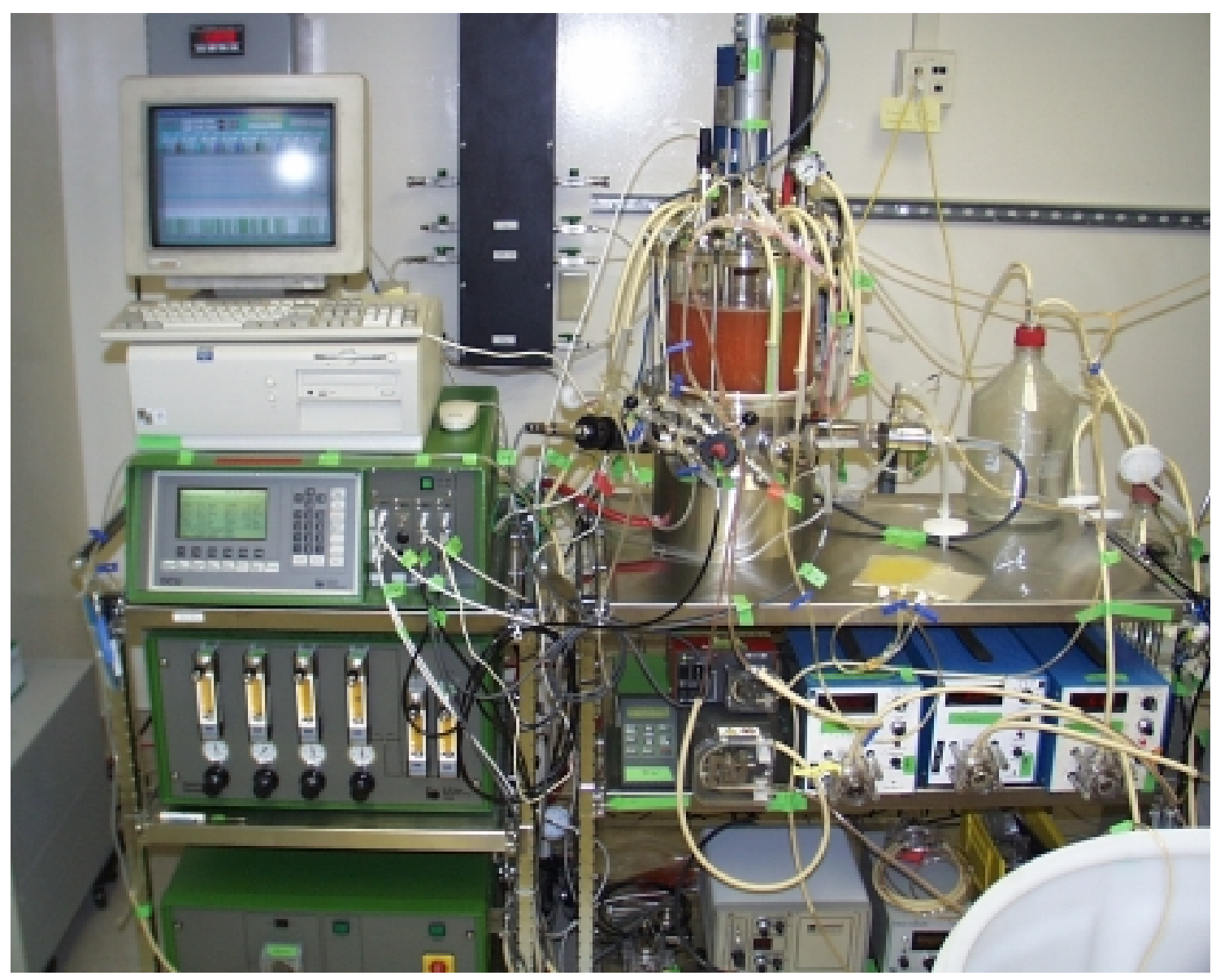

Figura 3.1 - Foto do sistema completo de fermentação, composto de tanque da Applikon, unidade de controle DCU da B.Braun, computador de controle rodando LabVIEW e demais bombas e acessórios

O sistema B.Braun é composto de 3 unidades: unidade de controle digital (DCU), unidade de comunicação e controle de temperatura da água da camisa e unidade de mistura de gases. Esta unidade é composta de 5 fluxômetros de massa (MFC, ou mass flow controller), modelo Auto-Trak 860, da Sierra Instruments (Monterrey, CA, EUA), que permitem a leitura e controle da vazão de gases. Há um fluxômetro para cada gás de entrada no tubo de silicone ( $\mathrm{ar}, \mathrm{O}_{2}, \mathrm{~N}_{2}$ e $\mathrm{CO}_{2}$ ), além de um para desviar parte da vazão para a cabeça do reator, mantendo uma pressão positiva nela. A DCU permite a conexão de todos os sensores, interfaceamento com computador e controle local de 
todas variáveis de processo. Encontra-se conectada a um microcomputador (Pentium $200 \mathrm{MHz}$, Compaq) que executa um software de supervisão e controle chamado LabVIEW, versão 4.0.1 (National Instruments, Austin, TX), responsável pelo armazenamento de dados, visualização "on-line" (através de várias telas gráficas) e execução do controle da bomba de purga (Figura 3.2).

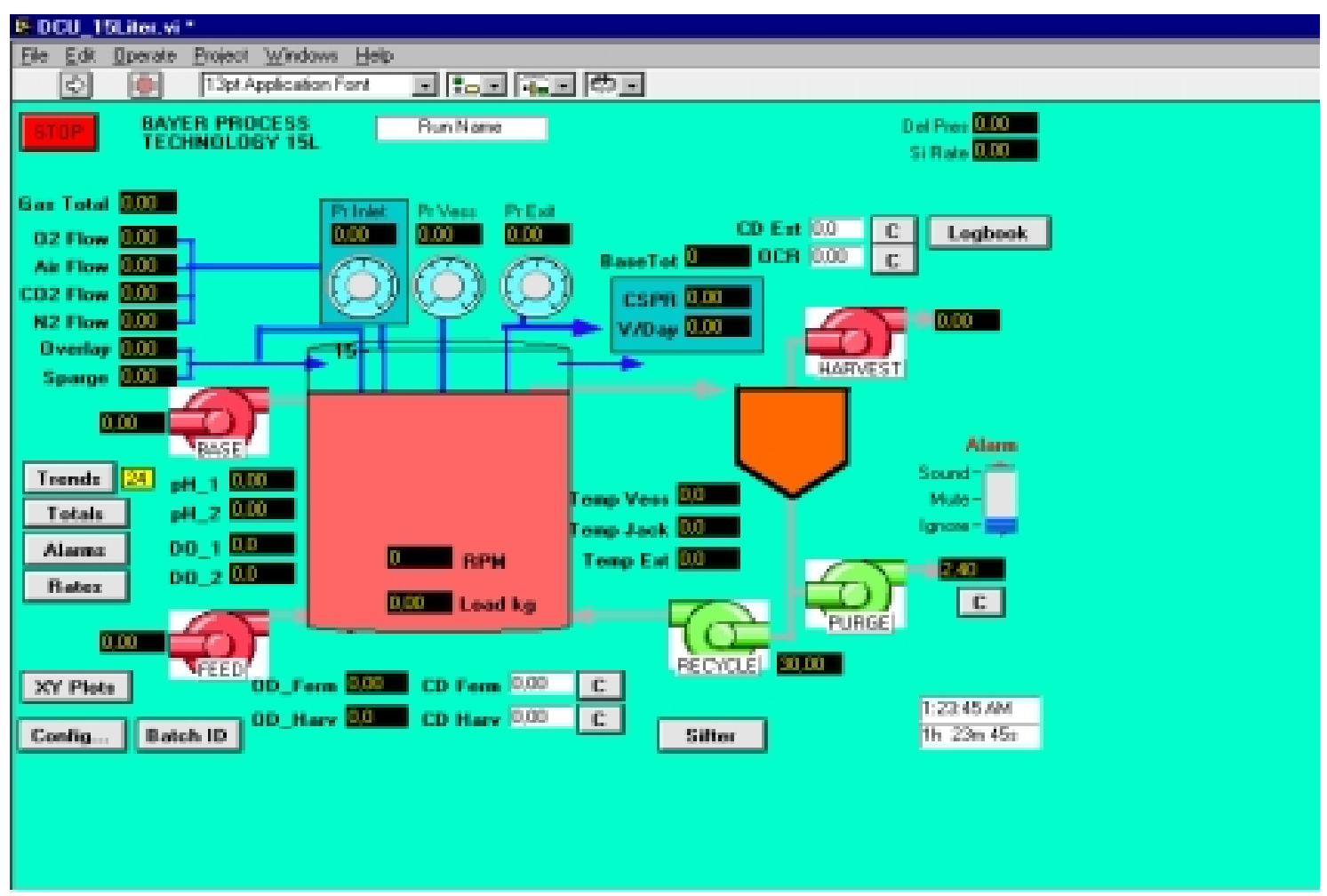

Figura 3.2 - Tela do programa de supervisão e controle da perfusão LabVIEW

O monitoramento e controle das variáveis de processo são executados por diversos sub-sistemas descritos a seguir.

a) Temperatura

A temperatura do processo ( $\mathrm{T}$ ) é monitorada através de termômetro do tipo termistor (Pt100), imerso em um poço em contato com o caldo de fermentação. A medida da temperatura do caldo é comparada com o valor desejado (set-point) e a atuação do controlador é a definição do valor de set-point da temperatura da água da 
camisa. Esse por sua vez é comparado com o valor medido (através de outro termistor) e aciona o controle de temperatura através do aquecimento (via acionamento de uma resistência elétrica) ou resfriamento (através da adição de água fresca da rede) da água da camisa.

b) $\mathrm{pH}$

Por se tratar de uma variável fundamental para o controle e em se tratando de ensaios longos, há dois sensores de $\mathrm{pH}$, um sendo usado no controle e outro simplesmente como reserva. Utilizaram-se eletrodos da Metler-Toledo (Wilmington, MA, EUA), modelo 405-DPAS-SC-K8S/325, tipo gel autoclavável. A leitura do pH do caldo é comparada com o valor de set-point e, nos casos normais de $\mathrm{pH}$ lido menor que o desejado, controla a adição automática de uma solução $0,1 \mathrm{~N}$ de hidróxido de sódio $(\mathrm{NaOH})$. Em caso contrário, tipicamente no início do cultivo, aciona o controlador de vazão do gás carbônico, que adicionado ao gás para transferência de oxigênio, circula pela tubulação de silicone, difunde-se pela membrana, dissolve-se ao meio e abaixa o pH devido ao equilíbrio $\mathrm{H}_{2} \mathrm{O}+\mathrm{CO}_{2} \leftrightarrow \mathrm{H}^{+}+\mathrm{HCO}_{3}^{-}$.

\section{c) Oxigênio Dissolvido (OD)}

A medida da concentração de oxigênio dissolvido (OD ou C), expressa em porcentagem da saturação com ar, é feita por dois eletrodos (o primeiro para o sinal de controle e outro como reserva), da Metler-Toledo (Wilmington, MA, EUA). Utilizaramse os modelos 34-100-3058 (membrana tipo A) e, posteriormente, o modelo InPro 6110/320/S/N (membrana tipo S-96), ambos com diâmetro de 12mm e comprimento de 320 mm, autoclaváveis, com medida amperométrica/ polarográfica (30 a 65nA de sinal). 
Para se manter o valor do oxigênio dissolvido controlado nesse sistema, deseja-se controlar a pressão na entrada do tubo de silicone, aumentando ou diminuindo a força motriz da transferência de oxigênio (conforme será visto no item 4.2). No entanto, optou-se por um sistema mais simples, aproveitando a malha de controle de oxigênio da DCU da B.Braun, que atua na vazão de gás, projetada para sistemas de aspersão. Como há uma perda de carga no tubo de silicone, e a pressão de saída é regulada, variar a vazão do oxigênio implica imediatamente num aumento na pressão de entrada e, portanto, na força motriz. Assim, quando a leitura de OD é inferior ao valor desejado (set-point), a DCU comanda o aumento da vazão de oxigênio através de seu controlador de vazão (fluxômetro de massa), pressurizando o tubo de silicone. Tal sistema, após a determinação dos parâmetros adequados do controlador PID, mostrou-se altamente eficiente, mantendo OD com variação inferior a 3\% durante o regime normal de operação.

d) Pressão

Devido à importância da pressão no sistema de transferência de oxigênio utilizado, tem-se 3 sensores elétricos de pressão acoplados à DCU, enviando constantemente os valores da pressão na entrada da tubulação de silicone $\left(\mathrm{P}_{\mathrm{e}}\right)$, na saída $\left(\mathrm{P}_{\mathrm{s}}\right)$, além da pressão na cabeça do fermentador $\left(\mathrm{P}_{\mathrm{f}}\right)$. São transdutores elétricos, modelo P-13 da Philips (Amsterdam, Holanda), fornecendo a pressão em atm. A pressão média na tubulação de silicone $\left(\mathrm{P}_{\mathrm{m}}\right)$ é calculada como a simples média aritmética de $\mathrm{P}_{\mathrm{e}}$ e $\mathrm{P}_{\mathrm{s}}$. 
e) Densidade Ótica (DO)

A densidade ótica do caldo fermentativo é usada para estimar a concentração celular. Para sua medida, usou-se o turbidímetro da Aquasant (Bubendorf, Suiça), modelo AS82, acoplado à sonda modelo AF44CS/R18B, composto de um emissor de infravermelho (940nm) e um detetor deste comprimento de onda da luz total refletida pelas partículas a sua frente. A intensidade do sinal refletido (zerada com o meio de cultura antes da inoculação), chamada de densidade ótica (DO), é usada como estimativa da concentração celular, após ser comparada com a medida da concentração celular $(\mathrm{X})$ (contada ao microscópio) e determinado um fator de calibração (DO/X). No ensaio típico, essa estimativa é utilizada como valor medido no sistema de controle da concentração celular, causando o acionamento da bomba de purga quando a concentração celular é superior à desejada.

f) Volume (V)

O sistema conta com um sensor de nível de líquido, modelo Level Plus SMT (MTS, Research Triangle Park, NC, EUA), acoplado a um monitor, modelo 1872 (Intelligent Controls, Saco, ME, EUA). Com base na posição do flutuador, o volume de líquido (V, em litros) é calculado e usado para comandar o acionamento da bomba de alimentação, para manter constante o volume do caldo no reator. Como há constantemente retirada de produto a uma vazão fixa, toda vez que o nível na dorna cai abaixo do set-point (equivalente a 12L), a DCU comanda o acionamento da bomba de alimentação (modelo 505Du/RL, da Watson-Marlow, Falmouth, Inglaterra), em modo liga/desliga (on/off). 
g) Frequência de agitação

O eixo com os dois impelidores é agitado através de um acoplamento mecânico (eliminando problemas de contaminação através de selo mecânico) por um motor na parte superior da cabeça do biorreator. Utilizou-se motor e controlador da Applikon (Holanda). Em todos os ensaios, a frequência de agitação foi mantida constante em 80 rpm, suficiente para manter a homogeneidade de um biorreator com volume útil de 12L, aerado por difusão através de membrana de silicone.

h) Suporte retrátil de eletrodos

Convém salientar que alguns dos eletrodos de $\mathrm{pH}$, oxigênio dissolvido (OD) e densidade ótica (DO) foram montados dentro de um suporte retrátil (retractable housing). Tal suporte permite a manipulação dos eletrodos sem a perda de esterilidade no sistema. Trata-se de uma estrutura com 2 câmaras, onde ao se retrair o eletrodo, ele perde contato com o meio de cultura, podendo ser manipulado sem comprometimento da esterilidade. Após sua substituição, conserto ou recalibração, o eletrodo é recolocado na câmara de esterilização, onde fica exposto a vapor a $120^{\circ} \mathrm{C}$ por 30 minutos, e após seu resfriamento, é reinserido no caldo de fermentação. Em se tratando de ensaios de longa duração (meses), tal possibilidade assegura a disponibilidade desses sinais, mesmo após uma obstrução ou falha. Para a manutenção do controle das variáveis, durante o ciclo de manipulação do eletrodo (tipicamente duas horas) passa-se a leitura das variáveis para a segunda sonda, caso do pH e OD, ou no caso da sonda de densidade ótica, desliga-se o controle da bomba de purga durante esse período. Foram utilizados dois suportes comerciais da Ingold Metler Toledo (modelo InTrac 797M 797 00-3007US ) para o pH e OD, e um protótipo da Aquasant (modelo AF44 CS/R 18B) para sua 
sonda de densidade ótica, cujos resultados de testes mostraram-se muito satisfatórios (MATANGUIHAN et al., 1999).

i) Espectrômetro de massa

O gás de saída do biorreator era em parte dirigido a um espectrômetro de massa de setor magnético, modelo MGA-1200 (Perkin-Elmer, Norwalk, Connecticut, EUA), com capacidade para medir com boa precisão a fração molar de oxigênio (yo2s), gás carbônico ( $\mathrm{y}_{\mathrm{CO} 2 \mathrm{~s}}$ ) e nitrogênio $\left(\mathrm{y}_{\mathrm{N} 2 \mathrm{~s}}\right.$ ) neste gás. As frações molares do gás de entrada na tubulação de silicone ( $\mathrm{y}_{\mathrm{O} 2 \mathrm{e}}, \mathrm{y}_{\mathrm{CO} 2 \mathrm{e}} \mathrm{e} \mathrm{y}_{\mathrm{N} 2 \mathrm{e}}$, respectivamente) são calculada com base nas vazões de cada gás, fornecidas pelos fluxômetros de massa. A vazão total de gás de entrada $\left(Q_{e}\right)$ também é calculada pela soma das vazões fornecidas pelos fluxômetros, porém a de saída $\left(\mathrm{Q}_{\mathrm{s}}\right)$ não foi medida. Ainda não operante, está sendo instalado um sistema de amostragem para permitir a escolha, entre várias linhas, de qual gás será analisado pelo equipamento. O controle das válvulas será comandado por um computador central, permitindo que os dados de cada biorreator sejam automaticamente enviados a cada computador de controle de fermentação.

\subsection{Rotina analítica}

Diariamente, uma série de parâmetros do processo são registrados e uma amostra de cerca de $50 \mathrm{~mL}$ é retirada do fermentador e analisada conforme Figura 3.3.

Os parâmetros registrados são: temperatura, $\mathrm{pH}$ (2 sensores), oxigênio dissolvido

(2 sensores), frequência de agitação, pressão na entrada e saída do tubo de silicone e dentro do reator, densidade ótica, volume de meio, vazão de saída de produto, vazão média purgada e vazão média de consumo de $\mathrm{NaOH}$ nas últimas 24 horas. 
Praticamente todos esses dados são automaticamente armazenados pelo sistema supervisório acoplado à DCU (LabVIEW) a cada 15 minutos. Além disso, há um computador acoplado à sonda Lasentec que a cada 30 minutos armazena a informação obtida por este equipamento para posterior análise.

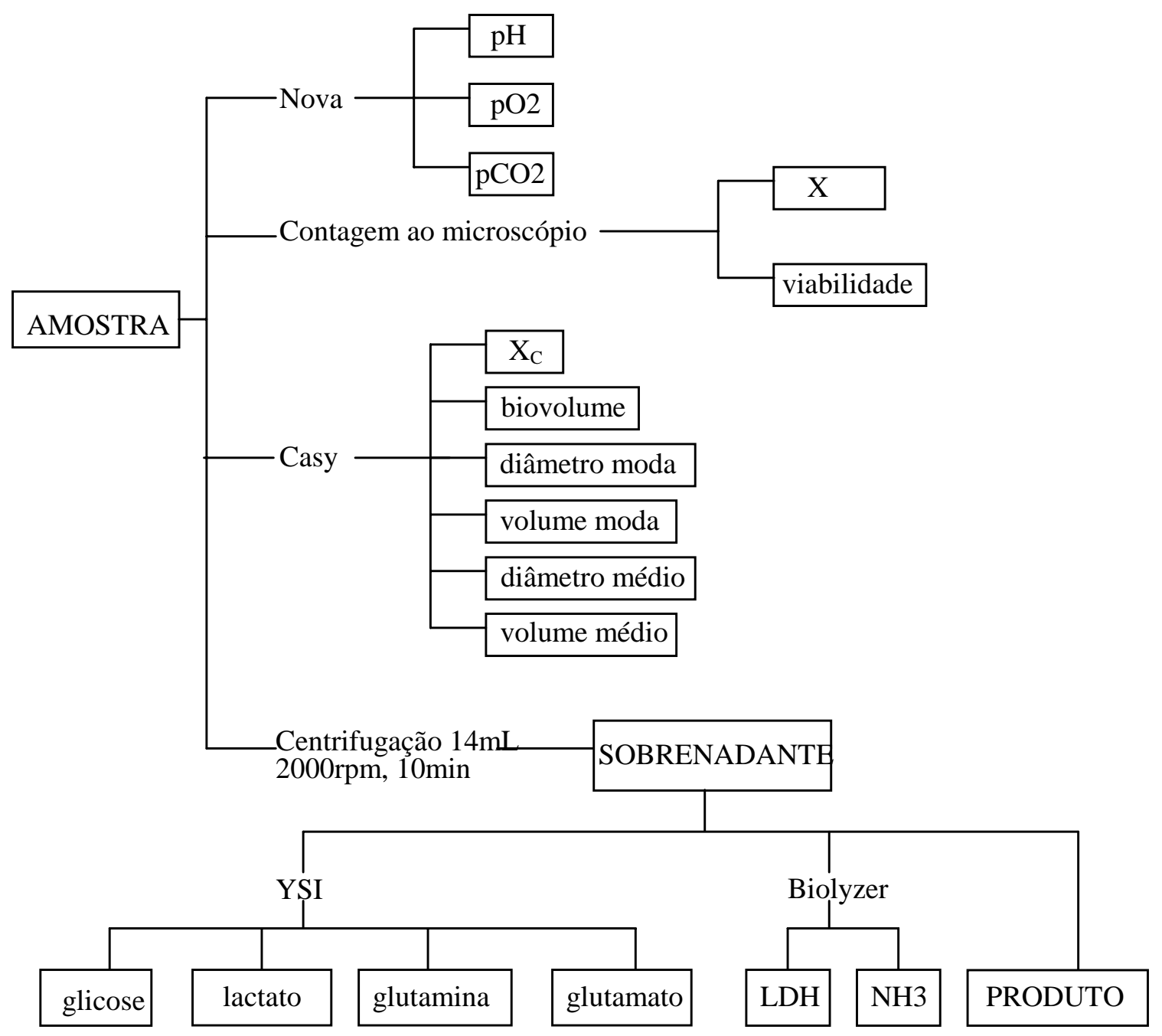

Figura 3.3 - Esquema da rotina analítica de tratamento da amostra

\section{pH, pO2 e pCO2 via NOVA}

Injeção de uma amostra logo após sua retirada do biorreator, para análise de $\mathrm{pH}$, pressão parcial de $\mathrm{O}_{2}\left(\mathrm{pO}_{2}\right)$ e pressão parcial de $\mathrm{CO}_{2}\left(\mathrm{pCO}_{2}\right)$, através do equipamento 
NOVA StatProfile 10 Plus Analyzer (Nova Biomedical Corp., Waltham, MA), composto basicamente de um sistema automático de injeção de uma amostra através de diferentes medidores.

\section{Contagem de células ao Microscópio (X e viabilidade)}

A concentração de células viáveis $(\mathrm{X})$ e viabilidade são determinadas através de uma contagem em volume conhecido de caldo (previamente diluído), realizada em hemacitômetro, modelo Bright Line Counting Chamber (Hausser Scientific, Horsham, PA, EUA), através da técnica de coloração com azul de tripan (Tripan Blue) (PHILLIPS, 1973). As células que permitirem a entrada do corante e tornarem-se azuladas não apresentam a membrana intacta, e são consideradas não viáveis, enquanto que as células transparentes são consideradas viáveis. A viabilidade é definida como a porcentagem de células viáveis em relação à quantidade total de células viáveis e não viáveis, e a concentração celular é expressa em milhões de células por mL (E6 cel/mL). Paralelamente se faz esta contagem em uma amostra retirada da linha de produto, e se determina a concentração celular total no produto $\left(\mathrm{X}_{\mathrm{P}}\right)$ e viabilidade.

\section{Glicose (Glic) e glutamina (Gln) via YSI}

Um amostra do sobrenadante é injetada em equipamentos YSI para determinação da concentração de glicose (Glic) e glutamina (Gln), expressas em mmol/L. O equipamento YSI 2700 Select (Yellow Springs Instruments Co., Yellow Springs, Ohio, EUA) utiliza enzimas oxidases específicas para vários substratos (como p.ex., L-lactato oxidase) para gerar $\mathrm{H}_{2} \mathrm{O}_{2}$, que é detectado eletroquimicamente num 
eletrodo de platina. Com o mesmo aparelho também foram determinadas as concentrações de lactato e glutamato.

\section{Amônia e LDH via Biolyzer}

Uma pequena alíquota de sobrenadante $(10 \mu \mathrm{L})$ é transferida para slides em equipamento Kodak Ektachem para determinação da concentração de amônia e LDH (enzima lactato desidrogenase). O Ektachem DT60 Analyzer e DTSC Module, conhecido como Biolyzer (Eastman Kodak Co., Rochester, New York, EUA) emprega sistema de slides específicos para cada composto. A amônia presente na amostra migra seletivamente através de diferentes camadas da membrana semi-permeável no slide, até atingir a última camada onde reagirá com o corante azul de bromofenol e após determinado tempo será medida a absorção. No slide para a determinação de LDH, processa-se a reação piruvato e $\mathrm{NADH}$ resultando lactato e $\mathrm{NAD}^{+}$, catalisada pela enzima. A evolução desta reação é monitorada através da mudança na densidade de reflexão, e de sua velocidade calcula-se a atividade de LDH. Os valores de LDH e amônia, assim como de lactato e glutamato, apesar de determinados em cada amostra, não serão apresentados neste trabalho, por fugirem ao seu escopo principal.

\section{Osmolalidade via Wescor (Osm)}

A osmolalidade (Osm, medida em mmol/ $\mathrm{kg}$ ou $\mathrm{mOsm} / \mathrm{kg}$ ) foi medida através do aparelho Vapro 5500 (Wescor, Logan, Utah, EUA), que se baseia no princípio da

diminuição da pressão de vapor. Após a devida calibração com padrões de 290 e $1000 \mathrm{mmol} / \mathrm{kg}$, uma pequena amostra $(10 \mu \mathrm{L})$ é colocada sobre um disco de papel e 
inserido dentro do aparelho, que decorridos 75 segundos exibe a osmolalidade da amostra.

\section{Produto (P)}

A determinação da concentração de produto (também chamada título) é realizada em laboratório de bioquímica especializado dentro da Bayer, empregando para rFVIII, ensaio de coagulação específico para fator VIII, e para o anticorpo murino IgG anti-TNF, método nefelométrico (medida da turbidez após a reação específica antígenoanticorpo). Os resultados da concentração de produto (P) são expressos em UA/mL, sendo UA uma unidade arbitrária.

\section{Distribuição de tamanho da célula e concentração celular via Casy}

Uma alíquota do sobrenadante é diluída 2500 vezes (para se ajustar a faixa de leitura, evitando entupimento) e succionada pelo equipamento Casy 1 Model TTC (Schaerfe System, Reutlingen, Alemanha), para a determinação da distribuição de tamanho das células e estimativa da concentração celular (Figura 3.4). 


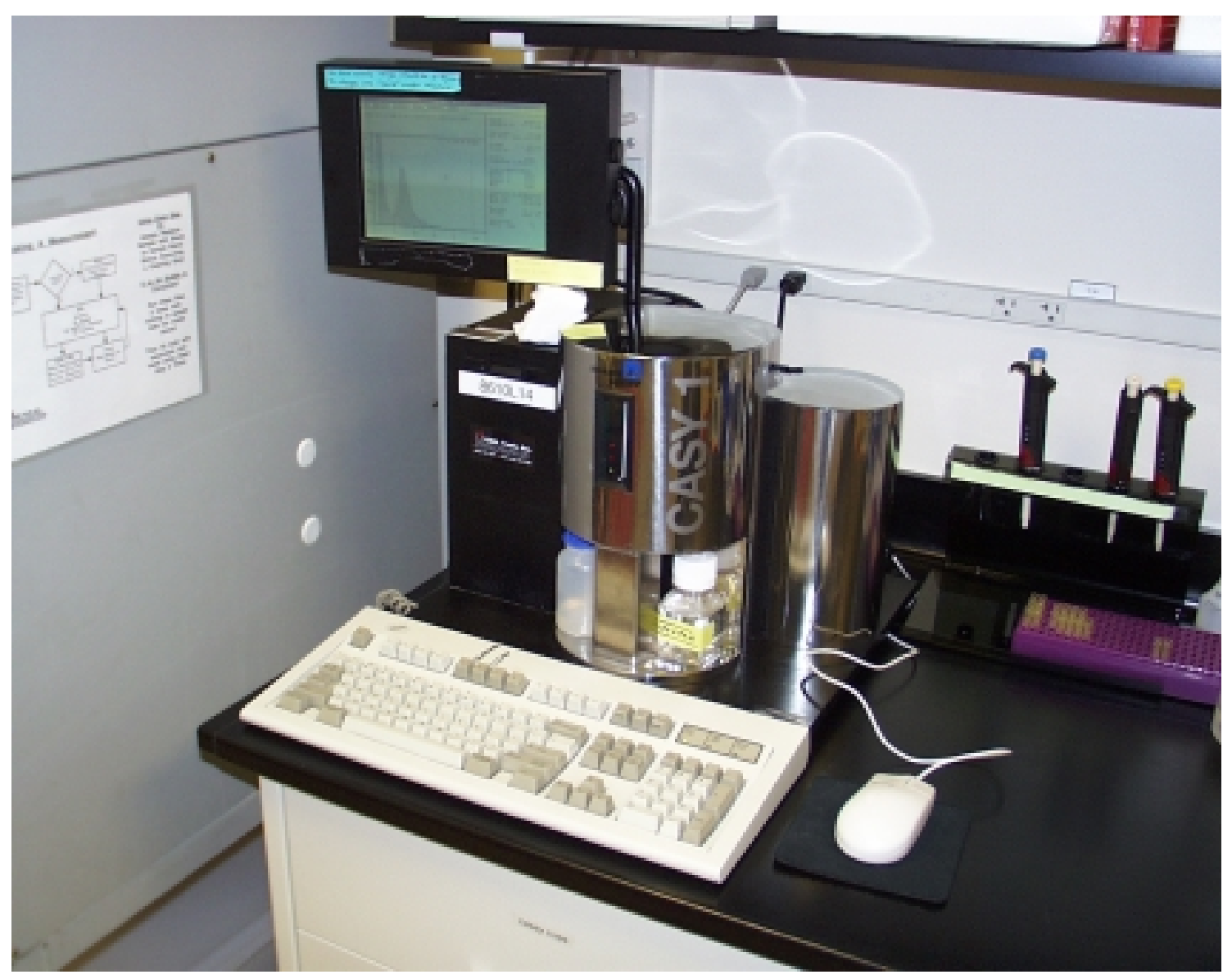

Figura 3.4 - Foto do sistema Casy, acoplado a microcomputador

O princípio de funcionamento deste aparelho é semelhante ao Coulter Counter (COULTER, 1956), onde a amostra é bombeada a capilares de diferentes diâmetros, e cada partícula que atravessa um orifício interfere na resistência elétrica medida entre dois eletrodos. Pela duração da interferência, estima-se o diâmetro da partícula, e seu volume é estimado considerando-se a célula esférica. No sistema Casy, há somente um capilar de $150 \mu \mathrm{m}$ de diâmetro e se usa uma curva de calibração para a faixa de 0 a $30 \mu \mathrm{m}$ ou de 0 a $50 \mu \mathrm{m}$ (Figura 3.5). O resultado típico do Casy se apresenta como uma distribuição gaussiana em torno de 10 a $20 \mu \mathrm{m}$, ligeiramente assimétrica (devido a grandes agregados) e com uma elevação abaixo de $10 \mu \mathrm{m}$ (debris celulares e células não 
viáveis). Além da distribuição dos diâmetros, o aparelho fornece alguns parâmetros calculados sobre um intervalo de diâmetros. Desta forma, são calculados:

- diâmetro moda ( $\mu \mathrm{m})$ (Maximum) $\left(\mathrm{D}_{\mathrm{i}}\right.$ tal que $\mathrm{N}_{\mathrm{i}}$ seja máximo)

- diâmetro médio $(\mu \mathrm{m})$ MeanDia $=\frac{\sum_{i=C L}^{C R}\left(D_{i} \cdot N_{i}\right)}{\sum_{i=C L}^{C R} N_{i}}$

- $\quad$ volume moda $(\mathrm{pL})\left(\right.$ Volume) $\left(1 / 6 . \pi\right.$.(diâmetro moda) $\left.{ }^{3}\right)$

- volume médio $(\mathrm{pL})$ MeanVol $=\frac{\sum_{\mathrm{i} C \mathrm{CL}}^{\mathrm{CR}}\left(\frac{1}{6} \cdot \pi \cdot \mathrm{D}_{\mathrm{i}}^{3} \cdot \mathrm{N}_{\mathrm{i}}\right)}{\sum_{\mathrm{i}=\mathrm{CL}}^{\mathrm{CR}} \mathrm{N}_{\mathrm{i}}}$

- $\quad$ biovolume $(\mu \mathrm{L} / \mathrm{mL})=$ fração de volume ocupado pelas células ou volume total das células dividido pelo volume da amostra

- $\quad$ concentração celular $(\mathrm{E} 6 \mathrm{cel} / \mathrm{mL})\left(\mathrm{X}_{\mathrm{C}}\right)$ = número de células por volume de amostra (via Casy)

onde $\mathrm{i}=$ cada um dos canais de medida, $\mathrm{CL}=$ limite inferior de diâmetro (cursor left), $\mathrm{CR}=$ limite superior de diâmetro (cursor right), $\mathrm{D}_{\mathrm{i}}=$ diâmetro do canal $\mathrm{i}, \mathrm{N}_{\mathrm{i}}=$ número de partículas (células) medidas no canal i 


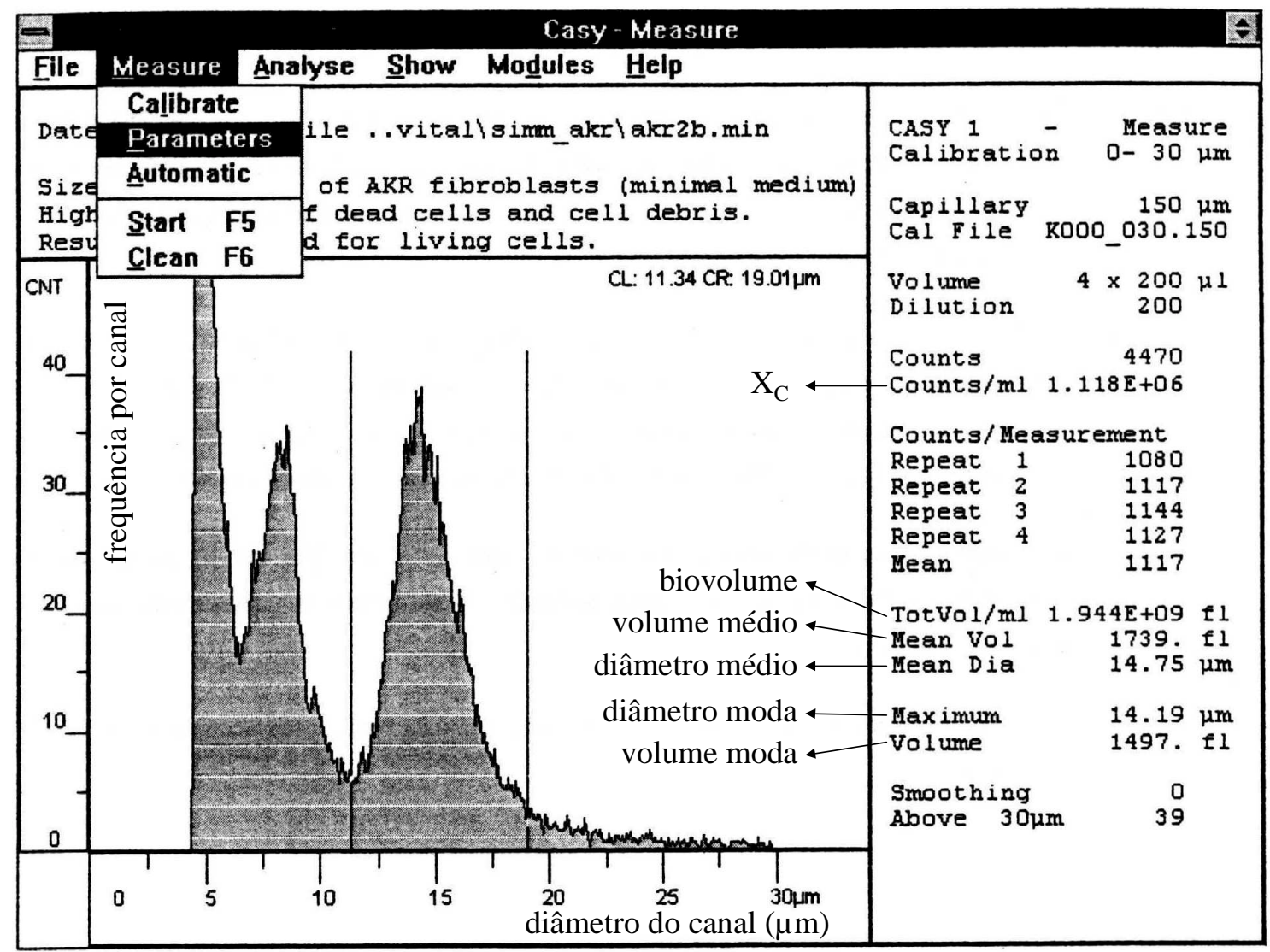

Figura 3.5 - Tela do programa de controle do sistema Casy, mostrando a curva de distribuição de diâmetros celulares e os vários parâmetros calculados sobre o intervalo de diâmetros indicado por CL $(11,34 \mu \mathrm{m})$ e CR $(19,01 \mu \mathrm{m})$

\subsection{Distribuição de tamanho da célula e concentração celular via Lasentec FBRM}

O Lasentec FBRM (Focused Beam Reflectance Measurement) M400L é uma sonda instalada no fermentador, que permite a estimativa da distribuição de tamanho de partículas (Figura 3.6). Fabricada pela Lasentec (Redmond, WA), tem sido utilizada no monitoramento "on-line" de processos químicos e físicos, como polimerizações e cristalizações (item 2.4.5). 


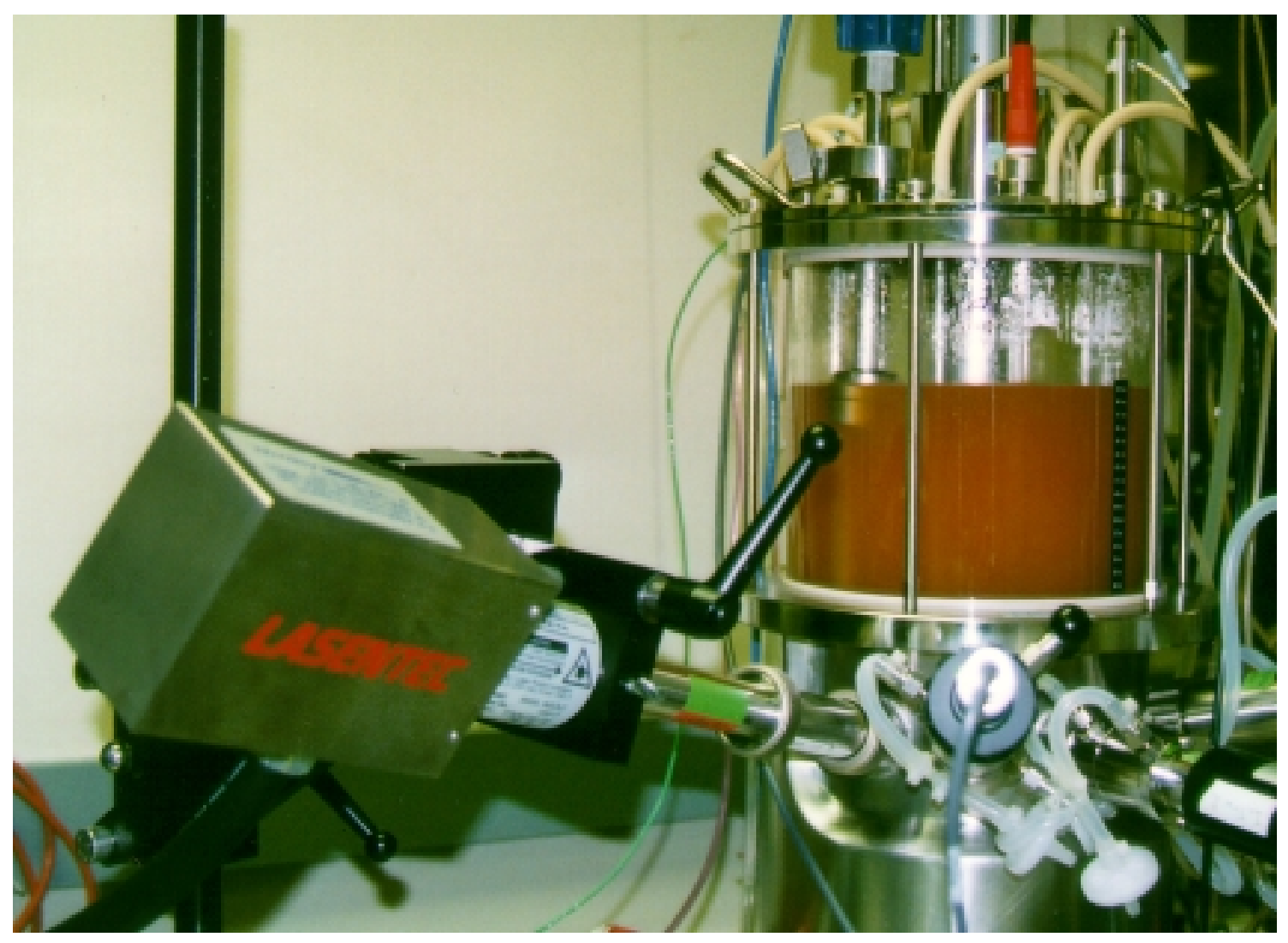

Figura 3.6 - Foto da sonda Lasentec FBRM inserida na lateral do fermentador

Apesar de ser um produto em uso comercial, sua aplicação no monitoramento de processos fermentativos é muito recente, não sendo conhecido até o momento nenhum trabalho científico publicado com sua utilização para esse fim.

Seu princípio de funcionamento baseia-se na análise da intensidade e duração da reflexão provocada por partículas ao serem iluminadas por um feixe rotativo de luz. Tal feixe é produzido no módulo central por um diodo laser (5mW, 780nm), enviado através de fibras óticas e encontra na sonda um sistema ótico em alta rotação que o encaminha ao meio de cultivo em alta velocidade $(2 \mathrm{~m} / \mathrm{s})$. Para processos em que o fluido apresenta baixas velocidades, como o caso do meio de cultura no fermentador utilizado, pode-se desprezar a velocidade da partícula e o tempo de duração da reflexão será diretamente proporcional ao comprimento da corda percorrida pelo feixe (Figura 3.7). 


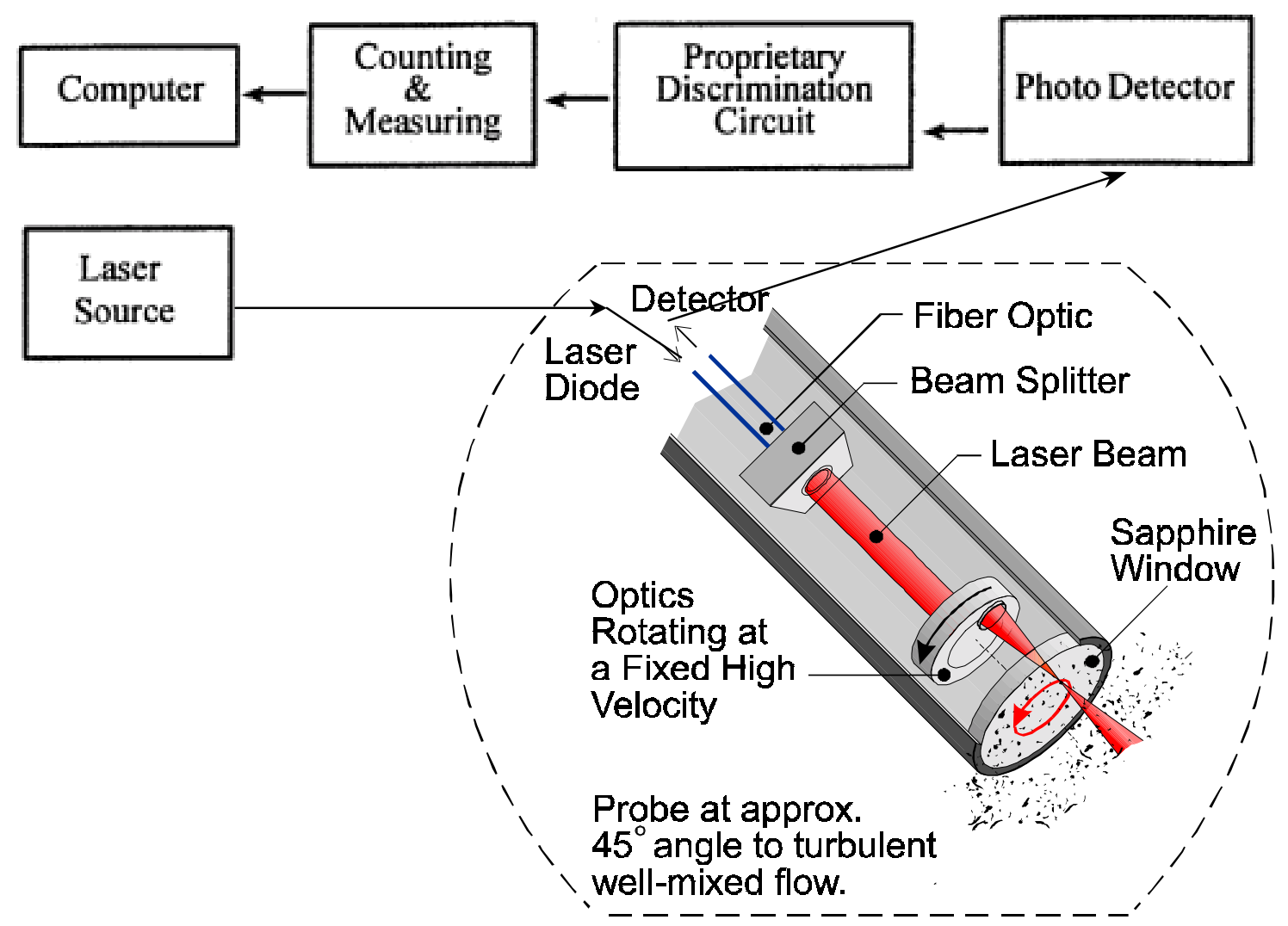

Figura 3.7 - Esquema do aparelho Lasentec FBRM, mostrando detalhe da ponta da sonda, onde se encontram as lentes giratórias fazendo o raio laser focar-se num ponto após a janela de safira, e o detetor do sinal refletido pelas partículas externas à sonda

Como o feixe pode atravessar a partícula em várias posições (não necessariamente em sua maior dimensão, o diâmetro), o resultado estatístico obtido com milhares de reflexões é a distribuição de comprimento de cordas das partículas em suspensão, como pode ser observado na Figura 3.8. Da análise dessa distribuição, e pela determinação de faixas de comprimentos onde mais provavelmente se situem as células (e não fragmentos ou aglomerados), pode-se estimar em tempo real a concentração celular e observar tendências a aumento ou diminuição do tamanho das células ao longo de um cultivo. Posteriormente este programa de aquisição e análise de dados foi 
atualizado para uma versão que permitia maior número de canais (comprimentos de cordas medidos).

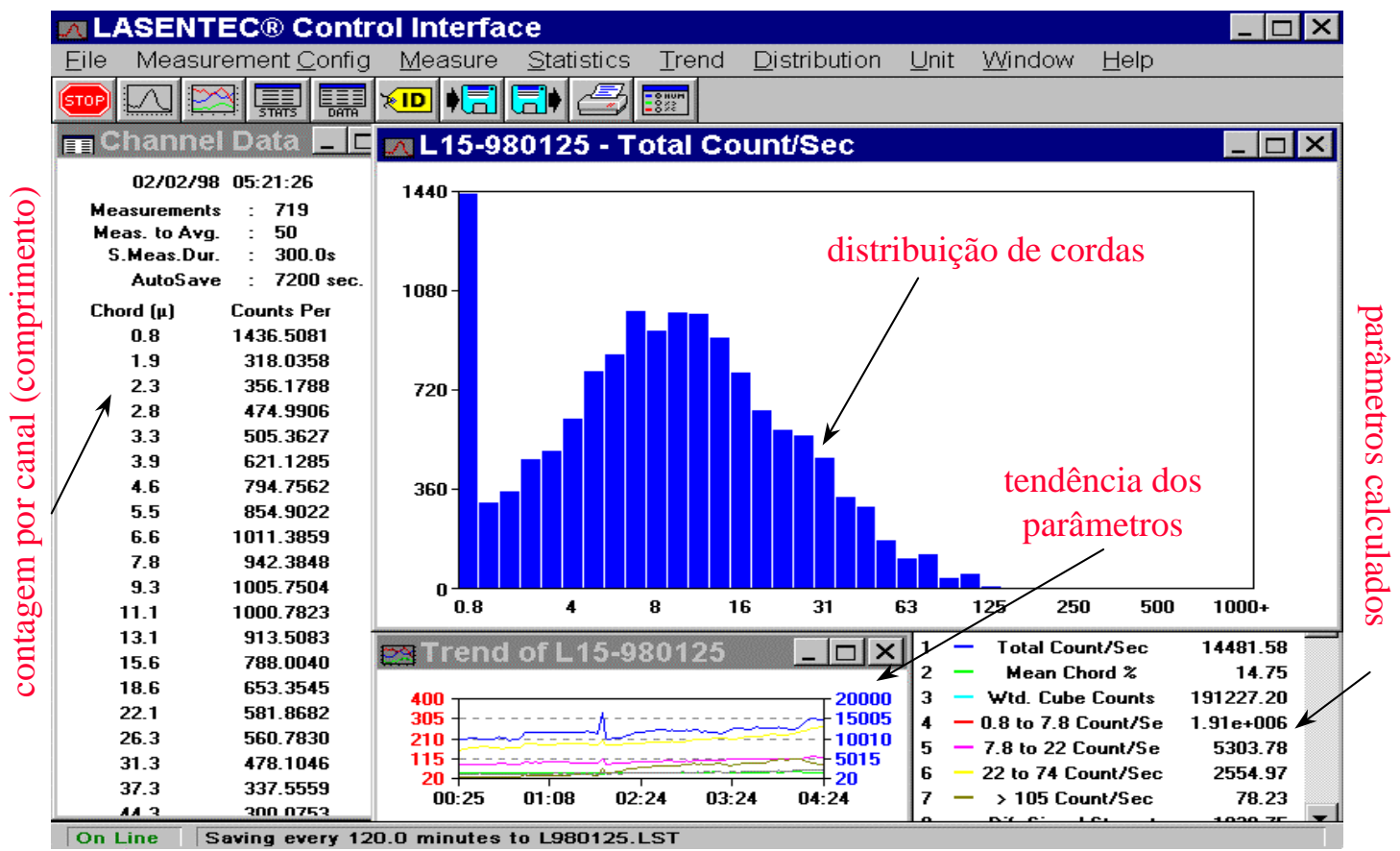

Figura 3.8 - Tela do programa de controle do Lasentec FBRM (versão utilizada no ensaio E5) 


\subsection{Cultivos realizados}

$\mathrm{Na}$ discussão dos resultados obtidos no capítulo seguinte, alguns ensaios realizados em biorreator de $15 \mathrm{~L}$ serão utilizados como exemplo do desenvolvimento de técnicas. Para facilitar a leitura, na Tabela 3.2 são apresentados as principais características destes ensaios. No Anexo, Tabelas A.1 a A.6, encontram-se os valores das principais variáveis destes ensaios, ao longo do tempo de cultivo.

Tabela 3.2 Ensaios apresentados e suas principais características

\begin{tabular}{|c|c|c|c|c|}
\hline ensaio & $\begin{array}{c}\text { célula } \\
\text { utilizada }\end{array}$ & produto & $\begin{array}{c}\text { duração } \\
\text { (dias) }\end{array}$ & principal objetivo \\
\hline E1 & BHK & rFVIII & 43 & oxigênio dissolvido \\
\hline E2 & BHK & rFVIII & 89 & agente tamponante e quelante \\
\hline E3 & BHK & rFVIII & 83 & oxigênio dissolvido \\
\hline E4 & BHK & rFVIII & 93 & temperatura \\
\hline E5 & hibridoma & anti-TNF & 91 & osmolalidade e tamanho da \\
célula (Lasentec)
\end{tabular}




\section{RESULTADOS E DISCUSSÃO}

\subsection{Processo de Perfusão}

O termo perfusão é empregado há muito tempo no cultivo de células animais, indicando ensaios contínuos onde as células são constantemente nutridas com meio de cultura fresco. O processo empregado neste trabalho pode ser definido, do ponto de vista de engenharia bioquímica, como um contínuo com retenção e recirculação externa de células (Figura 4.1). Continuamente parte do meio de cultura é retirado do fermentador e alimentado em um Sistema de Separação de Células (SSC) de alta eficiência, utilizando método gravitacional. Um dos efluentes, contendo elevada concentração celular, retorna ao reator (recirculação), enquanto que o outro, com concentração celular muito baixa (da ordem de 100 vezes menor que no fermentador), é retirado do sistema e enviado para a recuperação do produto. Para a manutenção do volume no biorreator, meio de cultura fresco é continuamente adicionado (controlado pelo sensor de nível).

Devido à alta eficiência do SSC, a concentração celular no reator tende a alcançar valores muito elevados, podendo ocorrer limitação na transferência de oxigênio. Nesta situação, haveria grande flutuação na concentração celular ao longo do processo, causando perturbações nas velocidades específicas de consumo e produção e, portanto, variabilidade na qualidade do produto. Para se evitar estas flutuações, há ainda um sistema de purga. Após a fase inicial de acumulação de células (cerca de 10 dias), toda vez que a concentração celular atinge o valor desejado, há o acionamento da bomba de purga, que elimina parte do caldo. Tal bomba pode ser comandada através de diferentes estratégias. A estratégia habitual consiste em acionar a bomba cada vez que a 
densidade ótica, medida pelo turbidímetro, atinja determinado valor, supondo que essa medida seja uma boa estimativa da concentração celular.

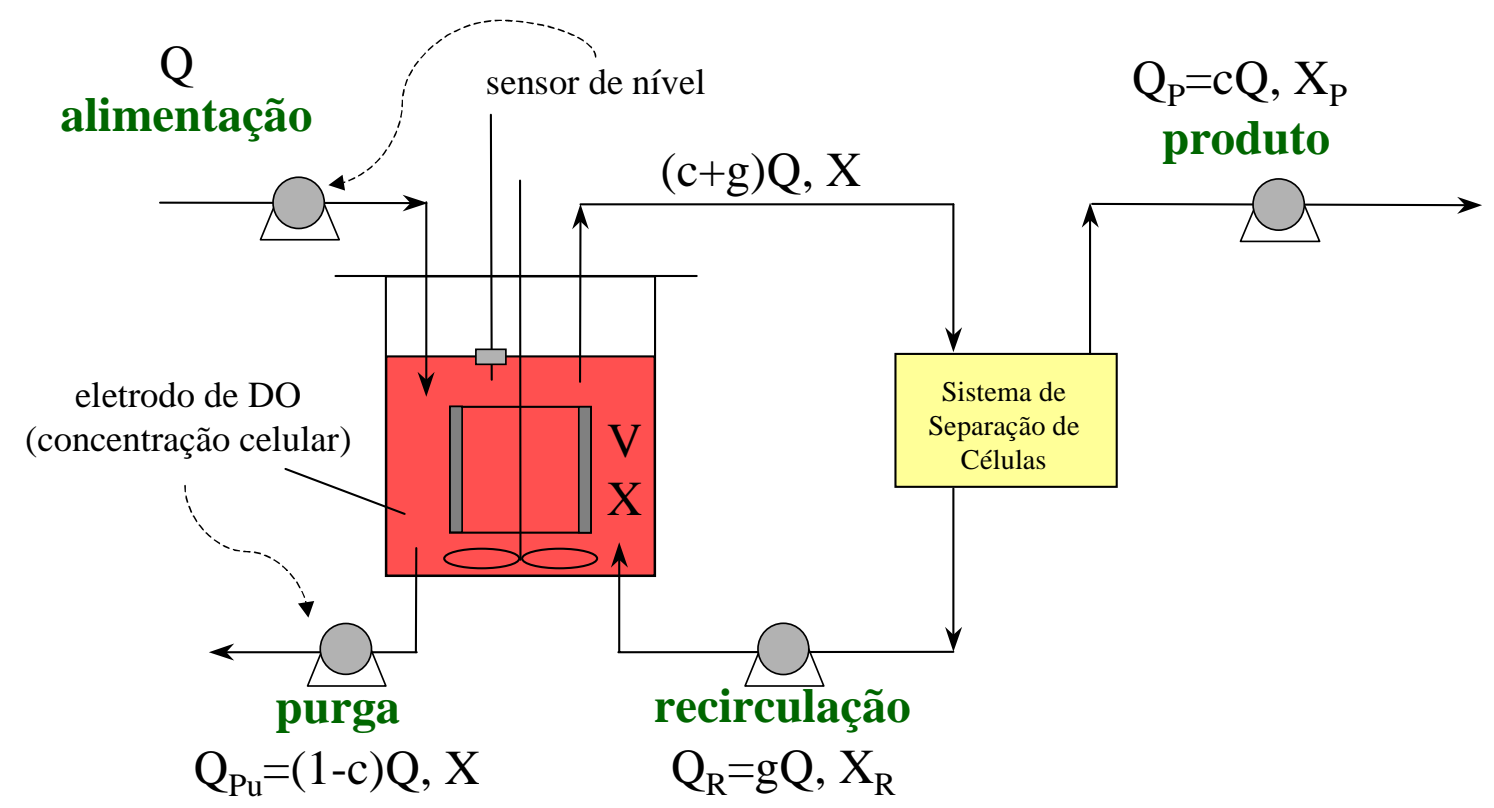

Figura 4.1 - Esquema de um sistema de cultivo em perfusão. Nomenclatura: Q=vazão de alimentação; $\mathrm{X}=$ concentração celular; $\mathrm{V}=$ volume de reação; índices $\mathrm{P}=$ linha de produto, $\mathrm{R}=$ linha de recirculação e $\mathrm{Pu}=$ linha de purga; $\mathrm{c}=$ fração da vazão de alimentação que sai na linha do produto; $g=$ fração da vazão de alimentação que sai na linha de purga

\subsubsection{Fase inicial}

O biorreator, após o preparo das conexões e da gaiola com a tubulação de silicone, é esterilizado e mantido por cerca de dois dias com meio de cultura estéril e todas suas bombas funcionando em circuito fechado, para verificar a esterilidade em todo sistema. Após esse período, o meio de cultura é substituído, pois um de seus componentes principais, a glutamina, degrada-se rapidamente à temperatura ambiente ou superior. $\mathrm{O}$ inóculo na maior parte dos ensaios foi obtido a partir de cerca de $0,5 \mathrm{~L}$ de 
caldo de um cultivo de outro fermentador do laboratório, que se encontrava em alta concentração celular (em torno de 20 milhões de células por mL), resultando em concentração celular inicial $\left(\mathrm{X}_{\mathrm{o}}\right)$ de cerca de $\frac{0,5 L .20 E 6 \mathrm{cél} / \mathrm{mL}}{12 L}=0,8 E 6 \mathrm{cé} / \mathrm{mL}$.

Quando não havia nenhum reator em condição estável para fornecer células como inóculo, este foi gerado através de sucessivos sub-cultivos em garrafas "Roller", a partir de uma ampola criopreservada com a cepa em uso.

Utilizando-se do meio presente no biorreator, as células se multiplicam exponencialmente, e, após cerca de 2 ou 3 dias, atingem a concentração celular da ordem de 2 E6 cel/mL. Para evitar que as células saiam da fase exponencial de crescimento por falta de algum substrato, monitora-se as concentrações de glicose e glutamina nesta fase. Quando se calcula que o substrato passará a ser limitante, inicia-se alimentação com meio fresco, acompanhada da retirada de meio exaurido, ou seja, inicia-se a perfusão.

Para tanto, aciona-se a bomba de recirculação simultaneamente com a de retirada de produto, ainda com vazão bastante baixa. A vazão de produto $\left(\mathrm{Q}_{\mathrm{P}}=\mathrm{CQ}\right)$ é corrigida diariamente, de forma a manter constante a vazão de alimentação por célula. Esta quantidade é chamada de vazão específica de perfusão expressa por unidade de célula (VEP), e equivale à tradução do inglês de Cell Specific Perfusion Rate (CSPR). Seu valor é determinado em função das características de cada célula e da composição do meio de cultura, sendo igual a $0,5 \mathrm{~nL}$ de meio/(célula.dia) nos cultivos com BHK, e 0,25nL de meio/(célula.dia) nos cultivos com hibridoma. A vazão específica de alimentação $(\mathrm{D}=\mathrm{Q} / \mathrm{V})$ é definida como o produto de VEP pela concentração celular $(\mathrm{X}$, em número de células por unidade de volume). Como referência, temos, para $\mathrm{VEP}=0,5 \mathrm{~nL} /\left(\right.$ cel.dia) e $\mathrm{X}=20 \mathrm{E} 6 \mathrm{cel} / \mathrm{mL}$, D resulta em $10 \mathrm{dia}^{-1}$, ou $0,42 \mathrm{~h}^{-1}$. Num reator de 
12 litros de volume útil, este número equivale a uma vazão de 120L/dia, ou $83,3 \mathrm{~mL} / \mathrm{min}$.

Durante essa fase de aumento de concentração celular, a bomba de purga não é acionada e, devido à grande eficiência do Sistema de Separação de Células (SSC), praticamente todas as células permanecem no reator, aumentando a concentração exponencialmente até chegar ao valor desejado.

Um exemplo de fase inicial do processo (Ensaio E3) é apresentado na Figura 4.2. Observa-se aqui que a concentração celular $(\mathrm{X})$ cresce de modo praticamente exponencial desde o inóculo, acompanhada pela densidade ótica (DO).

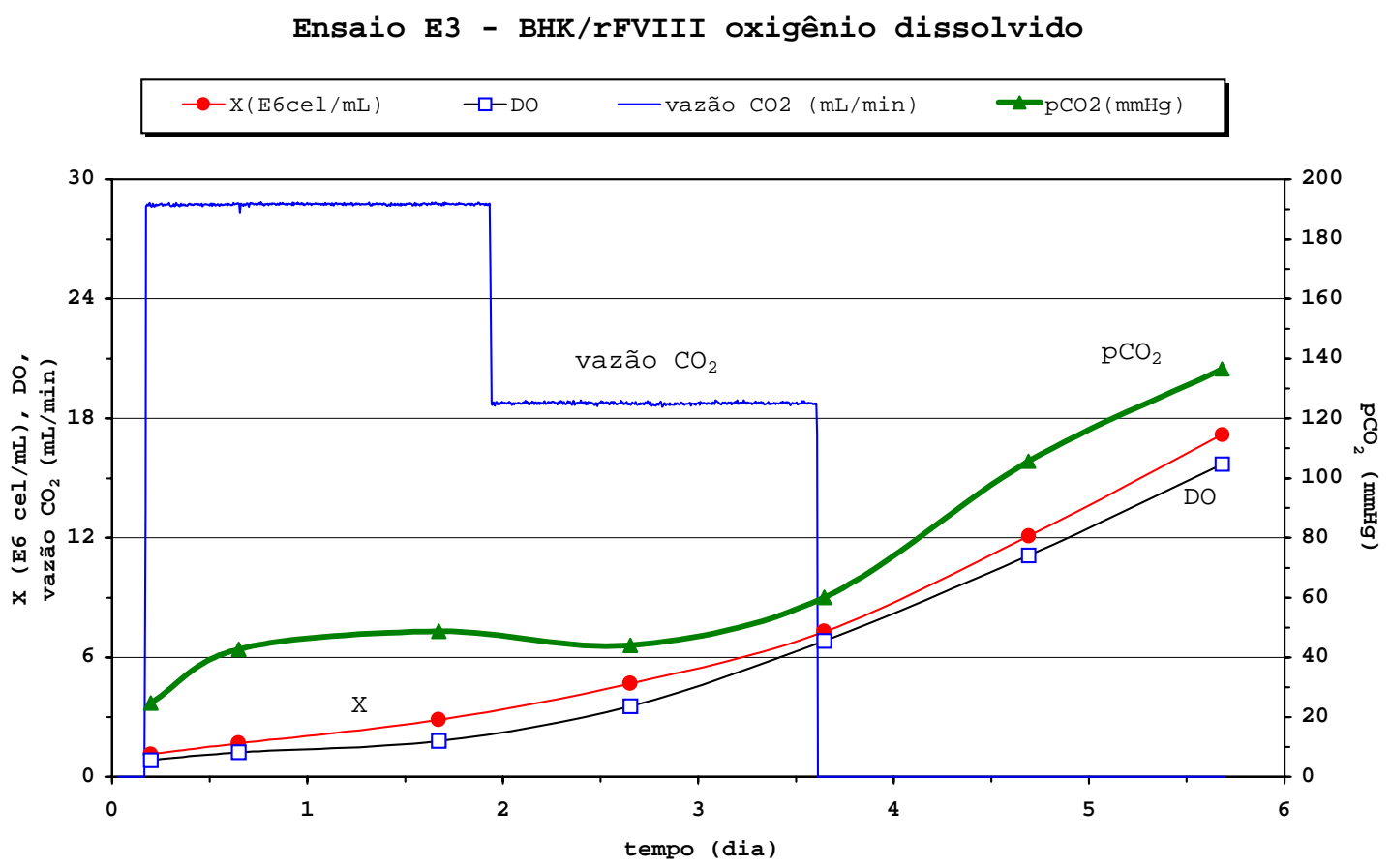

Figura 4.2 - Concentração celular, vazão de gás carbônico e pressão parcial de gás carbônico ao longo dos primeiros dias de cultivo do ensaio E3

Uma preocupação na fase inicial deste ensaio foi o controle da concentração de gás carbônico dissolvido $\left(\mathrm{p}_{\mathrm{CO} 2}\right)$. O gás carbônico, em concentrações muito altas 
(tipicamente acima de $150 \mathrm{mmHg}$, ou cerca de 0,2 atm), é tóxico para as células. No entanto, ensaios anteriores do grupo, cuja fase inicial apresentou valores de $\mathrm{p}_{\mathrm{CO} 2}$ abaixo de $38 \mathrm{mmHg}$ (equivalente à atmosfera de ar com $5 \%$ de $\mathrm{CO}_{2}$ ), sofreram algum tipo de inibição, tendo afetado a velocidade específica de crescimento $(\mu)$. Como no processo de perfusão somente o período em estado pseudo-estacionário gera produto que pode ser validado, deve-se evitar qualquer demora excessiva na fase inicial não produtiva, por exemplo devido à redução na velocidade de crescimento.

Posteriormente neste ensaio, durante a fase de perfusão, sob alta concentração celular, as células irão gerar suficiente $\mathrm{CO}_{2}$ através da respiração, de modo que a preocupação será manter p $_{\mathrm{CO} 2}$ baixo. No entanto, durante a fase inicial de acumulação de células, a quantidade de bicarbonato de sódio presente no meio deste ensaio não seria suficiente para manter a concentração de gás carbônico dissolvido adequada ao crescimento. Para contornar esta limitação, foi adicionado gás carbônico aos gases necessários ao controle da concentração de oxigênio dissolvido em 50\%. O perfil da vazão de gás carbônico e a pressão parcial deste gás no meio de cultivo ( $\left.\mathrm{p}_{\mathrm{CO} 2}\right)$ no meio ao longo dos primeiros dias de ensaio são também apresentados na Figura 4.2. Observa-se que ao longo dos primeiros dois dias de cultivo, graças à adição do gás carbônico, sua pressão parcial manteve-se muito próxima do valor desejado (38mmHg). Com o crescimento celular, e consequente produção maior de gás pela respiração, pôdese diminuir a vazão para $20 \mathrm{~mL} / \mathrm{min}$ a partir do dia 2 , até o dia 3,6 , quando não mais foi necessária a adição do gás. A partir daí, a produção pela biomassa, que já passava de 7E6 cel/mL, já era suficiente para evitar uma limitação do crescimento.

A concentração de oxigênio dissolvido é mantida constante em $50 \%$ através da variação da vazão dos gases que circulam pela membrana de silicone. Para que isso seja 
obtido ao longo destes 5 dias iniciais, são necessárias alterações manuais na escolha de quais gases são injetados na tubulação de silicone e com que vazão (Figura 4.3). No início do processo, com baixíssima concentração celular (em torno de 1E6 cel/mL), utiliza-se o gás nitrogênio com vazão fixa e ar com vazão controlada pelo sistema DCU. Com isso se varia a fração de oxigênio no gás presente na membrana de silicone, além de se alterar a pressão conforme o controlador varia a vazão do ar. Após algumas horas de cultivo, diminui-se gradualmente a vazão do gás nitrogênio. Na fase seguinte, alimenta-se a tubulação de silicone somente com ar, até que este não seja capaz de promover toda a transferência de oxigênio necessário ao cultivo, agora com mais células respirando. Passa-se então a fixar a vazão de ar e configurar o controlador para atuar na vazão de oxigênio. Nesta fase não se pode fixar a vazão de oxigênio e atuar sobre a vazão de ar, pois o controle atuaria na situação oposta da desejada, isto é, se a concentração de oxigênio dissolvido estiver acima da desejada, o fechamento da vazão de ar implicaria num aumento da fração de oxigênio e, portanto, da transferência de oxigênio, afastando cada vez mais a concentração de oxigênio dissolvido de seu setpoint. Posteriormente (não mostrado na Figura 4.3), a linha de ar será totalmente fechada, e circulará apenas o gás oxigênio pela tubulação de silicone. 


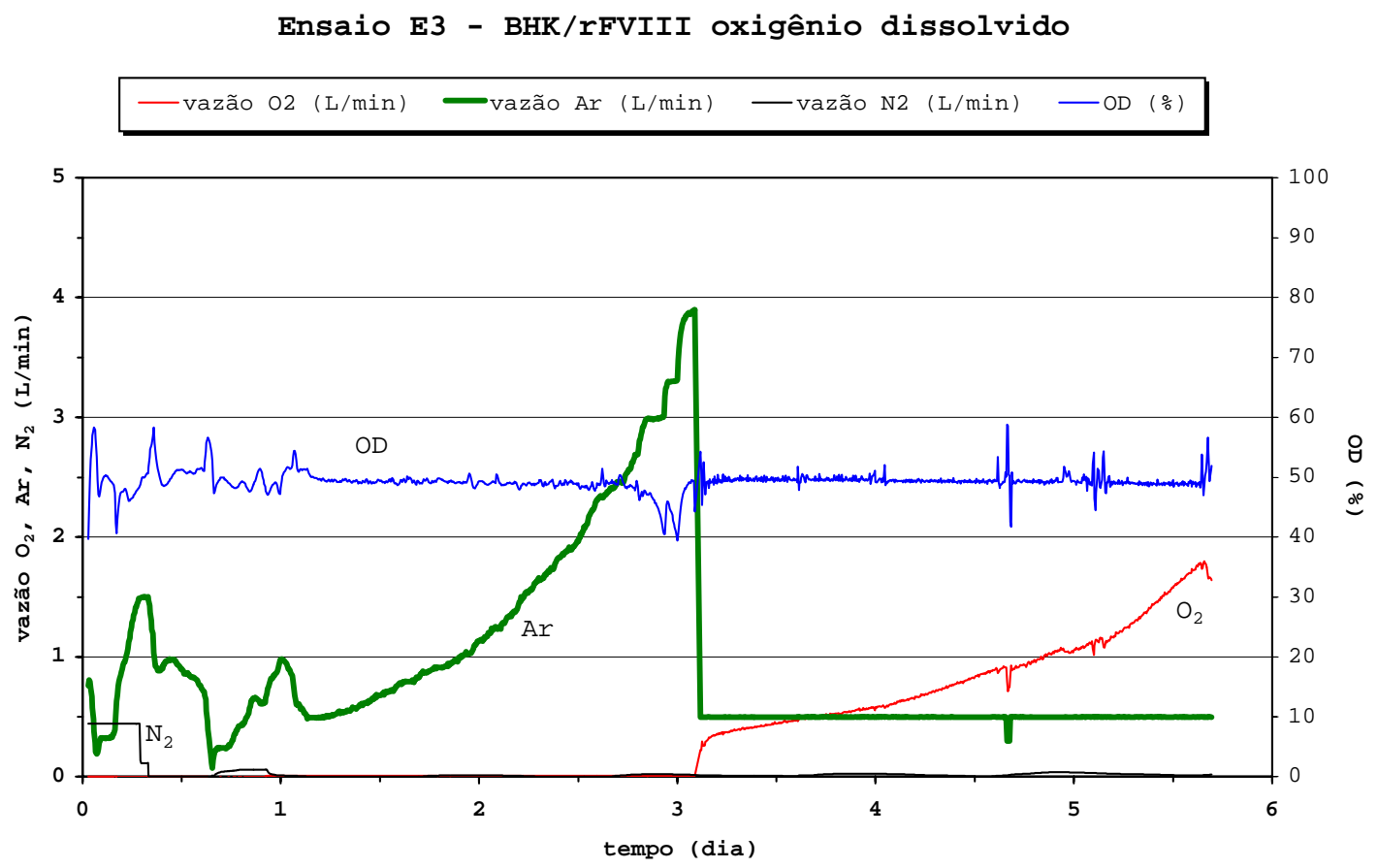

Figura 4.3 - Vazão de ar, nitrogênio e oxigênio e concentração de oxigênio dissolvido ao longo dos primeiros dias de cultivo do ensaio E3

\subsubsection{Fase em perfusão}

Quando se atinge a concentração celular (X) desejada, tipicamente 20E6 cel/mL, o programa LabVIEW passa a acionar a bomba de purga, retirando caldo de cultivo com alta concentração celular, permitindo que essa seja controlada. Para tanto, o sistema se baseia na estimativa da concentração celular dada pela medida "on-line" da densidade ótica (DO), multiplicada pelo fator $\mathrm{DO} / \mathrm{X}$, determinado durante o aumento da concentração celular. Nos dias seguintes, com base nas contagens com o hemacitômetro ao microscópio, tal fator é ajustado e obtém-se a primeira fase em regime pseudoestacionário. Deve-se lembrar que, diferentemente de um cultivo contínuo típico (quimiostato), a concentração celular não é controlada pelo residual da fonte de carbono, ou seja, pelo equilíbrio entre crescimento e lavagem. Neste caso, o processo é definido 
como um turbidostato, com a concentração celular mantida quase constante através de um controle externo ao sistema.

Após a primeira fase pseudo-estacionária, efetua-se alguma alteração no processo como, por exemplo, variação do set-point da temperatura ou da concentração de oxigênio dissolvido, e mantém-se assim o sistema por alguns dias (cerca de uma semana), para se obter dados suficientes para se definir o novo estado, a partir de médias das medidas diárias. Dessa forma, sucessivamente obtém-se valores médios para cada situação do processo.

Com base na nomenclatura empregada na Figura 4.1, pode-se fazer um balanço global das células totais no sistema (Equação 4.1)

$V \frac{d X}{d t}=V\left(\frac{d X}{d t}\right)_{\text {crescimento }}-Q_{P} X_{P}-Q_{P u} X$

Em estado estacionário, temos:

$$
\begin{aligned}
& V\left(\frac{d X}{d t}\right)_{\text {crescimento }}=c Q X_{P}+(1-c) Q X \\
& \mu X=\frac{Q}{V}\left[c X_{P}+(1-c) X\right]=D X\left[c \frac{X_{P}}{X}+1-c\right] \\
& \mu=D\left[1-c \frac{\left(X-X_{P}\right)}{X}\right]
\end{aligned}
$$

onde $\mu$ é a velocidade específica de crescimento, $\mathrm{D}=\mathrm{Q} / \mathrm{V}$ é a vazão específica de alimentação e c é a fração da vazão de alimentação que sai na linha do produto, com respectiva concentração celular $\mathrm{X}_{\mathrm{P}}$.

Ainda utilizando as definições da Figura 4.1, pode-se definir eficiência do SSC, como sendo a porcentagem das células que saem do reator que voltam após o separador (Equação 4.5). 
eficiência $($ em\% $)=\frac{Q_{R} X_{R}}{(c+g) Q X} 100=\frac{g X_{R}}{(c+g) X} 100$

Fazendo-se o balanço de células no Sistema de Separação de Células chega-se a Equação 4.6:

$$
V_{S S C} \frac{d X}{d t}=(c+g) Q X-c Q X_{P}-g Q X_{R}
$$

Em estado estacionário, temos:

$(c+g) X=c X_{P}-g X_{R}$

eficiência $($ em\% $)=\frac{(c+g) X-c X_{P}}{(c+g) X} 100$

Como visto acima, o sistema de perfusão com controle da concentração celular depende de uma boa estimativa "on-line" de X. Utilizando-se a densidade ótica para se fazer esta estimativa, pode-se de tempos em tempos recalibrar a avaliação simplesmente corrigindo a relação DO/X com base na última leitura do hemacitômetro.

Um bom exemplo de funcionamento disso está na Figura 4.4, que apresenta os valores de $\mathrm{X}$, DO e da relação DO/X a cada amostra. O ensaio E1 se iniciou com o mesmo objetivo do ensaio E3, que será visto adiante no item 4.2.1, porém devido a suspeita de uma contaminação, foi encerrado após 45 dias de cultivo. Tal contaminação acabou se mostrando muito perigosa, pois se alojava no biorreator de modo imperceptível, pois não alterava velocidades de consumo de substrato nem de crescimento, mas sim a qualidade do produto (má glicosilação). Neste ensaio E1, a relação DO/X se manteve em torno de 1,1 por boa parte do cultivo, requerendo uma recalibração para 0,7 após cerca de 25 dias de cultivo, provavelmente em consequência da alteração na temperatura do reator. 


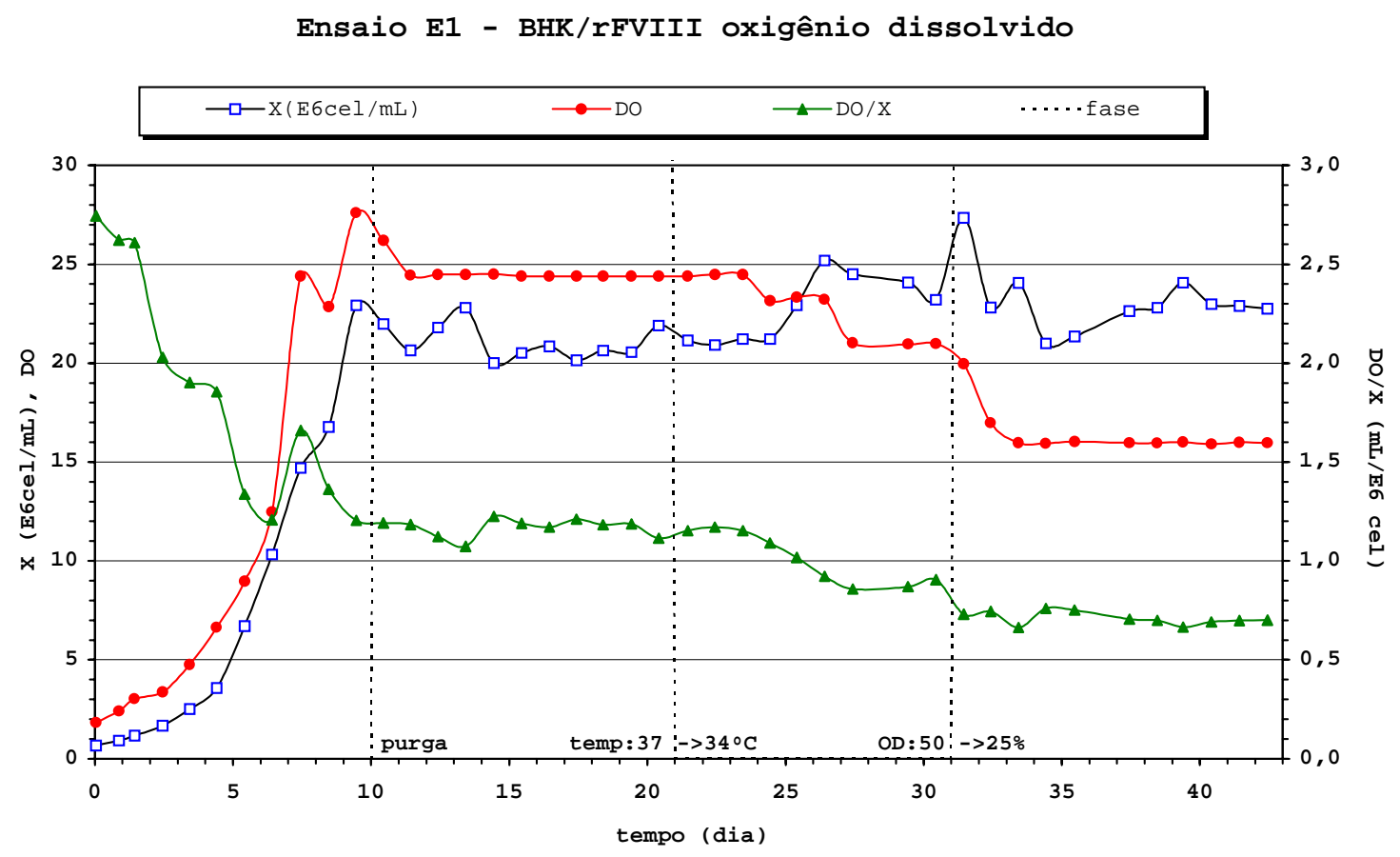

Figura 4.4 - X, DO, DO/X ao longo do ensaio E1

Como exemplo intermediário das situações de controle da concentração celular, o ensaio E3 (Figura 4.5) apresenta uma relação DO/X bastante estável em quase todo cultivo. No entanto, durante uma forte variação da concentração de oxigênio dissolvido entre os dias 60 e 70 de cultivo, a medida de densidade ótica aumentou enquanto a concentração celular caia rapidamente. Como consequência, DO/X praticamente triplicou seu valor e perdeu-se o controle da concentração celular, atingindo valores como 10E6 células/mL. Mesmo assim, convém salientar que neste período a vazão de purga manteve-se quase em zero (dados não apresentados), o que significa que a diminuição da concentração celular não teria sido evitada caso houvesse uma forma melhor de se estimar X. 


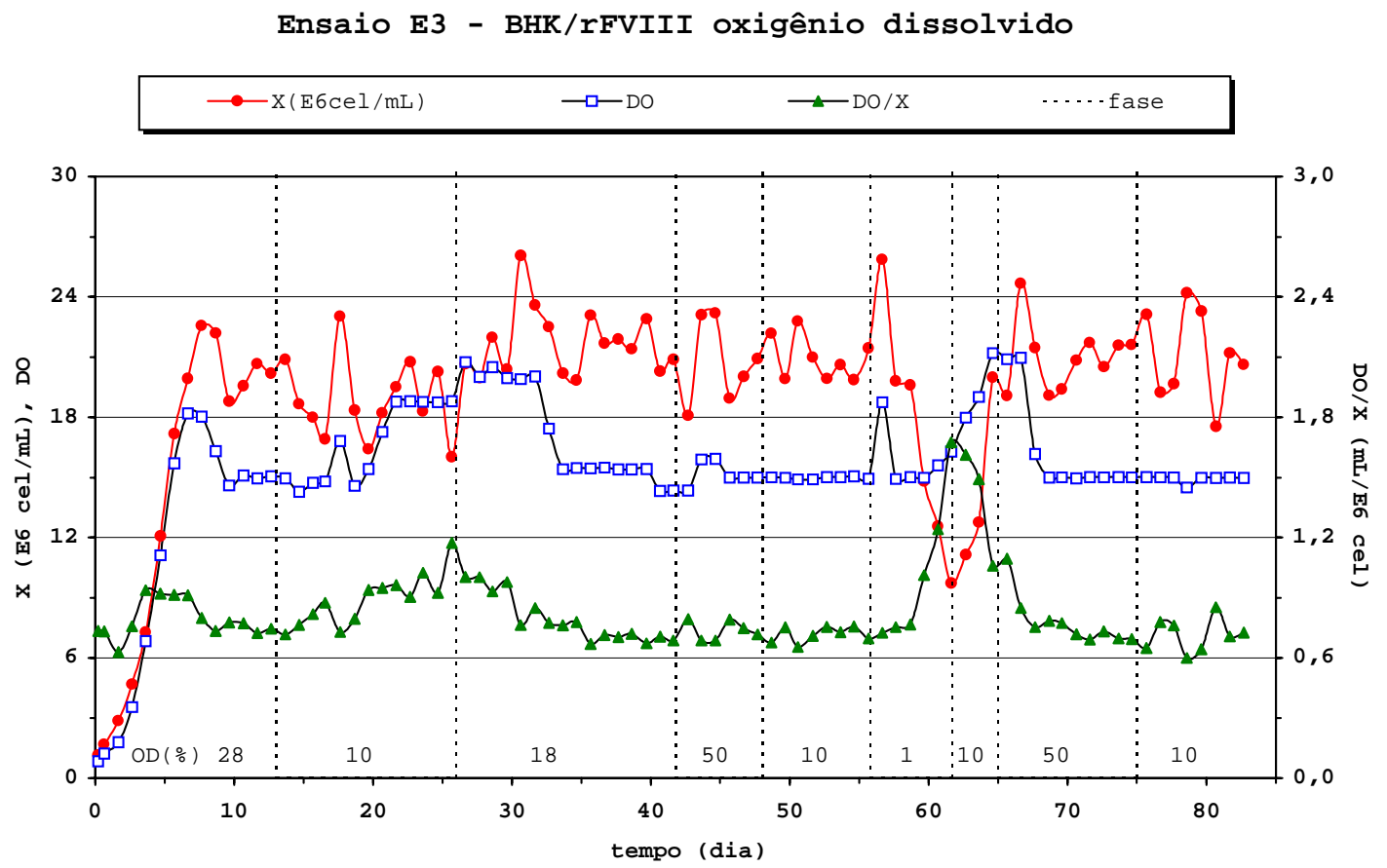

Figura 4.5 - Concentração celular (X), densidade ótica (DO) e fator de calibração (X/DO) em função do tempo, no ensaio E3

Ainda para a avaliação da utilização da densidade ótica para estimar a concentração celular, serão analisados os resultados do ensaio E2, cujo objetivo foi o estudo de diferentes agentes tamponantes e quelantes a serem adicionados ao meio de cultivo, para contornar um problema operacional.

O meio de cultura utilizado não apresentava bicarbonato de sódio em sua composição, para evitar que se atingisse valores muito elevados de gás carbônico dissolvido no caldo, que se demonstrou inibitório à produção de fator VIII pelas células BHK. Devido à falta do usual tampão no meio, grandes quantidades de hidróxido de sódio foram adicionados à linha de alimentação de meio, para manter o pH controlado em 6,80. Em função deste fato e da presença de metais no meio de cultura, começou a se perceber precipitações nesta linha, após o ponto de adição da base, pois o pH atingia 
pontualmente valores muito altos (superiores a 12). Por este fato, passou-se a buscar algum elemento a ser adicionado ao meio de cultura que evitasse a elevação brusca do $\mathrm{pH}$ na linha (agente tamponante), assim como ajudasse a sequestrar parte desses íons metálicos (agente quelante). Como resultado o ensaio E2 apresenta uma série de fases não completamente definidas, isto é, nas quais não se atingiu claramente um estado pseudo-estacionário, pois bastava se perceber a formação de precipitados na linha de alimentação de meio que se descontinuava o agente em estudo e se passava a uma nova fase. Durante todo o ensaio, desejou-se que a concentração celular se mantivesse constante e controlada em $20 \mathrm{E} 6 \mathrm{cel} / \mathrm{mL}$, e se utilizou novamente da estratégia de se calibrar a relação DO/X e acionar a bomba de purga, quando DO atingisse determinado valor. Os resultados dessa tentativa são apresentados na Figura 4.6. O que se observa nesta figura é que a concentração celular esteve muito mal controlada, flutuando entre 13 e 28 E6 cel/mL, devido à inconsistência da relação DO/X, que oscilou entre 0,70 e 1,35. Este exemplo demonstra claramente que nem sempre este sistema de controle da perfusão é eficaz, devendo se procurar alternativas para ensaios atípicos como esse. 


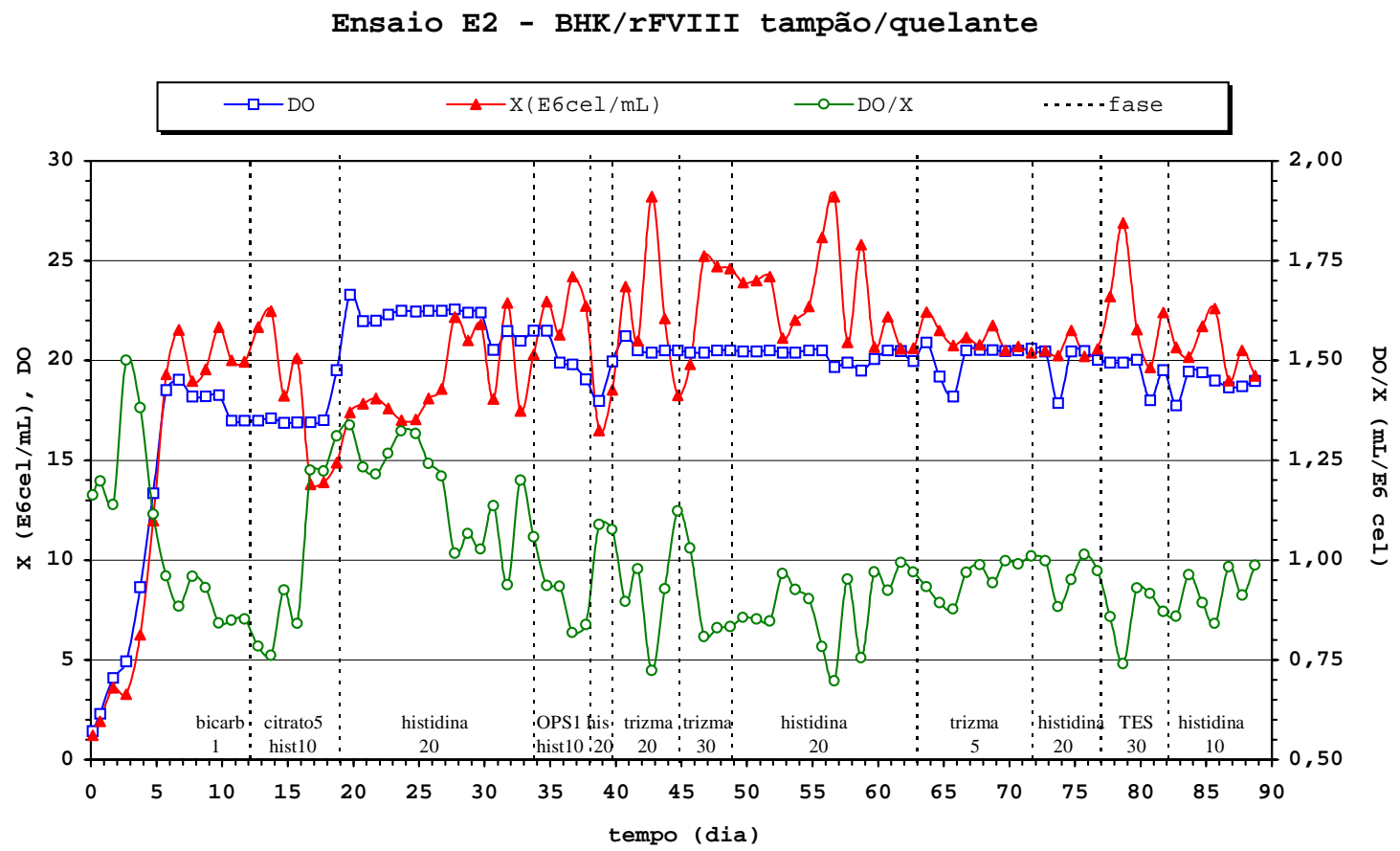

Figura 4.6 - X, DO, DO/X ao longo do ensaio E2

\subsubsection{Variáveis de processo / Memorial de cálculo}

A partir de cada amostra nos ensaios, uma série de dados é coletada, que pode ser sub-dividida em 3 categorias: leituras no biorreator, análise das amostras e parâmetros calculados. As leituras no biorreator, assim como o resultado das análises das amostras foram descritas no Capítulo 3. Por se tratar de ensaios em perfusão, o cálculo das velocidades específicas requer o uso das vazões líquidas, definidas no item anterior 4.1.2. Desta forma, se apresenta a seguir a forma de cálculo destas velocidades, assim como grandezas auxiliares.

Para cada variável, serão apresentados, a seguir, sua abreviatura, nome, unidade e seu valor real, obtido de uma amostra escolhida como referência: amostra 54, tempo de cultivo 53,7 dias, do ensaio E3. 
Desta forma, evita-se a apresentação de todos os dados obtidos, selecionando-se em cada caso aqueles mais significativos para a análise e discussão desenvolvidas. Tabelas com seus valores a cada instante de cultivo, de cada ensaio estão presentes no Anexo.

\begin{tabular}{|c|c|c|c|}
\hline abrev. & nome & unidade & valor $(\mathrm{i} / \mathrm{i}-1)$ \\
\hline $\mathrm{i}$ & amostra & & 54 \\
\hline $\mathrm{t}$ & tempo de cultivo & dia & $53,67 / 52,67$ \\
\hline $\mathrm{V}$ & volume de meio no biorreator & $\mathrm{L}$ & 12,00 \\
\hline $\mathrm{Q}_{\mathrm{P}}$ & vazão de retirada de produto & L/dia & 120,0 \\
\hline $\mathrm{Q}_{\mathrm{Pu}}$ & vazão de purga & $\mathrm{L} / \mathrm{dia}$ & 5,6 \\
\hline $\mathrm{Q}_{\mathrm{B}}$ & vazão de base $(\mathrm{NaOH})$ & $\mathrm{L} / \mathrm{dia}$ & 5,1 \\
\hline $\mathrm{Q}_{\mathrm{R}}$ & vazão de recirculação & L/dia & 86,4 \\
\hline $\mathrm{Q}_{\mathrm{L}}$ & vazão de líquidos & L/dia & 120,4 \\
\hline $\mathrm{X}$ & concentração celular (viáveis) & E6 cel/mL & 20,62 \\
\hline viab & viabilidade (\% viáveis dividido por total) & $\%$ & 98,4 \\
\hline$X_{t}$ & concentração celular total (viáveis + não-viáveis) & E6 cel/mL & $20,95 / 20,35$ \\
\hline$X_{\text {ref }}$ & concentração celular total de referência & E6 cel/mL & 20,27 \\
\hline$X_{P}$ & concentração celular total no produto & E6 cel/mL & 0,152 \\
\hline Glic & concentração de glicose & $\mathrm{mM}$ & $2,75 / 2,75$ \\
\hline Glic $_{\mathrm{A}}$ & concentração de glicose na alimentação & $\mathrm{mM}$ & 5,55 \\
\hline Gln & concentração de glutamina & $\mathrm{mM}$ & $2,51 / 2,47$ \\
\hline $\mathrm{Gln}_{\mathrm{A}}$ & concentração de glutamina na alimentação & $\mathrm{mM}$ & 5,00 \\
\hline $\mathrm{P}$ & concentração do produto (UA=unidades arbitrárias) & $\mathrm{UA} / \mathrm{mL}$ & $81 / 65$ \\
\hline$\mu$ & velocidade específica de crescimento & $1 /$ dia & 0,570 \\
\hline$\mu_{\text {Glic }}$ & velocidade específica de consumo de glicose & $\mathrm{pmol} / \mathrm{cel} / \mathrm{dia}$ & 1,39 \\
\hline$\mu_{\mathrm{Gln}}$ & velocidade específica de consumo de glutamina & $\mathrm{pmol} / \mathrm{cel} / \mathrm{dia}$ & 1,25 \\
\hline$\mu_{\mathrm{P}}$ & velocidade específica de produção & $\mu \mathrm{UA} / \mathrm{cel} / \mathrm{dia}$ & 33 \\
\hline \multicolumn{4}{|c|}{$X_{r e f}=\frac{\left(X t_{i}-X t_{i-1}\right)}{\ln \left(\frac{X t_{i}}{X t_{i-1}}\right)}=\frac{(20,95-20,35)}{\ln \left(\frac{20,95}{20,35}\right)}=20,65$} \\
\hline \multicolumn{4}{|c|}{$\frac{\left(X t_{i}-X t_{i-1}\right)}{t_{i}-t_{i-1}} V+X_{P} Q_{P}+X_{r e f} Q_{P u} \quad \frac{(20,95-20,35)}{53,67-52,67} 12+0,152.120+20,65.5,58$} \\
\hline \multicolumn{4}{|c|}{$\mu=\frac{X_{r e f} V}{20,65.12}$} \\
\hline
\end{tabular}




$$
\begin{aligned}
& \mu_{P}=\frac{\frac{\left(P_{i}-P_{i-1}\right) V}{t_{i}-t_{i-1}}+P_{i-1} Q_{L}}{X_{r e f} V}=\frac{\frac{(81-65) 12}{53,67-52,67}+65.120,5}{20,65.12}=32,4 \\
& \mu_{\text {Glic }}=\frac{\frac{\left(\text { Glic }_{i-1}-\text { Glic }_{i}\right) V}{t_{i}-t_{i-1}}+\left(\text { Glic }_{A}-\text { Glic }_{i}\right) Q_{L}}{X_{r e f} V}=\frac{\frac{(2,75-2,75) 12}{53,67-52,67}+(5,55-2,75) 120,5}{20,65.12}=1,36 \\
& \mu_{G l n}=\frac{\frac{\left(G \ln _{i-1}-G \ln _{i}\right) V}{t_{i}-t_{i-1}}+\left(G \ln _{A}-G \ln _{i}\right) Q_{L}}{X_{r e f} V}=\frac{\frac{(2,51-2,47) 12}{53,67-52,67}+(5-2,47) 120,5}{20,65.12}=1,23
\end{aligned}
$$

Com relação à perfusão descrita no item anterior, pode-se calcular a velocidade específica de crescimento da mesma amostra a partir da Equação 4.4, apresentando pequeno desvio em relação ao calculado anteriormente devido ao fato de se ter desconsiderado a vazão de hidróxido de sódio.

$\mu=D\left[1-c \frac{\left(X-X_{P}\right)}{X}\right]=\frac{125,6}{12}\left[1-0,96 \frac{(20,95-0,152)}{20,95}\right]=0,49$

onde $\mathrm{Q}=\mathrm{Q}_{\mathrm{P}}+\mathrm{Q}_{\mathrm{Pu}}=125,6 ; \mathrm{c}=\mathrm{Q}_{\mathrm{P}} / \mathrm{Q}=0,96$ e $\mathrm{g}=\mathrm{Q}_{\mathrm{R}} / \mathrm{Q}=0,69$

Da mesma forma, a partir da Equação 4.8, pode-se calcular a eficiência do SSC:

eficiência $($ em\% $)=\frac{(c+g) X-c X_{P}}{(c+g) X} 100=\frac{(0,96+0,69) 20,95-0,96.0,152}{(0,96+0,69) 20,95}=99,6$

\subsection{Sistema de transferência de oxigênio por difusão em membrana de silicone}

O oxigênio dissolvido, ou pressão parcial do gás oxigênio, é, sem dúvida, a variável de controle mais problemática em qualquer sistema fermentativo, devido à sua dinâmica muito rápida e devido à baixa solubilidade do gás no meio de cultura. Como visto anteriormente (item 2.3), nos cultivos com células animais, tenta-se evitar o uso de sistema de transferência de oxigênio por aspersão de gases, devido ao estresse por 
cisalhamento imposto à célula, em consequência da ruptura das bolhas de gás na superfície do líquido. O sistema empregado, livre de bolhas, utiliza difusão por membrana de silicone (Figuras 4.7 e 4.8).

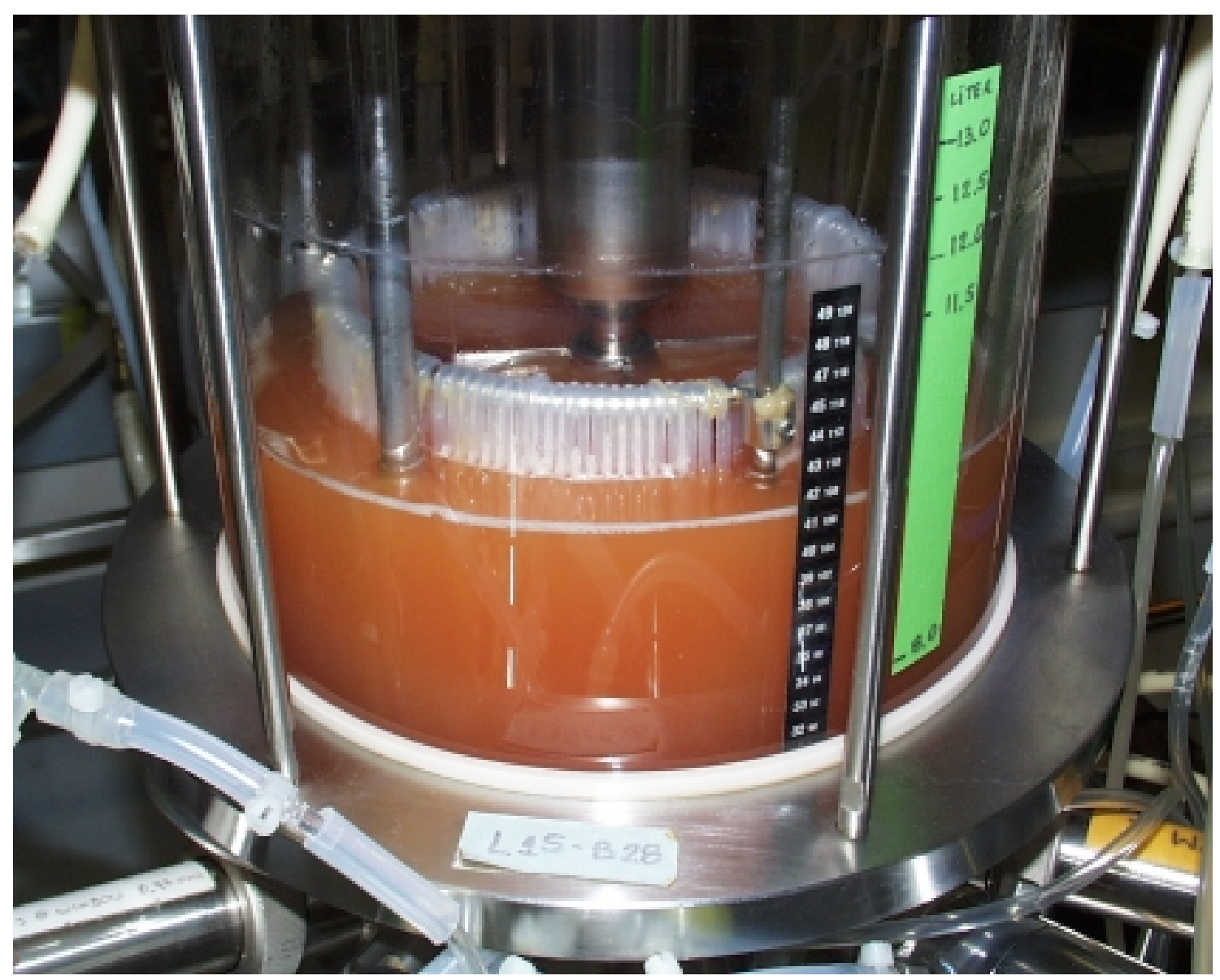

Figura 4.7 - Foto da gaiola de membrana de silicone parcialmente coberta por meio de cultura no final de um ensaio 


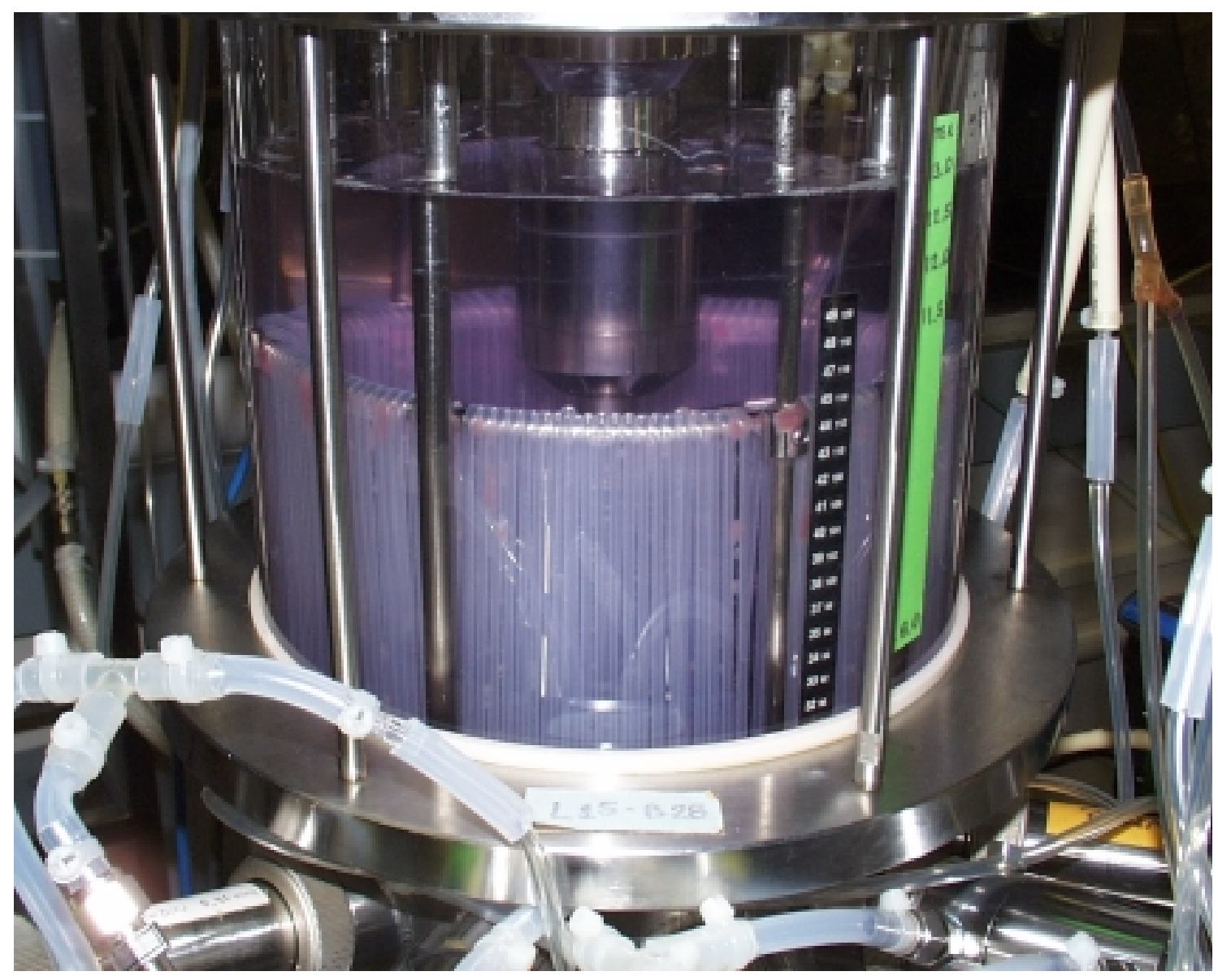

Figura 4.8 - Foto da gaiola de membrana de silicone coberta com hidróxido de sódio no final de um ensaio

Este sistema é composto por uma espécie de gaiola, onde é possível serem enroladas dezenas de metros de tubo de silicone. Os gases a serem transferidos para o meio de cultura circularão por este tubo sem contato direto com o meio, evitando-se a formação de bolhas. Utiliza-se o tubo Silastic Rx50 (Medical grade tubing special, modelo 85-1236-001) da Dow Corning Corp. (Midland, MI, EUA), com diâmetro interno de $2 \mathrm{~mm}$ e externo de $3,2 \mathrm{~mm}$. A gaiola é elaborada com cerca de $50 \mathrm{~m}(280 \mathrm{~g})$ de tubo. 
O esquema do sistema de transferência apresentado na Figura 4.9 mostra as principais variáveis envolvidas nesse processo. A pressão na saída da tubulação pode ser controlada em um valor superior à pressão atmosférica, através do uso de um regulador de pressão a montante, modelo 10BP, chamado de back-pressure regulator (Fairchild, Winston-Salem, NC, EUA). Além da pressão do gás de entrada $\left(\mathrm{P}_{\mathrm{e}}\right)$ e saída $\left(\mathrm{P}_{\mathrm{s}}\right)$, e de suas vazões $\left(\mathrm{Q}_{\mathrm{e}}\right.$ e $\mathrm{Q}_{\mathrm{s}}$ ), temos as frações molares de oxigênio (yo2e e $\mathrm{y}_{\mathrm{O} 2 \mathrm{~s}}$ ), nitrogênio $\left(\mathrm{y}_{\mathrm{N} 2 \mathrm{e}} \mathrm{e} \mathrm{y}_{\mathrm{N} 2 \mathrm{~s}}\right.$ ), e gás carbônico $\left(\mathrm{y}_{\mathrm{CO} 2 \mathrm{e}}\right.$ e $\left.\mathrm{y}_{\mathrm{CO} 2 \mathrm{~s}}\right)$. Durante um ensaio típico, o gás de entrada

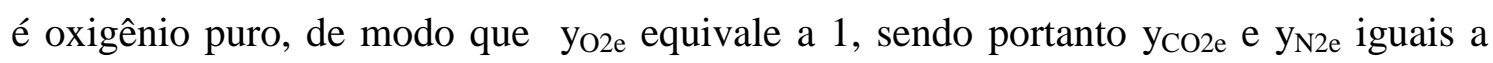
zero. Na saída observa-se a presença de gás carbônico $\left(\mathrm{y}_{\mathrm{CO} 2 \mathrm{~s}}>0\right)$ e tem-se, portanto, uma pequena diminuição em yoze, devido ao consumo de oxigênio pelas células na respiração, produzindo gás carbônico.

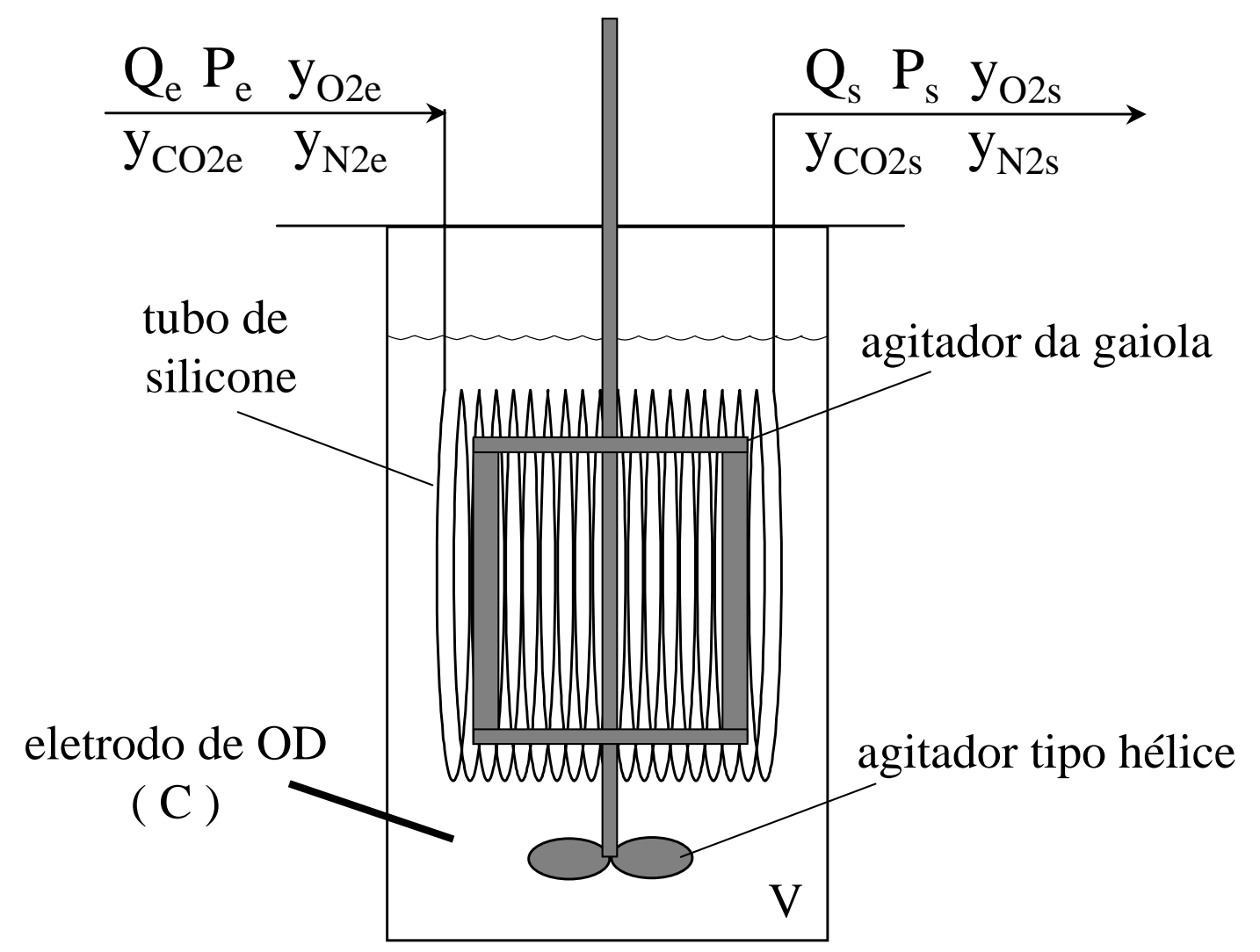

Figura 4.9 - Esquema do sistema de transferência de oxigênio por difusão em membrana de silicone 
A transferência é causada por difusão de oxigênio pela membrana de silicone, devido à diferença entre a pressão parcial de oxigênio interna e externa (meio de cultura) ao tubo. Como a concentração de oxigênio no reator é muito menor que aquela equivalente no tubo, gera-se uma elevada força motriz, responsável pela rápida difusão de oxigênio através da membrana de silicone.

A velocidade de transferência de oxigênio (OTR, ou Oxygen Transfer Rate) pode ser estimada com base nas várias resistências à transferência presentes neste sistema, conforme visto tipicamente em sistemas de aspersão convencionais (BAILEY; OLLIS, 1986) (Figura 4.10).

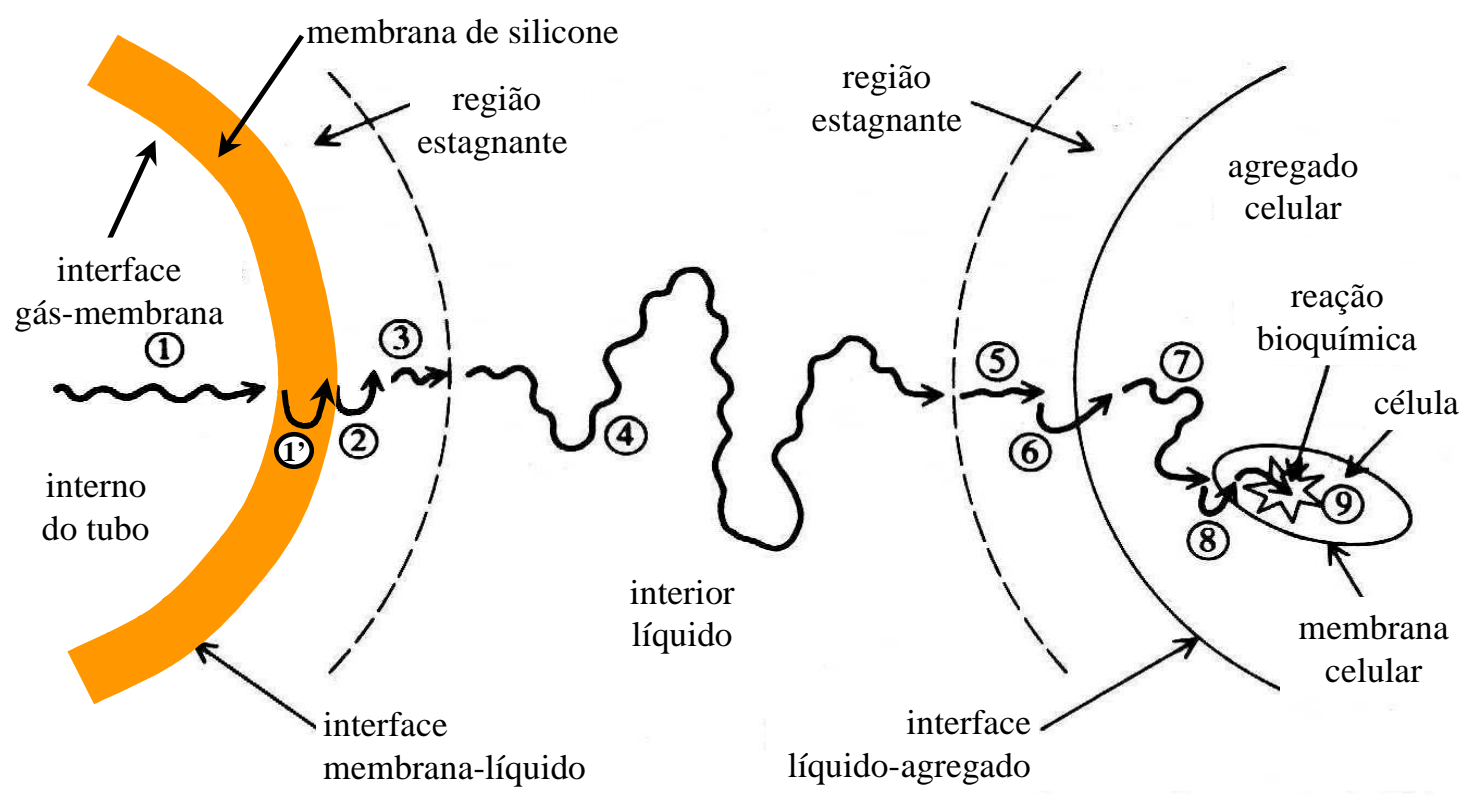

Figura 4.10 - Esquema da transferência de oxigênio do seio da tubulação de silicone até o interior de uma célula, mostrando as várias etapas do fenômeno. Observação: em relação à transferência convencional por aspersão, há no caso de aeração por membrana de silicone uma etapa a mais (chamada 1') entre (1) e (2), representando a difusão através da membrana 
O coeficiente global de transferência $\left(\mathrm{K}_{\mathrm{L}}\right)$ no caso do sistema com membrana de silicone apresenta ainda uma resistência devido à difusividade do oxigênio pelo silicone, podendo ser estimado pela Equação 4.9 (LEE et al., 1990)

$$
\frac{1}{K_{L}}=\frac{H r_{o} \ln \left(r_{o} / r_{i}\right)}{p}+\frac{1}{k_{L}}
$$

onde $\mathrm{k}_{\mathrm{L}}$ é a resistência devido ao filme líquido $(\mathrm{cm} / \mathrm{h}), \mathrm{H}$ é o coeficiente da lei de solubilidade de Henry, $\mathrm{r}_{\mathrm{o}}$ é o raio externo da membrana de silicone $(0,16 \mathrm{~cm}), \mathrm{r}_{\mathrm{i}}$ é o raio interno $(0,10 \mathrm{~cm})$ e p a permeabilidade da membrana ao oxigênio. $\mathrm{O}$ valor de $\mathrm{H}$ em água a $35^{\circ} \mathrm{C}$ é $0,03 \mathrm{~atm} /(\mathrm{mg} / \mathrm{L})$ (BLANCH; CLARK, 1997). Como o valor de $\mathrm{k}_{\mathrm{L}}$ não foi estimado e considerando que os dados da literatura do valor de $\mathrm{p}$ são muito contraditórios (LEE et al., 1990), optou-se por se utilizar o valor de $\mathrm{K}_{\mathrm{L}}$.a estimado da transferência de oxigênio em resposta a degrau, sob condições próximas das dos ensaios. Tais medidas foram realizadas com meio de cultura sem a presença de células, aplicando-se um degrau na composição do gás de circulação pela membrana. Os coeficientes volumétrico de transporte de oxigênio $\left(\mathrm{K}_{\mathrm{L}} \mathrm{a}\right)$ em cada ensaio foram calculados pelo método via eletrodo, segundo BLANCH; CLARK (1997), apresentando valores entre 2 e $3 h^{-1}$.

Como a pressão do gás no tubo cai ao longo de seu comprimento e, portanto, a concentração de oxigênio na interface membrana-líquido, é necessário integrar a contribuição de cada parcela do tubo no cálculo da transferência total de oxigênio. Desta forma, a velocidade de transferência de oxigênio (OTR) pode ser descrita pela Equação 4.10.

$$
O T R=\frac{2 \pi \cdot r_{o}}{V} \int_{0}^{L} K_{L}\left[C^{*}(l)-C\right] d l
$$


onde C é a concentração média de oxigênio dissolvido no líquido (mg/L), C*(l) a concentração de oxigênio dissolvido equivalente na interface da membrana gás-líquido na distância 1 a partir da entrada da tubulação, L é o comprimento da tubulação de silicone e V o volume de reação (L).

Considerando-se a frequência de agitação fixa, e desprezando-se a variação do raio e da permeabilidade em função da variação da pressão da membrana ao longo dos ensaios realizados, pode-se estimar que $\mathrm{K}_{\mathrm{L}}$ apresenta um valor fixo, independente do comprimento 1.

Chamando-se de a a área específica da membrana de silicone em relação ao volume de reação $\left(a=\frac{2 \pi L r_{o}}{V}\right)$, chega-se à Equação 4.11 .

OTR $=\frac{K_{L} a}{L} \int_{0}^{L}\left[C^{*}(l)-C\right] d l$

Para uma vazão constante, pode-se aproximar a variação da concentração de oxigênio dissolvido equivalente por uma variação linear, devido ao perfil linear da pressão dentro da tubulação.

Assim temos:

$O T R=K_{L} a\left(C^{*}-C\right)$

onde $C^{*}=\frac{\left(C_{e}^{*}-C_{s}^{*}\right)}{2}, \mathrm{C}_{\mathrm{e}}^{*}$ e $C^{*}{ }_{\mathrm{s}}$ são as concentrações equivalentes na entrada e saída da tubulação, respectivamente.

Utilizando a Lei de Henry, pode-se substituir as concentrações equivalentes na interface pelas pressões parciais de oxigênio:

$C_{e}^{*}=\frac{P_{e} y_{O e}}{H} ; C^{*}{ }_{s}=\frac{P_{s} y_{O s}}{H}$ 
onde $\mathrm{P}_{\mathrm{e}}$ e $\mathrm{P}_{\mathrm{s}}$ são as pressões totais do gás na entrada e na saída da tubulação de silicone e YOe e yos as frações molares de oxigênio no gás de entrada e saída, respectivamente.

Chamando-se $\mathrm{P}_{\mathrm{m}}$ a pressão na tubulação de silicone média da entrada e saída, e considerando-se desprezível (para esta análise) a variação da fração de oxigênio na

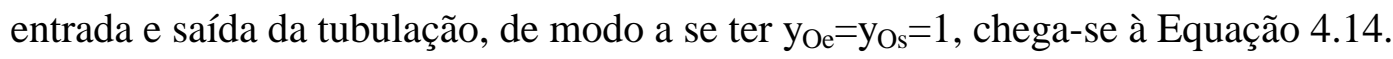

$$
O T R=K_{L} a\left(\frac{P_{m}}{H}-C\right)
$$

Fazendo-se o balanço do oxigênio, chega-se à Equação 4.15 .

$$
\frac{d C}{d t}=O T R-O U R=K_{L} a\left(\frac{P_{m}}{H}-C\right)-Q_{O 2} X
$$

onde $\mathrm{OUR}=\mathrm{Q}_{\mathrm{O} 2} \mathrm{X}(\mathrm{mg} /(\mathrm{L} . \mathrm{h}))$ é a velocidade de consumo de oxigênio, $\mathrm{Q}_{\mathrm{O} 2}$ é a velocidade específica de consumo de oxigênio, expressa em mg/(célula.h) e $X$ a concentração celular, expressa em célula/L.

Lembrando que a concentração de oxigênio dissolvido é mantida constante durante os ensaios (ou ainda considerando um curto intervalo de tempo no qual ela não varia significativamente), tem-se uma expressão aproximada para a velocidade respiração (Equação 4.16):

$$
Q_{O 2}=\frac{K_{L} a}{X}\left(\frac{P_{m}}{H}-C\right)
$$

Na maior parte dos ensaios realizados, a concentração de oxigênio dissolvido no reator foi mantida constante, controlada em $50 \%$ da saturação com ar. Isso equivale a dizer que $C=\frac{1 \mathrm{~atm} \cdot 0,21}{0,03 \mathrm{~atm} /(\mathrm{mg} / \mathrm{L})} \cdot 0,50=3,5 \mathrm{mg} / \mathrm{L}$

Como, nestes ensaios, $\mathrm{P}_{\mathrm{m}}$ manteve-se em torno de 2 atm (lembrando-se tratar de oxigênio puro), e portanto $P_{m}=\frac{2 \mathrm{~atm}}{0,03 \mathrm{~atm} /(\mathrm{mg} / \mathrm{L})}=67 \mathrm{mg} / \mathrm{L}$, chega-se a conclusão 
que durante estes ensaios se pode aproximar $\left(\frac{P_{m}}{H}-C\right) \approx \frac{P_{m}}{H}$. Desta forma, a velocidade de consumo de oxigênio passa a ser proporcional à pressão média na tubulação (Equação 4.17) e a velocidade específica de respiração proporcional à razão $\mathrm{P}_{\mathrm{m}} / \mathrm{X}$ (Equação 4.18).

$Q_{O 2} X=O U R=\frac{K_{L} a}{H} P_{m}$

$Q_{O 2}=\frac{K_{L} a}{H X} \cdot P_{m}$

Convém observar que, pela Equação 4.18, nos ensaios onde a concentração celular é mantida constante, a velocidade específica de respiração passa a ser proporcional à pressão média.

Para se verificar se estas simplificações são válidas, se apresenta a seguir uma comparação entre $\mathrm{P}_{\mathrm{m}}$ e OUR calculado diretamente pela quantidade de oxigênio consumido. Para tanto, utilizou-se um espectrômetro de massa conectado aos gases de saída do biorreator, em um ensaio onde se variou a concentração de oxigênio dissolvido no meio (Ensaio E3). Neste ensaio foi utilizada na entrada da tubulação de silicone uma mistura de oxigênio e ar.

A velocidade de consumo de oxigênio foi aqui calculada como a diferença entre a quantidade de oxigênio que ingressa e que sai a cada instante do biorreator. Como visto anteriormente, supõe-se que OUR=OTR para intervalos de tempo relativamente curtos (Equação 4.19).

$O U R=\frac{Q_{e} y_{e}-Q_{s} y_{s}}{V} M M_{O 2}=\frac{\left[\left(Q_{e O 2} \cdot 1+Q_{e A r} \cdot 0,209\right)-Q_{s} y_{s}\right]}{V} M M_{O 2}$

onde $\mathrm{MM}_{\mathrm{O} 2}$ é a massa molecular do oxigênio (32 $\left.\mathrm{g} / \mathrm{mol}\right), \mathrm{Q}_{\mathrm{e}}$ e $\mathrm{Q}_{\mathrm{s}}$ são as vazões molares de entrada e saída, e $y_{\mathrm{e}}$ e $\mathrm{y}_{\mathrm{s}}$ as frações molares de oxigênio no gás de entrada e saída, 
respectivamente, sendo $\mathrm{y}_{\mathrm{s}}$ medido pelo espectrômetro de massa. A vazão molar total de

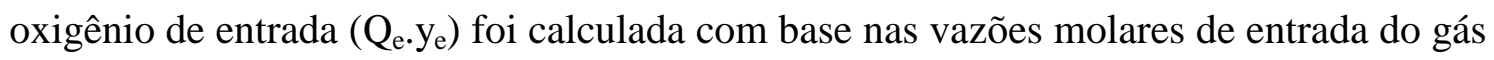
oxigênio $\left(\mathrm{Q}_{\mathrm{eO} 2}\right)$ e ar $\left(\mathrm{Q}_{\mathrm{eAr}}\right)$, multiplicadas por suas frações de oxigênio (1 e 0,209, respectivamente). Como não se media a vazão de saída, tentou-se utilizar o balanço de nitrogênio, com base na pequena vazão de ar empregada. No entanto, como a fração de nitrogênio resultava muito baixa, tal procedimento gerava estes valores muito imprecisos e, portanto, resolveu-se considerar nestes cálculos que a vazão total de entrada e saída eram iguais. Assim, Qe, determinada pela soma das leituras dos controladores de vazão de entrada dos vários gases, passa a ser igual a $\mathrm{Q}_{s}$, ou $\mathrm{Q}_{\mathrm{e}}=\mathrm{Q}_{\mathrm{s}}=\mathrm{Q}_{\mathrm{eO} 2}+\mathrm{Q}_{\mathrm{eAr}}+\mathrm{Q}_{\mathrm{eCO} 2}+\mathrm{Q}_{\mathrm{eN} 2}$. Os valores de OUR calculados, assim como os valores medidos utilizados em seus cálculos se encontram na Tabela A.7 (no Anexo).

A Figura 4.11 apresenta os valores de $\mathrm{P}_{\mathrm{m}}$ medidos e OUR calculados, segundo a Equação 4.11, bem como o valor de QO2 calculado a partir de OUR e da contagem celular ao microscópio, ao longo do ensaio E3. Observa-se aqui uma ótima correlação entre $\mathrm{P}_{\mathrm{m}}$ e OUR ao longo de todo o cultivo, validando as premissas assumidas anteriormente para se chegar a uma expressão simplificada para OUR, a partir das pressões medidas. Convém observar que no final deste longo cultivo, as duas curvas se afastam, indicando uma perda de proporcionalidade, possivelmente devido um entupimento da membrana de silicone e diminuição no valor de $\mathrm{K}_{\mathrm{L}} \mathrm{a}$. 


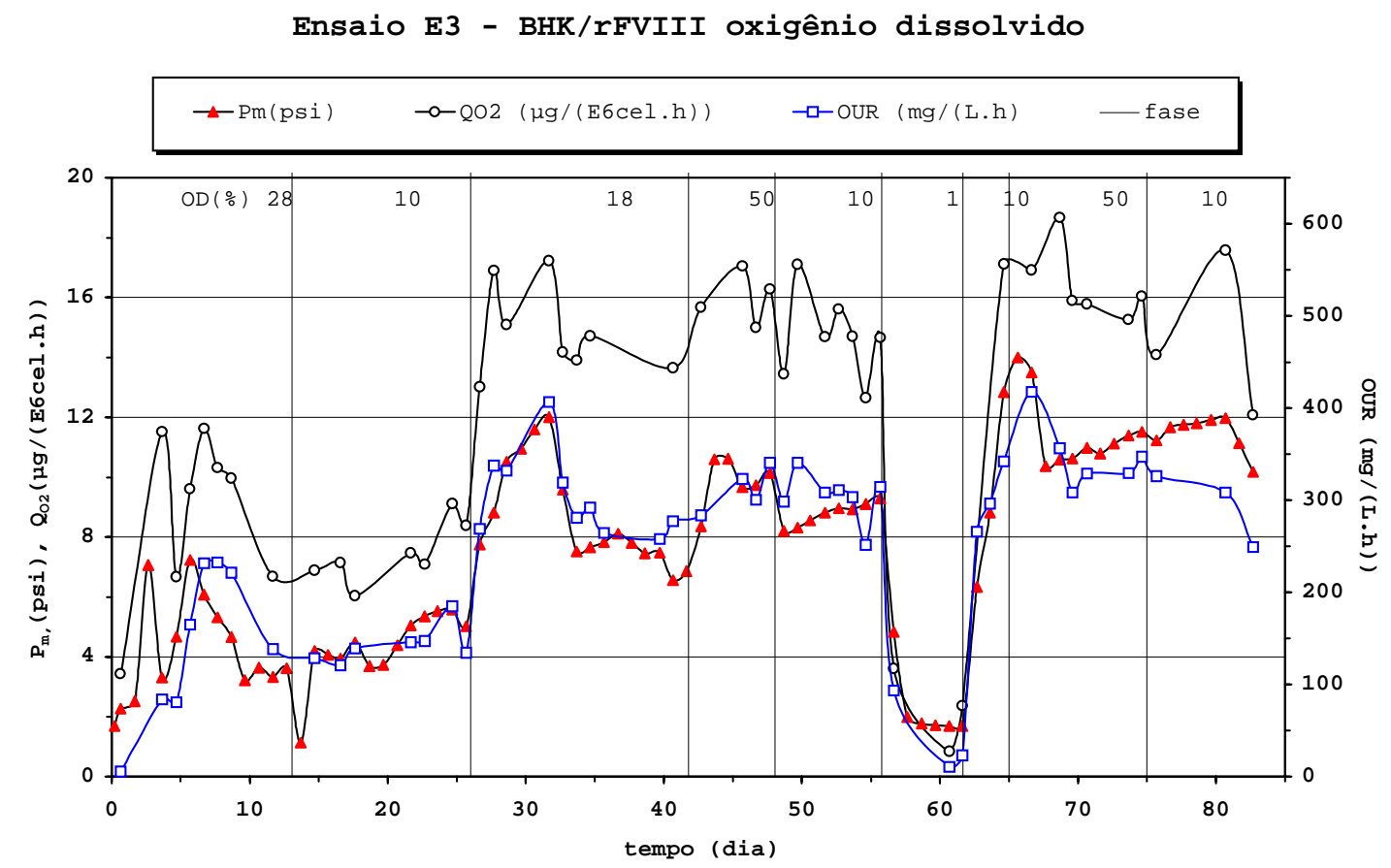

Figura 4.11 - Pressão média na tubulação de silicone $\left(\mathrm{P}_{\mathrm{m}}\right)$, velocidade de consumo de oxigênio (OUR) e velocidade específica de respiração $\left(\mathrm{Q}_{\mathrm{O} 2}\right)$ em função do tempo, no ensaio E3. Obs: para ajuste à escala, nesta figura Pm está expressa em psi

Da mesma figura conclui-se que a velocidade específica de respiração $\left(\mathrm{Q}_{\mathrm{O} 2}\right)$ variou menos ao longo do cultivo, apresentando valores em torno de $15 \mu \mathrm{g} /(\mathrm{E} 6 \mathrm{cel} . \mathrm{h})$, compatível com os resultados vistos no item 2.3. Por dois períodos este valor esteve abaixo de $10 \mu \mathrm{g} /($ E6cel.h), no início do cultivo na fase de OD=10\% e em torno de 60 dias de cultivo, com $\mathrm{OD}=1 \%$. Como havia uma grande discrepância entre as leituras das duas sondas de oxigênio dissolvido durante o início do ensaio, pode-se supor que o valor real de OD até 26 dias de cultivo é bastante inferior a 10\%, chegando a atingir uma limitação reduzindo o valor de Qo2.

$\mathrm{Na}$ figura 4.12, apresenta-se essas variáveis em função de OD, permitindo equacionar um modelo tradicional, do tipo saturação, conforme a Equação 4.20:

$Q_{O 2}=Q_{\text {O2máximo }} \frac{O D}{K_{O}+O D}$ 
Da figura 4.12, por tentativa e erro, obteve-se uma estimativa de Qo2máximo $=$ $17 \mu \mathrm{g} /\left(\right.$ E6cel.h) e $\mathrm{K}_{\mathrm{O}}=2 \%$, implicando em limitação à respiração sob concentrações de oxigênio dissolvido menores que 5 ou $10 \%$, bastante acima do valor de $1 \%$ encontrado por OZTURK; PALSSON, 1990.

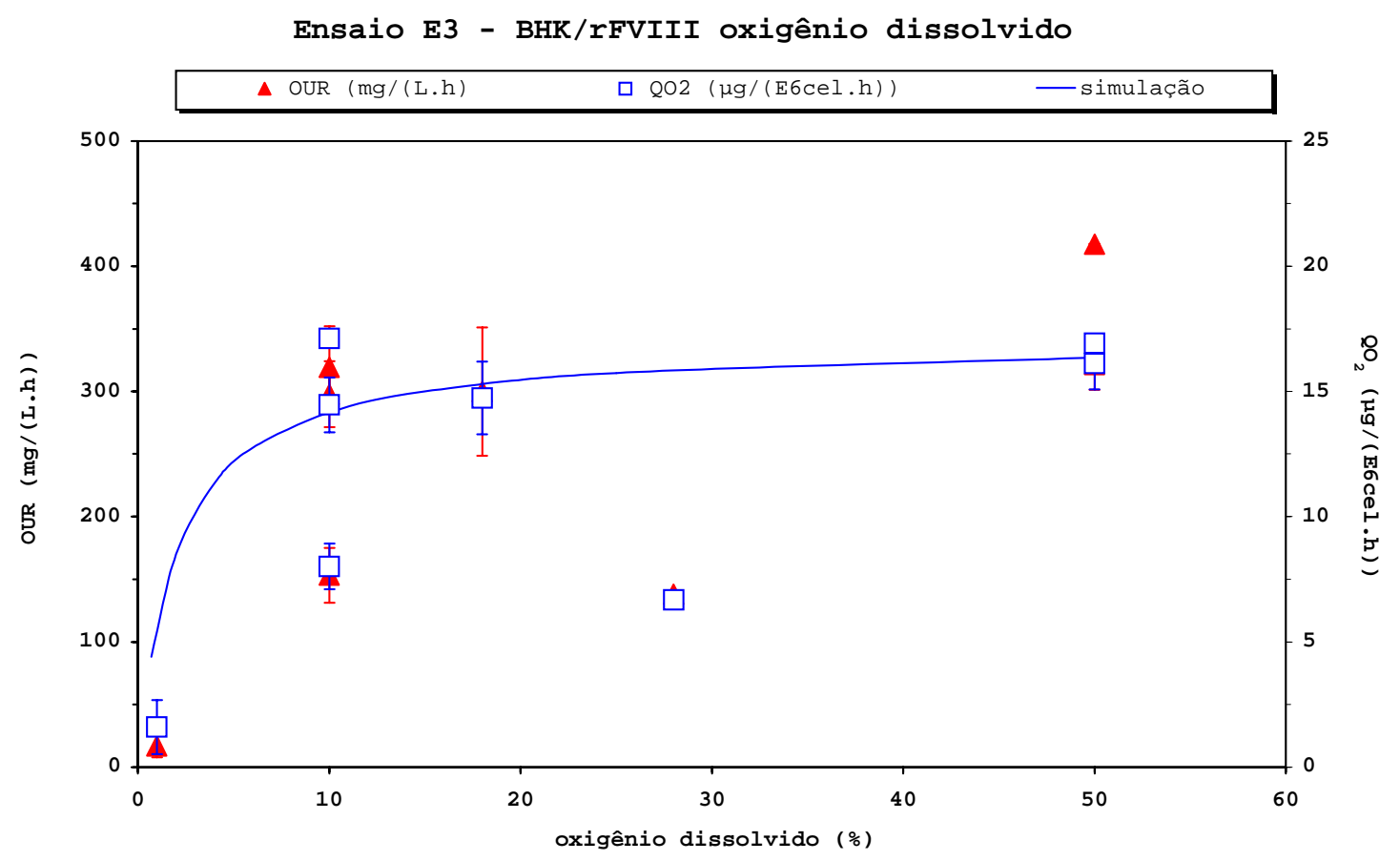

Figura 4.12 - Velocidade de consumo de oxigênio (OUR) e velocidade específica de respiração $\left(\mathrm{Q}_{\mathrm{O} 2}\right)$ (medida e simulada) em função da concentração de oxigênio dissolvido (OD), no ensaio E3

Com base no exposto acima, duas conclusões podem ser tiradas:

1) a medida das pressões de entrada e saída em sistemas de transferência de oxigênio por difusão em membranas de silicone apresenta a capacidade de estimar, de modo muito simples e imediato, a velocidade de transferência de oxigênio. 
2) na falta de medidas reais de OTR para determinação da constante de proporcionalidade, a variação de $\mathrm{P}_{\mathrm{m}}$ acompanha a variação de OTR, podendo ser utilizada no monitoramento do processo.

\subsubsection{Ensaio E3 - Influência de oxigênio dissolvido na produção de FVIII por BHK}

Esse ensaio teve como objetivo determinar a faixa ótima de oxigênio dissolvido para a produção do fator VIII recombinante.

Baseado no sistema de transferência descrito anteriormente, pode-se facilmente controlar a concentração de oxigênio dissolvido no biorreator através da atuação na vazão de oxigênio, causando variação na pressão média dentro do tubo de silicone e, consequentemente, na força motriz da transferência. Tal controle foi realizado com sucesso, embora tenha sofrido flutuações até que os parâmetros do controlador P-I-D (proporcional, integral e derivativo) atingissem valores adequados. Devido a várias falhas nos eletrodos e amplificadores de oxigênio dissolvido, neste ensaio foi necessário substituir a sonda de OD, responsável pelo controle pela sonda reserva. Este procedimento de alternar as sondas teve de ser executado ainda outras duas vezes.

Os resultados obtidos neste controle do oxigênio dissolvido, em diferentes valores (fases do cultivo), assim como a concentração celular e viabilidade das células são apresentados na Figura 4.13, onde se pode ainda observar a fase inicial de acúmulo de células (de 0 a 8 dias de cultivo). Neste cultivo, utilizou-se a densidade ótica como variável de controle da concentração celular, acionando-se a bomba de purga sempre que a DO superava determinado valor. 


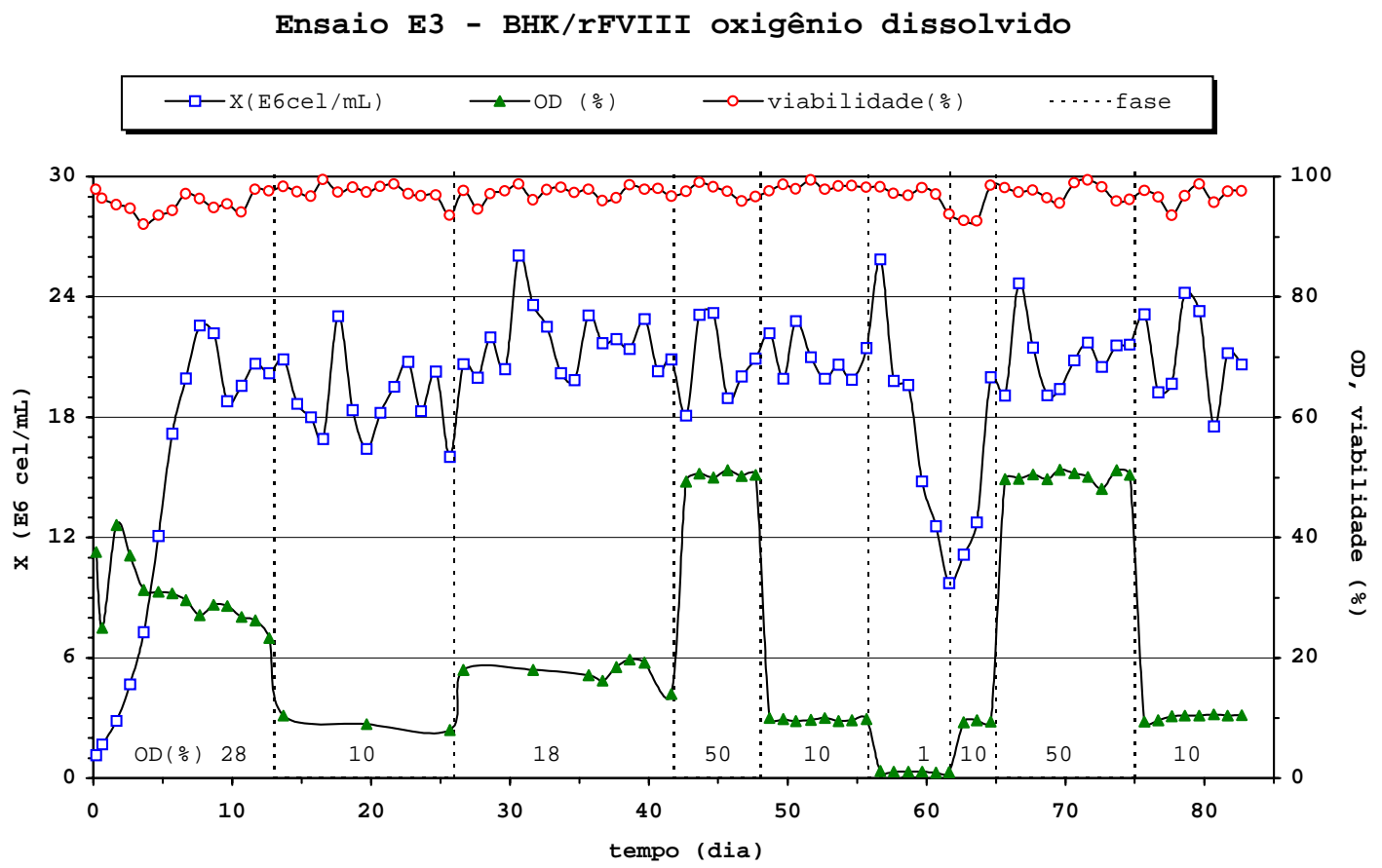

Figura 4.13 - Concentração celular (X), viabilidade e concentração de oxigênio dissolvido (OD) em função do tempo, no ensaio E3

Pode-se observar na Figura 4.13 que houve uma forte queda na concentração celular em torno de 60 dias de cultivo, sob oxigênio dissolvido em torno de 1\%. Durante este período, a bomba de purga esteve sempre inoperante, visto que DO não atingia seu set-point. Como mesmo assim havia um pequeno arraste através do sistema de separação de células e o crescimento celular era muito baixo neste valor de OD, o balanço de células foi negativo, diminuindo X com o tempo. Após a decisão de elevar o set-point de OD para 10\%, as células voltaram a crescer, recuperando-se a concentração desejada, acionando novamente a bomba de purga.

Ainda na Figura 4.13 percebe-se que a viabilidade das células esteve sempre alta (superior a 90\%), caindo abaixo de 95\% durante o período de crescimento quase nulo descrito acima. 
Na Figura 4.14 são apresentados os perfis das pressões de entrada, saída e média no sistema de transferência por difusão em membrana de silicone, ao longo do cultivo. Observa-se que no período com menor OD (1\%), quando o sistema requer uma menor transferência de oxigênio, todas as pressões apresentaram significativa queda, confirmando a relação entre a pressão e transferência. Há no entanto, ao longo do cultivo, flutuações que não podem ser explicadas por este motivo, fruto normalmente de falhas operacionais ou do equipamento.

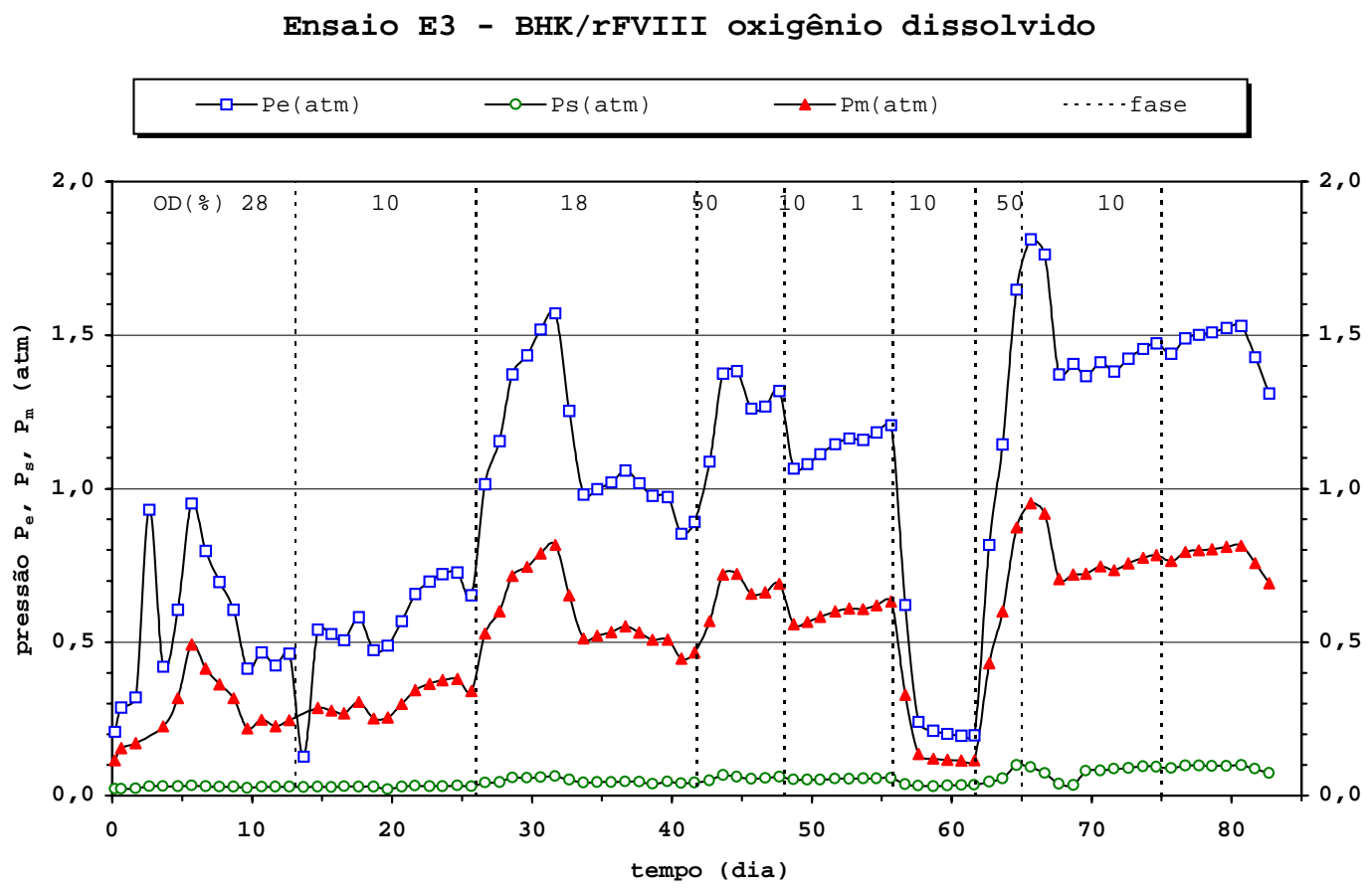

Figura 4.14 - Pressões na entrada $\left(\mathrm{P}_{\mathrm{e}}\right)$, saída $\left(\mathrm{P}_{\mathrm{s}}\right)$ e média (da entrada e saída) $\left(\mathrm{P}_{\mathrm{m}}\right)$ do sistema de transferência gasosa (tubo de silicone) em função do tempo, no ensaio E3

Observando-se novamente a Figura 4.11, percebe-se que somente na situação de OD muito próximo a zero (1\%) obteve-se significativa redução em Qo2. Isso significa que para as células BHK empregadas, a concentração crítica de oxigênio $\left(\mathrm{C}_{\text {crit }}\right.$, abaixo da qual oxigênio passa a ser um substrato limitante) situa-se entre 1 e $10 \%$, semelhante 
ao encontrado na maioria dos microrganismos. O que se observa ao longo da extensão do cultivo é um aumento sistemático de $\mathrm{P}_{\mathrm{m}}$, provavelmente como consequência da deposição de células sobre o tubo de silicone, reduzindo $\mathrm{K}_{\mathrm{L}}$ a e, portanto, dificultando a transferência. Neste caso, perde-se a relação simples entre $\mathrm{P}_{\mathrm{m}}$ e $\mathrm{Q}_{\mathrm{O} 2}$, e a estimativa baseada no balanço gasoso com a ajuda do espectrômetro de massa torna-se mais rigorosa.

A Figura 4.15 apresenta as velocidades específicas de crescimento e consumo da principal fonte de carbono (glicose) em função da concentração de oxigênio dissolvido em cada fase deste cultivo. Além do valor médio, a barra de erro representa o desvio padrão calculado para cada média. $O$ que se observa, conforme mencionado anteriormente, é que no período com OD muito baixo, as células crescem muito mais lentamente, com $\mu$ menor que $0,1 \mathrm{dia}^{-1}$ no período com OD controlado em $1 \%$. Já o consumo de glicose apresenta um comportamento oposto, aumentando quando há limitação de oxigênio. Tal comportamento, conhecido como Efeito Pasteur (DEVLIN, 1997), conhecido nos microrganismos facultativos é, na realidade, um conjunto de mecanismos. Mesmo não havendo limitação da fonte de carbono (glicose), a via glicolítica encontra-se, na presença de oxigênio em abundância, parcialmente bloqueada. No momento em que há uma limitação na oferta de oxigênio, esta via é desbloqueada, incentivando o consumo de glicose e geração de lactato. Deste fato pode se explicar o aumento de $\mu_{\text {Glic }}$ quando $\mathrm{OD}=1 \%$. 


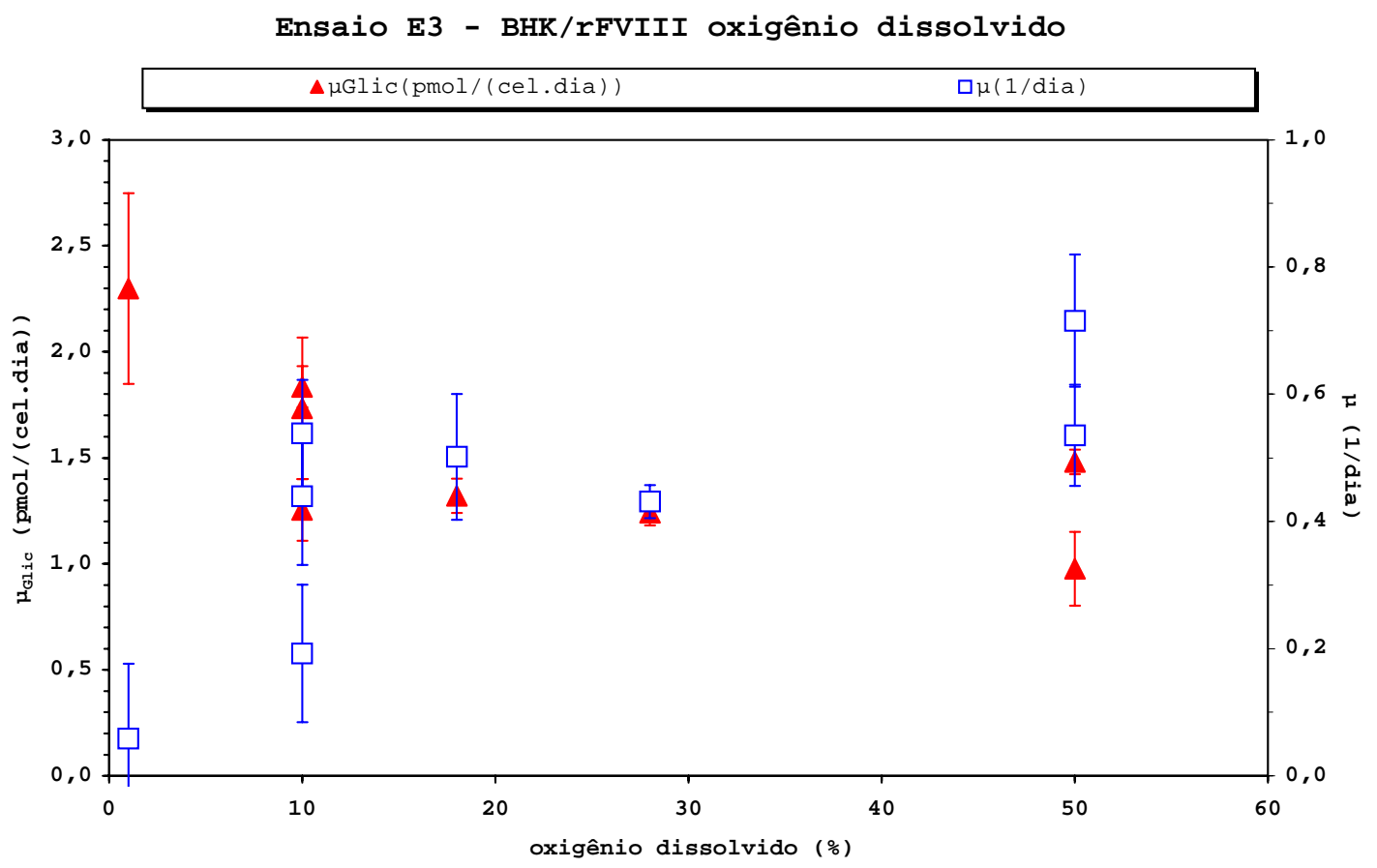

Figura 4.15 - Velocidades específicas de crescimento $(\mu)$ e consumo de glicose $\left(\mu_{\text {Glic }}\right)$ em função da concentração de oxigênio dissolvido, no ensaio E3

Por fim, pode-se analisar a influência da concentração de oxigênio dissolvido na produção de rFVIII, através dos valores de concentração de produto $(\mathrm{P})$ e velocidade específica de produção $\left(\mu_{\mathrm{P}}\right)$ (Figura 4.16). Observa-se um aumento destas grandezas sob valores maiores de OD, porém com um máximo em $28 \%$ e uma queda em $50 \%$, semelhante à uma inibição por excesso de substrato (o oxigênio). Tal fato contradiz o padrão utilizado na Bayer (controle de OD em 50\%). Considerando-se os vários problemas enfrentados com as sondas de oxigênio durante este cultivo, uma decisão mais conservadora seria realizar outro experimento para confirmar este resultado, antes de se decidir pela alteração no valor padrão de set-point de OD. 


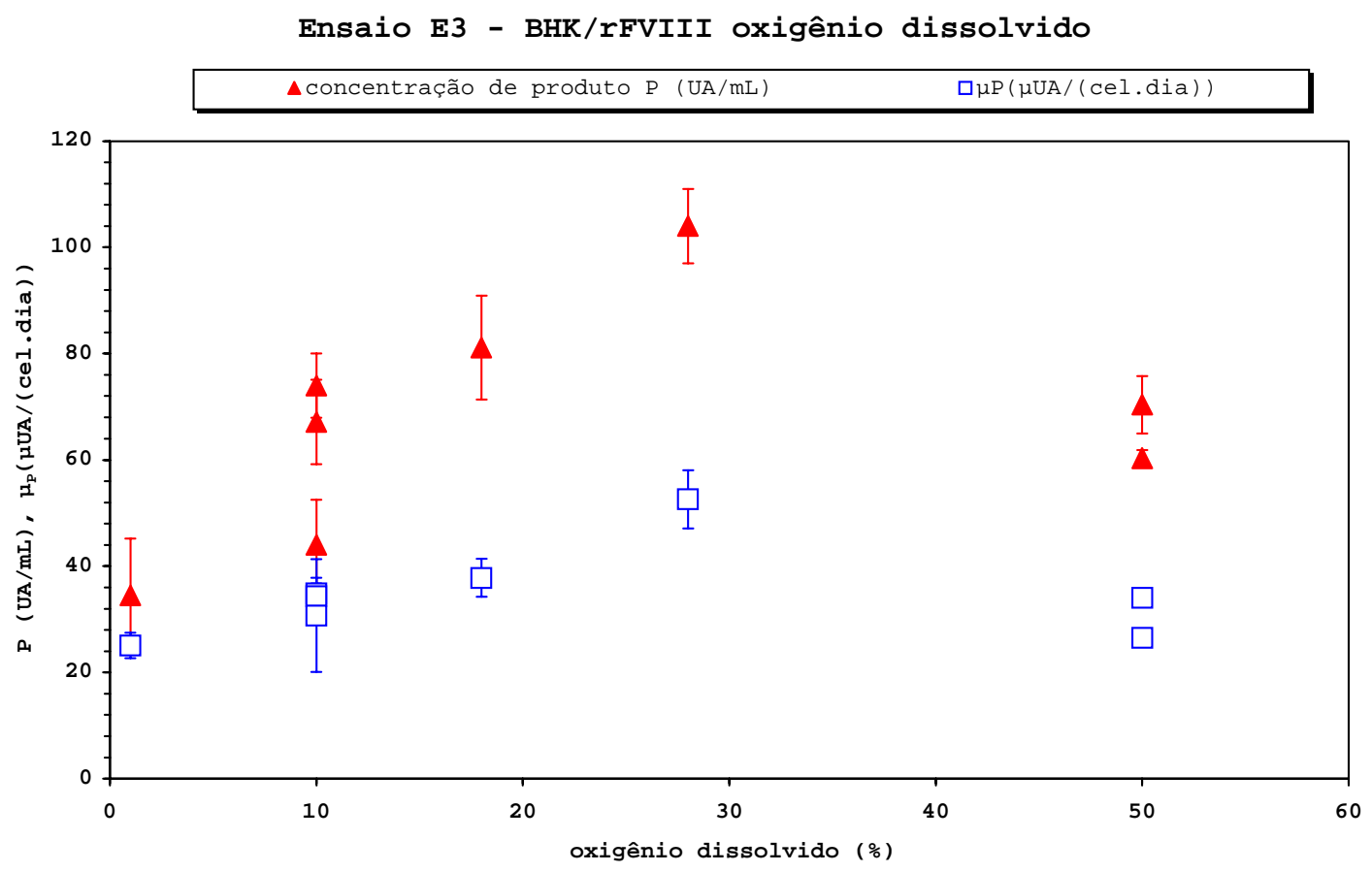

Figura 4.16 - Concentração de produto $(P)$ e velocidade específica de produção $\left(\mu_{P}\right)$ em função da concentração de oxigênio dissolvido, no ensaio E3

Claro esta, por outro lado, que no menor valor de OD testado (set-point=1\%) obteve-se os piores resultados do cultivo, tanto com relação à produção como crescimento e consumo de glicose, não servindo portanto como candidato a valor otimizado. 


\subsubsection{Ensaio E4 - Influência da temperatura na produção de FVIII por BHK}

No desenvolvimento do processo de perfusão, busca-se o maior número de células no biorreator, de modo a maximizar a produção. Como visto no item 4.1, pode-se operar o sistema sem o uso da bomba de purga, atingindo-se valores de concentração celular até superiores a $40 \mathrm{E} 6 \mathrm{cel} / \mathrm{mL}$, porém sacrificando-se a estabilidade do processo, e consequentemente a qualidade do produto. O sistema tem sua concentração celular máxima limitada por dois fatores: capacidade de transferência de oxigênio, visto que a tubulação de silicone pode romper se atingir uma pressão exagerada, e o sistema de separação de células, pois sua eficiência tende a cair com o aumento da concentração celular.

Para se avaliar o limite do sistema de transferência de oxigênio de um equipamento existente, e como este pode ser afetado pela temperatura de cultivo, realizou-se o ensaio $\mathrm{E} 4$, utilizando-se de um sistema de controle não padrão. $\mathrm{O}$ sistema de purga responde neste ensaio à pressão de entrada $\left(\mathrm{P}_{\mathrm{e}}\right)$, praticamente proporcional à pressão média $\left(\mathrm{P}_{\mathrm{m}}\right)$, pois a pressão de saída $\left(\mathrm{P}_{\mathrm{s}}\right)$ é mantida constante, quase igual a zero. Desta forma, ao invés de manter uma concentração celular constante, se mantém uma velocidade de consumo de oxigênio constante, o que poderia ser chamado de um respirostato.

Como visto na item 2.4, a velocidade específica de respiração das células de $\mathrm{BHK}$ varia com a temperatura. Dessa forma, atingido o regime a $34^{\circ} \mathrm{C}$, as células estarão crescendo, produzindo e respirando, sendo a velocidade de consumo de oxigênio (Qo2.X) proporcional à pressão média no tubo de silicone (Equação 4.17). Nos outros ensaios analisados até aqui, a bomba de purga era acionada ao atingir determinada 
densidade ótica, de forma a se tentar manter a concentração celular constante. Neste ensaio, a bomba será acionada quando a pressão de entrada no tubo de silicone $\left(\mathrm{P}_{\mathrm{e}}\right)$ atingir determinado valor (1,84atm, que é a pressão no estado pseudo-estacionário a $34^{\circ} \mathrm{C}$ ). Enquanto não se fizer nenhuma outra alteração no processo, esta nova regra da bomba de purga não deverá implicar em nenhuma mudança no regime, pois a velocidade específica de respiração não foi alterada.

Ao se iniciar uma nova fase do cultivo, a uma temperatura diferente da anterior (digamos $32^{\circ} \mathrm{C}$ ), o sistema responderá purgando células toda vez que a pressão atingir 1,84 atm (set-point de $\mathrm{P}_{\mathrm{e}}=12,35 \mathrm{psi}$ relativo), que equivale a determinado $\mathrm{Q}_{\mathrm{O} 2} \mathrm{X}$. Como nesta nova temperatura, a velocidade que cada célula respira $\left(\mathrm{Q}_{\mathrm{O} 2}\right)$ é menor, o valor de $\mathrm{X}$ aumentará inversamente proporcional a diminuição de $\mathrm{Q}_{\mathrm{O}}$, mantendo o produto $\mathrm{Q}_{\mathrm{O} 2}$.X constante. Assim, com este sistema, ao se variar a temperatura, obtém-se o valor máximo de células que podem ser sustentadas pelo sistema de transferência nas condições de ensaio padrão.

Este processo pode ser acompanhado através da análise da Figura 4.17, que apresenta as principais variáveis envolvidas nele, partindo de uma situação pseudo-estacionária. No instante $-8 \mathrm{~h}$, a temperatura é variada de 34,0 para $34,5^{\circ} \mathrm{C}$ (as alterações de temperatura eram feitas em passos de $0,5^{\circ} \mathrm{C} / 6 \mathrm{~h}$, para evitar estresse irreversível às células). Como consequência, observa-se uma flutuação na concentração de oxigênio dissolvido (pois as células em temperatura maior requerem mais oxigênio) e imediato aumento na vazão de oxigênio e pressão de entrada. Como a bomba de purga é acionada toda vez que a pressão de entrada atinge 12,35 psi relativo (ou 1,84atm), há uma forte perda de células nas 3 horas seguintes, resultando numa diminuição no valor da densidade ótica. Quando o sistema já estaria entrando em equilíbrio, e portanto 
acionando a purga intermitentemente, novo aumento da temperatura é comandado, repetindo o processo todo.

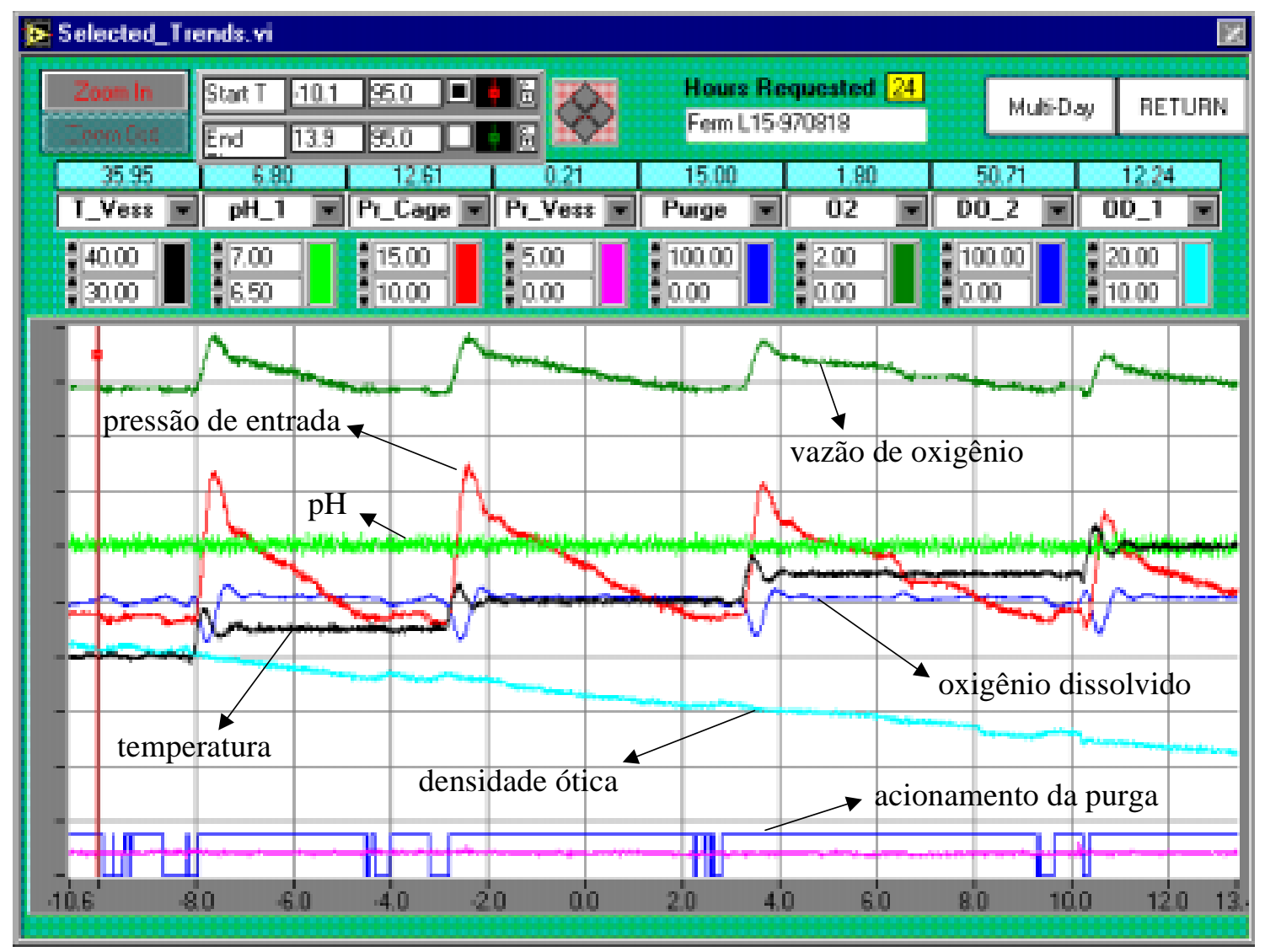

Figura 4.17 - Tela do programa de controle LabVIEW, mostrando os valores de diversas variáveis ao longo do tempo em torno do dia de cultivo 28 do ensaio E4

Na Figura 4.18, observa-se como a temperatura foi manipulada no ensaio E4 e a consequente variação da concentração celular. A viabilidade manteve-se superior a 90\% durante todo o cultivo. Com o sistema de manutenção de $\mathrm{Q}_{\mathrm{O} 2}$.X constante, em temperaturas menores atingiu-se concentração de células muito superior (cerca de 32E6 cel/mL a $\left.30{ }^{\circ} \mathrm{C}\right)$ àquela a $34{ }^{\circ} \mathrm{C}(20 \mathrm{E} 6$ células/mL), confirmando que a velocidade específica de consumo de oxigênio diminui com a diminuição da temperatura. Cabe observar também que algumas temperaturas foram estabelecidas mais de uma vez, como 
é o caso da temperatura padrão $34^{\circ} \mathrm{C}$ (3 vezes) e a da fase inicial do cultivo $37^{\circ} \mathrm{C}$ (duas vezes).

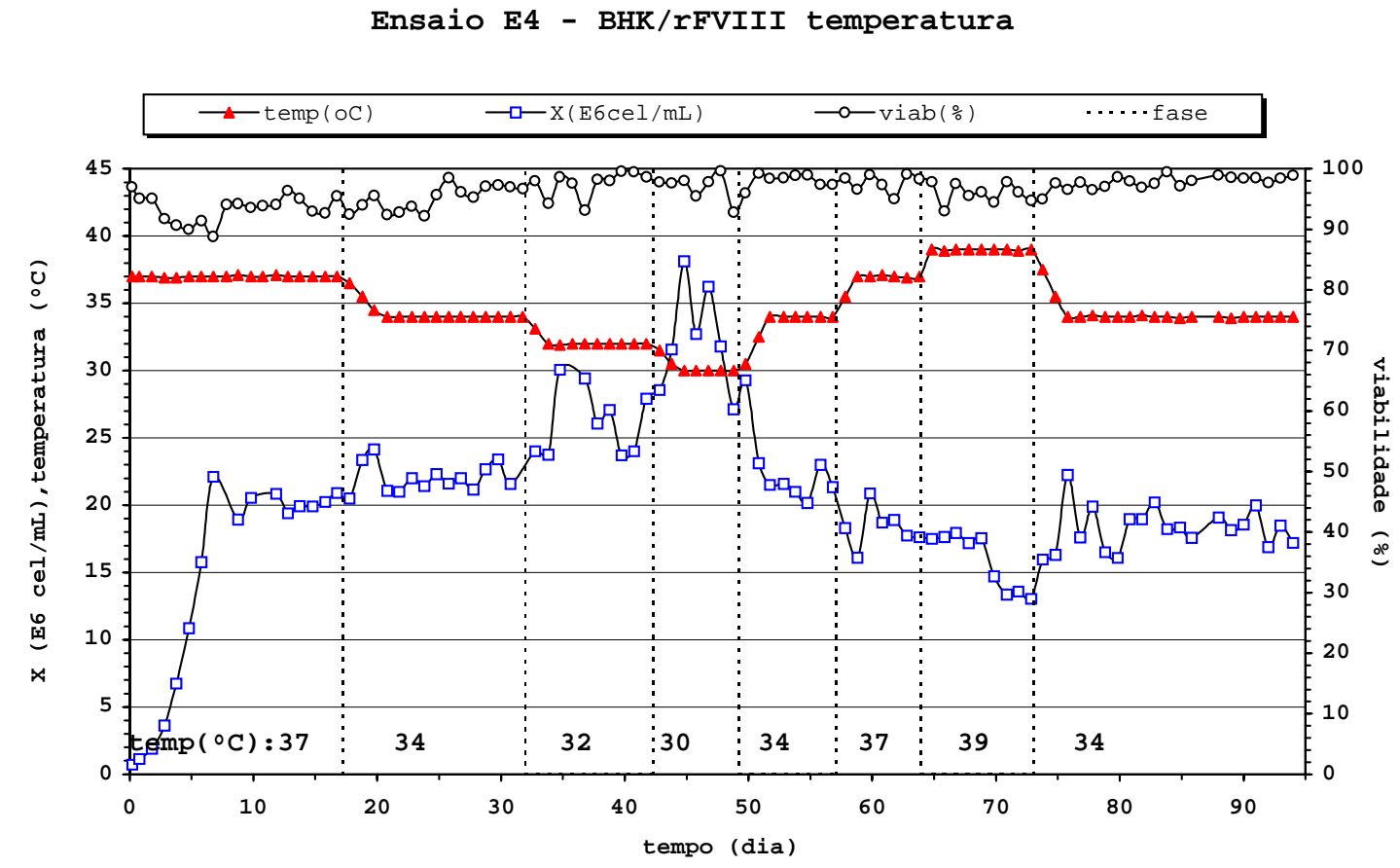

Figura 4.18 - Concentração celular (X), viabilidade e temperatura do caldo em função do tempo, no ensaio E4

A influência da temperatura pode também ser observada nas Figura 4.19 a 4.21, que apresenta valores médios ao longo de cada fase, como função da temperatura durante a fase. Além da média, em cada figura está representado o desvio padrão baseado nos valores de cada fase, na forma de barras de erro.

Na Figura 4.19 observa-se excelente correlação (inversa) da temperatura com a concentração celular suportada pelo sistema de transferência, enquanto que a velocidade específica de crescimento é maior em temperaturas mais elevadas, porém apresentando um valor máximo a $37^{\circ} \mathrm{C}$. 


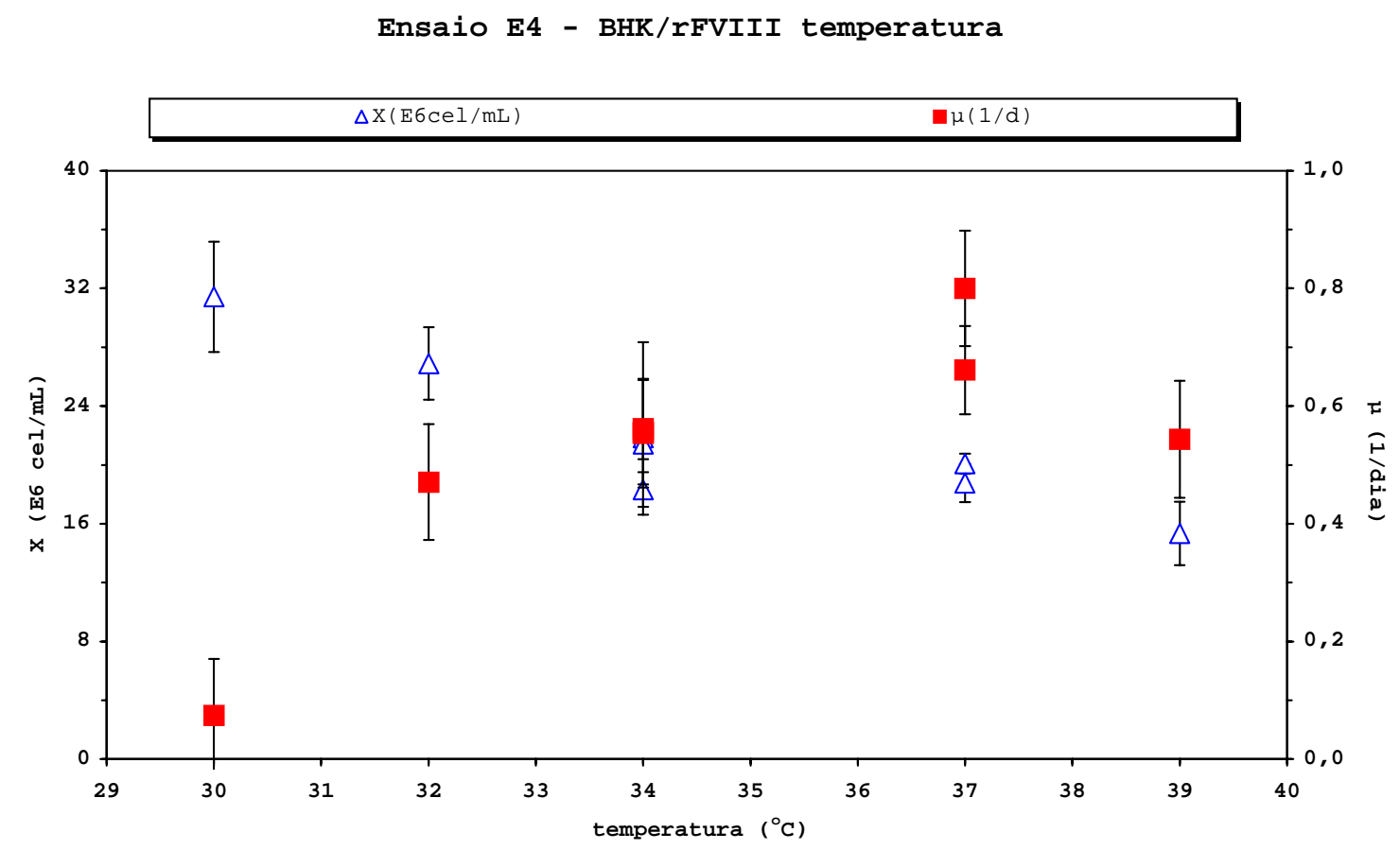

Figura 4.19 - Concentração celular $(\mathrm{X})$ e velocidade específica de crescimento $(\mu)$ em função da temperatura do caldo, no ensaio E4

O consumo dos substratos glicose e glutamina (Figura 4.20) apresenta uma relação linear crescente com o aumento da temperatura, indicando que todo o metabolismo celular trabalha mais rápido em altas temperaturas, porém existindo um patamar a partir do qual ele perde eficiência no crescimento $\left(37^{\circ} \mathrm{C}\right)$. 


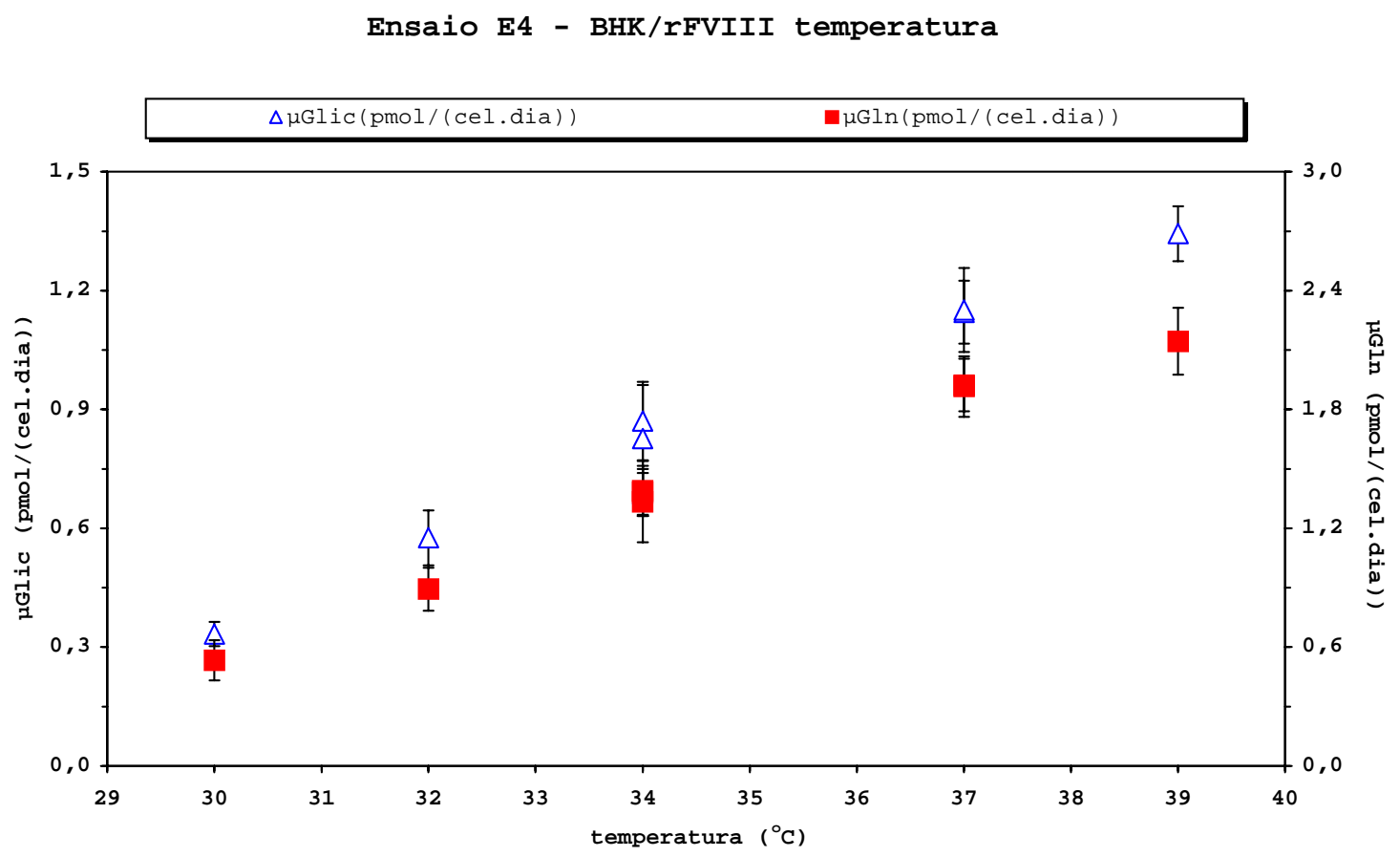

Figura 4.20 - Velocidade específica de consumo de glicose $\left(\mu_{\mathrm{Glic}}\right)$ e de glutamina $\left(\mu_{\mathrm{Gln}}\right)$ em função da temperatura do caldo, no ensaio E4

Apesar dessa tendência a maior consumo de substrato nas maiores temperaturas, a concentração de fator VIII assim como sua velocidade específica de produção decaiu a $39^{\circ} \mathrm{C}$ (Figura 4.21), atingindo máximo entre 34 e $37^{\circ} \mathrm{C}$. Tal faixa já é utilizada na Empresa, ocorrendo apenas a confirmação pelo presente ensaio. 


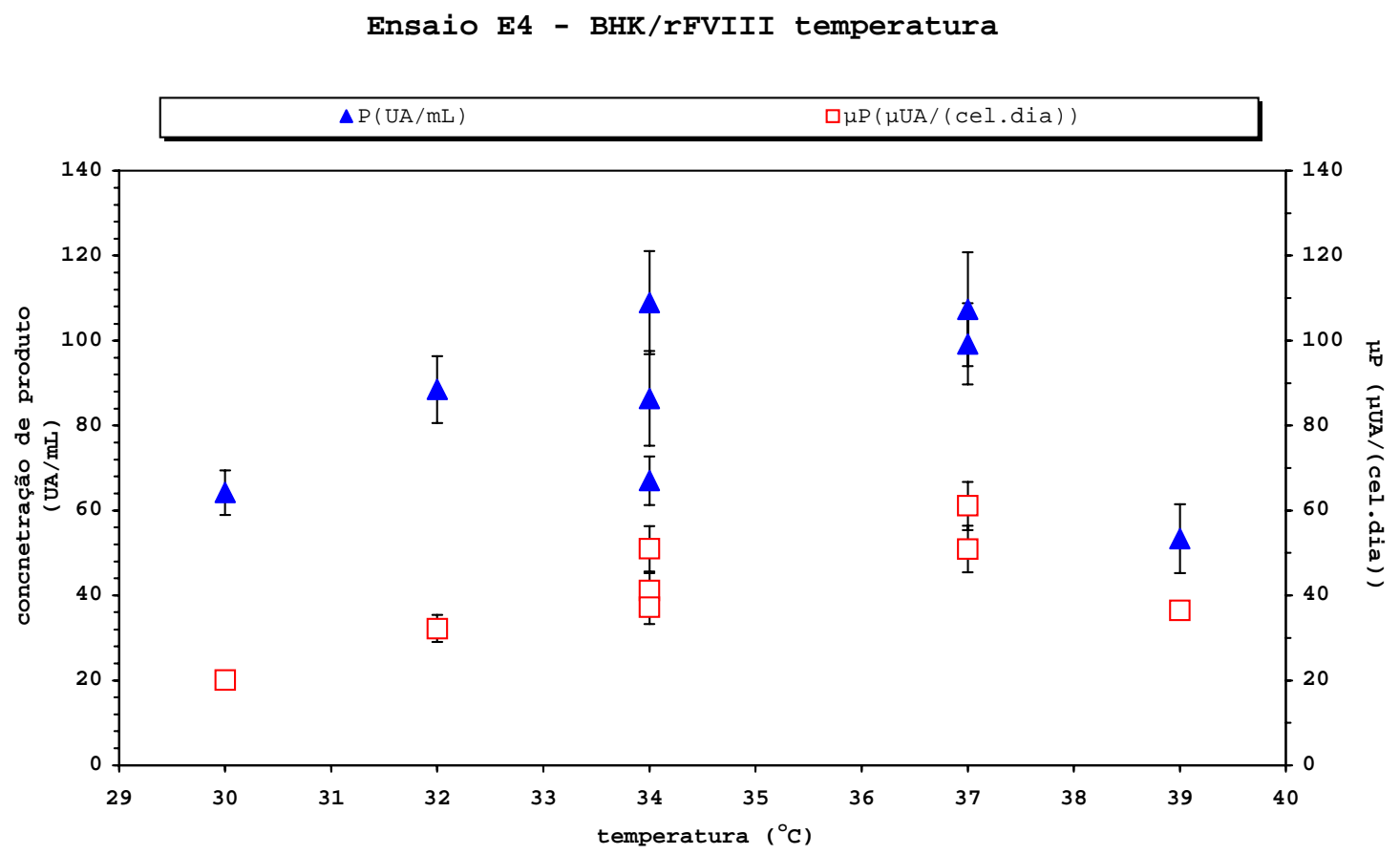

Figura 4.21 - Concentração de produto $(\mathrm{P})$ e velocidade específica de produção $(\mu \mathrm{P})$ em função da temperatura do caldo, no ensaio E4 (Obs: UA=unidade arbitrária)

Convém aqui salientar que ao longo das 3 fases a $34^{\circ} \mathrm{C}$, observou-se uma redução na concentração celular. Tal fato pode ser explicado por uma diminuição no coeficiente de transferência de oxigênio $\left(\mathrm{K}_{\mathrm{L}} \mathrm{a}\right)$ devido à deposição de meio e células na superfície do tubo de silicone ao longo dos 92 dias de ensaio. Da Equação 4.17, concluiu-se que Qo2.X será uma constante se fixada a pressão de entrada, sob a premissa de $\mathrm{K}_{\mathrm{L}}$ a constante. Se $\mathrm{K}_{\mathrm{L}}$ a diminui com o passar do cultivo, é natural se esperar que Q 2 .X diminua. Na medida que $\mathrm{Q}_{\mathrm{O} 2}$ é uma característica da célula a determinada temperatura, com a redução de $\mathrm{K}_{\mathrm{L}}$ a espera-se uma redução da concentração celular sustentada a determinada temperatura, conforme observado.

Evitados estes desvios devido ao entupimento da membrana de silicone, a estratégia utilizada de controle da bomba de purga permite, através deste ensaio, que se 
avalie a capacidade máxima de transferência de oxigênio de determinado equipamento já existente. Em outras palavras, quando se projeta um reator para comportar determinada concentração de células que respiram a uma certa velocidade, projeta-se emparalelo o sistema de transferência de oxigênio. No entanto, se o equipamento já existe, a estratégia utilizada permite que se avalie a concentraçãocelular máxima que o sistema de transferência suporta, para cada temperatura ensaiada. Lembrar que a limitação física do uso de membranas de silicone é a máxima pressão que a tubulação suporta, sem o risco de estourar.

Outra observação interessante é que neste ensaio, apesar de não se desejar controlar a concentração celular diretamente, a sonda de densidade ótica acompanhou a concentração celular durante todo o ensaio, de modo que a relação DO/X esteve entre 0,6 e 0,8 durante quase todo o ensaio (Figura 4.22). Desta forma, se neste ensaio se desejasse manter a concentração celular constante em $20 \mathrm{E} 6 \mathrm{cel} / \mathrm{mL}$, bastaria acionar a bomba de purga sempre que $\mathrm{DO}>14$, fazendo-se pequenos ajustes deste valor ao longo do ensaio (baseando-se nas contagens ao microscópio). A relação DO/X sofreu maiores alterações após 70 dias de cultivo, talvez devido à temperatura do cultivo alcançada $\left(39^{\circ} \mathrm{C}\right)$. 


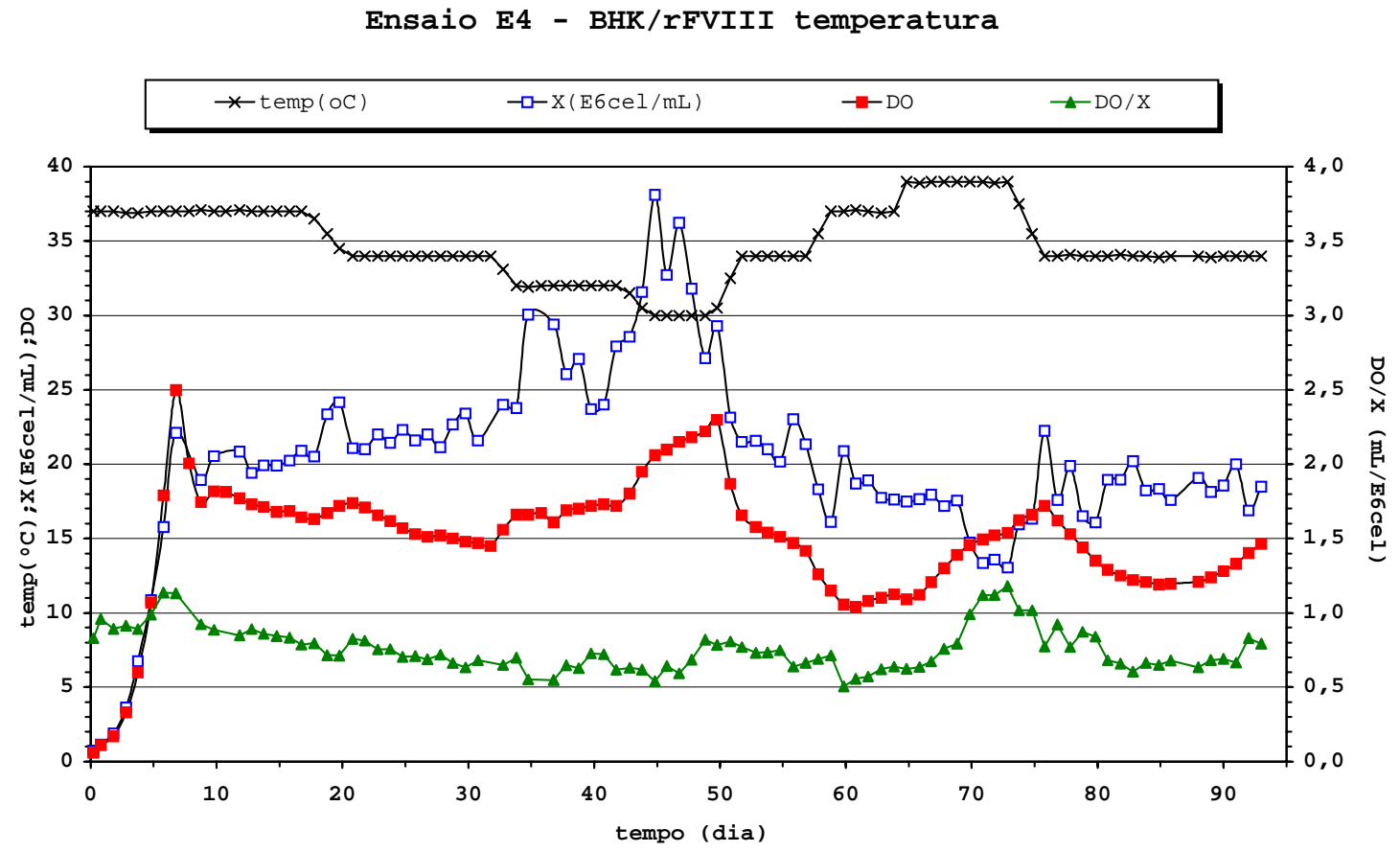

Figura 4.22 - Concentração celular (X), densidade ótica (DO), relação DO/X e temperatura do caldo em função do tempo, no ensaio E4 


\subsection{Monitoramento do Processo - Osmolalidade em cultivos de células animais}

Neste trabalho, como aplicação de técnicas de monitoramento, estudou-se a influência da osmolalidade do meio de cultura na produção de anti-TNF e rFVIII. A osmolalidade foi alterada através da simples adição de $\mathrm{NaCl}$ em diferentes quantidades ao meio de cultura que alimenta o biorreator continuamente.

Conforme visto no item 2.4, o aumento na osmolalidade do meio de cultivo acima do valor fisiológico $(290 \mathrm{mmol} / \mathrm{kg}$ ) provoca aumento da célula (diâmetro e volume) e, em certos casos, propicia maior produtividade. Como as células sofrem estresse em meio hiperosmótico, realizaram-se ensaios preliminares em garrafas "Roller" para determinação da eficiência do uso de betaína (15mM) como osmoprotetor.

\subsubsection{Ensaios em garrafas "Roller"}

Com o intuito de determinar valores máximos de osmolalidade para utilização no biorreator, assim como de analisar a eficiência da adição de betaína $(15 \mathrm{mM})$ como osmoprotetor para as células, realizou-se uma série de ensaios com o hibridoma A10G10, produtor do anticorpo anti-TNF, em garrafas "Roller" (roller bottles). O cultivo poderia ser chamado de batelada repetida. A cada dois dias, a concentração celular é medida (por contagem ao microscópio) e um volume desta cultura é adicionado a uma nova garrafa "Roller", completando-se o volume até 300mL com meio fresco, de tal forma que a concentração celular inicial $(0,5 \mathrm{E} 6 / \mathrm{mL})$ se mantenha em cada repique (sub-cultivo, ou passagem). A temperatura é mantida constante em $37^{\circ} \mathrm{C}$ e o $\mathrm{pH}$ oscila entre 6,8 e 7,0, em função do poder tamponante do meio e da atmosfera colocada na garrafa $\left(5 \% \mathrm{CO}_{2} \mathrm{em}\right.$ ar). 
Duas séries de ensaios em garrafas "Roller" foram realizadas com o objetivo de determinar faixas adequadas de osmolalidade para serem estudadas em reator, assim como verificar a eficiência da betaína como osmoprotetor. Os principais resultados destes ensaios em garrafas "Roller" estão apresentados na Tabela 4.1 e Figura 4.23.

Sem a adição de betaína, obteve-se maior concentração de produto $(\mathrm{P})$ e velocidade específica de produção $\left(\mu_{\mathrm{P}}\right)$ em meio com osmolalidade de $421 \mathrm{mmol} / \mathrm{kg}$, porém nesta condição o crescimento estava bastante prejudicado, como se pode avaliar pelos valores de $\mathrm{X}$, viabilidade e $\mu$. Com a adição de betaína, as células suportaram osmolalidades maiores, atingindo maior $\mathrm{P}$ e $\mu_{\mathrm{P}}$ com osmolalidade $470 \mathrm{mmol} / \mathrm{kg}$, apresentando os parâmetros de crescimento ligeiramente menores que na osmolalidade inferior (421 mmol/kg).

Com base nesses resultados, conclui-se pela eficiência da betaína e optou-se pela sua adição em meios com osmolalidade superior a $400 \mathrm{mmol} / \mathrm{kg}$ e fixou-se um limite para a osmolalidade no biorreator de $470 \mathrm{mmol} / \mathrm{kg}$. 
Tabela 4.1 - Resultados obtidos em garrafas "Roller" com hibridoma crescendo em meio com diferentes osmolalidades. Média dos valores obtidos após várias passagens

\begin{tabular}{|c|c|c|c|c|c|c|c|c|}
\hline \multirow{2}{*}{$\begin{array}{c}\begin{array}{c}\text { osmolalidade do meio } \\
(\mathrm{mmol} / \mathrm{kg})\end{array} \\
\text { adição de betaína }(15 \mathrm{mM})\end{array}$} & \multirow{2}{*}{$\begin{array}{r}321 \\
\text { sem }\end{array}$} & \multirow{2}{*}{$\begin{array}{l}376 \\
\text { sem }\end{array}$} & \multicolumn{2}{|c|}{421} & \multicolumn{2}{|c|}{470} & \multicolumn{2}{|c|}{520} \\
\hline & & & $\mathrm{COM}$ & sem & $\mathrm{COM}$ & sem & $\mathrm{COM}$ & sem \\
\hline $\begin{array}{l}\text { número de } \\
\text { passagens }\end{array}$ & 7 & 6 & 7 & 4 & 9 & 2 & 1 & 1 \\
\hline $\begin{array}{l}\text { concentração celular } \\
\text { X (E6 células/mL) }\end{array}$ & 1,8 & 1,5 & 1,8 & 0,7 & 1,4 & 0,4 & 0,4 & 0,0 \\
\hline $\begin{array}{l}\text { viabilidade } \\
(\%)\end{array}$ & 92 & 91 & 89 & 72 & 82 & 70 & 69 & 0 \\
\hline $\begin{array}{l}\text { velocidade específica de } \\
\text { crescimento } \mu\left(\mathrm{dia}^{-1}\right)\end{array}$ & 0,70 & 0,58 & 0,75 & 0,29 & 0,61 & - & - & - \\
\hline $\begin{array}{c}\text { concentração de produto } \\
\text { P (UA/mL) }\end{array}$ & 30 & 40 & 33 & 47 & 38 & 28 & 14 & 4 \\
\hline $\begin{array}{c}\text { velocidade específica de } \\
\text { produção } \mu \mathrm{P}(\mu \mathrm{UA} /(\text { cel.dia }))\end{array}$ & 27 & 40 & 30 & 61 & 35 & - & - & - \\
\hline $\begin{array}{l}\text { diâmetro médio } \\
\text { via Casy }(\mu \mathrm{m})\end{array}$ & 13,5 & 14,2 & 13,9 & 14,3 & 14,6 & - & 16,4 & - \\
\hline
\end{tabular}

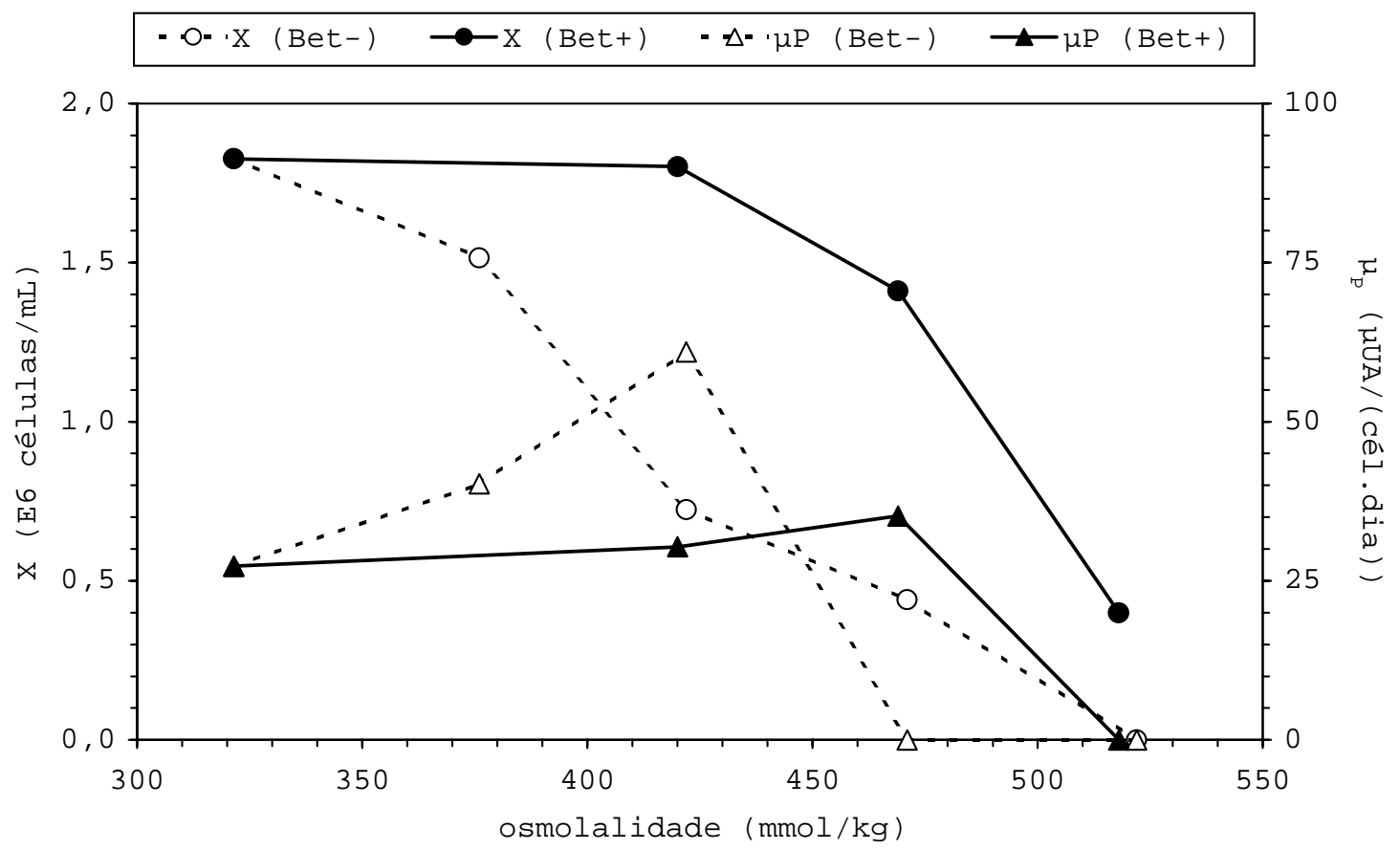

Figura 4.23 - Concentração celular $(\mathrm{X})$ e velocidade específica de produção $(\mu \mathrm{P})$ obtidas em garrafas "Roller" com hibridoma crescendo em meio com diferentes osmolalidades, 
com a adição de betaína (Bet+) e sem (Bet-). Média dos valores obtidos após várias passagens (repiques)

\subsubsection{Ensaio E5 - Influência da osmolalidade na produção de anti-TNF por hibridoma}

Baseado nos resultados dos ensaios preliminares em garrafas "Roller", realizouse o ensaio E5, com duração de 91 dias, objetivando-se estudar a influência do aumento da osmolalidade na produção do anticorpo anti-TNF por hibridoma em biorreator. Este foi inoculado com $0,73 \mathrm{E} 6 \mathrm{cel} / \mathrm{mL}$ e esteve em processo batelada por 4 dias, quando foi iniciada a retirada de produto e reposição de meio (volume constante), ajustando-se diariamente a vazão de retirada. Neste ensaio, a velocidade específica de perfusão (VEP) foi fixada em $0,25 \mathrm{~nL}$ de meio/célula/dia. Atingindo-se a concentração celular desejada (20E6 cel/mL), iniciou-se a purga de caldo.

Durante todo este ensaio, desejou-se manter a concentração celular constante. No início, ainda não se contava com um sistema automático de acionamento da bomba de purga, de modo que a vazão era ajustada diariamente, com base na contagem celular. Posteriormente, no dia 36, o programa rodando no LabVIEW foi atualizado e passou a poder controlar a bomba de purga. Como até aquele momento percebeu-se que a relação densidade ótica $(\mathrm{DO})=\mathrm{f}(\mathrm{X})$ variava nas mudanças de osmolalidade, optou-se por utilizar a pressão de entrada $\left(\mathrm{P}_{\mathrm{e}}\right)$ como variável a ser controlada pela bomba de purga, semelhante ao visto no ensaio E4. Por dificuldades operacionais (defeitos na sonda de OD e limitações do regulador de pressão a montante), mudou-se, a partir do dia 53, a variável de controle da purga para a densidade ótica, mantendo-se esta estratégia até o final do ensaio, embora com constantes ajustes do fator da relação $\mathrm{DO}=\mathrm{f}(\mathrm{X})$. Os valores 
de $\mathrm{X}$ obtidos ao longo do ensaio, assim como da viabilidade das células e a osmolalidade medida do caldo podem ser observados na Figura 4.24.

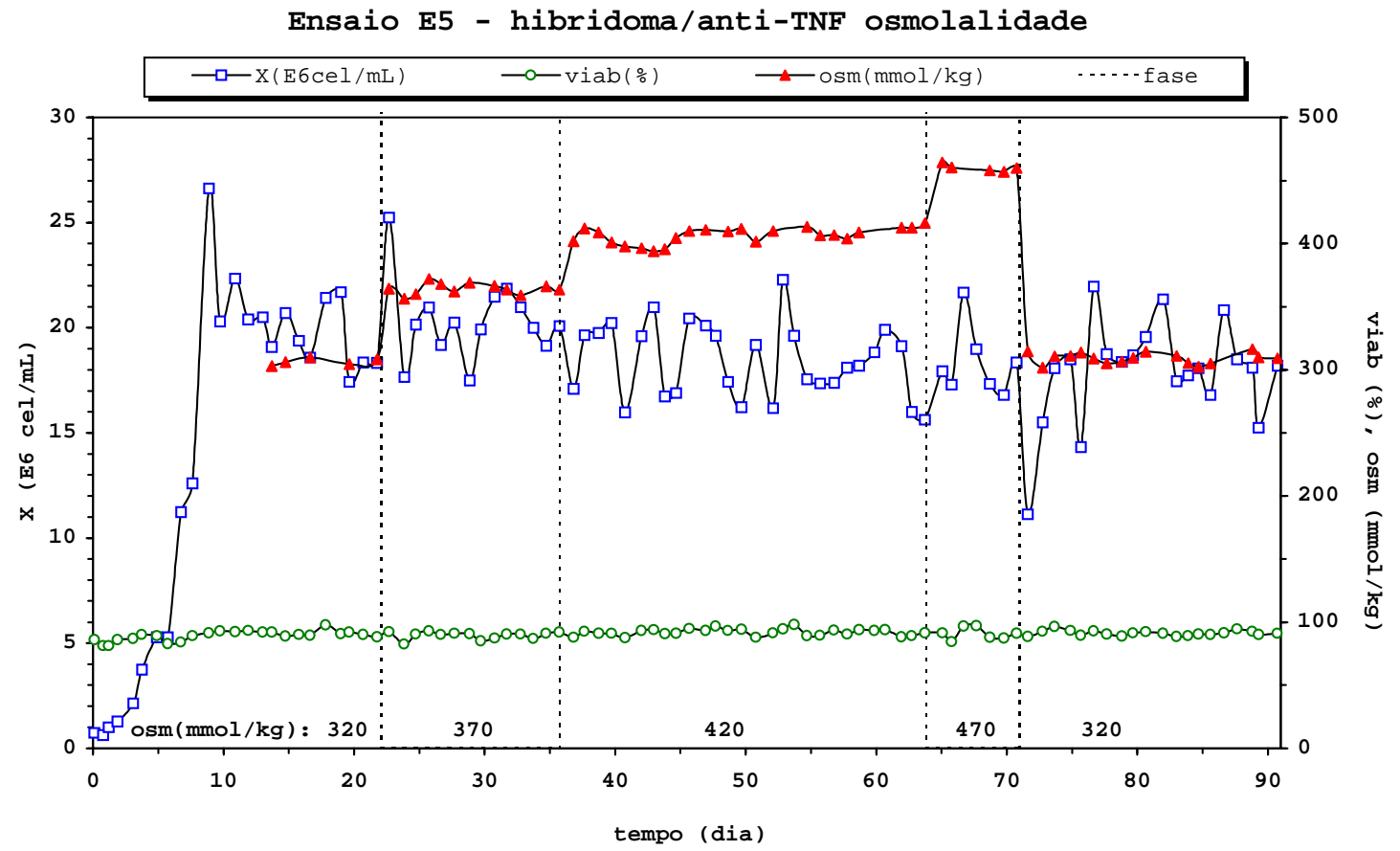

Figura 4.24 - Concentração celular (X), viabilidade e osmolalidade do caldo em função do tempo, no ensaio E5

A velocidade específica de produção em biorreator foi semelhante àquela obtida nos ensaios em garrafas "Roller" (Figura 4.25). Neste ensaio, foi realizada uma correção ao longo do tempo dos valores da concentração de produto, devido a um atenuamento observado no método de dosagem. Além disso, devido a problemas decorrentes à longa duração do cultivo, ao se retornar à condição inicial de $320 \mathrm{mmol} / \mathrm{kg}$, não se obteve valores idênticos à primeira fase, em especial com relação transferência de oxigênio, indicando obstrução do sistema de transferência de oxigênio. 


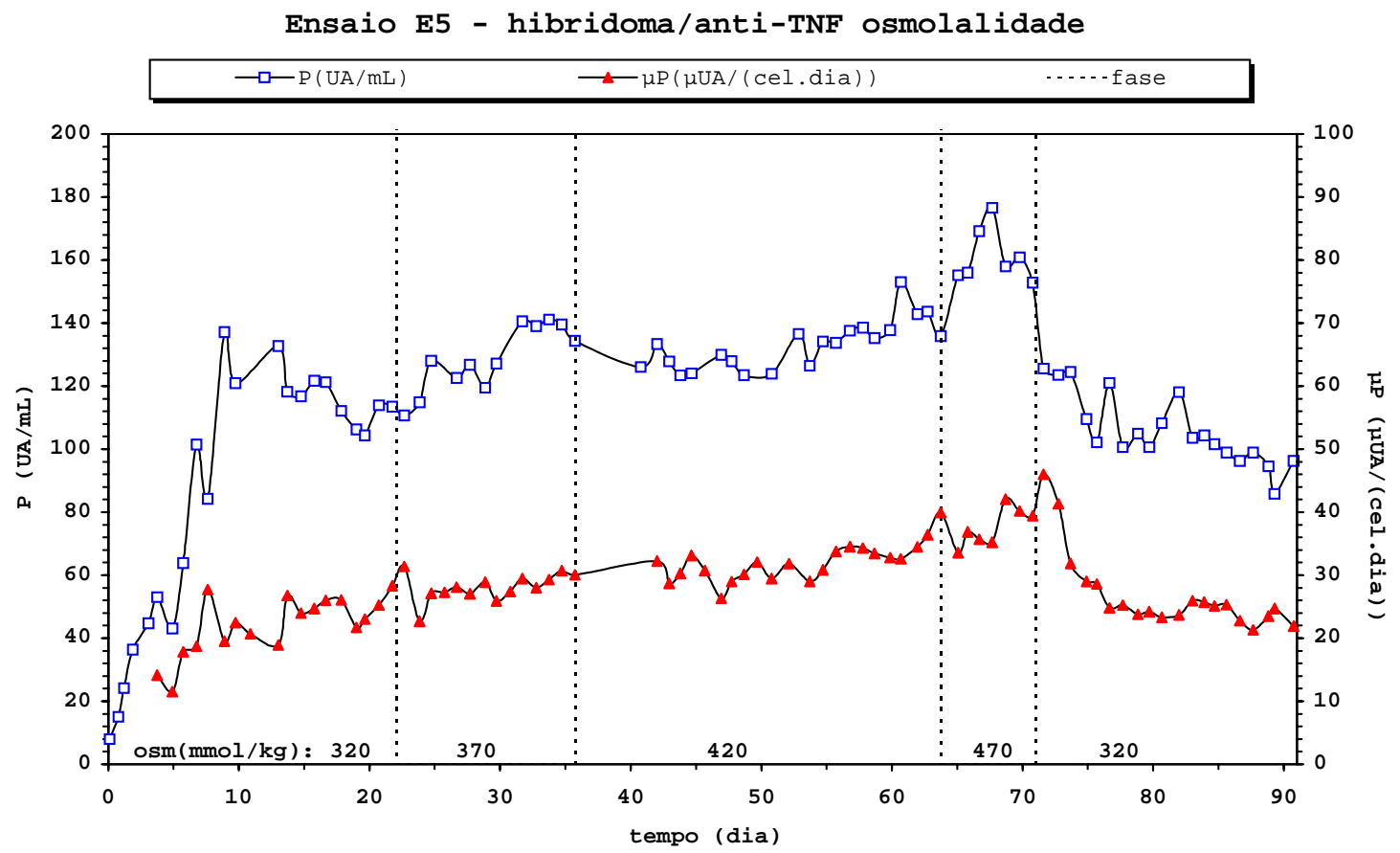

Figura 4.25 - Concentração de produto $(\mathrm{P})$ e velocidade específica de produção $(\mu \mathrm{P})$ em função do tempo, no ensaio E5

Neste ensaio, pode-se observar (Figura 4.26) que o aumento de osmolalidade do caldo gera um aumento no consumo de glicose por célula, semelhante ao observado no ensaio E4, provavelmente devido à ineficiência no consumo de glicose sob alta pressão osmótica. O consumo de glutamina, por outro lado, aparentemente não sofre influência da osmolalidade. Lembrar aqui que as células encontram-se maiores equando cultivadas em maiores osmolalidades, o que será utilizado na discussão a seguir. 


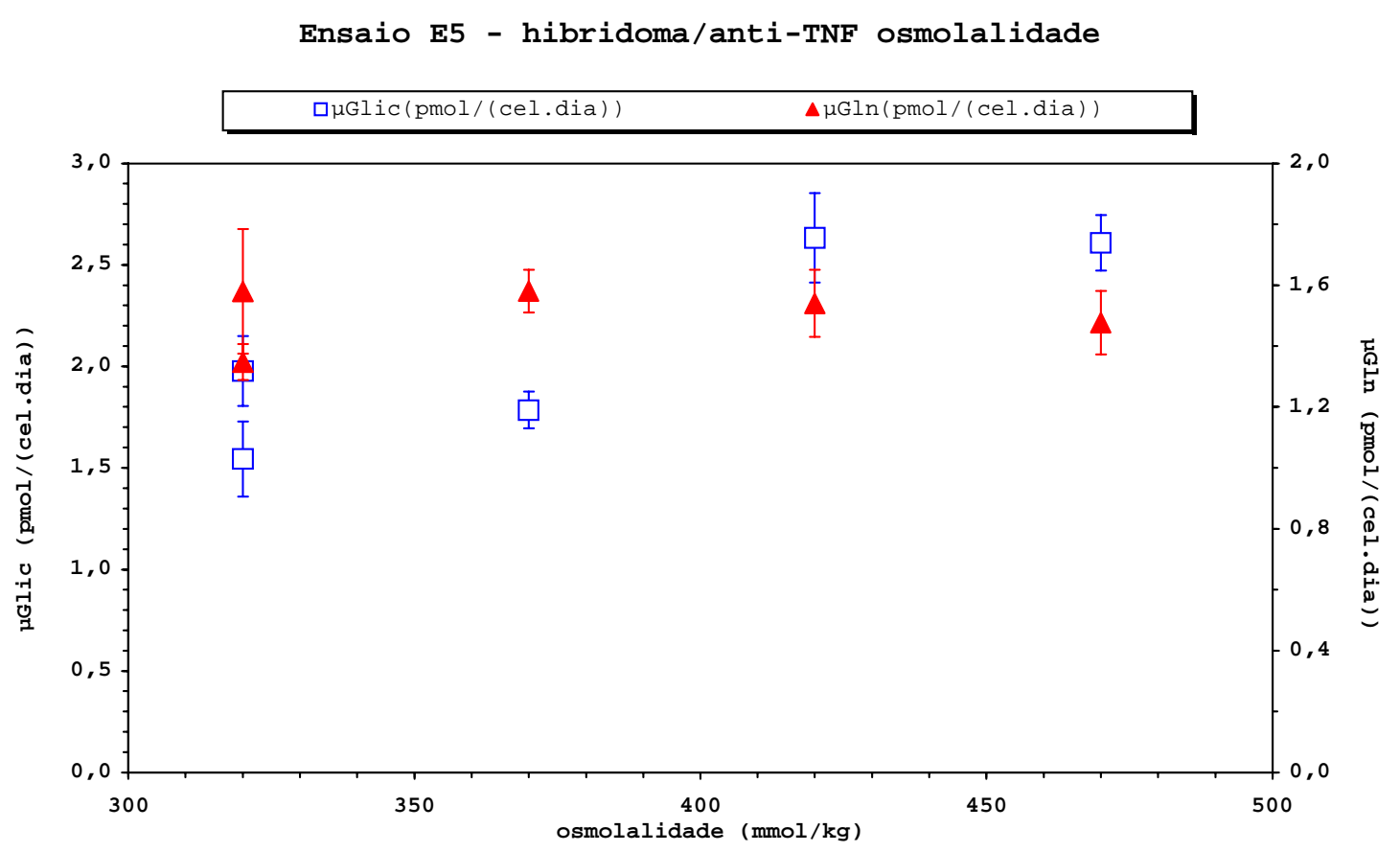

Figura 4.26 - Velocidades específicas de consumo de glicose $\left(\mu_{\mathrm{Glic}}\right)$ e glutamina $\left(\mu_{\mathrm{Gln}}\right)$ em função da osmolalidade do caldo, no ensaio E5

Com relação à velocidade específica de crescimento $(\mu)$, não foi observado nenhum comportamento claro, ao longo das várias fases de cultivo (Figura 4.27). No entanto, quando se analisa $\mathrm{P}_{\mathrm{m}}$, a média da pressão na entrada $\left(\mathrm{P}_{\mathrm{e}}\right)$ e na saída $\left(\mathrm{P}_{\mathrm{s}}\right)$ do tubo de silicone, observa-se que a média desses valores em altas osmolalidades é claramente superior. 


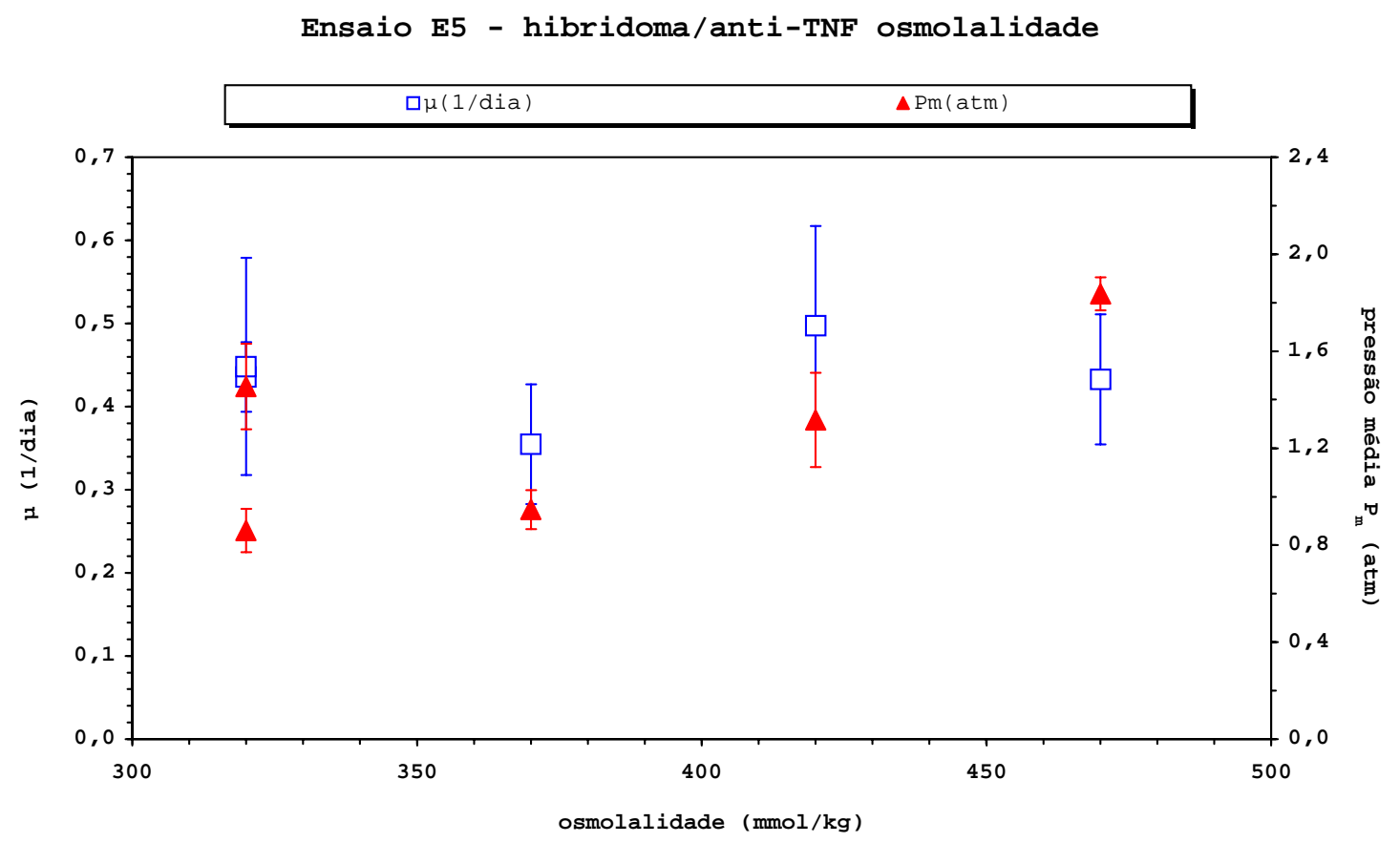

Figura 4.27 - Velocidades específicas de crescimento e pressão média no sistema de transferência de oxigênio (tubo de silicone) em função da osmolalidade do caldo, no ensaio E5

Conforme a Equação 4.18, mantida a concentração celular aproximadamente constante, $\mathrm{P}_{\mathrm{m}}$ passa a ser aproximadamente proporcional à velocidade específica de consumo de oxigênio ( $\left.\mathrm{Q}_{\mathrm{O} 2}\right)$. A Figura 4.27 mostra que em altas osmolalidades, há a necessidade de maiores pressões na tubulação, indicando que o Q significativamente, de modo análogo ao aumento da velocidade de consumo de oxigênio. Após cerca de 2 meses de cultivo, retornando-se à condição de osmolalidade igual a 320mmol/kg, observou-se a necessidade de uma maior pressão na tubulação, indicando um prejuízo na transferência, provavelmente devido ao depósito de células na tubulação, ou eventualmente devido a uma alteração irreversível das células. Mesmo assim, a conclusão anterior da correlação entre Q Q2 $_{2}$ e osmolalidade não perde validade, 
pois observa-se ainda diminuição de $\mathrm{P}_{\mathrm{m}}$ quando se reduziu a osmolalidade de 470 para $320 \mathrm{mmol} / \mathrm{kg}$.

Com relação ao tamanho da célula, os resultados obtidos comprovam os dados da literatura (OZTURK; PALSSON, 1991), como se observa na Figura 4.28. Tanto o diâmetro como o volume médios das células apresentam uma clara correlação com a pressão osmótica do caldo. Tal fato deverá ser considerado na hora de se comparar resultados em diferentes osmolalidades. Os dados aqui apresentados relativos ao tamanho das células foram obtidos através do aparelho Casy, cujo procedimento para análise, como dito anteriormente no item 3.3.7, requer o manuseio da amostra. Este inclui a diluição de cerca de 2500 vezes, para que a concentração de partículas se situe na faixa de medidas. Considerando-se que o procedimento de diluição altera o grau original de agregação das células no biorreator, a estimativa de tamanho por método "off-line" pode conduzir a conclusões errôneas. 


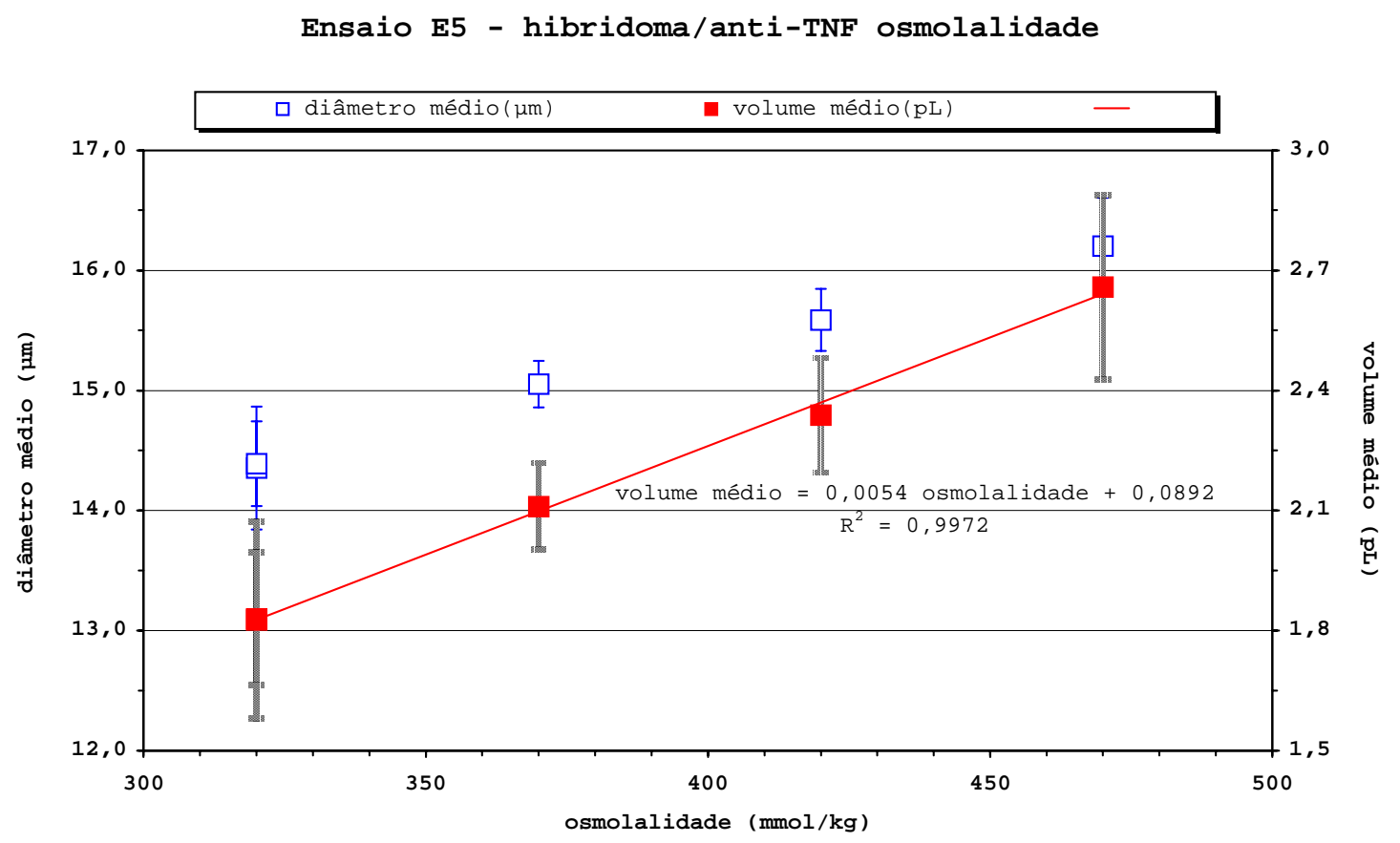

Figura 4.28 - Diâmetro e volume médios das células (biovolume) em função da osmolalidade do caldo, no ensaio E5

Buscando contornar este problema, em especial em situações onde a agregação das células é parte importante do processo, estudou-se o uso de um equipamento para estimativa "on-line" da concentração e tamanho das células: Lasentec FBRM (vide item 3.4).

A Figura 4.29 mostra dados preliminares da sonda Lasentec até o momento de sua falha (dia 51), em função dos resultados obtidos "off-line" com Casy. O tamanho de corda médio estimado pelo Lasentec é calculado restringindo-se a faixa de cordas medidas, de modo a se poder desprezar pequenos debris celulares e grandes agregados. Para o cálculo apresentado nesta figura, limitou-se a cordas entre 0,8 e 22,1 $\mu \mathrm{m}$. Observa-se com o aumento da osmolalidade, uma tendência de aumento no diâmetro celular, através do aparelho Casy, acompanhada pela resposta da sonda Lasentec. Com a 
falha da sonda, não se pôde acompanhar o processo durante o período com maior osmolalidade (e consequente maior diâmetro celular), de modo que esses são ainda resultados preliminares.

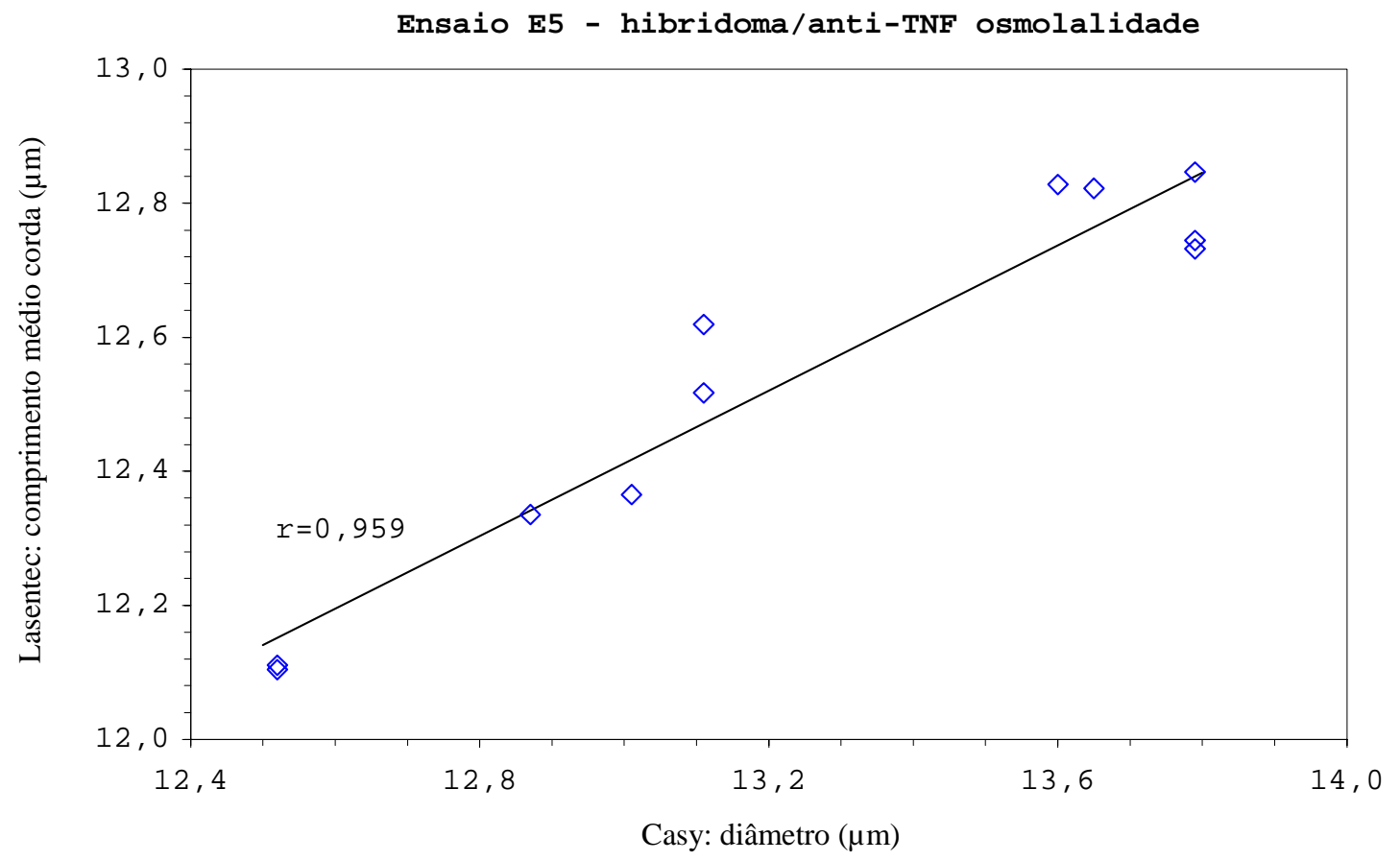

Figura 4.29 - Comprimento médio das cordas medidas "on-line" pelo Lasentec FBRM em função do diâmetro medido "off-line" pelo aparelho Casy TTC, no ensaio E5

Lembrando que as velocidades específicas, tais como consumo de glicose e produção, são normalmente calculadas em função do número de células nos processos com células animais, torna-se importante sua análise nos casos em que há uma variação no tamanho de cada célula. A dúvida que pode surgir seria se produziu mais porque realmente houve um aumento na capacidade de síntese do produto, ou simplesmente porque existe nesta situação maior massa celular produzindo? Nos processos com microrganismos, onde o denominador das velocidades específicas costuma ser a concentração celular calculada como massa seca, tal problema não aparece. Se há mais 
massa, há mais matéria produzindo o produto, independente se são mais células ou células maiores. Já nestes processos, como os cultivos de células de mamíferos, que utilizam a contagem de células como fator de relativização da velocidade de produção, a dúvida só pode ser resolvida através da estimativa do volume celular. Supõe-se aqui que a produção seja proporcional ao volume celular, premissa que em muitas situações não se comprova.

A Figura 4.30 apresenta as médias da concentração de produto obtidas no ensaio E5 como função da osmolalidade, assim como a velocidade específica de produção calculadas de duas formas. A primeira, padrão $\left(\mu_{\mathrm{P}}\right)$, dividindo-se a velocidade de produção pela concentração celular expressa como número de células por volume, obtendo-se quantidade de produto por célula e por tempo. A segunda forma, $\mu_{\mathrm{P}}[\mathrm{biovol}]$, foi calculada utilizando-se como concentração celular o biovolume, que representa a fração do caldo ocupado por células, obtendo-se quantidade de produto por volume celular por tempo.

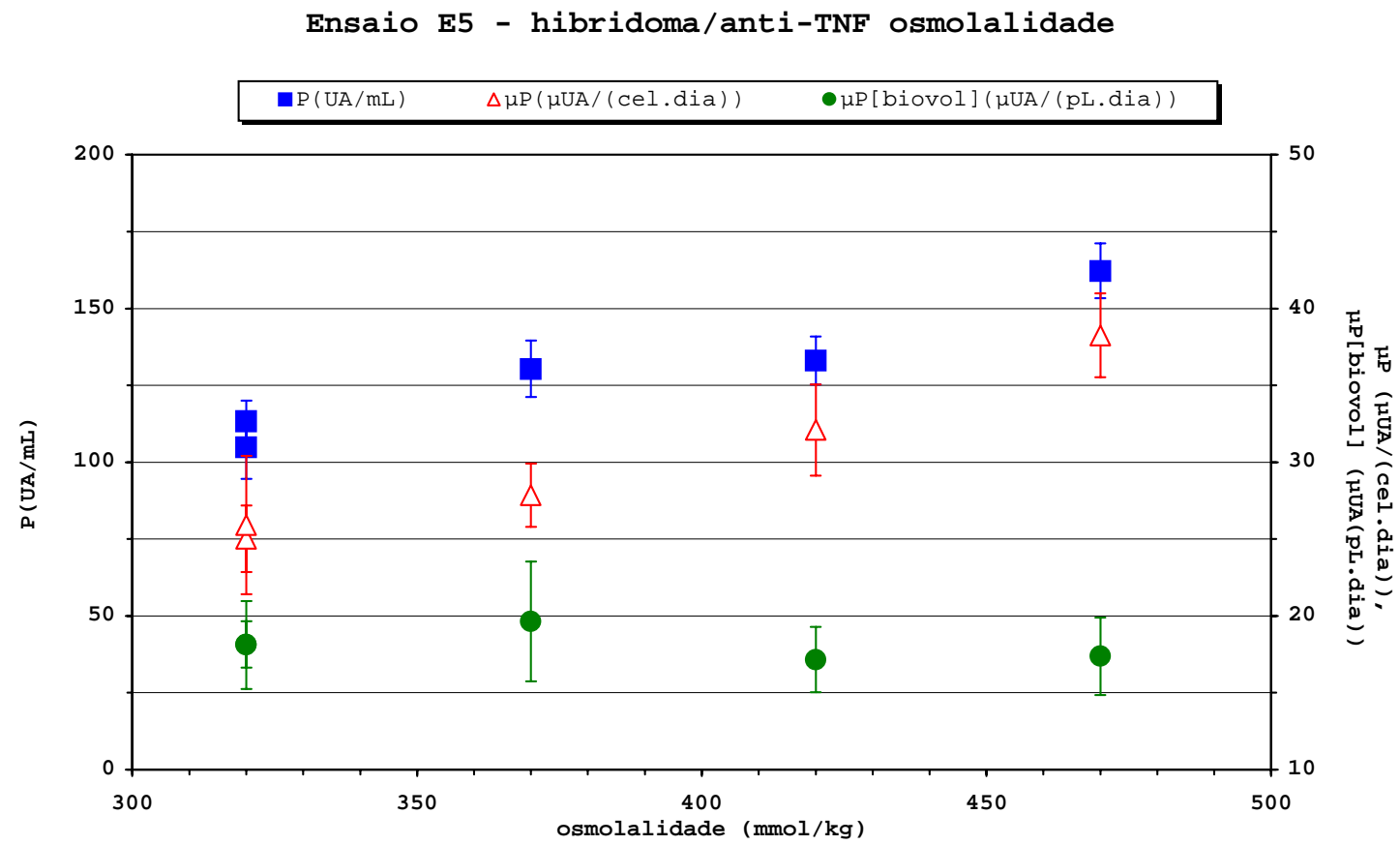


Figura 4.30 - Concentração de produto (P) e velocidades específicas de produção calculadas com base no número de células $(\mu \mathrm{P})$ e no volume celular ( $\mu \mathrm{P}[$ biovol]), em função da osmolalidade do caldo, no ensaio E5 (Obs: UA=unidade arbitrária)

Através desta segunda fórmula de cálculo, não ocorre um aumento na velocidade de produção (específica por volume) como decorrência do aumento na osmolalidade, (ainda Figura 4.30). $\mathrm{O}$ que se observa é a independência entre $\mu_{\mathrm{P}}[$ biovol] e osmolalidade, levando a crer que a conclusão anterior que altas osmolalidades aumentam a produção pode ser simplesmente devido à forma de cálculo da produção, por célula (numérica), e não por volume (ou "massa celular"). Raciocínio análogo poderia ser feito na análise do aumento da velocidade específica de consumo de glicose ou de respiração.

Devido à importância do acompanhamento do tamanho das células, como observado acima, torna-se ainda mais valiosa a tentativa de utilizar uma sonda, como a Lasentec, que avalie em tempo real variações no tamanho das células.

\subsubsection{Ensaio E6 - Avaliação da sonda Lasentec}

Para permitir uma melhor avaliação da sonda Lasentec FBRM, em especial devido a uma evolução em seu "hardware" e "software", foi realizado ainda um ensaio com células BHK em meios com diferentes pressões osmóticas, de modo a se ter uma sensível variação no tamanho das células. Não havendo, neste ensaio, interesse na produção e portanto a obtenção de estados estacionários, a variação da osmolalidade foi realizada em poucos dias, suficientes porém para as células reagirem às novas 
condições. Desta forma, neste ensaio não se pode definir estados pseudo-estacionário a cada novo valor de osmolalidade.

A figura 4.31 apresenta, para o ensaio E6, a concentração celular, viabilidade e osmolalidade no período em que esta foi aumentada em relação ao meio basal, em função do tempo de cultivo. Observa-se que nenhum estado estacionário foi atingido. No entanto, como se pode ver pela figura 4.32, as células BHK aumentaram de diâmetro e volume após o aumento na osmolalidade, semelhantemente ao observado com as células de hibridoma produtoras de anticorpo monoclonal. Interessante notar que mesmo após a diminuição da osmolalidade as células se mantiveram maiores, provavelmente devido ao fato de não se ter dado tempo suficiente para o reajuste.

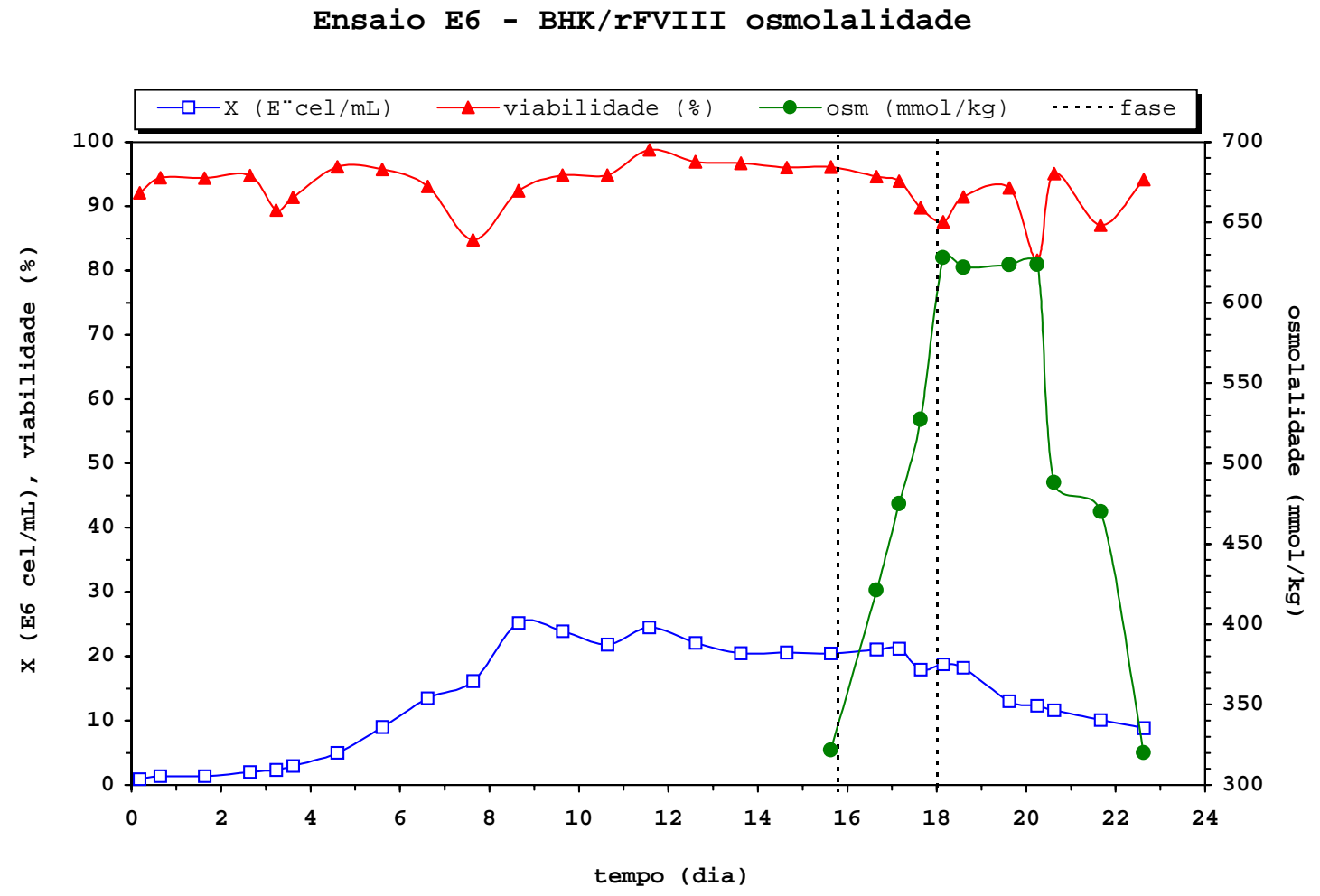

Figura 4.31 - Concentração celular (X), viabilidade e osmolalidade do caldo em função do tempo, no ensaio E6 


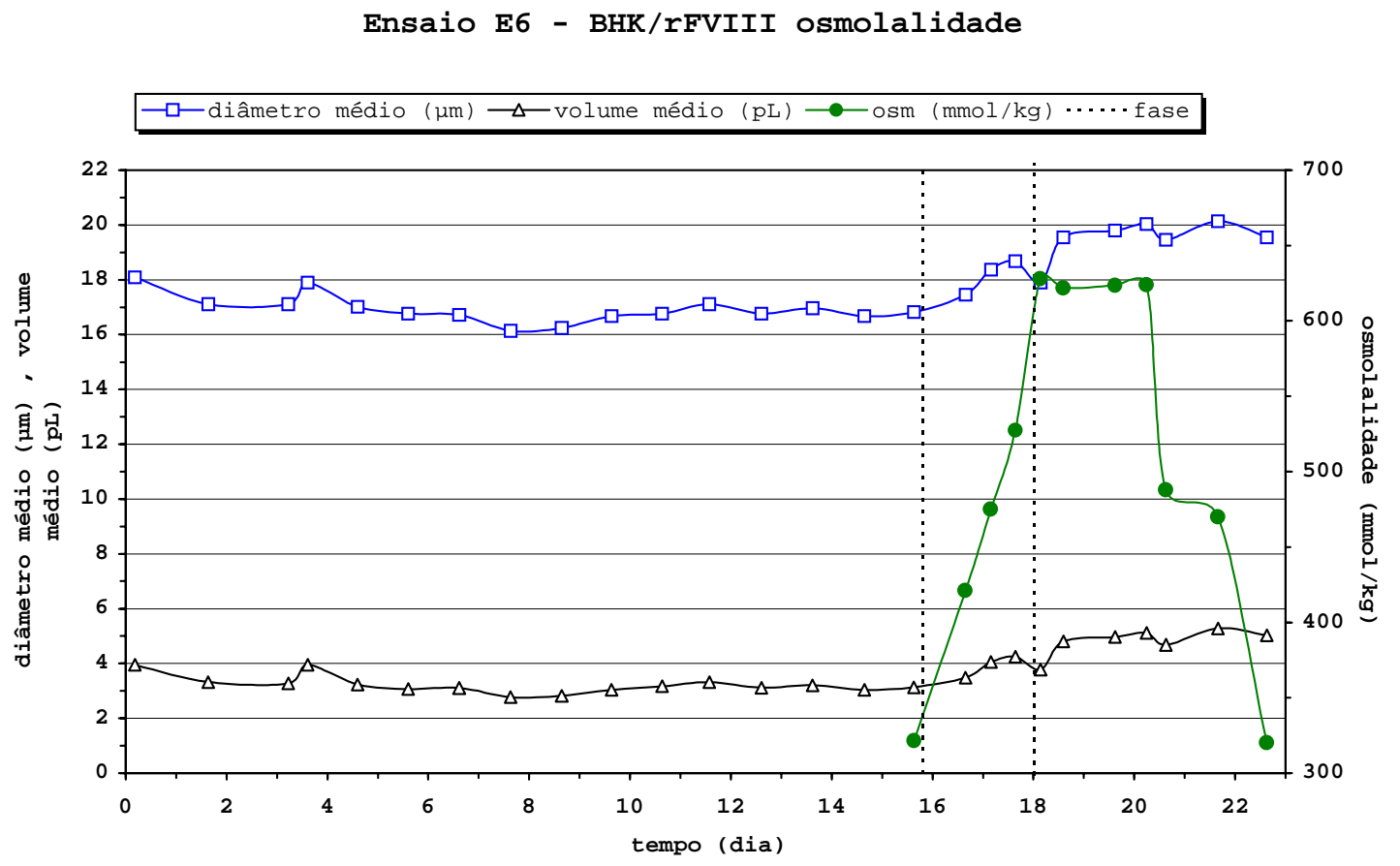

Figura 4.32 - Diâmetro e volume celular médios e osmolalidade do caldo em função do tempo, no ensaio E6

Paralelamente à medida " off-line" via Casy, monitorou-se o tamanho das células através da sonda Lasentec, na esperança de observar com o equipamento novo uma correlação clara entre as medidas "on-line" e o aumento das células, semelhante ao que obteve no ensaio com hibridoma.

Infelizmente, no entanto, as leituras da sonda Lasentec não corresponderam aos aumento de tamanho celular. Como se pode observar pela figura 4.33, a curva "comprimento médio das cordas" sofre flutuações durante a fase de crescimento das células, na parte à esquerda do gráfico. No entanto, justamente quando as células começam a crescer, segundo observação "off-line", esta curva se estabiliza, sem indicar nenhum tendência de aumento. A conclusão que se tira deste resultado é que a sonda não foi sensível à variação de tamanho observada pelo aparelho Casy, e ela não deve ser recomendada para tal aplicação. Acredita-se que os poucos resultados obtidos com a 
sonda anterior (até que apresentasse defeito) se ajustaram às medidas "off-line" mais por sorte do que precisão.

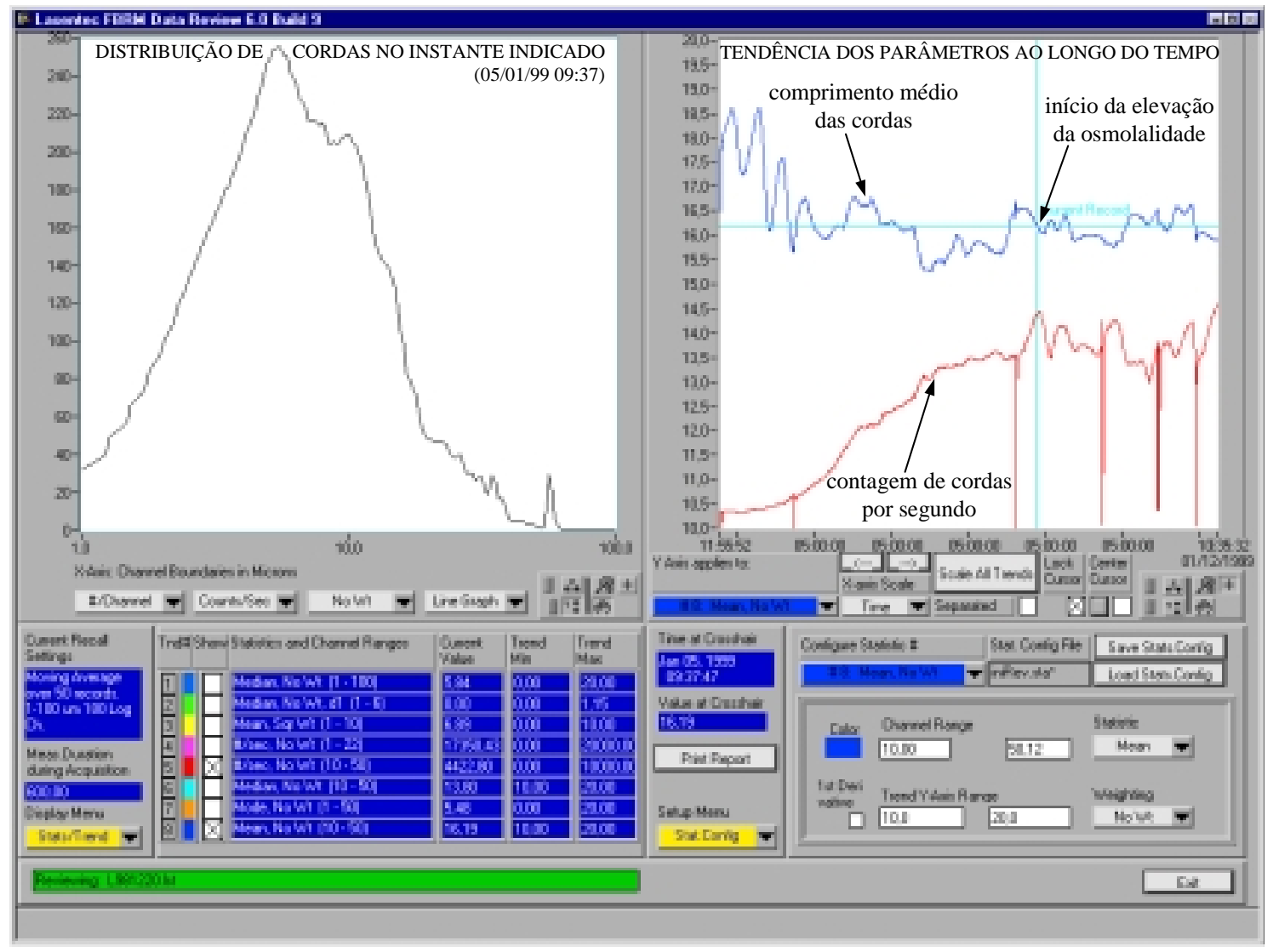

Figura 4.33 - Resultado da sonda Lasentec ao longo do ensaio E6, não apresentando correlação com o aumento do tamanho das células observado via Casy

Por outro lado, observando-se ainda a Figura 4.33, percebe-se que a curva "contagem de cordas por segundo" acompanhou o crescimento celular na fase inicial do ensaio, e flutouo a partir do início da elevação da osmolalidade semelhantemente ao observado por contagem ao microscópio.

Paralelamente, outro estudo foi feito no ensaio (E1), no qual desejava-se avaliar a aplicabilidade da sonda no monitoramento da concentração celular. Como se pode observar na figura 4.34, gerada a partir dos dados da sonda Lasentec em paralelo com outras formas de avaliar a concentração celular no ensaio E1, o número de cordas 
contadas pela sonda Lasentec se correlaciona muito bem com a concentração celular medida via contagem ao microscópio, sendo equivalente a outros métodos apresentados (densidade ótica e concentração celular via Casy). Desta forma, se sugere que no futuro se teste novamente esta sonda e, após a acumulação satisfatória de dados, recomenda-se validá-la como método confiável de estimativa de concentração celular para operar processos em perfusão.

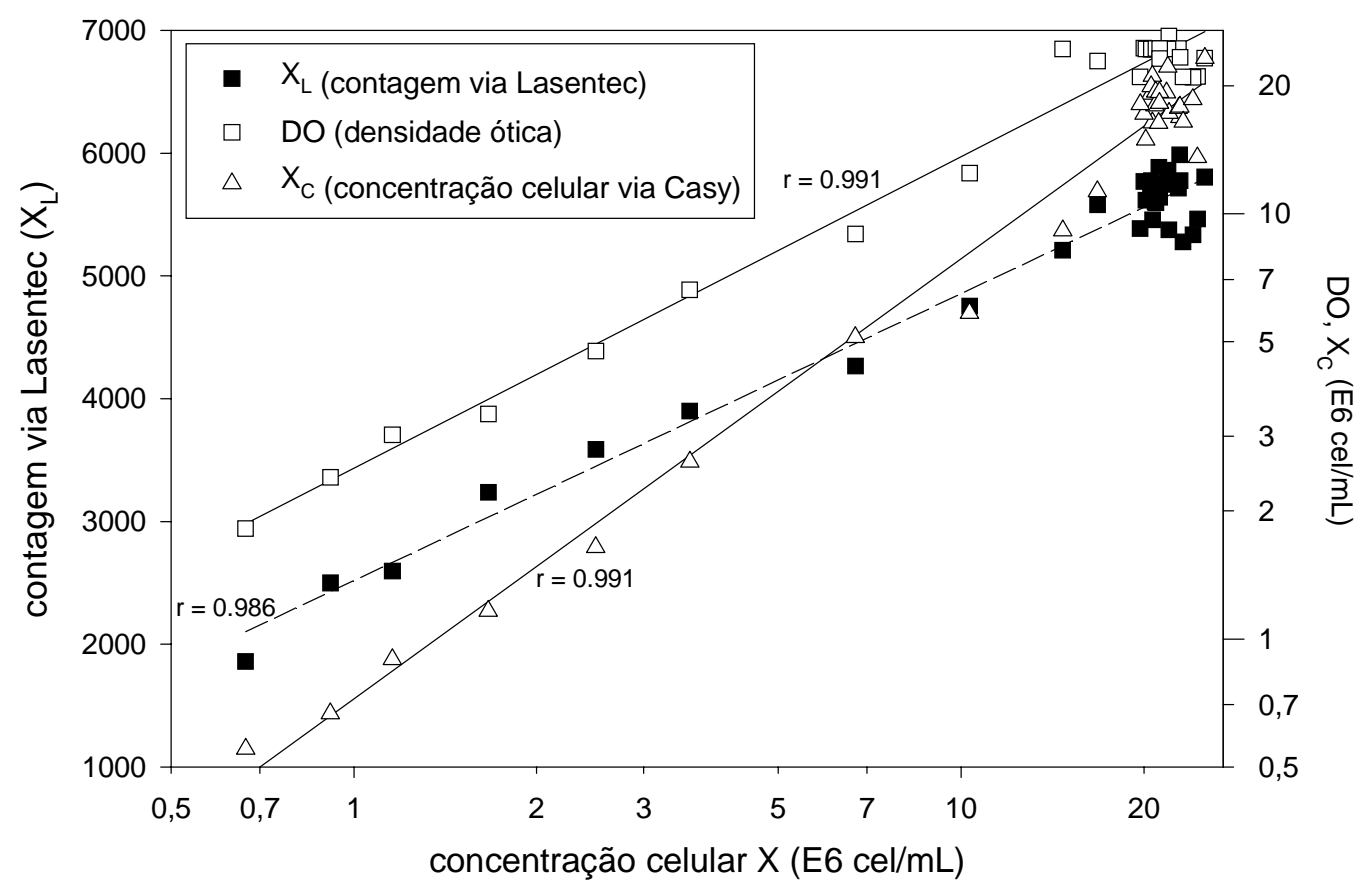

Figura 4.34 - Estimativa da concentração celular através de diferentes métodos aplicados às amostras do ensaio E1 


\section{CONCLUSÕES}

Com base no exposto no Capítulo 4 - Resultados e Discussões, pode-se concluir deste trabalho que:

- O processo de cultivo de células animais em sistema de perfusão apresentado permite que se mantenha o biorreator por pelo menos 3 meses em regime pseudoestacionário, com controle satisfatório das principais variáveis envolvidas.

- Tal processo permite que se estude a influência de fatores como temperatura, oxigênio dissolvido, osmolalidade no crescimento e produção, através do estabelecimento de fases do cultivo onde se obtenha suficiente número de dados para elaboração de médias de parâmetros representativas.

- Para a manutenção do sistema, é fundamental uma boa estimativa "on-line" da concentração celular, sendo esta a variável a ser mantida constante pela utilização da bomba de purga.

- O emprego da densidade ótica para estimativa da concentração celular é adequado para a maioria dos casos, necessitando-se porém proceder uma recalibração ocasional do fator densidade ótica/concentração celular.

- Pela utilização de estatégias alternativas de controle da bomba de purga, pode-se obter informações extras do sistema como, por exemplo, máxima capacidade de transferência de oxigênio para determinado equipamento já construído.

- A fase inicial do processo em perfusão requer especial atenção, no sentido de se evitar carência de gás carbônico dissolvido no meio ou controle impreciso da concentração de oxigênio dissolvido, que provocariam uma diminuição na velocidade de crescimento e eventual dano às células.

- O sistema empregado de transferência de oxigênio por difusão em membrana de silicone propicia, com grande vantagem sobre a aspersão direta, um ambiente livre de bolhas, que em muitos casos causam danos às células animais. 
- Por ser menos eficiente que a aspersão, a tubulação de silicone requer o emprego de gás oxigênio puro em sua alimentação, o que aumenta em 5 vezes a força-motriz da transferência de oxigênio e permite suprir cultivos em alta concentração celular.

- Graças ao fato da transferência ser regulada pela pressão média na tubulação, o sistema de controle da concentração de oxigênio dissolvido é simples e eficaz.

- Outra consequência desse fato é a possibilidade de se monitorar em tempo real a velocidade de consumo de oxigênio, através do simples emprego de manômetros.

- O ensaio realizado com diferentes concentrações de oxigênio dissolvido permitiu estabelecer uma faixa segura de operação do processo (entre 10 e $50 \%$ da saturação), além de sugerir a concentração abaixo da qual as velocidades específicas são afetadas (5 a 10\%).

- A partir do ensaio em diferentes temperaturas, pode-se determinar a capacidade máxima de transferência de oxigênio de um sistema de perfusão já existente, tendo em vista a limitação da tubulação de silicone para pressões muito altas.

- Além disso, esse ensaio confirmou os resultados publicados anteriormente com a mesma célula em meio de cultura diferente, com relação à influência da temperatura nas diferentes velocidades específicas de crescimento, consumo de substratos, respiração e produção.

- Como demonstração da importância do monitoramento no cultivo de células animais, o ensaio com diferentes osmolalidades permitiu que se estudasse a resposta das células ao estresse hiperosmótico em regime pseudo-estacionário, tendo-se atingido a osmolalidade de $470 \mathrm{mmol} / \mathrm{kg}$, graças à adição do osmo-protetor betaína. Além do aumento de diversas velocidades específicas (consumo de glicose, respiração, produção), o aumento da osmolalidade induziu a um aumento no tamanho das células.

- Devido a esse aumento de tamanho, elaborou-se um questionamento sobre o que é velocidade específica de produção em processos como o de células animais, onde se costuma medir a concentração celular através de uma contagem, suscetível à influência do aumento do tamanho celular. 
- Os resultados preliminares da sonda Lasentec FBRM pareceram indicar um grande potencial para monitoramento "on-line" da distribuição de tamanho das células, porém os dados de um ensaio posterior mostraram que o aparelho não tem sensibilidade suficiente para esta aplicação.

- No entanto, nos dois ensaios a sonda apresentou boa correlação entre o número de partículas contados e a concentração celular, sendo portanto um sistema capaz de estimar a concentração celular em tempo real.

- Do exposto acima, o presente trabalho contribui para o desenvolvimento de técnicas de operação do sistema de perfusão e do sistema de transferência de oxigênio através difusão em membrana de silicone, além de demonstrar a importância do adequado monitoramento de processos, em particular em cultivos com células animais. 


\section{REFERÊNCIAS BIBLIOGRÁFICAS}

AUNINS, J. G.; HENZLER, H.-J. (1993) Aeration in cell culture bioreactors. In: Biotechnology: a multi-volume comprehensive treatise, REHM, H.-J.; REED, G. (eds.), $2^{\text {nd }}$ edition, Weinheim, VCH Verlag, v.3, p.219-281.

BAILEY, J. E.; OLLIS, D. F. (1986) Biochemical Engineering Fundamentals, $2^{\text {nd }}$ edition, Singapore, McGraw-Hill, 984p.

BIBILA, T. A.; ROBINSON, D. K. (1995) In pursuit of the optimal fed-batch process for monoclonal antibody production. Biotechnol. Prog, v.11, p. 1-13.

BLANCH, H. W.; CLARK, D. S. (1997) Biochemical Engineering, New York, Marcel Dekker, 702p.

BUTLER, M. (1991) The characteristics and growth of cultured cells. In: BUTLER, M. Mammalian cell biotechnology: A practical approach, Oxford, Oxford University Press, p.1-25.

CASEY, E.; GLENNON, B.; HAMER, G. (1999) Oxygen mass transfer characteristics in a membrane-aerated biofilm reactor. Biotecnol. Bioeng., v.62, n.2, p.183-192.

CHAN, S. Y. (1994) Characterization of recombinant BHK-21 endogenous particles: Rtype particles. Biologicals v.22, p.121-125.

CHAN, S. Y.; LEMBACH, K. J. (1991) Genetic characterization of recombinant BHK-21 cells expressing factor VIII. Seminars in hematology, v.28, n.2, supl.1, p.10-16.

CHERLET, M.; MARC, A. (1999) Hybridoma cell behavior in continuous culture under hyperosmotic stress. Cytotechnology, v.29, p.71-84.

CHUPPA, S.; TSAI, Y.-S.; YOON, S.; SHACKLEFORD, S.; ROZALES, C.; BHAT, R.; TSAY, G.; MATANGUIHAN, C.; KONSTANTINOV, K.; NAVEH, D. (1997) Fermentor temperature as a tool for control of high-density perfusion cultures of mammalian cells. Biotechnol. Bioeng., v.55, n.2, p.328-338.

COULTER, W. H. (1956) Proc. Soc. Natl. Elect. Conf. v.12, p.1034.

DEVLIN, T. M. (ed.) (1997) Textbook of biochemistry: with clinical correlations, New

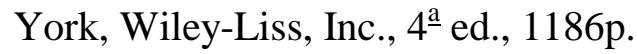

EMERY, A. N.; JAN, D. C. H.; AL-RUBEAI, M. (1995) Oxygenation of intensive cellculture system. Appl. Microbiol. Biotechnol., v.43, n.6, p.1028-1033.

FENGE, C.; KLEIN, C.; HEUR, C.; SIEGEL, U.; FRAUNE, E. (1993) Agitation, aeration and perfusion modules for cell culture bioreactors. Cytotechnology, v. 11, n.3, p.233-244.

GAMBHIR, A.; ZHANG, C.; EUROPA, A.; HU, W.-S. (1999) Analysis of the use of fortified medium in continuous culture of mammalian cells. Cytotechnology, v.31, p.243-254.

GARCIA-PEREZ, A.; BURG, M. B. (1991) Renal medullary organic osmolytes. Phisiological Reviews, v.71, n.4, p.1081-1115. 
GENENTECH (1985) New recombinant functional human Factor-VIII or derivatives, Patente US 160,457, 06/Novembro/1985.

GRIFFITHS, J. B. (1992) Animal cell culture processes - batch or continuous (query). $J$. Biotechnology, v.22, n.1-2, p.21-30.

HANDA-CORRIGAN, A. (1991) Bioreactors for mammalian cells. In: BUTLER, M. Mammalian cell biotechnology: A practical approach, New York, Oxford University Press, p.138-158.

HEIDEMANN, R.; LÜTKEMEYER, D.; BÜNTEMEYER, H.; LEHMANN, J. (1998) Effects of dissolved oxygen levels and the role of extra-and intracellular amino acid concentrations upon the metabolism of mammalian cell lines during batch and continuous cultures. Cytotechnology, v.26, p.185-197.

HENZLER, H. J.; KAULING, D. J. (1993) Oxygenation of cell cultures. Bioprocess Engineering, v.9, p.61-75.

HIRONAKA, T.; FURUKAWA, K.; ESMON, P. C.; YOKOTA, T.; BROWN, J. E.; SAWADA, S.; FOURNEL, M. A.; KATO, M.; MINAGA, T.; KOBATA, A. (1993) Structural study of the sugar chains of porcine factor VIII - Tissue- and speciesspecific glycosylation of factor VIII. Archives of Biochemistry and Biophysics, v.307, n.2, p. 316-330.

JAEGER, V.; KOBOLD, A. (1995) Propagation of Spodoptera frugiperda cells (Sf9) and production of recombinant proteins with the baculo virus expression system using improved spinner flasks with membrane aeration. Biotechnol. Tech, v.9, n.6, p.435-440.

JAN, D. C. H.; PETCH, D. A.; HUZEL, N.; BUTLER, M. (1997) The effect of dissolved oxygen on the metabolic profile of a murine hybridoma grown in serumfree medium in continuous culture. Biotechnol. Bioeng., v. 54, n.2, p.153-164.

JENKINS, N.; PAREKH, R. B.;JAMES, D.C. (1996) Getting the glycosylation right: Implications for the biotechnology industry. Nature Biotechnology. v.14, n.8, p.975981.

JORJANI, P.; OZTURK, S. S. (1999) Effects of cell density and temperature on oxygen comsumption rates for different mammalian cell lines. Biotechnol. Bioeng., v.64, n.3, p.349-356.

KANOKWAREE, K.; DORAN, P. M. (1998) Application of membrane tubing aeration and perfluorocarbon to improve oxygen delivery to hairy root cultures. Biotechnol. Prog., v.14, p.479-486.

KELLEY, B. D.; CHIOU, T.-W.; ROSENBERG, M.; WANG, D. I. C. (1993) Industrial animal cell culture. In: Biotechnology: a multi-volume comprehensive treatise, REHM, H.-J.; REED, G. (eds.), $2^{\text {nd }}$ edition, Weinheim, VCH Verlag, v.3, p.23-38.

KILBURN, D. (1991) Monitoring and control of bioreactors. In: BUTLER, M. Mammalian cell biotechnology: A practical approach, New York, Oxford University Press, p.159-185.

KONSTANTINOV, K. B. (1996) Monitoring and control of the physiological state of cell cultures. Biotechnol. Bioeng., v.52, p.271-289. 
KONSTANTINOV, K. B.; TSAI, Y. S.; MOLES, D.; MATANGUIHAN, R. (1996) Control of long-term perfusion $\mathrm{CHO}$ cell culture using glucose auxostat. Biotechnol. Progress, v.12, p.100-109.

KONSTANTINOV, K.; CHUPPA, S.; SAJAN, E.; TSAI, Y.; YOON, S.; GOLINI, F. (1994) Real-time biomass-concentration monitoring in animal-cell cultures. Tibtech, v. 12., p.324-333.

KONSTANTINOV, K. B.; PAMBAYUN, R.; MATANGUIHAN, R.; YOSHIDA, T. (1992) On-line monitoring of hybridoma cell growth using a laser turbidity sensor. Biotechnol. Bioeng., v.40, p.1337-1342.

KONZ, J. O.; KING, J.; COONEY, C. L. (1998) Effects of oxygen on recombinant protein expression. Biotechnol. Progress, v.14, p.393-409.

LAKHOTIA, S.; BAUER, K. D.; PAPOUTSAKIS, E. T. (1993) Fluid-mechanical forces in agitated bioreactors reduce the CD13 and CD33 surface protein content of HL60 cells. Biotechnol. Bioeng., v.41, n.9, p.868-877.

LEE, E. K.; HUANG, L.; LEE, Y. H. (1990) Effect of liquid properties and flow on liquid film mass transfer coefficient in silicone membrane oxygenation. Biotechnol. Bioeng., v.36, p.530-533.

LIM, H. S.; CHANG, K.H.; KIM, J. H. (1999) Effect of oxygen partial pressure on production of animal virus (VSV). (1999) Cytotechnology, v.31, p.265-270.

LIN, J.; TAKAGI, M.; QU, Y.; GAO, P.; YOSHIDA, T. (1999) Enhanced monoclonal antibody production by gradual increase of osmotic pressure. Cytotechnology, v.29 p.27-33.

LINDL, T. (1996) Development of human monoclonal antibodies: A review. Cytotechnology, v.21, p.183-193.

LIU, W.; CLARK, N. N.; KARAMAVRUC, A. I. (1996) General method for the transformation of chord-length data to a local bubble-size distribution. AIChE Journal, v.42, n.10, p.2713-2720.

LUCKE, B.; McCUTCHEON, M. (1932) The living cell as an osmotic system and its permeability to water. Physiol. Rev., v.12, p.68-139.

MAINS, R. E.; CULLEN, E. I.; MAY, V.; EIPPER, B. A. (1987) The role of secretory granules in peptide biosynthesis. Ann. NY Acad. Sci., v.493, p.278-291.

MATANGUIHAN, R.; MENESES, R.; SAJAN, E.; TONSO, A.; KONSTANTINOV, K.; NAVEH, D. (1999) Reliable on-line monitoring of cell concentration in perfusion mammalian cell culture using a retractable optical density probe. Abstr. Pap. Am. Chem. Soc., 217 ${ }^{\text {th }}$ Meeting, 21 a 25/Março, Anaheim, CA, EUA.

MICHAELS, J. D.; MALLIK, A. K.; PAPOUTSAKIS, E. (1996) Sparging and agitation-induced injury of cultured animal cells: Do cell-to-bubble interactions in the bulk liquid injure cells? Biotecnology and Bioengineering, v.51, p.399-409.

MILES (1993) Antibody specific for tumor necrosis factor binding site of tumor necrosis factor receptor, Patente US 525,570, 03/Fevereiro/1993. 
MILLER, W. M.; WILKE, C. R.; BLANCH, H.W. (1987) Effects of dissolved oxygen concentration on hybridoma growth and metabolism in continuous culture. J. Cell Physiol. v.132, n.3, p.524-530.

MONNIER, O.; KLEIN, J. P.; HOFF, C.; RATSIMBA, B. (1996) Particle size determination by laser reflection: Methodology and problems. Part. Part. Syst. Charact. v. 13 p. 10-17.

MOREIRA, J. L.; CRUZ, P. E.; SANTANA, P. C.; FELICIANO, A. S.; LEHMANN, J.; CARRONDO, M. J. T. (1995) Influence of power input and aeration method on mass transfer in a laboratory animal cell culture vessel. J. Chem. Technol. Biotechnol, v.62, n.2, p.118-131.

OEHLER, R.; HEFEL, B.; ROTH, E. (1996) Determination of cell volume changes by an inulin-urea assay in 96-well plates: A comparison with Coulter counter analysis. Analytical Biochemistry, v.241, p.269-271.

OYAAS, K.; ELLINGSEN, T. E.; DYRSET, N.; LEVINE, D. W. (1994) Hyperosmotic hybridoma cell culture: Increased monoclonal antibody production with addition of glycine betaine. Biotechnol. Bioeng., v.44, p. 991-998.

OZTURK, S. S.; THRIFT, J. C.; BLACKIE, J. D.; NAVEH, D. (1997) Real-time monitoring and control of glucose and lactate concentrations in a mammalian cell perfusion reactor. Biotechnol. Bioeng., v.53, n.4, p.372-378.

OZTURK, S. S. (1996) Engineering challenges in high density cell culture systems. Cytotechnology, v.22, p.3-16.

OZTURK, S. S.; THRIFT, J. C.; BLACKIE, J. D.; NAVEH, D. (1995) Real-time monitoring of protein secretion in mammalian cell fermentation: Measurement of monoclonal antibodies using a computer-controlled HPLC system (BioCad/RPM). Biotechnol. Bioeng., v.48, p.201-206.

OZTURK, S. S.; PALSSON, B. O. (1991) Effect of medium osmolarity on hibridoma growth, metabolism, and antibody production. Biotechnol. Bioeng., v.37, p.989-993.

OZTURK, S. S.; PALSSON, B. O. (1990) Effects of dissolved oxygen on hybridoma cell growth, metabolism, and antibody production kinetics in continuous culture. Biotechnol. Prog., v.6, n.6, p.437-446.

PAPOUTSAKIS, E. T.; (1991) Fluid-mechanical damage of animal cells in bioreactors. Trends-Biotechnology, v.9, n.12, p.427-37.

PHILLIPS, H. J. (1973) In: Tissue Culture: Methods and Applications (ed. P.F. Kruse Jr. e M. K. Patterson), p.406. Academic Press, New York.

PHILLIPS, J. M.; WALLING, D. E. (1998) Calibration of a Par-Tec 200 laser backscatter probe for in situ sizing of fluvial suspended sediment. Hydrological Processes, v. 12, p. 221-231.

POLASTRI, G. D. (1997) Development of the cell culture process for the large-scale production of the recombinant tissue plasminogen-activator Activase. Abstr. Pap. Am. Chem. Soc., $213^{\text {th }}$ Meeting, Pt.1, Biot145. 
RAMIREZ, O. T.; MUTHARASAN, R. (1990) Cell cycle-and growth phase-dependent variations in size distribution, antibody productivity, and oxygen demand in hybridoma cultures. Biotechnol. Bioeng., v.36, p.839-848.

REDMAN, T.; ROHANI, S.; STRATHDEE, G. (1997) Control of the crystal mean size in a pilot plant potash crystallizer. Trans IChemE, v.75, part. A, p.183-192.

REITER, M.; ZACH, N.; GAIDA, T.; BLUEML, G.; DOBLHOFF-DIER, O.; UNTERLUGGAUER, F. (1992) Oxygenation in fluidized bed bioreactors using the microsparging technique. Anim. Cell-Technol. p. 386-390.

RICHMOND, W. R.; JONES, R. L.; FAWELL, P. D. (1998) The relationship between particle aggregation and rheology in mixed silica-titania suspensions. Chemical Engineering Journal, v. 71, p. 67-75.

ROGNONI, F.; GIANESELLO, D.; MADDALENA, F.; GIUNTINI, I.; DETLEV, H. (1999) Influence of osmolarity and $\mathrm{pH}$ increase to achieve a reduction of monoclonal antibodies aggregates in a production process. Citotechnology, v.29, p.11-25.

RUFFIEUX, P. A.; STOCKAR, U.; MARISON, I. W. (1998) Measurement of volumetric (OUR) and determination of specific $\left(\mathrm{qO}_{2}\right)$ oxygen uptake rates in animal cell cultures. Journal of Biotechnology, v.63, p.85-95.

RYU, J. S.; LEE, G. M. (1999) Application of hypoosmolar medium to fed-batch culture of hybridoma cells for improvement of culture longevity. Biotechnol. Bioeng., v.62, n.1, p.120-123.

SAMBANIS, A.; HU, W.-S. (1993) Cell culture bioreactors. In: Biotechnology: a multivolume comprehensive treatise, REHM, H.-J.; REED, G. (eds.), $2^{\text {nd }}$ edition, Weinheim, VCH Verlag, v.3, p.105-126.

SEEWÖSTER, T.; LEHMANN, J. (1997) Cell size distribution as a parameter for the predermination of exponential growth during repeated batch cultivation of $\mathrm{CHO}$ cells. Biotechnol. Bioeng., v.55, n.5, p.793-797.

SEN, S.; SRIENC, F.; HU, W.-S. (1989) Distinct volume distribution of viable and nonviable hybridoma cells: A flow cytometric study. Cytotechnology, v.2, p.85-94.

SIMMONS, M. J. H.; LANGSTON, P. A.; BURBIDGE, A. S. (1999) Particle and droplet size analysis from chord distribution. Powder Technology, v. 102, p. 75-83.

SINGH, V. (1996) On-line measurement of oxygen uptake in cell culture using the dynamic method. Biotechnol. Bioeng., v.52, p.443-448.

SUHR, H.; WEHNERT, G.; SCHNEIDER, K.; BITTNER, C.; SCHOLZ, T.; GEISSLER, P.; JÄHNE, B.; SCHEPER, T. (1995) In situ microscopy for on-line characterization of cell-populations in bioreactors, including cell-concentration measurements by depth from focus. Biotechnol. Bioeng., v. 47 p. 106-116.

TATICEK, R. A.; SHULER, M. L. (1997) Effect of elevated oxygen and glutamine levels on foreign protein production at high cell densities using the insect cellbaculovirus expression system. Biotechnol. Bioeng., v.54, n.2, p.142-152.

TONSO, A.; MATANGUIHAN, C.; KONSTANTINOV, K.; NAVEH, D. (1998) Online monitoring of cell size distribution in mammalian cell culture. Abstracts, Cell 
Culture Engineering VI, Engineering Foundation Conferences, San Diego, CA, EUA, 7 a 12/Fevereiro.

VRIEZEN, N.; ROMEIN, B.; LUYBEN, K. C. A. M.; DIJKEN, J. P. (1997) Effects of glutamine supply on growth and metabolism of mammalian cells in chemostat culture. Biotechnol. Bioeng., v.54, n.3, p.272-286.

WEIDEMANN, R.; LUDWIG, A.; KRETZMER, G. (1994) Low temperature cultivation: a step toward process optimization. Cytotechnology, v.15, n.1-3, p.111116.

WIRTH, M.; HAUSER, H. (1993) Genetic engineering of animal cells. In: Biotechnology: a multi-volume comprehensive treatise, REHM, H.-J.; REED, G. (eds.), $2^{\text {nd }}$ edition, Weinheim, VCH Verlag, v.2, p.663-744.

WOLFE, R. A. (1993) Media for cell culture. In: Biotechnology: a multi-volume comprehensive treatise, REHM, H.-J.; REED, G. (eds.), $2^{\text {nd }}$ edition, Weinheim, VCH Verlag, v.3, p.141-156.

WU, J.; GOOSEN, M. F. A. (1994) Investigation of air-liquid interfacial damage of animal cells in a falling film-flow device. Biotechnol. Tech., v.8, n.2, p. 111-116.

WU, P.; OZTURK, S. S.; BLACKIE, J. D.; THRIFT, J. C.; FIGUEROA, C.; NAVEH, D. (1995) Evaluation and applications of optical cell density probes in mammalian cell bioreactors. Biotechnol. Bioeng., v.45, p.495-502.

ZENG, A. P.; HU, W.-S.; DECKWER, W. D. (1998) Variation of stoichiometric ratios and their correlation for monitoring and control of animal cell cultures. Biotechnol. Prog., v.14, n.3, p.434-441.

ZHANG, J.; COLLINS, A.; CHEN, M.; KNYAZEV, I.; GENTZ, R. (1998) Highdensity perfusion culture of insect cells with a BioSep ultrasonic filter. Biotechnol. Bioeng., v. 59, n.3, p.351-359.

ZHANG, S.; HANDA-CORRIGAN, A.; SPIER, R. E. (1993) A comparison of oxygenation methods for high-density perfusion cultures of animal cells. Biotechnol. Bioeng., v.41, p.685-692. 
ANEXO

Tabela A.1 - Valor das principais variáveis ao longo do tempo, do ensaio E1 (notação de acordo com Lista de Símbolos)

\begin{tabular}{|c|c|c|c|c|c|c|c|c|c|c|c|c|c|}
\hline $\begin{array}{c}\mathrm{t} \\
\text { dia }\end{array}$ & $\begin{array}{l}\mathrm{Pm} \\
\mathrm{atm}\end{array}$ & $\begin{array}{l}\text { OD } \\
\%\end{array}$ & DO & $\begin{array}{c}\mathrm{X} \\
\text { E6cel/mL }\end{array}$ & $\begin{array}{c}\text { viab } \\
\%\end{array}$ & $\begin{array}{l}\text { Glic } \\
\mathrm{mM}\end{array}$ & $\begin{array}{l}\text { Gln } \\
\mathrm{mM}\end{array}$ & $\begin{array}{c}P \\
\mathrm{UA} / \mathrm{mL}\end{array}$ & $\begin{array}{c}\text { Xref } \\
\text { E6cel } / \mathrm{mL}\end{array}$ & $\begin{array}{c}\mu \\
1 / \text { dia }\end{array}$ & $\begin{array}{c}\mu \text { Glic } \\
\mathrm{pmol} / \text { (cel.dia) }\end{array}$ & $\begin{array}{c}\mu \mathrm{Gln} \\
\mathrm{pmol} / \text { (cel.dia) }\end{array}$ & $\begin{array}{c}\mu \mathrm{P} \\
\mu \mathrm{UA} / \text { (cel.dia) }\end{array}$ \\
\hline 0,04 & 0,08 & 48,3 & 1,82 & 0,66 & 90,1 & 7,61 & 3,80 & 0 & 0,00 & 0,00 & 0,00 & 0,00 & 0 \\
\hline 0,87 & 0,31 & 49,5 & 2,40 & 0,92 & 87,4 & 7,61 & 2,30 & 0 & 0,78 & 0,48 & 1,58 & 0,00 & 0 \\
\hline 1,45 & 0,30 & 50,0 & 3,02 & 1,16 & 89,8 & 7,61 & \begin{tabular}{|l|l}
1,07 \\
\end{tabular} & 45 & 1,03 & 0,41 & 1,64 & 0,00 & 0 \\
\hline 2,45 & 0,27 & 49,4 & 3,38 & 1,67 & 89,3 & 6,17 & 0,56 & 56 & 1,40 & 0,41 & 1,32 & 1,66 & 33 \\
\hline 3,44 & 0,19 & 51,2 & 4,76 & 2,50 & 90,0 & 6,17 & 0,25 & 73 & 2,06 & 0,46 & 1,02 & 1,44 & 29 \\
\hline 4,41 & 0,22 & 49,3 & 6,63 & 3,57 & 89,3 & 6,11 & 0,22 & 66 & 3,01 & 0,42 & 1,09 & 1,90 & 27 \\
\hline 5,42 & 0,27 & 50,7 & 8,96 & 6,70 & 91,8 & 6,22 & 0,17 & 78 & 4,97 & 0,66 & 0,92 & 1,58 & 24 \\
\hline 6,41 & 0,38 & 48,9 & 12,47 & 10,32 & 99,2 & 6,33 & 0,17 & 79 & 8,38 & 0,38 & 1,06 & 1,84 & 30 \\
\hline 7,46 & 0,21 & 42,9 & 24,40 & 14,70 & 90,7 & 6,22 & 0,18 & 81 & 12,38 & 0,50 & 1,08 & 1,89 & 31 \\
\hline 8,47 & 0,43 & 43,1 & 22,85 & 16,77 & 91,7 & 6,11 & 0,69 & 84 & 15,71 & 0,17 & 0,84 & 1,42 & 24 \\
\hline 9,46 & 0,54 & 50,4 & 27,60 & 22,92 & 94,7 & 6,22 & 0,57 & 91 & 19,69 & 0,45 & 1,04 & 1,72 & 34 \\
\hline 10,44 & 0,60 & 50,3 & 26,20 & 21,98 & 94,9 & 6,22 & 4,58 & 102 & 22,45 & 0,48 & 1,14 & 2,07 & 41 \\
\hline 11,44 & 0,80 & 51,7 & 24,45 & 20,65 & 94,7 & 6,17 & 4,83 & 107 & 21,31 & 0,47 & 1,12 & 1,16 & 49 \\
\hline 12,42 & 0,85 & 51,4 & 24,48 & 21,80 & 95,2 & 6,17 & \begin{tabular}{|l|}
4,57 \\
\end{tabular} & 111 & 21,22 & 0,51 & 1,02 & 1,15 & 51 \\
\hline 13,42 & 0,89 & 58,6 & 24,48 & 22,80 & 96,2 & 6,22 & 4,84 & 102 & 22,30 & 0,51 & 1,07 & 1,12 & 50 \\
\hline 14,44 & 0,97 & 49,4 & 24,50 & 20,00 & 94,1 & 6,22 & \begin{tabular}{|l|}
4,92 \\
\end{tabular} & 86 & 21,37 & 0,44 & 1,09 & 1,10 & 48 \\
\hline 15,45 & 0,81 & 50,4 & 24,40 & 20,52 & 88,6 & 6,22 & 4,88 & 117 & 20,26 & 0,61 & 1,04 & 1,14 & 45 \\
\hline 16,46 & 0,82 & 51,3 & 24,40 & 20,85 & 94,0 & 6,22 & 4,93 & 98 & 20,68 & 0,37 & 0,97 & 1,09 & 56 \\
\hline 17,43 & 0,84 & 50,0 & 24,40 & 20,15 & 94,4 & 6,28 & 4,83 & 118 & 20,50 & 0,37 & 1,00 & 1,11 & 49 \\
\hline 18,40 & 0,77 & 48,5 & 24,40 & 20,64 & 99,1 & 6,39 & 4,94 & 97 & 20,39 & 0,30 & 0,99 & 1,17 & 57 \\
\hline 19,43 & 0,76 & 48,3 & 24,40 & 20,56 & 96,1 & 6,44 & 5,07 & 75 & 20,60 & 0,32 & 0,98 & 1,12 & 46 \\
\hline 20,41 & 0,71 & 50,4 & 24,40 & 21,90 & 97,3 & 6,39 & 5,50 & 83 & 21,22 & 0,36 & 0,90 & 1,03 & 37 \\
\hline 21,47 & 0,79 & 51,7 & 24,40 & 21,15 & 95,6 & 6,44 & 5,70 & 86 & 21,52 & 0,29 & 0,66 & 0,93 & 39 \\
\hline 22,45 & 0,85 & 48,9 & 24,48 & 20,92 & 96,1 & 6,50 & 5,67 & 91 & 21,03 & 0,29 & 0,66 & 0,90 & 42 \\
\hline 23,45 & 0,89 & 50,3 & 24,48 & 21,22 & 96,7 & 6,72 & 5,66 & 104 & 21,07 & 0,38 & 0,74 & 0,92 & 44 \\
\hline 24,44 & 0,84 & 48,3 & 23,16 & 21,22 & 95,4 & 6,56 & 5,70 & 86 & 21,22 & 0,43 & 0,78 & 0,96 & 49 \\
\hline 25,41 & 0,88 & 49,2 & 23,33 & 22,93 & 96,5 & 6,50 & 5,67 & 98 & 22,06 & 0,42 & 0,78 & 0,93 & 40 \\
\hline 26,42 & 0,91 & 51,6 & 23,23 & 25,20 & 98,1 & 6,50 & 5,50 & 82 & 24,05 & 0,38 & 0,72 & 0,81 & 40 \\
\hline 27,43 & 0,78 & 49,9 & 21,02 & 24,50 & 96,5 & 6,83 & \begin{tabular}{|l|}
5,74 \\
\end{tabular} & 85 & 24,85 & 0,52 & 0,74 & 0,85 & 34 \\
\hline 28,44 & 0,84 & 48,0 & 21,00 & 19,72 & 97,6 & 6,83 & 5,55 & 87 & 22,02 & 0,11 & 0,88 & 0,86 & 39 \\
\hline 29,44 & 0,87 & 52,5 & 20,95 & 24,08 & 93,7 & 6,78 & 5,72 & 92 & 21,83 & 0,54 & 0,86 & 0,93 & 40 \\
\hline 30,45 & 0,82 & 25,0 & 20,98 & 23,20 & 97,4 & 7,06 & 5,38 & 90 & 23,64 & 0,20 & 0,73 & 0,70 & 39 \\
\hline 31,45 & 0,75 & 26,4 & 19,97 & 27,35 & 97,7 & 6,06 & 5,53 & 74 & 25,22 & 0,60 & 0,79 & 0,72 & 35 \\
\hline 32,43 & 0,54 & 24,6 & 16,98 & 22,82 & 98,9 & 5,89 & 6,25 & 76 & 25,02 & 0,41 & 0,78 & 0,73 & 31 \\
\hline 33,44 & 0,51 & 26,1 & 15,97 & 24,06 & 96,2 & 5,94 & 5,93 & 72 & 23,43 & 0,43 & 0,75 & 0,75 & 33 \\
\hline 34,43 & 0,53 & 24,0 & 15,94 & 21,00 & 93,8 & 5,94 & 5,75 & 71 & 22,50 & 0,22 & 0,82 & 0,74 & 32 \\
\hline 35,47 & 0,55 & 24,8 & 16,03 & 21,35 & 98,4 & 5,94 & 5,80 & 76 & 21,17 & 0,39 & 0,83 & 0,83 & 34 \\
\hline 36,45 & 0,48 & 27,1 & 17,01 & 21,23 & 98,4 & 6,00 & 6,04 & 79 & 21,29 & 0,59 & 1,00 & 1,02 & 45 \\
\hline 37,45 & 0,58 & 45,4 & 15,96 & 22,63 & 98,4 & 6,00 & 5,96 & 78 & 21,92 & 0,36 & 0,77 & 0,72 & 36 \\
\hline 38,46 & 0,59 & 109,4 & 15,96 & 22,80 & 97,7 & 5,89 & 6,00 & 80 & 22,71 & 0,42 & 0,78 & 0,72 & 35 \\
\hline 39,39 & 0,60 & 18,3 & 16,01 & 24,07 & 97,4 & 5,83 & \begin{tabular}{|l|l|}
5,87 \\
\end{tabular} & 86 & 23,43 & 0,45 & 0,74 & 0,69 & 35 \\
\hline 40,42 & 0,61 & 16,9 & 15,90 & 22,98 & 96,4 & 5,83 & 5,81 & 76 & 23,52 & \begin{tabular}{|l|}
0,36 \\
\end{tabular} & 0,75 & 0,72 & 36 \\
\hline 41,43 & 0,61 & 16,7 & 16,00 & 22,90 & 98,3 & 5,89 & 5,75 & 82 & 22,94 & 0,40 & 0,86 & 0,76 & 34 \\
\hline 42,45 & 0,61 & 16,9 & 15,96 & 22,76 & 97,9 & 5,89 & 5,98 & 96 & 22,83 & 0,38 & 0,88 & 0,78 & 36 \\
\hline
\end{tabular}


Tabela A.2 - Valor das principais variáveis ao longo do tempo, do ensaio E2 (notação de acordo com Lista de Símbolos)

\begin{tabular}{|c|c|c|c|c|c|c|c|c|c|c|c|c|c|}
\hline $\begin{array}{c}\mathrm{t} \\
\text { dia }\end{array}$ & $\begin{array}{l}\mathrm{Pm} \\
\mathrm{atm}\end{array}$ & $\begin{array}{l}\text { OD } \\
\%\end{array}$ & $\overline{\mathrm{DO}}$ & $\begin{array}{c}\mathrm{X} \\
\text { E6cel/mL }\end{array}$ & $\begin{array}{c}\text { viab } \\
\%\end{array}$ & $\begin{array}{l}\text { Glic } \\
\mathrm{mM}\end{array}$ & $\begin{array}{l}\text { Gln } \\
\mathrm{mM}\end{array}$ & $\begin{array}{c}\mathrm{P} \\
\mathrm{UA} / \mathrm{mL}\end{array}$ & $\begin{array}{c}\text { Xref } \\
\text { E6cel } / \mathrm{mL}\end{array}$ & $\begin{array}{c}\mu \\
1 / \text { dia }\end{array}$ & $\begin{array}{c}\mu \mathrm{Glic} \\
\mathrm{pmol} / \text { (cel.dia) }\end{array}$ & $\begin{array}{c}\mu \mathrm{Gln} \\
\mathrm{pmol} / \text { (cel.dia) }\end{array}$ & $\begin{array}{c}\mu \mathrm{P} \\
\mu \mathrm{UA} / \text { (cel.dia) }\end{array}$ \\
\hline 0,13 & 0,47 & 49,5 & 1,43 & 1,23 & 96,1 & 5,24 & 8,24 & 0 & 0,00 & 0,00 & 0,00 & 0,00 & 0 \\
\hline 0,69 & 0,67 & 49,4 & 2,30 & 1,92 & 92,3 & 3,82 & 6,35 & 73 & 1,55 & 0,92 & 1,93 & 0,00 & 0 \\
\hline 1,68 & 0,50 & 48,1 & 4,10 & 3,60 & 92,8 & 0,66 & 1,64 & 101 & 2,67 & 0,68 & 1,09 & 0,00 & 11 \\
\hline 2,68 & 0,94 & 48,9 & 4,92 & 3,28 & 95,1 & 2,24 & 3,95 & 96 & 3,44 & 0,00 & 3,11 & 6,63 & 71 \\
\hline 3,75 & 0,54 & 49,7 & 8,65 & 6,26 & 93,7 & 2,69 & 2,07 & 137 & 4,61 & 0,66 & 1,56 & 2,30 & 54 \\
\hline 4,73 & 0,77 & 49,6 & 13,35 & 11,98 & 94,3 & 2,46 & 1,84 & 130 & 8,81 & 0,71 & 1,48 & 3,57 & 65 \\
\hline 5,74 & 0,82 & 49,4 & 18,52 & 19,30 & 96,6 & 2,72 & 2,73 & 168 & 15,35 & 0,52 & 1,42 & 3,60 & 61 \\
\hline 6,70 & 0,81 & 50,1 & 19,03 & 21,53 & 97,3 & 3,31 & 3,69 & 133 & 20,39 & 0,34 & 1,38 & 3,44 & 80 \\
\hline 7,72 & 0,77 & 51,7 & 18,19 & 18,96 & 99,7 & 3,54 & 4,30 & 118 & 20,22 & 0,58 & 1,18 & 2,93 & 68 \\
\hline 8,73 & 0,81 & 51,5 & 18,20 & 19,56 & 99,4 & 3,46 & 4,18 & 142 & 19,26 & 0,74 & 1,27 & 2,91 & 65 \\
\hline 9,74 & 0,82 & 50,7 & 18,26 & 21,67 & 94,7 & 3,19 & 5,65 & 166 & 20,60 & \begin{tabular}{|l|}
0,69 \\
\end{tabular} & 1,16 & 2,81 & 71 \\
\hline 10,73 & 0,73 & 49,5 & 16,99 & 20,00 & 96,4 & 3,38 & 5,83 & 155 & 20,82 & 0,57 & 1,20 & 1,98 & 81 \\
\hline 11,70 & 0,73 & 49,9 & 16,99 & 19,93 & 97,6 & 3,34 & 5,72 & 143 & 19,96 & 0,58 & 1,18 & 1,93 & 78 \\
\hline 12,74 & 0,85 & 49,5 & \begin{tabular}{|l|l}
16,99 \\
\end{tabular} & 21,67 & 94,1 & 3,16 & 5,01 & 174 & 20,79 & \begin{tabular}{|l|l}
0,67 \\
\end{tabular} & 1,12 & 1,90 & 70 \\
\hline 13,72 & 0,85 & 51,5 & 17,11 & 22,47 & 95,6 & 3,84 & 5,10 & 169 & 22,07 & 0,52 & 1,18 & 2,19 & 79 \\
\hline 14,71 & 0,79 & 52,7 & 16,87 & 18,24 & 99,3 & 3,59 & 4,98 & 148 & 20,28 & 0,37 & 1,15 & 2,45 & 84 \\
\hline 15,70 & 0,80 & 52,3 & 16,90 & 20,10 & 93,5 & 3,64 & 5,10 & 153 & 19,15 & 0,65 & 1,08 & 2,63 & 78 \\
\hline 16,73 & 0,79 & 49,8 & 16,91 & 13,80 & 88,6 & 3,51 & 5,48 & 126 & 16,75 & 0,18 & 1,14 & 2,90 & 90 \\
\hline 17,74 & 0,78 & 50,2 & 17,00 & 13,90 & 87,1 & 3,71 & 5,45 & 125 & 13,85 & 0,47 & 1,46 & 3,20 & 91 \\
\hline 18,73 & 0,93 & 49,3 & 19,51 & 14,88 & 90,5 & 4,22 & 5,17 & 125 & 14,38 & 0,23 & 1,33 & 2,96 & 85 \\
\hline 19,73 & 1,16 & 51,1 & 23,29 & 17,40 & 94,3 & 4,57 & 5,54 & 129 & 16,11 & 0,34 & 1,10 & 2,85 & 77 \\
\hline 20,73 & 1,30 & 50,1 & 21,97 & 17,83 & 88,7 & 3,50 & 4,50 & 176 & 17,61 & 0,37 & 0,82 & 2,46 & 74 \\
\hline 21,73 & 1,24 & 47,4 & 22,00 & 18,10 & 89,6 & 2,80 & 3,99 & 135 & 17,96 & 0,34 & 1,35 & 2,81 & 94 \\
\hline 22,66 & 1,57 & 49,6 & 22,30 & 17,60 & 88,4 & 1,88 & 3,77 & 173 & 17,85 & 0,34 & 1,71 & 3,13 & 76 \\
\hline 23,66 & 1,58 & 50,8 & 22,49 & 17,00 & 84,0 & 2,45 & 3,96 & 177 & 17,30 & 0,43 & 2,17 & 3,49 & 99 \\
\hline 24,75 & 1,54 & 50,2 & 22,45 & 17,05 & 91,4 & 3,11 & 4,21 & 155 & 17,02 & 0,33 & 1,90 & 3,45 & 101 \\
\hline 25,74 & 1,55 & 50,6 & 22,48 & 18,10 & 90,6 & 3,01 & 4,30 & 164 & 17,57 & 0,48 & 1,56 & 2,94 & 88 \\
\hline 26,73 & 1,55 & 49,0 & 22,49 & 18,58 & 86,3 & 2,89 & 4,16 & 165 & 18,34 & 0,54 & 1,60 & 2,99 & 89 \\
\hline 27,72 & 1,61 & 47,9 & 22,55 & 22,17 & 95,7 & 2,94 & 3,65 & 129 & 20,32 & 0,46 & 1,46 & 2,65 & 78 \\
\hline 28,73 & 1,61 & 50,8 & 22,40 & 21,00 & 96,3 & 3,11 & 3,19 & 147 & 21,58 & 0,38 & 1,32 & 2,75 & 60 \\
\hline 29,72 & 1,65 & 51,5 & 22,40 & 21,80 & 95,2 & 2,93 & 3,14 & 152 & 21,40 & 0,49 & 1,34 & 3,03 & 68 \\
\hline 30,68 & 1,47 & 51,2 & 20,54 & 18,08 & 89,8 & 3,02 & 3,48 & 135 & 19,88 & 0,53 & 1,50 & 3,33 & 77 \\
\hline 31,73 & 1,59 & 49,0 & 21,47 & 22,88 & 96,2 & 3,03 & 3,14 & 169 & 20,39 & 0,57 & 1,33 & 2,93 & 67 \\
\hline 32,73 & 1,57 & 50,2 & 20,98 & 17,48 & 89,9 & 3,12 & 3,61 & 155 & 20,06 & 0,36 & 1,41 & 3,21 & 84 \\
\hline 33,74 & 1,65 & 48,5 & 21,49 & 20,30 & 89,8 & 3,13 & 2,87 & 196 & 18,85 & 0,63 & 1,42 & 3,23 & 84 \\
\hline 34,73 & 1,74 & 42,2 & 21,49 & 22,95 & 92,9 & 2,86 & 2,97 & 153 & 21,60 & 0,56 & 1,26 & 3,13 & 88 \\
\hline 35,73 & 1,65 & 51,5 & 19,90 & 21,30 & 93,8 & 2,90 & 3,38 & 130 & 22,11 & 0,63 & 1,34 & 3,06 & 68 \\
\hline 36,71 & 1,68 & 53,9 & 19,80 & 24,20 & 98,8 & 2,14 & 3,19 & 132 & 22,72 & 0,62 & 1,31 & 2,71 & 57 \\
\hline 37,72 & 1,57 & 47,9 & 19,05 & 22,73 & 89,3 & 2,74 & 2,80 & 157 & 23,46 & 0,72 & 1,53 & 2,73 & 57 \\
\hline 38,73 & 1,26 & 49,4 & 17,97 & 16,50 & 86,4 & 3,14 & 2,81 & 127 & 19,45 & 0,41 & 1,59 & 3,58 & 80 \\
\hline 39,75 & 1,46 & 49,7 & 19,95 & 18,53 & 86,3 & 3,08 & 2,42 & 182 & 17,50 & 0,50 & 1,53 & 3,67 & 73 \\
\hline 40,74 & 1,63 & 50,1 & 21,22 & 23,70 & 91,2 & 2,89 & 3,30 & 102 & 21,01 & 0,70 & 1,30 & 3,38 & 81 \\
\hline 41,68 & 1,61 & 51,2 & 20,51 & 20,98 & 89,7 & 2,96 & 3,28 & 117 & 22,31 & 0,52 & 1,37 & 2,82 & 46 \\
\hline 42,73 & 1,64 & 50,7 & 20,40 & 28,20 & 99,6 & 2,83 & 3,15 & 109 & 24,41 & 0,81 & 1,20 & 2,45 & 47 \\
\hline 43,73 & 1,64 & 49,4 & 20,50 & 22,10 & 96,1 & 3,00 & 2,94 & 101 & 25,03 & 0,46 & 1,17 & 2,46 & 43 \\
\hline 44,72 & 1,64 & 48,8 & 20,50 & 18,25 & 87,1 & 3,42 & 3,65 & 73 & 20,11 & 0,45 & 1,38 & 3,24 & 48 \\
\hline 45,66 & 1,73 & 51,5 & 20,40 & 19,80 & 81,9 & 3,25 & 3,50 & 79 & 19,01 & 0,78 & 1,47 & 2,92 & 38 \\
\hline 46,73 & 1,74 & 49,7 & 20,40 & 25,23 & 96,6 & 3,09 & 3,42 & 71 & 22,41 & 0,59 & 1,25 & 2,50 & 34 \\
\hline 47,72 & 1,77 & 48,8 & 20,50 & 24,70 & 93,9 & 3,09 & 3,34 & 82 & 24,96 & 0,52 & 1,17 & 2,28 & 28 \\
\hline 48,71 & 1,76 & 49,2 & 20,50 & 24,60 & 97,6 & 3,11 & 3,17 & 79 & 24,65 & 0,46 & 1,25 & 2,28 & 32 \\
\hline 49,71 & 1,76 & 48,5 & 20,46 & 23,90 & 96,8 & 3,52 & 3,50 & 76 & 24,25 & 0,42 & 1,27 & 2,40 & 32 \\
\hline 50,72 & 1,68 & 51,3 & 20,46 & 24,00 & 100,0 & 2,94 & 4,02 & 95 & 23,95 & 0,24 & 1,16 & 2,21 & 32 \\
\hline 51,73 & 1,69 & 50,0 & 20,50 & 24,20 & 96,4 & 3,44 & 2,57 & 111 & 24,10 & 0,60 & 1,21 & 2,11 & 40 \\
\hline 52,70 & 1,65 & 51,6 & 20,40 & 21,12 & 85,9 & 3,36 & 3,04 & 115 & 22,63 & 0,52 & 1,26 & 3,09 & 49 \\
\hline 53,67 & 1,63 & 50,5 & 20,40 & 22,02 & 83,2 & 3,13 & 2,35 & 134 & 21,57 & 0,60 & 1,30 & 2,90 & 54 \\
\hline
\end{tabular}


Tabela A.2 - Valor das principais variáveis ao longo do tempo, do ensaio E2 (Cont.) (notação de acordo com Lista de Símbolos)

\begin{tabular}{|c|c|c|c|c|c|c|c|c|c|c|c|c|c|}
\hline $\begin{array}{c}\mathrm{t} \\
\mathrm{dia}\end{array}$ & $\begin{array}{l}\mathrm{Pm} \\
\mathrm{atm}\end{array}$ & $\begin{array}{l}\mathrm{OD} \\
\%\end{array}$ & $\mathrm{DO}$ & $\begin{array}{c}\mathrm{X} \\
\text { E6cel/mL }\end{array}$ & $\begin{array}{c}\text { viab } \\
\%\end{array}$ & $\begin{array}{l}\text { Glic } \\
\mathrm{mM}\end{array}$ & $\begin{array}{l}\text { Gln } \\
\text { mM }\end{array}$ & $\begin{array}{c}P \\
\mathrm{UA} / \mathrm{mL}\end{array}$ & $\begin{array}{c}\text { Xref } \\
\text { E6cel } / \mathrm{mL}\end{array}$ & $\begin{array}{c}\mu \\
1 / \text { dia }\end{array}$ & $\begin{array}{c}\mu \text { Glic } \\
\text { pmol/(cel.dia) }\end{array}$ & $\begin{array}{c}\mu \mathrm{Gln} \\
\mathrm{pmol} / \text { (cel.dia) }\end{array}$ & $\begin{array}{c}\mu \mathrm{P} \\
\mu \mathrm{UA} / \text { (cel.dia) }\end{array}$ \\
\hline 54,72 & 1,63 & 49,8 & 20,50 & 22,70 & 97,8 & 2,67 & 2,78 & 115 & 22,36 & 0,34 & 1,33 & 3,20 & 58 \\
\hline 55,72 & 1,64 & 50,1 & 20,50 & 26,16 & 96,3 & 2,71 & 3,65 & 124 & 24,39 & 0,64 & 1,26 & 2,75 & 47 \\
\hline 56,67 & 1,58 & 49,5 & \begin{tabular}{|l}
19,67 \\
\end{tabular} & 28,20 & 95,6 & 2,70 & 3,57 & 114 & 27,17 & 0,51 & 1,13 & 2,12 & 44 \\
\hline 57,67 & 1,59 & 50,2 & 19,90 & 20,90 & 92,9 & 2,66 & 3,72 & 92 & 24,37 & 0,33 & 1,26 & 2,35 & 43 \\
\hline 58,71 & 1,55 & 50,1 & 19,50 & 25,80 & 96,6 & 3,09 & 3,76 & 70 & 23,26 & 0,64 & 1,33 & 2,29 & 37 \\
\hline 59,71 & 1,57 & 50,6 & 20,07 & 20,68 & 96,5 & 3,04 & 3,83 & 94 & 23,15 & 0,37 & 1,10 & 2,28 & 30 \\
\hline 60,73 & 1,52 & 50,6 & 20,50 & 22,18 & 95,0 & 3,22 & 3,85 & 96 & 21,42 & 0,77 & 1,28 & 2,56 & 44 \\
\hline 61,73 & 1,54 & 50,5 & 20,47 & 20,60 & 95,2 & 3,26 & 3,58 & 107 & 21,38 & 0,39 & 1,17 & 2,58 & 45 \\
\hline 62,69 & 1,31 & 49,4 & 19,98 & 20,60 & 96,5 & 2,89 & 3,87 & 91 & 20,60 & 0,32 & 1,33 & 2,86 & 55 \\
\hline 63,68 & 1,21 & 53,7 & 20,90 & 22,41 & 96,9 & 2,60 & 4,26 & 82 & 21,49 & 0,35 & 1,30 & 2,54 & 40 \\
\hline 64,67 & 1,28 & 54,9 & 19,20 & 21,50 & 98,1 & 1,97 & 3,92 & 73 & 21,95 & 0,14 & 1,50 & 2,24 & 35 \\
\hline 65,71 & 1,20 & 50,6 & 18,19 & 20,75 & 98,0 & 2,09 & 4,00 & 80 & 21,12 & 1,30 & 1,69 & 2,43 & 33 \\
\hline 66,72 & 1,52 & 49,0 & 20,50 & 21,15 & 91,4 & 1,98 & 3,72 & 94 & 20,95 & 0,70 & 1,71 & 2,72 & 38 \\
\hline 67,74 & 1,48 & 49,6 & 20,52 & 20,78 & 95,0 & 2,58 & 3,81 & 100 & 20,96 & 0,52 & 1,78 & 2,81 & 45 \\
\hline 68,72 & 1,46 & 49,7 & 20,52 & 21,75 & 96,5 & 2,88 & 3,93 & 109 & 21,26 & 0,61 & 1,51 & 2,81 & 47 \\
\hline 69,70 & 1,42 & 48,2 & 20,47 & 20,50 & 94,5 & 2,89 & 3,93 & 101 & 21,12 & 0,50 & 1,42 & 2,64 & 51 \\
\hline 70,67 & 1,43 & 48,0 & 20,50 & 20,70 & 94,5 & 4,91 & 5,44 & 84 & 20,60 & 0,51 & 1,37 & 2,86 & 48 \\
\hline 71,68 & 1,45 & 48,8 & 20,60 & 20,40 & 97,1 & 3,01 & 3,59 & 86 & 20,55 & 0,67 & 0,54 & 1,93 & 42 \\
\hline 72,73 & 1,44 & 42,3 & 20,45 & 20,48 & 97,2 & 3,33 & 3,40 & 121 & 20,44 & 0,42 & 1,46 & 2,95 & 43 \\
\hline 73,73 & 1,06 & 50,5 & 17,87 & 20,25 & 95,3 & 3,17 & 3,51 & 100 & 20,36 & 0,67 & 1,25 & 3,02 & 57 \\
\hline 74,73 & 1,43 & 50,6 & 20,45 & 21,50 & 97,1 & 2,96 & 2,91 & 105 & 20,87 & 0,53 & 1,22 & 2,87 & 48 \\
\hline 75,74 & 1,45 & 45,5 & 20,48 & 20,20 & 90,8 & 2,33 & 2,82 & 118 & 20,84 & 0,48 & 1,35 & 3,12 & 50 \\
\hline 76,73 & 1,40 & 50,0 & 20,02 & 20,58 & 95,5 & 2,58 & 2,70 & 125 & 20,39 & 0,56 & 1,62 & 3,31 & 58 \\
\hline 77,68 & 1,49 & 50,2 & 19,90 & 23,20 & 99,1 & 1,27 & 2,96 & 96 & 21,86 & 0,56 & 1,56 & 3,06 & 54 \\
\hline 78,68 & 1,43 & 51,2 & 19,90 & 26,88 & 99,6 & 1,52 & 2,82 & 98 & 24,99 & 0,80 & 1,75 & 2,61 & 38 \\
\hline 79,73 & 1,50 & 51,0 & 20,04 & 21,55 & 96,0 & 1,69 & 2,55 & 89 & 24,12 & 0,40 & 1,72 & 2,74 & 39 \\
\hline 80,73 & 1,26 & 59,6 & 18,00 & 19,65 & 97,0 & 1,77 & 2,90 & 86 & 20,59 & 0,42 & 1,92 & 3,41 & 42 \\
\hline 81,73 & 1,45 & 51,0 & 19,51 & 22,40 & 97,0 & 2,41 & 3,00 & 80 & 20,99 & 0,79 & 1,90 & 3,28 & 40 \\
\hline 82,72 & 1,28 & 48,7 & 17,75 & 20,65 & 96,3 & 2,96 & 2,77 & 65 & 21,51 & 0,35 & 1,55 & 2,99 & 35 \\
\hline 83,69 & 1,47 & 47,1 & \begin{tabular}{|l|}
19,44 \\
\end{tabular} & 20,18 & 97,6 & 3,11 & 3,02 & 54 & 20,41 & 0,56 & 1,49 & 3,24 & 32 \\
\hline 84,71 & 1,36 & 49,9 & \begin{tabular}{|l}
19,40 \\
\end{tabular} & 21,72 & 97,4 & 2,95 & 2,68 & 80 & 20,94 & 0,64 & 1,42 & 3,06 & 27 \\
\hline 85,68 & 1,32 & 51,1 & \begin{tabular}{|l}
19,00 \\
\end{tabular} & 22,60 & 98,7 & 3,73 & 2,39 & 79 & 22,16 & 0,24 & 1,38 & 2,99 & 36 \\
\hline 86,73 & 1,25 & 50,3 & 18,66 & 18,98 & 92,9 & 3,01 & 2,46 & 70 & 20,74 & 0,61 & 1,27 & 3,38 & 36 \\
\hline 87,74 & 1,29 & 49,2 & 18,70 & 20,50 & 94,5 & 3,76 & 2,62 & 101 & 19,73 & 0,85 & 1,57 & 3,59 & 37 \\
\hline 88,72 & 1,36 & 51,0 & 18,97 & 19,23 & 98,0 & 3,56 & 2,68 & 78 & 19,86 & 0,66 & 1,37 & 3,33 & 48 \\
\hline
\end{tabular}


Tabela A.3 - Valor das principais variáveis ao longo do tempo, do ensaio E3 (notação de acordo com Lista de Símbolos)

\begin{tabular}{|c|c|c|c|c|c|c|c|c|c|}
\hline $\begin{array}{c}\mathrm{t} \\
\mathrm{dia}\end{array}$ & $\begin{array}{l}\mathrm{Pm} \\
\mathrm{atm}\end{array}$ & $\begin{array}{l}\text { OD } \\
\%\end{array}$ & $\mathrm{DO}$ & $\begin{array}{c}\mathrm{X} \\
\text { E6cel } / \mathrm{mL}\end{array}$ & $\begin{array}{c}\text { viab } \\
\%\end{array}$ & $\begin{array}{l}\text { Glic } \\
\mathrm{mM}\end{array}$ & $\begin{array}{l}\text { Gln } \\
\text { mM }\end{array}$ & $\begin{array}{c}P \\
\mathrm{UA} / \mathrm{mL}\end{array}$ & $\begin{array}{c}\text { Xref } \\
\text { E6cel } / \mathrm{mI}\end{array}$ \\
\hline 0,20 & 0,11 & 37,6 & 0,84 & 1,14 & 97,9 & 5,11 & 3,90 & 0 & 0,00 \\
\hline 0,65 & 0,15 & 25,0 & 1,23 & 1,68 & 96,4 & 4,25 & 3,86 & 37 & 1,39 \\
\hline 1,67 & 0,17 & 42,1 & \begin{tabular}{|l|l|}
1,80 \\
\end{tabular} & 2,86 & 95,3 & 2,64 & 2,67 & 78 & 2,22 \\
\hline 2,65 & & 37,0 & 3,55 & 4,68 & 94,7 & 2,04 & 2,31 & 100 & 3,70 \\
\hline 3,65 & 0,23 & 31,3 & 6,83 & 7,28 & 92,1 & 1,70 & 1,94 & 101 & 5,88 \\
\hline 4,69 & 0,32 & 31,0 & 11,11 & 12,08 & 93,5 & 1,42 & 1,69 & 94 & 9,48 \\
\hline 5,68 & 0,49 & 30,7 & 15,70 & 17,18 & 94,4 & 1,94 & 2,11 & 110 & 14,48 \\
\hline 6,68 & 0,41 & 29,6 & 18,20 & 19,94 & 97,2 & 2,53 & 2,71 & 112 & 18,53 \\
\hline 7,66 & 0,36 & 27,1 & 18,03 & 22,57 & 96,3 & 2,74 & 3,13 & 88 & 21,23 \\
\hline 8,67 & 0,32 & 28,8 & 16,31 & 22,20 & 94,9 & 3,11 & 3,39 & 121 & 22,38 \\
\hline 9,65 & 0,22 & 28,6 & 14,60 & 18,80 & 95,4 & & & 113 & 20,45 \\
\hline 10,67 & 0,25 & 26,8 & 15,10 & 19,57 & 94,1 & 3,15 & 3,57 & 107 & 19,18 \\
\hline 11,68 & 0,23 & 26,2 & 14,96 & 20,67 & 97,9 & 2,92 & 3,52 & 96 & 20,11 \\
\hline 12,67 & 0,25 & 23,3 & 15,05 & 20,20 & 97,6 & 2,84 & 3,54 & 109 & 20,43 \\
\hline 13,69 & & 10,4 & 14,96 & 20,88 & 98,4 & 2,50 & 3,60 & 101 & 20,54 \\
\hline 14,69 & 0,29 & & 14,29 & 18,67 & 97,5 & 2,67 & 3,60 & 90 & 19,75 \\
\hline 15,68 & 0,28 & & 14,73 & 18,00 & 96,8 & & & 85 & 18,33 \\
\hline 16,57 & 0,27 & & 14,80 & 16,92 & 99,5 & 2,17 & 3,94 & 79 & 17,45 \\
\hline 17,63 & 0,31 & & 16,81 & 23,05 & 97,4 & 2,06 & 3,34 & 70 & 19,83 \\
\hline 18,68 & 0,25 & & 14,58 & 18,35 & 98,2 & 2,38 & 3,65 & 67 & 20,61 \\
\hline 19,68 & 0,25 & 9,0 & 15,42 & 16,42 & 97,4 & 2,22 & 3,56 & 63 & 17,37 \\
\hline 20,68 & 0,30 & & 17,28 & 18,22 & 98,3 & 1,83 & 3,47 & 63 & 17,30 \\
\hline 21,67 & 0,34 & & 18,78 & 19,52 & 98,7 & 1,64 & 3,37 & 73 & 18,86 \\
\hline 22,68 & 0,36 & & 18,80 & 20,77 & 97,1 & 1,70 & 3,37 & 78 & 20,14 \\
\hline 23,60 & 0,38 & & 18,77 & 18,30 & 96,8 & 1,50 & 3,55 & 72 & 19,51 \\
\hline 24,68 & 0,38 & & 18,76 & 20,28 & 96,9 & 1,96 & 3,37 & 69 & 19,27 \\
\hline 25,67 & 0,34 & 8,0 & 18,80 & 16,02 & 93,5 & 2,43 & 3,50 & 52 & 18,07 \\
\hline 26,65 & 0,53 & 18,0 & 20,75 & 20,66 & 97,7 & 2,50 & 3,17 & 67 & 18,24 \\
\hline 27,69 & 0,60 & & 20,02 & 19,97 & 94,6 & 2,58 & 3,32 & 84 & 20,31 \\
\hline 28,60 & 0,72 & & 20,51 & 22,00 & 97,1 & 2,53 & 3,20 & 93 & 20,97 \\
\hline 29,66 & 0,75 & & 19,96 & 20,40 & 97,6 & 2,32 & 3,20 & 94 & 21,19 \\
\hline 30,63 & 0,79 & & 19,90 & 26,07 & 98,8 & 2,27 & 3,09 & 94 & 23,12 \\
\hline 31,68 & 0,82 & 18,0 & 20,03 & 23,60 & 96,1 & 2,51 & 3,11 & 88 & 24,81 \\
\hline 32,67 & 0,65 & & 17,43 & 22,52 & 97,8 & 2,62 & 3,47 & 89 & 23,06 \\
\hline 33,68 & 0,51 & & 15,41 & 20,20 & 98,2 & 2,77 & 3,45 & 83 & 21,34 \\
\hline 34,66 & 0,52 & & 15,47 & 19,85 & 97,3 & 2,86 & 3,53 & 82 & 20,02 \\
\hline 35,67 & 0,53 & 17,1 & 15,45 & 23,08 & 97,9 & 2,72 & 3,44 & 79 & 21,42 \\
\hline 36,68 & 0,55 & 16,2 & 15,49 & 21,70 & 96,0 & 2,44 & 3,35 & 86 & 22,38 \\
\hline 37,67 & 0,53 & 18,5 & 15,40 & 21,90 & 96,5 & 2,50 & 3,37 & 82 & 21,80 \\
\hline 38,62 & 0,51 & 19,7 & 15,40 & 21,40 & 98,6 & 2,80 & 3,81 & 65 & 21,65 \\
\hline 39,70 & 0,51 & 19,2 & 15,42 & 22,90 & 97,9 & 3,02 & 3,42 & 79 & 22,14 \\
\hline 40,67 & 0,45 & & 14,33 & 20,30 & 98,0 & 3,07 & 2,54 & 69 & 21,57 \\
\hline 41,63 & 0,47 & 14,0 & 14,34 & 20,88 & 96,8 & 2,95 & 3,33 & 65 & 20,59 \\
\hline 42,69 & 0,57 & 49,3 & 14,34 & 18,08 & 97,6 & 3,34 & 3,20 & 69 & 19,45 \\
\hline 43,65 & 0,72 & 50,6 & 15,89 & 23,12 & 99,0 & 4,09 & 2,99 & 78 & 20,50 \\
\hline 44,65 & 0,72 & 50,0 & 15,93 & 23,20 & 98,3 & 3,38 & 2,75 & 74 & 23,16 \\
\hline 45,68 & 0,66 & 51,2 & 14,99 & 18,95 & 97,5 & 3,46 & 2,82 & 65 & 21,00 \\
\hline
\end{tabular}


Tabela A.3 - Valor das principais variáveis ao longo do tempo, do ensaio E3 (Cont.) (notação de acordo com Lista de Símbolos)

\begin{tabular}{|c|c|c|c|c|c|c|c|c|c|}
\hline $\begin{array}{c}\mathrm{t} \\
\mathrm{dia}\end{array}$ & $\begin{array}{l}\mathrm{Pm} \\
\mathrm{atm}\end{array}$ & $\begin{array}{l}\text { OD } \\
\%\end{array}$ & DO & $\begin{array}{c}\mathrm{X} \\
\text { E6cel/mL }\end{array}$ & $\begin{array}{c}\text { viab } \\
\%\end{array}$ & $\begin{array}{l}\text { Glic } \\
\mathrm{mM}\end{array}$ & $\begin{array}{l}\text { Gln } \\
\mathrm{mM}\end{array}$ & $\begin{array}{c}\mathrm{P} \\
\mathrm{UA} / \mathrm{mL}\end{array}$ & $\begin{array}{c}\text { Xref } \\
\text { E6cel/mL }\end{array}$ \\
\hline 46,68 & 0,66 & 50,2 & 14,99 & 20,03 & 95,9 & 3,45 & 2,60 & 67 & 19,49 \\
\hline 47,68 & 0,69 & 50,4 & 14,99 & 20,93 & 96,7 & 3,34 & 2,56 & 68 & 20,48 \\
\hline 48,70 & 0,56 & 10,0 & 15,01 & 22,20 & 97,6 & 3,14 & 2,61 & 66 & 21,56 \\
\hline 49,69 & 0,57 & 9,8 & 14,98 & 19,92 & 98,7 & 3,12 & 2,60 & 61 & 21,04 \\
\hline 50,60 & 0,58 & 9,5 & 14,90 & 22,80 & 97,9 & 3,34 & 2,64 & 74 & 21,33 \\
\hline 51,67 & 0,60 & 9,7 & 14,90 & 21,00 & 99,4 & 3,06 & 2,47 & 70 & 21,89 \\
\hline 52,67 & 0,61 & 10,0 & 15,02 & 19,92 & 97,9 & 2,75 & 2,47 & 65 & 20,46 \\
\hline 53,67 & 0,61 & 9,5 & 15,02 & 20,62 & 98,4 & 2,75 & 2,51 & 81 & 20,27 \\
\hline 54,63 & 0,62 & 9,6 & 15,05 & 19,88 & 98,5 & 2,82 & 2,50 & 74 & 20,25 \\
\hline 55,68 & 0,63 & 9,8 & 14,93 & 21,45 & 98,2 & 2,65 & 2,48 & 80 & 20,66 \\
\hline 56,67 & 0,33 & 1,2 & 18,76 & 25,87 & 98,3 & 1,15 & 2,37 & 66 & 23,59 \\
\hline 57,64 & 0,14 & 1,1 & 14,92 & 19,82 & 97,2 & 1,68 & 2,45 & 58 & 22,71 \\
\hline 58,69 & 0,12 & 1,1 & 15,02 & 19,60 & 96,9 & 1,89 & 2,50 & 50 & 19,71 \\
\hline 59,68 & 0,12 & 1,1 & 14,98 & 14,80 & 98,1 & 1,96 & 2,53 & 33 & 17,09 \\
\hline 60,69 & 0,11 & 0,9 & 15,60 & 12,57 & 97,1 & 2,22 & 2,64 & 28 & 13,65 \\
\hline 61,62 & 0,12 & 1,0 & 16,29 & 9,73 & 93,7 & 2,12 & 3,25 & 27 & 11,09 \\
\hline 62,68 & 0,43 & 9,3 & 17,99 & 11,15 & 92,7 & 3,14 & 3,06 & 48 & 10,42 \\
\hline 63,63 & 0,60 & 9,6 & 19,02 & 12,76 & 92,6 & 3,08 & 2,94 & 38 & 11,94 \\
\hline 64,63 & 0,87 & 9,4 & 21,20 & 20,00 & 98,5 & 2,57 & 2,71 & 50 & 16,11 \\
\hline 65,65 & 0,95 & 49,7 & 20,90 & 19,08 & 98,1 & 2,43 & 2,59 & 62 & 19,54 \\
\hline 66,65 & 0,92 & 49,8 & 20,96 & 24,68 & 97,4 & 2,07 & 2,46 & 59 & 21,76 \\
\hline 67,67 & 0,71 & 50,5 & 16,17 & 21,48 & 97,7 & 2,83 & 2,60 & 60 & 23,04 \\
\hline 68,69 & 0,72 & 49,7 & 15,00 & 19,10 & 96,5 & 2,79 & 2,44 & 57 & 20,27 \\
\hline 69,60 & 0,72 & 51,3 & 15,01 & 19,40 & 95,6 & 2,85 & 2,69 & 78 & 19,25 \\
\hline 70,65 & 0,75 & 50,7 & 14,96 & 20,83 & 99,0 & 2,68 & 3,09 & 68 & 20,11 \\
\hline 71,61 & 0,73 & 50,1 & 15,02 & 21,72 & 99,5 & 2,48 & 2,37 & 71 & 21,27 \\
\hline 72,63 & 0,76 & 48,1 & 15,01 & 20,52 & 98,3 & 2,48 & 2,85 & 72 & 21,11 \\
\hline 73,68 & 0,78 & 51,2 & 15,02 & 21,58 & 95,9 & 2,55 & 3,05 & 69 & 21,05 \\
\hline 74,64 & 0,78 & 50,4 & 15,01 & 21,63 & 96,2 & 2,53 & 2,84 & 90 & 21,60 \\
\hline 75,69 & 0,76 & 9,4 & 15,02 & 23,13 & 97,7 & 2,63 & 3,12 & 68 & 22,37 \\
\hline 76,69 & 0,79 & 9,6 & 15,01 & 19,25 & 96,6 & 2,55 & 3,10 & 87 & 21,13 \\
\hline 77,66 & 0,80 & 10,3 & 14,99 & 19,68 & 93,6 & 2,85 & 2,85 & 48 & 19,46 \\
\hline 78,60 & 0,80 & 10,4 & 14,50 & 24,20 & 96,8 & 2,41 & 2,74 & 60 & 21,86 \\
\hline 79,64 & 0,81 & 10,4 & 14,98 & 23,30 & 98,7 & 2,41 & 2,76 & 67 & 23,75 \\
\hline 80,69 & 0,81 & 10,6 & 14,97 & 17,55 & 95,7 & 2,32 & 2,43 & 63 & 20,29 \\
\hline 81,68 & 0,76 & 10,4 & 15,00 & 21,20 & 97,6 & 2,11 & 2,32 & 69 & 19,32 \\
\hline 82,69 & 0,69 & 10,5 & 14,97 & 20,63 & 97,6 & 2,28 & 2,69 & 56 & 20,91 \\
\hline
\end{tabular}


Tabela A.3 - Valor das principais variáveis ao longo do tempo, do ensaio E3 (Cont.) (notação de acordo com Lista de Símbolos)

\begin{tabular}{|c|c|c|c|c|c|c|}
\hline $\begin{array}{c}\mathrm{t} \\
\mathrm{dia}\end{array}$ & $\begin{array}{c}\mu \\
1 / \text { dia }\end{array}$ & $\begin{array}{c}\mu \text { Glic } \\
\text { pmol/(cel.dia) }\end{array}$ & $\begin{array}{c}\mu \mathrm{Gln} \\
\mathrm{pmol} /(\text { cel.dia })\end{array}$ & $\begin{array}{c}\mu \mathrm{P} \\
\mu \mathrm{UA} /(\text { cel.dia })\end{array}$ & $\begin{array}{c}\text { OUR } \\
\mathrm{mg} /(\mathrm{L} . \mathrm{h}\end{array}$ & $\begin{array}{c}\text { QO2 } \\
\mu \mathrm{g} /(\text { E6cel.h })\end{array}$ \\
\hline 0,20 & & & & 0 & & \\
\hline 0,65 & 0,91 & 1,37 & & & 6 & 3,4 \\
\hline 1,67 & 0,56 & 1,22 & & 32 & & \\
\hline 2,65 & 0,54 & 1,16 & 0,70 & 33 & & \\
\hline 3,65 & 0,51 & 1,41 & 0,97 & 39 & 84 & 11,5 \\
\hline 4,69 & 0,52 & 1,43 & 1,09 & 36 & 81 & 6,7 \\
\hline 5,68 & 0,43 & 1,62 & 1,36 & 39 & 165 & 9,6 \\
\hline 6,68 & 0,66 & 1,65 & 1,37 & 51 & 232 & 11,6 \\
\hline 7,66 & 0,31 & 1,37 & 1,07 & 50 & 233 & 10,3 \\
\hline 8,67 & 0,49 & 1,25 & 0,85 & 41 & 221 & 10,0 \\
\hline 9,65 & 0,32 & & & 60 & & \\
\hline 10,67 & 0,46 & & & 58 & & \\
\hline 11,68 & 0,43 & 1,20 & 0,70 & 52 & 138 & 6,7 \\
\hline 12,67 & 0,41 & 1,28 & 0,72 & 47 & & \\
\hline 13,69 & 0,43 & 1,32 & 0,70 & 52 & & \\
\hline 14,69 & 0,32 & 1,52 & 0,70 & 50 & 129 & 6,9 \\
\hline 15,68 & 0,24 & & & 48 & & \\
\hline 16,57 & 0,28 & & & 48 & 121 & 7,1 \\
\hline 17,63 & 0,43 & 1,63 & 0,48 & 37 & 139 & 6,0 \\
\hline 18,68 & 0,19 & 1,65 & 0,80 & 33 & & \\
\hline 19,68 & 0,05 & 1,75 & 0,74 & 37 & & \\
\hline 20,68 & 0,21 & 1,83 & 0,78 & 34 & & \\
\hline 21,67 & 0,22 & 1,86 & 0,76 & 32 & 146 & 7,5 \\
\hline 22,68 & 0,32 & 1,83 & 0,76 & 35 & 147 & 7,1 \\
\hline 23,60 & 0,08 & 1,90 & 0,81 & 38 & & \\
\hline 24,68 & 0,36 & 1,96 & 0,70 & 35 & 185 & 9,1 \\
\hline 25,67 & 0,12 & 1,89 & 0,87 & 36 & 134 & 8,4 \\
\hline 26,65 & 0,38 & 1,63 & 0,76 & 28 & 269 & 13,0 \\
\hline 27,69 & 0,36 & 1,46 & 0,89 & 33 & 338 & 16,9 \\
\hline 28,60 & 0,40 & 1,39 & 0,77 & 40 & 332 & 15,1 \\
\hline 29,66 & 0,31 & 1,40 & 0,83 & 43 & & \\
\hline 30,63 & 0,67 & 1,38 & 0,76 & 40 & & \\
\hline 31,68 & 0,38 & 1,29 & 0,75 & 37 & 407 & 17,2 \\
\hline 32,67 & 0,59 & 1,33 & 0,84 & 39 & 319 & 14,2 \\
\hline 33,68 & 0,54 & 1,38 & 0,72 & 42 & 281 & 13,9 \\
\hline 34,66 & 0,49 & 1,39 & 0,78 & 41 & 292 & 14,7 \\
\hline 35,67 & 0,61 & 1,26 & 0,68 & 38 & 265 & \\
\hline 36,68 & 0,43 & 1,28 & 0,69 & 36 & & \\
\hline 37,67 & 0,51 & 1,42 & 0,76 & 39 & & \\
\hline 38,62 & 0,45 & 1,40 & 0,78 & 37 & & \\
\hline 39,70 & 0,57 & 1,23 & 0,52 & 30 & 258 & \\
\hline 40,67 & 0,45 & 1,19 & 0,70 & 37 & 277 & 13,7 \\
\hline 41,63 & 0,52 & 1,21 & 1,24 & 33 & & \\
\hline 42,69 & 0,39 & 1,33 & 0,86 & 34 & 284 & 15,7 \\
\hline 43,65 & 0,61 & 1,04 & 0,87 & 34 & & \\
\hline 44,65 & 0,51 & 0,67 & 0,87 & 34 & & \\
\hline 45,68 & 0,42 & 1,05 & 1,09 & 35 & 323 & 17,1 \\
\hline
\end{tabular}


Tabela A.3 - Valor das principais variáveis ao longo do tempo, do ensaio E3 (Cont.) (notação de acordo com Lista de Símbolos)

\begin{tabular}{|c|c|c|c|c|c|c|}
\hline $\begin{array}{c}\mathrm{t} \\
\mathrm{dia}\end{array}$ & $\begin{array}{c}\mu \\
1 / \text { dia }\end{array}$ & $\begin{array}{c}\mu \text { Glic } \\
\text { pmol/(cel.dia) }\end{array}$ & $\begin{array}{c}\mu \mathrm{Gln} \\
\mathrm{pmol} /(\text { cel.dia })\end{array}$ & $\begin{array}{c}\mu \mathrm{P} \\
\mu \mathrm{UA} /(\text { cel.dia })\end{array}$ & $\begin{array}{c}\text { OUR } \\
\mathrm{mg} /(\mathrm{L} . \mathrm{h}\end{array}$ & $\begin{array}{c}\text { QO2 } \\
\mu \mathrm{g} /(\text { E6cel.h }\end{array}$ \\
\hline 46,68 & 0,61 & 1,09 & 1,12 & 34 & 300 & 15,0 \\
\hline 47,68 & 0,53 & 1,04 & 1,18 & 33 & 341 & 16,3 \\
\hline 48,70 & 0,53 & 1,04 & 1,15 & 32 & 299 & 13,4 \\
\hline 49,69 & 0,40 & 1,16 & 1,15 & 31 & 341 & 17,1 \\
\hline 50,60 & 0,65 & 1,15 & 1,14 & 30 & & \\
\hline 51,67 & 0,44 & 1,03 & 1,07 & 34 & 308 & 14,7 \\
\hline 52,67 & 0,49 & 1,24 & 1,25 & 34 & 311 & 15,6 \\
\hline 53,67 & 0,57 & 1,39 & 1,25 & 33 & 303 & 14,7 \\
\hline 54,63 & 0,48 & 1,39 & 1,23 & 40 & 252 & 12,7 \\
\hline 55,68 & 0,61 & 1,33 & 1,21 & 36 & 315 & 14,7 \\
\hline 56,67 & 0,29 & 1,22 & 1,00 & 31 & 93 & 3,6 \\
\hline 57,64 & 0,25 & 1,87 & 1,13 & 28 & & \\
\hline 58,69 & 0,24 & 1,86 & 1,23 & 28 & & \\
\hline 59,68 & 0,00 & 2,02 & 1,38 & 27 & & \\
\hline 60,69 & 0,00 & 2,47 & 1,71 & 22 & 11 & 0,8 \\
\hline 61,62 & 0,00 & 2,85 & 2,07 & 24 & 23 & 2,4 \\
\hline 62,68 & 0,24 & 3,08 & 1,60 & 27 & 266 & \\
\hline 63,63 & 0,36 & 1,97 & 1,57 & 38 & 296 & \\
\hline 64,63 & 0,52 & 1,50 & 1,21 & 23 & 342 & 17,1 \\
\hline 65,65 & & 1,50 & 1,14 & 26 & & \\
\hline 66,65 & 0,64 & 1,42 & 1,07 & 28 & 418 & 16,9 \\
\hline 67,67 & 0,79 & 1,53 & 1,15 & 26 & & \\
\hline 68,69 & 0,58 & 1,37 & 1,19 & 30 & 356 & 18,7 \\
\hline 69,60 & 0,64 & 1,45 & 1,36 & 31 & 308 & 15,9 \\
\hline 70,65 & 0,67 & 1,37 & 1,18 & 39 & 329 & 15,8 \\
\hline 71,61 & 0,68 & 1,39 & 0,88 & 33 & & \\
\hline 72,63 & 0,58 & 1,46 & 1,27 & 34 & & \\
\hline 73,68 & 0,73 & 1,47 & 1,04 & 34 & 330 & 15,3 \\
\hline 74,64 & 0,66 & 1,41 & 0,91 & 33 & 347 & 16,1 \\
\hline 75,69 & 0,71 & 1,36 & 0,99 & 40 & 326 & 14,1 \\
\hline 76,69 & 0,50 & 1,41 & 0,90 & 33 & & \\
\hline 77,66 & 0,75 & 1,54 & 0,97 & 43 & & \\
\hline 78,60 & 0,88 & 1,26 & 0,98 & 23 & & \\
\hline 79,64 & 0,64 & 1,35 & 0,97 & 26 & & \\
\hline 80,69 & 0,48 & 1,58 & 1,11 & 33 & 308 & 17,6 \\
\hline 81,68 & 0,80 & 1,69 & 1,33 & 33 & & \\
\hline 82,69 & 0,53 & 1,62 & 1,28 & 32 & 249 & 12,1 \\
\hline
\end{tabular}


Tabela A.4 - Valor das principais variáveis ao longo do tempo, do ensaio E4 (notação de acordo com Lista de Símbolos)

\begin{tabular}{|c|c|c|c|c|c|c|c|c|c|c|c|c|c|c|}
\hline $\begin{array}{c}\mathrm{t} \\
\text { dia }\end{array}$ & $\begin{array}{l}\text { temp } \\
{ }^{\circ} \mathrm{C}\end{array}$ & $\begin{array}{l}\mathrm{Pm} \\
\mathrm{atm}\end{array}$ & $\begin{array}{c}\text { OD } \\
\%\end{array}$ & $\overline{D O}$ & $\begin{array}{c}\mathrm{X} \\
\text { E6cel/mL }\end{array}$ & $\begin{array}{c}\text { viab } \\
\%\end{array}$ & $\begin{array}{l}\text { Glic } \\
\mathrm{mM}\end{array}$ & $\begin{array}{l}\text { Gln } \\
\mathrm{mM}\end{array}$ & $\begin{array}{c}\mathrm{P} \\
\mathrm{UA} / \mathrm{mL}\end{array}$ & $\begin{array}{c}\text { Xref } \\
\text { E6cel } / \mathrm{mL}\end{array}$ & $\begin{array}{c}\mu \\
1 / \text { dia }\end{array}$ & $\begin{array}{c}\mu \text { Glic } \\
\mathrm{pmol} /(\mathrm{cel} \cdot \text { dia })\end{array}$ & $\begin{array}{c}\mu \mathrm{Gln} \\
\mathrm{pmol} / \text { (cel.dia) }\end{array}$ & $\begin{array}{c}\mu \mathrm{P} \\
\mu \mathrm{UA} / \text { (cel.dia) }\end{array}$ \\
\hline 0.22 & 37,00 & 0.13 & 51.0 & 0.60 & 0,73 & 97.0 & 433 & 2,20 & 27 & 0,00 & |00 & & & 0 \\
\hline 0,79 & 37,00 & 0,15 & 50,0 & 1,10 & 1,15 & 95,1 & 3,07 & \begin{tabular}{|l|l}
0,72 \\
\end{tabular} & 62 & 0,92 & & 2,38 & & 67 \\
\hline 1,81 & 37,00 & 0,25 & 54,5 & \begin{tabular}{|l|l}
1,69 \\
\end{tabular} & 1,90 & 95,1 & 2,33 & 0,26 & 80 & 1,49 & 0,52 & 1,30 & 1,11 & 32 \\
\hline 2,81 & 36,90 & 0,24 & 49,5 & 3,31 & 3,63 & 91,7 & 2,81 & 0,25 & 88 & 2,67 & 0,74 & 1,03 & 1,77 & 33 \\
\hline 3,76 & 36,90 & 0,36 & 54,2 & 6,00 & 6,74 & 90,7 & 3,09 & 0,23 & 92 & 5,02 & 0,74 & 0,95 & 1,74 & 33 \\
\hline 4,79 & 37,00 & 0,35 & 54,0 & 10,70 & 10,85 & 90,0 & 3,70 & 0,18 & 96 & 8,63 & 0,55 & 0,90 & 1,87 & 37 \\
\hline 5,80 & 37,00 & 0,52 & 52,8 & 17,90 & 15,76 & 91,4 & 3,15 & 0,18 & 93 & 13,15 & \begin{tabular}{|l|}
0,57 \\
\end{tabular} & 0,79 & 1,94 & 39 \\
\hline 6,77 & 37,00 & 0,74 & 48,2 & 24,98 & 22,10 & 88,8 & 2,93 & 0,29 & 114 & 18,75 & \begin{tabular}{|l|l}
0,57 \\
\end{tabular} & 1,00 & 1,98 & 39 \\
\hline 7,82 & 37,00 & 0,59 & 49,8 & 20,04 & & 94,1 & 3,39 & 1,22 & 97 & 21,89 & \begin{tabular}{|l|l|}
0,79 \\
\end{tabular} & 1,21 & 2,25 & 53 \\
\hline 8,75 & 37,10 & 0,49 & 50,3 & 17,45 & 18,93 & 94,2 & 3,35 & \begin{tabular}{|l|l}
1,57 \\
\end{tabular} & 99 & 20,27 & \begin{tabular}{|l|}
0,58 \\
\end{tabular} & 1,09 & 1,92 & 49 \\
\hline 9,80 & 37,00 & 0,59 & 50,5 & 18,17 & 20,54 & 93,6 & 3,17 & 1,25 & 111 & 19,72 & 0,63 & 1,11 & 1,70 & 50 \\
\hline 10,75 & 37,00 & 0,61 & 50,6 & 18,13 & & 93,9 & 3,38 & 1,18 & 103 & 21,23 & & 1,15 & 1,81 & 53 \\
\hline 11,84 & 37,10 & 0,44 & 49,9 & 17,70 & 20,84 & 94,1 & & 1,12 & 81 & 21,38 & 0,63 & 0,99 & 1,80 & 47 \\
\hline 12,80 & 37,00 & 0,42 & 54,6 & 17,30 & 19,40 & 96,4 & 3,09 & 1,09 & 89 & 20,11 & 0,54 & 0,76 & 1,95 & 41 \\
\hline 13,74 & 37,00 & 0,44 & 51,9 & 17,13 & 19,92 & 95,1 & 3,25 & 1,14 & 100 & 19,66 & 0,71 & 1,26 & 2,01 & 46 \\
\hline 14,79 & 37,00 & 0,44 & 51,1 & 16,79 & 19,90 & 93,0 & 3,20 & 1,29 & 110 & 19,91 & 0,70 & 1,19 & 2,00 & 52 \\
\hline 15,80 & 37,00 & 0,44 & 49,2 & 16,85 & 20,23 & 92,7 & 3,31 & 1,35 & & 20,06 & 0,68 & 1,19 & 1,88 & 57 \\
\hline 16,75 & 37,00 & 0,43 & 50,3 & 16,42 & 20,90 & 95,5 & 3,31 & 1,43 & 103 & 20,56 & \begin{tabular}{|l|}
0,69 \\
\end{tabular} & 1,12 & 1,82 & 61 \\
\hline 17,77 & 36,50 & 0,43 & 52,0 & 16,30 & 20,50 & 92,5 & 3,07 & 1,40 & 96 & 20,70 & 0,65 & 1,13 & 1,77 & 51 \\
\hline 18,80 & 35,50 & 0,43 & 50,5 & 16,70 & 23,35 & 94,0 & 3,08 & 1,42 & 98 & 21,89 & & 1,17 & 1,69 & 45 \\
\hline 19,76 & 34,50 & 0,43 & 50,3 & 17,20 & 24,15 & 95,6 & 2,95 & 1,35 & 111 & 23,75 & \begin{tabular}{|l|l|}
0,39 \\
\end{tabular} & 1,08 & 1,55 & 43 \\
\hline 20,81 & 34,00 & 0,43 & 50,0 & 17,38 & 21,06 & 92,4 & 4,12 & 1,85 & 104 & 22,57 & 0,41 & 1,13 & 1,67 & 50 \\
\hline 21,78 & 34,00 & 0,43 & 51,0 & 17,08 & 21,00 & 92,8 & 3,88 & 2,07 & & 21,03 & \begin{tabular}{|l|}
0,57 \\
\end{tabular} & 0,71 & 1,55 & 50 \\
\hline 22,83 & 34,00 & 0,43 & 50,2 & 16,56 & 21,99 & 93,8 & 3,70 & 2,22 & 101 & 21,49 & \begin{tabular}{|l|l}
0,58 \\
\end{tabular} & 0,81 & 1,41 & \\
\hline 23,80 & 34,00 & 0,43 & 50,8 & 16,18 & 21,42 & 92,2 & 3,69 & 2,24 & 115 & 21,70 & \begin{tabular}{|l|}
0,56 \\
\end{tabular} & 0,87 & 1,31 & 48 \\
\hline 24,79 & 34,00 & 0,43 & 47,3 & 15,70 & 22,30 & 95,7 & 3,67 & 2,02 & 121 & 21,86 & \begin{tabular}{|l|}
0,53 \\
\end{tabular} & 0,87 & 1,28 & 54 \\
\hline 25,78 & 34,00 & 0,43 & 50,9 & 15,30 & 21,60 & 98,5 & 3,62 & 2,05 & 86 & 21,95 & 0,52 & 0,89 & 1,40 & 55 \\
\hline 26,77 & 34,00 & 0,43 & 50,7 & 15,10 & 22,00 & 96,2 & 3,66 & 2,09 & 89 & 21,80 & 0,44 & 0,90 & 1,38 & 40 \\
\hline 27,78 & 34,00 & 0,43 & 47,7 & 15,20 & 21,15 & 95,3 & \begin{tabular}{|l|l|}
3,74 \\
\end{tabular} & 2,20 & 118 & 21,57 & 0,53 & 0,89 & 1,38 & 44 \\
\hline 28,77 & 34,00 & 0,43 & 46,6 & 15,00 & 22,67 & 97,1 & 3,71 & 2,13 & 119 & 21,90 & 0,75 & 0,85 & 1,31 & 55 \\
\hline 29,79 & 34,00 & 0,43 & 47,2 & 14,80 & 23,40 & 97,3 & 3,83 & 2,31 & 116 & 23,03 & 0,68 & 0,82 & 1,29 & 53 \\
\hline 30,77 & 34,00 & 0,43 & 47,2 & 14,70 & 21,58 & 97,0 & 3,79 & 2,13 & 116 & 22,48 & 0,54 & 0,79 & 1,22 & 53 \\
\hline 31,78 & 34,00 & 0,42 & 47,3 & 14,50 & & 96,7 & \begin{tabular}{|l|l}
3,71 \\
\end{tabular} & 2,30 & 113 & 20,37 & 0,54 & 0,90 & 1,46 & 58 \\
\hline 32,76 & 33,10 & 0,43 & 50,4 & 15,60 & 24,00 & 98,0 & 3,61 & 1,74 & 75 & 21,51 & & 0,88 & 1,26 & 52 \\
\hline 33,83 & 32,00 & 0,43 & 46,2 & 16,60 & 23,76 & 94,3 & 4,06 & 2,60 & 77 & 23,88 & & 0,80 & 1,40 & 31 \\
\hline 34,77 & 31,90 & 0,43 & 46,0 & 16,60 & 30,06 & 98,6 & 4,11 & 2,55 & 89 & 26,79 & \begin{tabular}{|l|}
0,60 \\
\end{tabular} & 0,57 & 0,91 & 30 \\
\hline 35,78 & 32,00 & 0,43 & 44,5 & 16,70 & & 97,6 & \begin{tabular}{|l|l}
4,37 \\
\end{tabular} & 2,79 & 85 & 30,87 & 0,45 & 0,47 & 0,81 & 29 \\
\hline 36,78 & 32,00 & 0,43 & 50,0 & 16,10 & 29,40 & 93,2 & 4,03 & 2,65 & 92 & 30,54 & 0,37 & 0,40 & 0,73 & 28 \\
\hline 37,79 & 32,00 & 0,42 & 49,9 & 16,90 & 26,06 & 98,2 & 3,99 & 2,68 & 95 & 27,70 & & 0,55 & 0,85 & 33 \\
\hline 38,79 & 32,00 & 0,43 & 50,3 & 17,00 & 27,08 & 98,0 & 3,98 & 2,61 & 94 & 26,57 & \begin{tabular}{|l|}
0,39 \\
\end{tabular} & 0,59 & 0,88 & 36 \\
\hline 39,75 & 32,00 & 0,43 & 50,1 & 17,20 & 23,70 & 99,6 & 3,95 & 2,46 & 72 & 25,35 & \begin{tabular}{|l|}
0,37 \\
\end{tabular} & 0,64 & 0,96 & 37 \\
\hline 40,76 & 32,00 & 0,43 & 49,7 & 17,30 & 24,00 & 99,5 & 4,20 & 2,69 & & 23,85 & 0,57 & 0,68 & 1,10 & 31 \\
\hline 41,75 & 32,00 & 0,43 & 49,4 & 17,20 & 27,92 & 98,6 & 4,06 & 2,63 & 92 & 25,91 & \begin{tabular}{|l|}
0,55 \\
\end{tabular} & 0,53 & 0,90 & 33 \\
\hline 42,81 & 31,50 & 0,42 & 49,1 & 18,03 & 28,56 & 97,8 & 4,27 & 2,74 & 80 & 28,24 & \begin{tabular}{|l|}
0,32 \\
\end{tabular} & 0,52 & 0,84 & 32 \\
\hline 43,80 & 30,50 & 0,42 & 49,1 & 19,49 & 31,57 & 97,6 & 4,32 & 2,76 & 70 & 30,04 & 0,22 & 0,42 & 0,74 & 26 \\
\hline 44,82 & 30,00 & 0,41 & 49,6 & 20,59 & 38,12 & 98,0 & 4,42 & 2,82 & 73 & 34,74 & 0,29 & 0,35 & 0,64 & 20 \\
\hline 45,77 & 30,00 & 0,42 & 50,9 & 20,98 & 32,72 & 95,5 & 4,40 & 2,99 & 72 & 35,35 & \begin{tabular}{|l|}
0,01 \\
\end{tabular} & 0,32 & 0,62 & 21 \\
\hline 46,76 & 30,00 & 0,42 & 50,0 & 21,50 & 36,24 & 97,8 & 4,53 & 3,64 & 62 & 34,45 & 0,21 & 0,33 & 0,60 & 21 \\
\hline 47,76 & 30,00 & 0,42 & 49,7 & 21,80 & 31,80 & 99,6 & 4,48 & 3,45 & 62 & 33,97 & 0,00 & 0,30 & 0,39 & 18 \\
\hline 48,82 & 30,00 & 0,43 & 50,5 & 22,20 & 27,12 & 92,8 & 4,19 & 3,25 & 61 & 29,40 & 0,08 & 0,38 & 0,52 & 21 \\
\hline 49,78 & 30,50 & 0,50 & 51,0 & 22,98 & 29,28 & 96,0 & 4,51 & 3,08 & 76 & 28,19 & \begin{tabular}{|l|l|}
0,17 \\
\end{tabular} & 0,47 & 0,61 & 22 \\
\hline 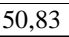 & 32,50 & 0,43 & 49,5 & 18,69 & 23,13 & 99,2 & 4,34 & 3,03 & 70 & 26,08 & \begin{tabular}{|l|}
0,33 \\
\end{tabular} & 0,42 & 0,76 & 30 \\
\hline 51,74 & 34,00 & 0,42 & 49,6 & 16,56 & 21,51 & 98,4 & \begin{tabular}{|l}
4,27 \\
\end{tabular} & 2,81 & 87 & 22,31 & 0,50 & 0,57 & 0,91 & 33 \\
\hline 52,84 & 34,00 & 0,42 & 50,0 & 15,77 & 21,57 & 98,5 & 4,14 & 2,14 & 88 & 21,54 & 0,51 & 0,62 & 1,02 & 42 \\
\hline 53,79 & 34,00 & 0,43 & 50,7 & 15,40 & 21,00 & 98,9 & 4,19 & 2,02 & 84 & 21,28 & 0,52 & 0,68 & 1,38 & 43 \\
\hline 54,76 & 34,00 & 0,43 & 50,2 & 15,10 & 20,16 & 99,0 & 3,95 & \begin{tabular}{|l|l|}
1,87 \\
\end{tabular} & 69 & 20,58 & \begin{tabular}{|l|}
0,53 \\
\end{tabular} & 0,70 & 1,49 & 42 \\
\hline 55,83 & 34,00 & 0,42 & 50,7 & 14,70 & 23,01 & 97,4 & 4,13 & 2,29 & 99 & 21,55 & \begin{tabular}{|l|l|}
0,71 \\
\end{tabular} & 0,76 & 1,52 & 35 \\
\hline 56,81 & 34,00 & 0,43 & 51,0 & 14,16 & 21,34 & 97,4 & 4,02 & 2,22 & 92 & 22,16 & \begin{tabular}{|l|}
0,50 \\
\end{tabular} & 0,67 & 1,26 & 46 \\
\hline 57,82 & 35,50 & 0,43 & 50,0 & 12,59 & 18,30 & 98,4 & 3,65 & 1,97 & 110 & 19,78 & 0,63 & 0,83 & 1,46 & 50 \\
\hline 58,81 & 37,00 & 0,44 & 50,4 & 11,50 & 16,11 & 96,6 & 3,62 & \begin{tabular}{|l|l}
1,70 \\
\end{tabular} & 114 & 17,18 & \begin{tabular}{|l|}
0,84 \\
\end{tabular} & 1,18 & 1,85 & 68 \\
\hline 59,83 & 37,00 & 0,43 & 50,5 & 10,56 & 20,88 & 99,0 & \begin{tabular}{|l}
3,73 \\
\end{tabular} & 1,72 & 127 & 18,39 & & 1,11 & 1,90 & 66 \\
\hline 60,79 & 37,10 & 0,42 & 50,9 & 10,40 & 18,70 & 97,4 & 3,41 & 1,71 & 108 & 19,77 & 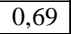 & 0,99 & 1,76 & 67 \\
\hline 61,78 & 37,00 & 0,43 & 49,4 & 10,80 & 18,90 & 95,0 & 3,32 & 1,48 & 93 & 18,80 & \begin{tabular}{|l|}
0,91 \\
\end{tabular} & 1,21 & 1,84 & 60 \\
\hline
\end{tabular}


Tabela A.4 - Valor das principais variáveis ao longo do tempo, do ensaio E4 (Cont.) (notação de acordo com Lista de Símbolos)

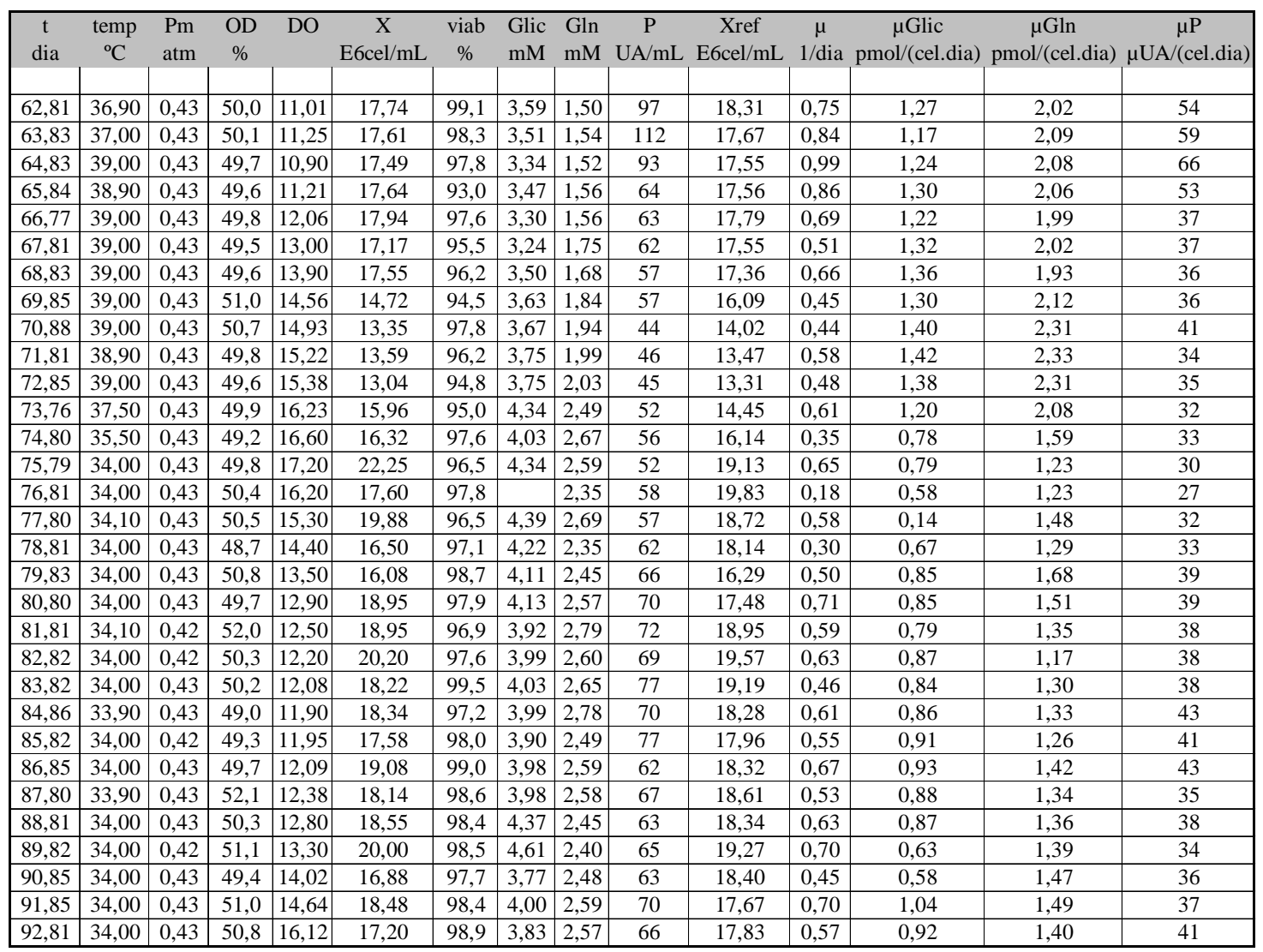


Tabela A.5 - Valor das principais variáveis ao longo do tempo, do ensaio E5 (notação de acordo com Lista de Símbolos)

\begin{tabular}{|c|c|c|c|c|c|c|c|c|c|c|c|c|}
\hline $\begin{array}{c}\mathrm{t} \\
\mathrm{dia}\end{array}$ & $\begin{array}{c}\text { osm } \\
\mathrm{mmol} / \mathrm{kg}\end{array}$ & $\begin{array}{l}\mathrm{Pm} \\
\mathrm{atm}\end{array}$ & $\begin{array}{c}\mathrm{OD} \\
\%\end{array}$ & $\mathrm{DO}$ & $\begin{array}{c}\mathrm{X} \\
\text { E6cel/mL }\end{array}$ & $\begin{array}{c}\text { viab } \\
\%\end{array}$ & $\begin{array}{l}\text { Glic } \\
\mathrm{mM}\end{array}$ & $\begin{array}{l}\text { Gln } \\
\mathrm{mM}\end{array}$ & $\begin{array}{c}P \\
U A / m L\end{array}$ & $\begin{array}{c}\text { Xref } \\
\text { E6cel } / \mathrm{mL}\end{array}$ & $\begin{array}{c}\mu \\
1 / \text { dia }\end{array}$ & $\begin{array}{c}\mu \text { Glic } \\
\text { pmol/(cel.dia) }\end{array}$ \\
\hline 0,11 & & 0,00 & 47,9 & 0,50 & 0,73 & 86,0 & 21,22 & 7,55 & 8 & 0,00 & & \\
\hline 0,76 & & 0,00 & 50,1 & 1,20 & 0,63 & 81,0 & 18,78 & 6,35 & 15 & 0,68 & & \\
\hline 1,20 & & 0,00 & 49,2 & 1,80 & 1,00 & 81,0 & 18,00 & 5,66 & 24 & 0,80 & & \\
\hline 1,87 & & 0,00 & 49,0 & 3,20 & 1,27 & 86,0 & 15,83 & 4,21 & 36 & 1,13 & & \\
\hline 3,08 & & 0,00 & 50,3 & 4,90 & 2,14 & 87,0 & 15,00 & 3,54 & 45 & 1,67 & & \\
\hline 3,74 & & 0,00 & 49,1 & 7,10 & 3,74 & 90,0 & 13,67 & 3,35 & 53 & 2,87 & & \\
\hline 4,91 & & 0,00 & 49,3 & 11,20 & 5,27 & 89,0 & & & 43 & 4,46 & & \\
\hline 5,74 & & 0,00 & 49,6 & 14,50 & 5,28 & 83,0 & 13,17 & 3,25 & 64 & 5,27 & & \\
\hline 6,75 & & 0,00 & 49,3 & 25,00 & 11,24 & 84,0 & & & 101 & 7,89 & & \\
\hline 7,61 & & 0,00 & 48,6 & 31,00 & 12,60 & 89,0 & 13,89 & 3,10 & 84 & 11,91 & & \\
\hline 8,89 & & 0,00 & 48,5 & 46,60 & 26,63 & 91,4 & 13,44 & 2,98 & 137 & 18,75 & 0,66 & \\
\hline 9,73 & & 0,00 & 50,2 & 39,80 & 20,30 & 92,9 & 14,50 & 3,07 & 121 & 23,32 & & 1,27 \\
\hline 10,88 & & 0,00 & 50,4 & 41,90 & 22,34 & 92,3 & 14,72 & & & 21,30 & 0,52 & 1,29 \\
\hline 11,89 & & 0,00 & 50,8 & 40,80 & 20,40 & 93,1 & 14,89 & 3,05 & & 21,36 & 0,36 & 1,27 \\
\hline 13,01 & & 0,00 & 50,2 & 41,60 & 20,50 & 92,0 & 14,56 & 2,76 & 133 & 20,45 & 0,42 & 1,28 \\
\hline 13,70 & 303 & 0,00 & 50,5 & 42,30 & 19,08 & 92,0 & 14,61 & 3,21 & 118 & 19,78 & 0,31 & 1,40 \\
\hline 14,75 & 306 & 0,00 & 51,2 & 42,90 & 20,70 & 88,9 & 14,56 & 3,47 & 117 & 19,88 & 0,52 & 1,35 \\
\hline 15,77 & & 0,00 & 50,5 & 43,90 & 19,38 & 89,9 & 14,72 & 3,81 & 122 & 20,03 & 0,39 & 1,40 \\
\hline 16,65 & 310 & 0,55 & 50,1 & 42,40 & 18,58 & 89,6 & 13,56 & 3,77 & 121 & 18,98 & 0,40 & 1,47 \\
\hline 17,84 & & 0,80 & 50,5 & 42,70 & 21,42 & 97,8 & 14,00 & 3,69 & 112 & 19,97 & 0,45 & 1,66 \\
\hline 19,00 & & 0,80 & 50,6 & 41,10 & 21,70 & 90,6 & 15,39 & 3,41 & 106 & 21,56 & 0,50 & 1,36 \\
\hline 19,64 & 305 & 0,80 & 49,7 & 41,40 & 17,43 & 91,9 & 14,06 & 3,85 & 104 & 19,49 & & 1,39 \\
\hline 20,72 & & 0,90 & 48,9 & 43,00 & 18,35 & 90,2 & 13,94 & 3,59 & 114 & 17,89 & 0,46 & 1,71 \\
\hline 21,75 & 308 & 1,00 & 50,7 & 43,80 & 18,33 & 88,2 & 13,33 & 2,73 & 114 & 18,34 & 0,42 & 1,83 \\
\hline 22,66 & 364 & 1,00 & 50,7 & 42,20 & 25,25 & 92,2 & 14,67 & & 111 & 21,61 & & 2,13 \\
\hline 23,84 & 357 & 1,00 & 49,9 & 41,20 & 17,65 & 82,3 & 12,94 & 2,20 & 115 & 21,22 & & \\
\hline 24,73 & 360 & 1,00 & 50,2 & 41,20 & 20,15 & 90,4 & 12,78 & 2,45 & 128 & 18,87 & 0,46 & 1,99 \\
\hline 25,74 & 372 & 0,95 & 50,0 & 40,70 & 20,97 & 92,9 & 12,94 & 2,34 & & 20,56 & 0,45 & 1,85 \\
\hline 26,67 & 368 & 0,85 & 50,5 & 38,70 & 19,18 & 89,9 & 13,89 & 2,36 & 123 & 20,06 & 0,33 & 1,81 \\
\hline 27,69 & 362 & 0,85 & 48,9 & 37,80 & 20,25 & 90,8 & 14,00 & 2,28 & 127 & 19,71 & 0,43 & 1,69 \\
\hline 28,86 & 369 & 0,75 & 50,2 & 36,80 & 17,50 & 90,7 & 13,89 & 2,22 & 119 & 18,84 & 0,25 & 1,76 \\
\hline 29,71 & & 1,00 & 48,6 & 41,00 & 19,93 & 85,1 & 12,44 & 1,95 & 127 & 18,69 & 0,34 & 1,73 \\
\hline 30,77 & 367 & 1,00 & 48,1 & 42,40 & 21,48 & 87,2 & 13,00 & 2,05 & & 20,70 & 0,40 & 1,86 \\
\hline 31,69 & 364 & 1,01 & 47,7 & 42,00 & 21,85 & 90,6 & 13,11 & 2,02 & 141 & 21,66 & 0,31 & 1,69 \\
\hline 32,77 & 359 & 1,00 & 48,8 & 41,90 & 20,98 & 90,4 & 13,28 & 2,03 & 139 & 21,41 & 0,33 & 1,69 \\
\hline 33,74 & & 1,00 & 48,5 & 41,10 & 20,00 & 86,8 & 13,17 & 2,10 & 141 & 20,49 & 0,35 & 1,75 \\
\hline 34,72 & 366 & 0,95 & 48,0 & 40,60 & 19,15 & 90,8 & 13,44 & 2,03 & 140 & 19,57 & 0,23 & 1,83 \\
\hline 35,72 & 364 & 0,95 & 49,4 & 40,90 & 20,08 & 92,0 & 13,83 & 1,90 & 134 & 19,61 & 0,37 & 1,75 \\
\hline 36,81 & 402 & 0,95 & 48,9 & 35,70 & 17,10 & 87,7 & 11,28 & 1,88 & & 18,55 & 0,41 & 2,03 \\
\hline 37,65 & 412 & 1,00 & 52,1 & 35,70 & 19,65 & 92,5 & 11,11 & 1,71 & & 18,35 & 0,57 & 2,61 \\
\hline 38,74 & 409 & 1,06 & 48,0 & 34,70 & 19,75 & 91,1 & 11,06 & 3,00 & & 19,70 & 0,50 & 2,50 \\
\hline 39,71 & 401 & 1,06 & 50,3 & 32,50 & 20,22 & 90,9 & 11,39 & & & 19,98 & 0,51 & 2,42 \\
\hline 40,76 & 398 & 1,06 & 51,1 & 32,90 & 15,98 & 87,5 & 11,61 & 3,44 & 126 & 18,02 & 0,28 & 2,69 \\
\hline 42,02 & 396 & 1,13 & 49,9 & 34,10 & 19,60 & 93,2 & 11,17 & 3,11 & 133 & 17,73 & 0,57 & 2,70 \\
\hline 42,94 & 394 & 1,15 & 48,6 & 32,99 & 20,98 & 93,9 & 11,22 & 3,23 & 128 & 20,28 & 0,56 & 2,38 \\
\hline 43,81 & 396 & 1,14 & 50,5 & 32,37 & 16,73 & 90,6 & 11,94 & 3,47 & 123 & 18,77 & 0,34 & 2,57 \\
\hline 44,66 & 405 & 1,15 & 48,7 & 33,18 & 16,90 & 91,0 & 11,50 & 3,36 & 124 & 16,81 & 0,54 & 2,78 \\
\hline
\end{tabular}


Tabela A.5 - Valor das principais variáveis ao longo do tempo, do ensaio E5 (Cont.) (notação de acordo com Lista de Símbolos)

\begin{tabular}{|c|c|c|c|c|c|c|c|c|c|c|c|c|}
\hline $\begin{array}{c}\mathrm{t} \\
\mathrm{dia}\end{array}$ & $\begin{array}{c}\mathrm{osm} \\
\mathrm{mmol} / \mathrm{kg}\end{array}$ & $\begin{array}{l}\mathrm{Pm} \\
\text { atm }\end{array}$ & $\begin{array}{c}\text { OD } \\
\%\end{array}$ & DO & $\begin{array}{c}\mathrm{X} \\
\text { E6cel/mL }\end{array}$ & $\begin{array}{c}\text { viab } \\
\%\end{array}$ & $\begin{array}{l}\text { Glic } \\
\mathrm{mM}\end{array}$ & $\begin{array}{l}\text { Gln } \\
\text { mM }\end{array}$ & $\begin{array}{c}\mathrm{P} \\
\mathrm{UA} / \mathrm{mL}\end{array}$ & $\begin{array}{c}\text { Xref } \\
\text { E6cel } / \mathrm{mL}\end{array}$ & $\begin{array}{c}\mu \\
1 / \mathrm{dia}\end{array}$ & $\begin{array}{c}\mu \text { Glic } \\
\text { pmol/(cel.dia) }\end{array}$ \\
\hline 45,68 & 410 & 1,21 & 50,6 & 35,80 & 20,45 & 94,7 & 11,72 & 3,13 & & 18,62 & 0,71 & 2,66 \\
\hline 46,94 & 411 & 1,21 & 51,6 & 34,80 & 20,10 & 93,2 & 12,11 & 3,97 & 130 & 20,27 & 0,52 & 2,30 \\
\hline 47,72 & & 1,20 & 50,8 & 33,60 & 19,62 & 96,7 & 13,00 & 4,12 & 128 & 19,86 & 0,42 & 2,24 \\
\hline 48,66 & 410 & 1,20 & 49,6 & 33,76 & 17,43 & 93,0 & 12,50 & 4,00 & 123 & 18,50 & 0,44 & 2,31 \\
\hline 49,68 & 412 & 1,18 & 49,6 & 33,40 & 16,23 & 94,2 & 12,50 & 4,01 & & 16,82 & 0,45 & 2,67 \\
\hline 50,78 & 402 & 1,51 & 28,0 & 35,97 & 19,18 & 87,7 & & 3,53 & 124 & 17,66 & 0,74 & 2,76 \\
\hline 52,10 & 410 & 1,25 & 47,2 & 35,91 & 16,18 & 91,2 & 12,00 & 3,94 & & 17,64 & 0,46 & \\
\hline 52,85 & & 1,50 & 47,0 & 39,80 & 22,29 & 94,6 & 10,61 & 3,47 & 137 & 19,07 & 0,75 & 2,48 \\
\hline 53,71 & & 1,39 & 46,5 & 38,20 & 19,62 & 98,1 & 10,72 & 3,70 & 126 & 20,93 & 0,35 & 2,54 \\
\hline 54,71 & 413 & 1,42 & 44,2 & 38,24 & 17,55 & 89,2 & 10,44 & 3,92 & 134 & 18,57 & 0,49 & 2,82 \\
\hline 55,70 & 407 & 1,52 & 44,1 & 39,51 & 17,35 & 89,4 & 10,22 & 3,64 & 134 & 17,45 & 0,43 & 3,01 \\
\hline 56,78 & 407 & 1,49 & 42,8 & 39,42 & 17,38 & 93,4 & 10,17 & 3,45 & 138 & 17,36 & 0,49 & 3,11 \\
\hline 57,77 & 404 & 1,54 & 46,2 & 39,23 & 18,10 & 90,4 & 10,44 & 3,73 & 139 & 17,74 & 0,56 & 3,01 \\
\hline 58,67 & 409 & 1,53 & 43,5 & 38,85 & 18,20 & 94,1 & 11,33 & 3,80 & 135 & 18,15 & 0,42 & 2,80 \\
\hline 59,86 & & 1,55 & 43,1 & 38,70 & 18,83 & 93,3 & 10,22 & 3,68 & 138 & 18,51 & , & 2,54 \\
\hline 60,67 & & 1,53 & 42,8 & 38,69 & 19,90 & 94,1 & 10,00 & 3,71 & 153 & 19,36 & 0,54 & 2,63 \\
\hline 61,94 & 413 & 1,51 & 47,1 & 38,65 & 19,13 & 88,2 & 11,17 & 3,81 & 143 & 19,51 & 0,53 & 2,60 \\
\hline 62,73 & 413 & 1,53 & 44,8 & 38,12 & 15,99 & 89,1 & 11,33 & 3,92 & 144 & 17,51 & 0,26 & 2,66 \\
\hline 63,72 & 416 & 1,53 & 43,0 & 37,79 & 15,63 & 91,4 & 11,83 & 3,62 & 136 & 15,81 & 0,47 & \\
\hline 65,06 & 464 & 1,81 & 42,2 & 34,80 & 17,93 & 91,2 & 9,89 & 3,25 & 155 & 16,75 & & 2,44 \\
\hline 65,79 & 460 & 1,88 & 41,2 & 38,39 & 17,30 & 84,3 & 10,17 & 3,18 & 156 & 17,61 & 0,33 & 2,66 \\
\hline 66,68 & & 1,89 & 42,4 & 38,59 & 21,68 & 96,7 & 9,50 & & 169 & 19,41 & 0,51 & 2,51 \\
\hline 67,67 & & 1,90 & 65,5 & 38,56 & 18,98 & 97,1 & 9,56 & & 177 & 20,30 & & 2,41 \\
\hline 68,70 & 458 & 1,73 & 53,6 & 35,93 & 17,33 & 88,0 & 11,33 & 3,58 & 158 & 18,14 & 0,49 & 2,75 \\
\hline 69,77 & 457 & 1,79 & 90,2 & 38,21 & 16,80 & 87,4 & 10,11 & 3,24 & 161 & 17,06 & 0,37 & 2,57 \\
\hline 70,76 & 460 & 1,83 & 42,3 & 38,07 & 18,35 & 91,1 & 10,11 & 3,22 & 153 & 17,56 & 0,47 & 2,75 \\
\hline 71,61 & 15 & 1,25 & 50,2 & 38,02 & 11,13 & 88,4 & 13,33 & 4,10 & 126 & 14,44 & & \\
\hline 72,75 & 302 & 0,95 & 15,2 & 43,05 & 15,50 & 92,6 & 13,61 & 3,79 & 124 & 13,19 & 0,70 & \\
\hline 73,67 & 311 & 1,38 & 63,8 & 45,50 & 18,08 & 96,4 & 13,28 & 3,53 & 124 & 16,76 & 0,54 & 1,99 \\
\hline 74,88 & 311 & 1,12 & 69,5 & 45,40 & 18,50 & 93,0 & 12,61 & 3,54 & 110 & 18,29 & 0,48 & 1,94 \\
\hline 75,68 & 314 & 1,23 & 79,7 & 45,62 & 14,33 & 89,6 & 12,83 & 3,67 & 102 & 16,33 & & \\
\hline 76,66 & 309 & 1,51 & 51,9 & 54,86 & 21,97 & 92,9 & 12,39 & 3,06 & 121 & 17,88 & 0,66 & 1,98 \\
\hline 77,66 & 305 & 1,43 & 51,9 & 52,07 & 18,75 & 90,5 & 11,44 & 3,16 & 101 & 20,32 & 0,34 & 1,97 \\
\hline 78,82 & 307 & 1,46 & 49,6 & 52,02 & 18,38 & 88,9 & 11,50 & 3,20 & 105 & 18,56 & 0,43 & 2,30 \\
\hline 79,70 & 309 & 1,52 & 50,5 & 52,07 & 18,70 & 91,2 & 12,07 & 2,12 & 101 & 18,54 & 0,39 & 2,24 \\
\hline 80,66 & 314 & 1,58 & 49,1 & 51,85 & 19,56 & 92,1 & 10,89 & 1,95 & 108 & 19,13 & 0,45 & 2,14 \\
\hline 81,98 & & 1,57 & 47,1 & 52,17 & 21,36 & 91,0 & & 1,75 & 118 & 20,45 & 0,57 & 1,98 \\
\hline 83,01 & 311 & 1,58 & 49,6 & 51,91 & 17,45 & 88,5 & 13,31 & 1,68 & 104 & 19,34 & 0,24 & \\
\hline 83,90 & 305 & 1,62 & 50,6 & 51,88 & 17,73 & 89,1 & 13,33 & 2,13 & 104 & 17,59 & 0,45 & 1,94 \\
\hline 84,69 & 302 & 1,60 & 49,1 & 52,08 & 18,08 & 90,5 & 13,20 & 2,37 & 102 & 17,90 & 0,45 & 1,91 \\
\hline 85,61 & 305 & 1,57 & 55,8 & 51,81 & 16,80 & 90,2 & 13,44 & 1,62 & 99 & 17,43 & 0,36 & 1,98 \\
\hline 86,63 & & 1,55 & 50,4 & 52,20 & 20,85 & 91,4 & & 1,58 & 96 & 18,75 & 0,61 & 1,59 \\
\hline 87,64 & & 1,53 & 50,2 & 52,00 & 18,50 & 94,3 & 13,28 & 1,57 & 99 & 19,65 & 0,25 & \\
\hline 88,83 & 316 & 1,49 & 50,1 & 52,00 & 18,10 & 92,6 & 13,28 & 1,55 & 95 & 18,30 & 0,45 & 1,89 \\
\hline 89,29 & 310 & 1,43 & 49,3 & 51,98 & 15,25 & 90,2 & 14,22 & 1,63 & 86 & 16,63 & 0,29 & 2,03 \\
\hline 90,75 & 309 & 1,52 & 50,2 & 54,99 & 18,20 & 90,9 & 13,23 & 1,54 & 96 & 16,68 & 0,43 & 1,78 \\
\hline
\end{tabular}


Tabela A.5 - Valor das principais variáveis ao longo do tempo, do ensaio E5 (Cont.) (notação de acordo com Lista de Símbolos)

\begin{tabular}{|c|c|c|c|c|c|c|c|}
\hline $\begin{array}{c}\mathrm{t} \\
\mathrm{dia}\end{array}$ & $\begin{array}{c}\mu \mathrm{Gln} \\
\mathrm{pmol} / \text { (cel.dia) }\end{array}$ & $\begin{array}{c}\mu \mathrm{P} \\
\mu \mathrm{UA} / \text { (cel.dia) }\end{array}$ & $\begin{array}{c}\mu \mathrm{P}[\text { biovol }] \\
\mu \mathrm{UA} /(\mathrm{pL} . \text { dia })\end{array}$ & $\begin{array}{c}\mathrm{X}_{\mathrm{C}} \\
\text { E6cel/mL }\end{array}$ & $\begin{array}{l}\text { biovol } \\
\mu \mathrm{L} / \mathrm{mL}\end{array}$ & $\begin{array}{c}\text { diâm. médio } \\
\mu \mathrm{m}\end{array}$ & $\begin{array}{l}\text { vol. médio } \\
\text { pL }\end{array}$ \\
\hline 0,11 & 0,00 & & & 0,3 & 0,5 & 13,79 & 1,62 \\
\hline 0,76 & & & & 0,5 & 0,9 & 14,09 & 1,73 \\
\hline 1,20 & & & & 0,5 & 0,9 & 14,33 & 1,88 \\
\hline 1,87 & & & & 1,3 & 2,4 & 14,53 & 1,90 \\
\hline 3,08 & & & & 1,4 & 2,6 & 14,43 & 1,86 \\
\hline 3,74 & 1,25 & 14 & & & & & \\
\hline 4,91 & 0,98 & 12 & & & & & \\
\hline $\begin{array}{l}5,74 \\
\end{array}$ & & 18 & 11 & 4,8 & 8,7 & 14,33 & 1,80 \\
\hline 6,75 & 1,29 & 19 & 12 & 9,7 & 17,4 & 14,23 & 1,79 \\
\hline 7,61 & & 28 & 9 & 20,8 & 40,0 & 14,53 & 1,93 \\
\hline 8,89 & 1,36 & 20 & 15 & 21,0 & 35,4 & 14,04 & 1,69 \\
\hline 9,73 & 1,15 & 22 & 20 & 15,6 & 23,2 & 13,55 & 1,48 \\
\hline 10,88 & 1,21 & 21 & & & & & \\
\hline 11,89 & & & & 20,1 & & 15,94 & 2,75 \\
\hline 13,01 & 1,32 & 19 & 13 & 17,2 & 29,3 & 13,99 & 1,70 \\
\hline 13,70 & & 27 & 27 & 11,5 & 18,8 & 13,89 & 1,63 \\
\hline 14,75 & 1,34 & 24 & 26 & 12,6 & 18,9 & 13,55 & 1,50 \\
\hline 15,77 & 1,33 & 25 & 20 & 15,4 & 24,1 & 13,75 & 1,57 \\
\hline 16,65 & 1,27 & 26 & & 15,6 & & 14,97 & 2,10 \\
\hline 17,84 & 1,30 & 26 & & 24,0 & & 15,16 & 2,24 \\
\hline 19,00 & & 22 & & 17,7 & & 14,23 & 1,76 \\
\hline 19,64 & 1,42 & 23 & 17 & 14,2 & 24,3 & 14,14 & 1,72 \\
\hline 20,72 & 1,41 & 25 & 17 & 15,9 & 26,7 & 14,09 & 1,68 \\
\hline 21,75 & 1,35 & 28 & 19 & 16,0 & 27,5 & 14,14 & 1,72 \\
\hline 22,66 & & 31 & 29 & 16,0 & 27,4 & 14,18 & 1,72 \\
\hline 23,84 & & 23 & & 17,7 & & 15,31 & 2,20 \\
\hline 24,73 & 1,71 & 27 & & 24,6 & & 15,21 & 2,22 \\
\hline 25,74 & 1,49 & 27 & & 27,7 & & 15,45 & 2,37 \\
\hline 26,67 & 1,55 & 28 & 19 & 13,8 & 28,6 & 15,01 & 2,08 \\
\hline 27,69 & 1,57 & 27 & 18 & 15,1 & 29,9 & 14,87 & 1,98 \\
\hline 28,86 & 1,68 & 29 & 17 & 15,1 & 30,6 & 14,92 & 2,04 \\
\hline 29,71 & 1,54 & 26 & 16 & 16,0 & 32,0 & 14,87 & 2,00 \\
\hline 30,77 & 1,58 & 27 & 16 & 17,6 & 35,8 & 14,92 & 2,04 \\
\hline 31,69 & 1,48 & 29 & 20 & 15,4 & 31,7 & 14,87 & 2,06 \\
\hline 32,77 & 1,51 & 28 & 26 & 10,5 & 22,2 & 15,06 & 2,12 \\
\hline 33,74 & 1,59 & 29 & 19 & 15,3 & 31,3 & 14,87 & 2,04 \\
\hline 34,72 & 1,63 & 31 & 27 & 10,4 & 22,0 & 15,11 & 2,12 \\
\hline 35,72 & 1,63 & 30 & 18 & 15,6 & 33,8 & 15,21 & 2,17 \\
\hline 36,81 & & & & 12,6 & 27,6 & 15,26 & 2,19 \\
\hline 37,65 & & & & 12,6 & & 15,36 & 2,20 \\
\hline 38,74 & & & & 20,7 & & 15,26 & 2,25 \\
\hline 39,71 & & & & 20,5 & & 15,84 & 2,55 \\
\hline 40,76 & & & & 13,1 & & & 2,11 \\
\hline 42,02 & 1,61 & 32 & 17 & 15,3 & 37,1 & 15,80 & 2,43 \\
\hline 42,94 & 1,47 & 29 & 18 & 14,2 & 32,7 & 15,60 & 2,31 \\
\hline 43,81 & 1,60 & 30 & 15 & 15,0 & 33,3 & 15,41 & 2,22 \\
\hline 44,66 & 1,71 & 33 & 18 & 14,2 & 30,6 & 15,31 & 2,16 \\
\hline
\end{tabular}


Tabela A.5 - Valor das principais variáveis ao longo do tempo, do ensaio E5 (Cont.) (notação de acordo com Lista de Símbolos)

\begin{tabular}{|c|c|c|c|c|c|c|c|}
\hline $\begin{array}{c}\mathrm{t} \\
\mathrm{dia}\end{array}$ & $\begin{array}{c}\mu \mathrm{Gln} \\
\mathrm{pmol} / \text { (cel.dia) }\end{array}$ & $\begin{array}{c}\mu \mathrm{P} \\
\mu \mathrm{UA} / \text { (cel.dia) }\end{array}$ & $\begin{array}{c}\mu \mathrm{P}[\text { biovol }] \\
\mu \mathrm{UA} /(\mathrm{pL} . \text { dia })\end{array}$ & $\begin{array}{c}\mathrm{X}_{\mathrm{C}} \\
\text { E6cel/mL }\end{array}$ & $\begin{array}{l}\text { biovol } \\
\mu \mathrm{L} / \mathrm{mL}\end{array}$ & $\begin{array}{c}\text { diâm. médio } \\
\mu \mathrm{m}\end{array}$ & $\begin{array}{l}\text { vol. médio } \\
\text { pL }\end{array}$ \\
\hline 45,68 & 1,62 & 31 & & 18,5 & & 15,80 & 2,48 \\
\hline 46,94 & 1,52 & 26 & 15 & 15,6 & 35,9 & 15,41 & 2,30 \\
\hline 47,72 & 1,33 & 29 & 13 & 17,9 & 43,0 & 15,70 & 2,40 \\
\hline 48,66 & 1,39 & 30 & 22 & 10,9 & 24,0 & 15,26 & 2,19 \\
\hline 49,68 & 1,59 & 32 & 17 & 12,9 & 30,7 & 15,70 & 2,38 \\
\hline 50,78 & 1,52 & 29 & 17 & 14,1 & 32,6 & 15,55 & 2,32 \\
\hline 52,10 & 1,70 & 32 & 18 & 12,4 & 28,2 & 15,55 & 2,28 \\
\hline 52,85 & 1,35 & & & 19,0 & & 15,89 & 2,53 \\
\hline 53,71 & 1,42 & 29 & & 19,7 & & 16,24 & 2,68 \\
\hline 54,71 & 1,52 & 31 & 18 & 13,9 & 29,6 & 15,16 & 2,13 \\
\hline 55,70 & 1,51 & 34 & 15 & 16,3 & 40,2 & 15,89 & 2,46 \\
\hline 56,78 & 1,62 & 35 & 17 & 15,9 & 36,3 & 15,45 & 2,28 \\
\hline 57,77 & 1,64 & 34 & 19 & 14,8 & 33,3 & 15,45 & 2,25 \\
\hline \begin{tabular}{|l|l|}
58,67 \\
\end{tabular} & 1,51 & 33 & & 12,1 & & 15,21 & 2,22 \\
\hline 59,86 & 1,52 & 33 & & 18,6 & & 15,80 & 2,53 \\
\hline 60,67 & 1,48 & 33 & & 24,3 & & 15,75 & 2,46 \\
\hline 61,94 & 1,46 & 35 & 19 & 15,6 & 35,5 & 15,55 & 2,28 \\
\hline 62,73 & 1,61 & 36 & 15 & 16,3 & 39,2 & 15,75 & 2,40 \\
\hline 63,72 & 1,73 & 40 & 19 & 14,3 & 33,2 & 15,60 & 2,32 \\
\hline 65,06 & 1,57 & 34 & 19 & 14,0 & 32,3 & 15,55 & 2,31 \\
\hline 65,79 & 1,47 & 37 & 15 & 16,7 & 42,9 & 15,94 & 2,57 \\
\hline 66,68 & 1,32 & 36 & & 24,0 & & 16,92 & 3,09 \\
\hline 67,67 & 1,60 & 35 & & 17,5 & & 16,33 & 2,70 \\
\hline 68,70 & & 42 & 20 & 14,5 & 36,6 & 15,99 & 2,53 \\
\hline 69,77 & 1,46 & 40 & 17 & 14,8 & 39,0 & 16,24 & 2,64 \\
\hline 70,76 & 1,54 & 39 & & 13,8 & & 15,80 & 2,42 \\
\hline 71,61 & & 46 & 28 & 9,5 & 18,2 & 14,62 & 1,92 \\
\hline 72,75 & 1,64 & 41 & & 11,9 & & 14,28 & 1,77 \\
\hline 73,67 & 1,37 & 32 & 23 & 13,7 & 24,7 & 14,33 & 1,81 \\
\hline 74,88 & 1,36 & 29 & & 23,7 & & 15,21 & 2,25 \\
\hline 75,68 & 1,53 & 29 & 18 & 12,8 & 22,9 & 14,33 & 1,80 \\
\hline 76,66 & 1,25 & 25 & 20 & 16,0 & 27,1 & 14,09 & 1,70 \\
\hline 77,66 & 1,36 & 25 & 19 & 14,6 & 24,8 & 14,09 & 1,69 \\
\hline 78,82 & 1,44 & 24 & 14 & 14,7 & 31,2 & 15,01 & 2,12 \\
\hline 79,70 & 1,34 & 24 & 21 & 13,2 & 22,0 & 14,04 & 1,67 \\
\hline 80,66 & 1,66 & 23 & 15 & 17,7 & 31,1 & 14,14 & 1,76 \\
\hline 81,98 & 1,61 & 24 & & 20,5 & & 14,82 & 1,99 \\
\hline 83,01 & 1,75 & 26 & 19 & 13,8 & 24,3 & 14,23 & 1,76 \\
\hline 83,90 & & 26 & & 11,0 & & 13,84 & 1,59 \\
\hline 84,69 & 1,79 & 25 & 18 & 14,2 & 25,3 & 14,33 & 1,78 \\
\hline 85,61 & 1,71 & 25 & 17 & 13,6 & 24,6 & 14,38 & 1,81 \\
\hline 86,63 & 1,83 & 23 & & 18,7 & & 14,58 & 1,93 \\
\hline 87,64 & 1,75 & 21 & 13 & 16,9 & 30,1 & 14,33 & 1,78 \\
\hline 88,83 & 1,90 & 24 & & 18,8 & & 14,82 & 2,01 \\
\hline 89,29 & & 25 & 18 & 12,2 & 20,7 & 14,14 & 1,69 \\
\hline 90,75 & & 22 & 20 & 10,5 & 19,6 & 14,43 & 1,86 \\
\hline
\end{tabular}


Tabela A.6 - Valor das principais variáveis ao longo do tempo, do ensaio E6 (notação de acordo com Lista de Símbolos)

\begin{tabular}{|c|c|c|c|c|c|c|c|c|c|c|c|}
\hline $\begin{array}{c}\mathrm{t} \\
\mathrm{dia}\end{array}$ & $\begin{array}{c}\text { osm } \\
\mathrm{mmol} / \mathrm{kg}\end{array}$ & $\begin{array}{l}\mathrm{Pm} \\
\mathrm{atm}\end{array}$ & $\begin{array}{l}\text { OD } \\
\%\end{array}$ & DO & $\begin{array}{c}\mathrm{X} \\
\text { E6cel } / \mathrm{mL}\end{array}$ & $\begin{array}{l}\text { viab } \\
\%\end{array}$ & $\begin{array}{l}\text { Glic } \\
\mathrm{mM}\end{array}$ & $\begin{array}{l}\text { Gln } \\
\text { mM }\end{array}$ & $\begin{array}{c}\mathrm{P} \\
\mathrm{UA} / \mathrm{mL}\end{array}$ & $\begin{array}{c}\text { Xref } \\
\text { E6cel/mL }\end{array}$ & $\begin{array}{c}\mu \\
1 / \mathrm{dia}\end{array}$ \\
\hline 0,18 & & 35 & 2,6 & 1,70 & 93 & 92,1 & 18 & 9,24 & 32 & & \\
\hline 0,64 & & 39 & 9,5 & 2,07 & 36 & 4,4 & 4,17 & 7,60 & 63 & 1,13 & 0,82 \\
\hline 1,63 & & 11 & 49,3 & 1,80 & 1,35 & 94,4 & 2,46 & 4,99 & 76 &, 35 & 00 \\
\hline 2,64 & & 0,14 & 61,0 & 2,63 & 2,00 & 94,8 & 1,87 & 3,67 & 77 & 1,65 & 0,56 \\
\hline 3,23 & & 0,28 & 49,4 & 4,30 & 2,36 & 89,4 & 1,39 & 2,30 & 67 & 2,18 & 0,42 \\
\hline 3,61 & & 0,38 & 49,9 & 4,36 & 2,97 & 91,4 & 2,70 & 3,95 & 87 & 2,65 & 0,61 \\
\hline 4,60 & & 0,22 & 49,9 & 5,96 & 5,00 & 96,2 & 2,67 & 4,24 & 123 & 3,90 & 0,51 \\
\hline 5,61 & & 0,29 & 49,6 & 8,97 & 9,00 & 95,7 & 2,44 & 4,02 & 138 & 6,81 & 0,65 \\
\hline 6,62 & & 0,47 & 49,8 & 13,94 & 13,50 & 93,1 & 1,94 & 2,42 & 16 & 11,10 & 0,49 \\
\hline 7,63 & & 67 & 49,2 &, 06 & 15 & 84,8 & 1,89 & 2,34 & 1 & 4,79 & 0,39 \\
\hline 8,65 & & 8 & 50,6 & 2,55 & 20 & 92,4 & 1,98 & 2,58 & & 0,34 & 1,06 \\
\hline 9,64 & & 33 & 49,7 & 9,10 & 23,93 & 94,8 & 2,76 & 4,14 & 13 & 4,56 & 0,65 \\
\hline 10,64 & & 0,54 & 49,9 & 16,64 & 21,85 & 94,9 & 3,12 & 4,75 & 150 & 22,87 & 0,60 \\
\hline 11,58 & & 0,51 & 52,4 & 16,40 & 24,50 & 98,8 & 3,07 & 5,24 & 152 & 23,15 & 0,55 \\
\hline 12,61 & & 0,46 & 49,1 & 14,99 & 22,10 & 96,9 & 3,11 & 5,13 & 141 & 23,28 & 0,56 \\
\hline 13,62 & & 0,42 & 51,0 & 14,02 & 20,50 & 96,7 & 3,28 & 5,16 & 100 & 21,29 & 0,51 \\
\hline 14,65 & & & 49,2 & 14,00 & 20,60 & 96,0 & 3,34 & 5,09 & 10 & 0,55 & 0,55 \\
\hline 15,63 & 322 & 0,43 & 49,4 & 14,00 & 20,45 & 96,1 & 3,33 & 5,01 & 9 & 20,52 & 0,44 \\
\hline 16,66 & 421 & 46 & 50,2 & 13,97 & 21,08 & 94,6 & 3,42 & 5,42 & 92 & 20,76 & 0,43 \\
\hline 17,16 & 475 & 5 & 50,0 & 14,00 & 21,18 & 93,9 & 3,55 & 5,43 & 7 & 21,13 & 0,26 \\
\hline 17,64 & 528 & 0,42 & 50,1 & 13,99 & 17,93 & 89,7 & 3,59 & 5,80 & 4 & 19,51 & 0,18 \\
\hline 18,14 & 620 & 0,40 & 50,0 & 13,81 & 18,77 & 87,6 & 3,82 & 6,24 & 4 & 18,35 & 0,39 \\
\hline 18,60 & 622 & 0,38 & 50,2 & 13,97 & 18,20 & 91,5 & 3,85 & 6,65 & 29 & 18,48 & 0,19 \\
\hline 19,62 & 624 & 0,11 & 50,3 & 19,96 & 13,00 & 92,9 & 4,13 & 7,46 & 33 & 15,45 & 0,02 \\
\hline 20,25 & 624 & 0,08 & 50,1 & 17,56 & 12,30 & 81,6 & 4,37 & 7,47 & 26 & 12,65 & 0,14 \\
\hline 20,63 & 488 & 0,05 & 50,2 & 20,40 & 11,60 & 95,1 & 4,41 & 8,06 & 3 & 11,95 & 0,00 \\
\hline 21,66 & 470 & 0,10 & 49,8 & 13,97 & 10,10 & 87,1 & 4,33 & 7,19 & 51 & 10,83 & 0,11 \\
\hline 22,63 & 320 & 0,15 & 49,9 & 15,59 & 8,83 & 94,1 & 4,40 & 6,92 & 69 & 9,45 & 0,00 \\
\hline
\end{tabular}


Tabela A.6 - Valor das principais variáveis ao longo do tempo, do ensaio E6 (Cont.) (notação de acordo com Lista de Símbolos)

\begin{tabular}{|c|c|c|c|c|c|c|c|}
\hline $\begin{array}{c}\mathrm{t} \\
\mathrm{dia}\end{array}$ & $\begin{array}{c}\mu \mathrm{Glic} \\
\mathrm{pmol} / \text { (cel.dia) }\end{array}$ & $\begin{array}{c}\mu \mathrm{Gln} \\
\mathrm{pmol} / \text { (cel.dia) }\end{array}$ & $\begin{array}{c}\mu \mathrm{P} \\
\mu \mathrm{UA} / \text { (cel.dia) }\end{array}$ & $\begin{array}{c}\mathrm{X}_{\mathrm{C}} \\
\text { E6cel/mL }\end{array}$ & $\begin{array}{l}\text { biovol } \\
\mu \mathrm{L} / \mathrm{mL}\end{array}$ & $\begin{array}{c}\text { diâm. médio } \\
\mu \mathrm{m}\end{array}$ & $\begin{array}{c}\text { vol. médio } \\
\text { pL }\end{array}$ \\
\hline 0,18 & & & 0 & 0,9 & 3,6 & 18,09 & 3,95 \\
\hline 0,64 & 1,93 & & 59 & & & & \\
\hline 1,63 & 1,26 & & 9 & 1,1 & 3,8 & 17,11 & 3,32 \\
\hline 2,64 & 1,66 & 1,32 & 33 & & & & \\
\hline 3,23 & 1,57 & 0,97 & 17 & 2,4 & 7,8 & 17,11 & 3,27 \\
\hline 3,61 & 1,88 & 7,49 & 71 & 2,9 & 11,3 & 17,90 & 3,95 \\
\hline 4,60 & 1,71 & 3,69 & 61 & 4,8 & 15,5 & 17,02 & 3,24 \\
\hline 5,61 & 1,53 & 2,97 & 66 & 8,9 & 27,3 & 16,77 & 3,07 \\
\hline 6,62 & 1,22 & 2,11 & 55 & 14,3 & 44,3 & 16,72 & 3,11 \\
\hline 7,63 & 1,57 & 3,29 & 72 & 19,9 & 55,1 & 16,14 & 2,77 \\
\hline 8,65 & 1,45 & 3,06 & 57 & 24,1 & 67,9 & 16,24 & 2,82 \\
\hline 9,64 & 1,45 & 3,14 & 63 & 24,3 & $\begin{array}{l}73,9 \\
\end{array}$ & 16,67 & 3,04 \\
\hline 10,64 & 1,25 & 2,69 & 63 & 19,4 & 61,2 & 16,77 & 3,16 \\
\hline 11,58 & 1,07 & 2,34 & 66 & 20,7 & 68,4 & 17,11 & 3,31 \\
\hline 12,61 & 1,11 & 2,12 & 67 & 19,1 & 59,4 & 16,77 & 3,12 \\
\hline 13,62 & 1,18 & 2,37 & 67 & 19,2 & 61,2 & 16,97 & 3,20 \\
\hline 14,65 & 1,13 & 2,41 & 50 & 15,6 & 47,3 & 16,67 & 3,04 \\
\hline 15,63 & 1,10 & 2,44 & 52 & 16,2 & 50,6 & 16,82 & 3,13 \\
\hline 16,66 & 1,08 & 2,45 & 47 & 17,2 & $\begin{array}{l}59,9 \\
\end{array}$ & 17,46 & 3,49 \\
\hline 17,16 & 1,02 & 2,21 & 43 & 17,1 & 69,1 & 18,38 & 4,05 \\
\hline 17,64 & 1,04 & 2,43 & 35 & 17,2 & 72,9 & 18,68 & 4,24 \\
\hline 18,14 & 1,07 & 2,38 & 25 & 13,5 & 51,2 & 17,90 & 3,78 \\
\hline 18,60 & 0,94 & 2,10 & 21 & 15,6 & 74,9 & 19,56 & 4,80 \\
\hline 19,62 & 1,10 & 2,25 & 19 & 12,1 & 60,0 & 19,80 & 4,96 \\
\hline 20,25 & 1,10 & 2,00 & 25 & 9,7 & 49,7 & 20,04 & 5,11 \\
\hline 20,63 & 0,98 & 2,24 & 23 & 9,7 & 45,4 & 19,46 & 4,68 \\
\hline 21,66 & 1,06 & 1,70 & 33 & 8,4 & 44,6 & 20,14 & 5,29 \\
\hline 22,63 & 1,28 & 2,92 & 56 & 8,1 & 40,6 & 19,56 & 5,03 \\
\hline
\end{tabular}


Tabela A.7 - Valor das variáveis utilizadas para o cálculo da velocidade específica de respiração $\left(\mathrm{Q}_{\mathrm{O} 2}\right)$, ao longo do tempo, do ensaio E3 (notação de acordo com Lista de Símbolos)

\begin{tabular}{|c|c|c|c|c|c|c|c|c|c|c|}
\hline $\begin{array}{c}\text { tempo } \\
\text { dia }\end{array}$ & $\begin{array}{l}\mathrm{V} \\
\mathrm{L}\end{array}$ & $\mathrm{ysCO} 2$ & $\mathrm{ysO} 2$ & ysN2 & $\begin{array}{c}\mathrm{QeAr} \\
\mathrm{mmol} / \mathrm{h}\end{array}$ & $\begin{array}{c}\mathrm{QeO} 2 \\
\mathrm{mmol} / \mathrm{h}\end{array}$ & $\begin{array}{c}\text { QeN2 } \\
\mathrm{mmol} / \mathrm{h}\end{array}$ & $\begin{array}{l}\mathrm{QeCO} 2 \\
\mathrm{mmol} / \mathrm{h}\end{array}$ & $\begin{array}{c}\mathrm{Qe} \\
\mathrm{mmol} / \mathrm{h}\end{array}$ & $\begin{array}{c}\text { OUR } \\
\mathrm{mg} /(\text { L.h })\end{array}$ \\
\hline 0,6 & 12,47 & 0,0465 & 0,2012 & 0,7545 & 1790 & 3 & 0 & 71 & 1864 & 5,8 \\
\hline 1,1 & 12,00 & 0,0493 & 0,2033 & 0,7499 & 1295 & 13 & 7 & 71 & 1387 & 4,4 \\
\hline 1,2 & 12,00 & 0,0583 & 0,2012 & 0,7429 & 1196 & 16 & 0 & 71 & 1283 & 20,4 \\
\hline 1,9 & 12,00 & 0,0384 & 0,2055 & 0,7586 & 2635 & 15 & 30 & 71 & 2751 & 1,2 \\
\hline 3,6 & 12,00 & 0,0337 & 0,5664 & 0,4012 & 1236 & 1165 & 10 & 46 & 2458 & 83,8 \\
\hline 4,6 & 12,00 & 0,0147 & 0,7084 & 0,2777 & 1239 & 2287 & 25 & 0 & 3551 & 80,8 \\
\hline 5,0 & 11,97 & 0,0143 & 0,7341 & 0,2525 & 1235 & 2696 & 84 & 0 & 4015 & 17,0 \\
\hline 5,6 & 12,00 & 0,0113 & 0,8120 & 0,1772 & 1241 & 4439 & 30 & 0 & 5710 & 165,3 \\
\hline 6,1 & 12,00 & 0,0114 & 0,8190 & 0,1702 & 1234 & 4589 & 50 & 0 & 5872 & 99,2 \\
\hline 6,6 & 12,00 & 0,0145 & 0,9780 & 0,0076 & 5 & 4629 & 11 & 0 & 4645 & 231,8 \\
\hline 7,2 & 11,99 & 0,0231 & 0,9700 & 0,0071 & 5 & 2478 & 30 & 0 & 2513 & 110,6 \\
\hline 8,0 & 11,99 & 0,0183 & 0,9744 & 0,0073 & 5 & 3201 & 18 & 0 & 3224 & 161,5 \\
\hline 8,2 & 11,99 & 0,0175 & 0,9750 & 0,0073 & 1 & 3364 & 0 & 0 & 3366 & 221,4 \\
\hline 11,8 & 12,00 & 0,0228 & 0,9703 & 0,0070 & 4 & 2423 & 18 & 0 & 2445 & 138,1 \\
\hline 12,1 & 11,99 & 0,0216 & 0,9711 & 0,0074 & 7 & 2687 & 10 & 0 & 2704 & 165,0 \\
\hline 12,6 & 12,00 & 0,0207 & 0,9720 & 0,0073 & 3 & 2713 & 0 & 0 & 2716 & 196,6 \\
\hline 12,8 & 12,00 & 0,0217 & 0,9710 & 0,0073 & 7 & 2604 & 27 & 0 & 2637 & 118,3 \\
\hline 13,0 & 12,00 & 0,0202 & 0,9725 & 0,0073 & 4 & 2713 & 0 & 0 & 2716 & 191,4 \\
\hline 13,8 & 12,00 & 0,0559 & 0,9310 & 0,0135 & 4 & 402 & 4 & 0 & 409 & 57,6 \\
\hline 14,2 & 11,99 & 0,0174 & 0,6740 & 0,3090 & 1237 & 1930 & 0 & 0 & 3167 & 143,6 \\
\hline 14,6 & 12,00 & 0,0164 & 0,6753 & 0,3094 & 1234 & 1921 & 0 & 0 & 3155 & 128,6 \\
\hline 15,0 & 12,00 & 0,0164 & 0,6798 & 0,3045 & 1235 & 1964 & 0 & 0 & 3199 & 126,0 \\
\hline 15,9 & 11,99 & 0,0169 & 0,6674 & 0,3169 & 1234 & 1781 & 8 & 0 & 3024 & 56,2 \\
\hline 17,0 & 11,99 & 0,0171 & 0,6642 & 0,3122 & 1238 & 1847 & 17 & 0 & 3103 & 121,1 \\
\hline 17,6 & 12,00 & 0,0158 & 0,6981 & 0,2870 & 1235 & 2174 & 0 & 0 & 3409 & 139,2 \\
\hline 17,9 & 11,99 & 0,0175 & 0,6455 & 0,3383 & 1240 & 1651 & 19 & 0 & 2909 & 86,1 \\
\hline 19,0 & 12,00 & 0,0183 & 0,6503 & 0,3326 & 1237 & 1676 & 6 & 0 & 2918 & 97,3 \\
\hline 19,6 & 12,00 & 0,0173 & 0,6538 & 0,3300 & 1232 & 1667 & 0 & 0 & 2899 & 77,5 \\
\hline 20,6 & 11,99 & 0,0160 & 0,6945 & 0,2904 & 1232 & 2042 & 0 & 0 & 3274 & 68,3 \\
\hline 21,6 & 12,00 & 0,0139 & 0,7346 & 0,2522 & 1236 & 2654 & 0 & 0 & 3890 & 146,1 \\
\hline 21,9 & 11,99 & 0,0140 & 0,7374 & 0,2495 & 1237 & 2697 & 0 & 0 & 3934 & 145,2 \\
\hline 22,9 & 11,98 & 0,0135 & 0,7489 & 0,2384 & 1234 & 2874 & 0 & 0 & 4108 & 147,3 \\
\hline 24,6 & 12,00 & 0,0124 & 0,7719 & 0,2148 & 1235 & 3352 & 0 & 0 & 4587 & 185,1 \\
\hline 25,6 & 11,99 & 0,0141 & 0,7325 & 0,2541 & 1239 & 2613 & 0 & 0 & 3852 & 134,5 \\
\hline 26,6 & 11,97 & 0,0099 & 0,9205 & 0,0699 & 486 & 5615 & 0 & 0 & 6101 & 269,0 \\
\hline 27,9 & 11,99 & 0,0084 & 0,9326 & 0,0590 & 483 & 7063 & 0 & 0 & 7546 & 337,5 \\
\hline 28,6 & 12,00 & 0,0077 & 0,9390 & 0,0534 & 488 & 7987 & 0 & 0 & 8475 & 348,8 \\
\hline 28,9 & 11,99 & 0,0073 & 0,9415 & 0,0512 & 484 & 8375 & 0 & 0 & 8859 & 361,8 \\
\hline 31,6 & 11,99 & 0,0066 & 0,9490 & 0,0446 & 484 & 10018 & 0 & 0 & 10503 & 406,6 \\
\hline 32,6 & 11,99 & 0,0079 & 0,9375 & 0,0540 & 486 & 7579 & 0 & 0 & 8065 & 319,4 \\
\hline 33,6 & 12,01 & 0,0101 & 0,9187 & 0,0713 & 482 & 5507 & 0 & 0 & 5989 & 281,1 \\
\hline 34,0 & 12,01 & 0,0099 & 0,9199 & 0,0704 & 486 & 5593 & 0 & 0 & 6079 & 273,2 \\
\hline 34,6 & 12,01 & 0,0099 & 0,9196 & 0,0706 & 486 & 5660 & 0 & 0 & 6146 & 292,3 \\
\hline 35,6 & 12,01 & 0,0095 & 0,9235 & 0,0670 & 484 & 5823 & 0 & 0 & 6308 & 264,6 \\
\hline 40,7 & 12,00 & 0,0113 & 0,9060 & 0,0829 & 483 & 4571 & 0 & 0 & 5054 & 248,0 \\
\hline 42,6 & 12,01 & 0,0094 & 0,9268 & 0,0639 & 484 & 6204 & 0 & 0 & 6689 & 283,4 \\
\hline 42,9 & 12,01 & 0,0092 & 0,9277 & 0,0632 & 485 & 6304 & 0 & 0 & 6789 & 285,1 \\
\hline 43,0 & 12,01 & 0,0091 & 0,9283 & 0,0620 & 485 & 6420 & 0 & 0 & 6905 & 296,7 \\
\hline 44,9 & 12,01 & 0,0072 & 0,9431 & 0,0499 & 485 & 8658 & 0 & 0 & 9143 & 363,6 \\
\hline 45,9 & 12,01 & 0,0082 & 0,9361 & 0,0559 & 488 & 7422 & 0 & 0 & 7910 & 317,9 \\
\hline
\end{tabular}


Tabela A.7 - Valor das variáveis utilizadas para o cálculo da velocidade específica de respiração $\left(\mathrm{Q}_{\mathrm{O} 2}\right)$, ao longo do tempo, do ensaio E3 (Cont.) (notação de acordo com Lista de Símbolos)

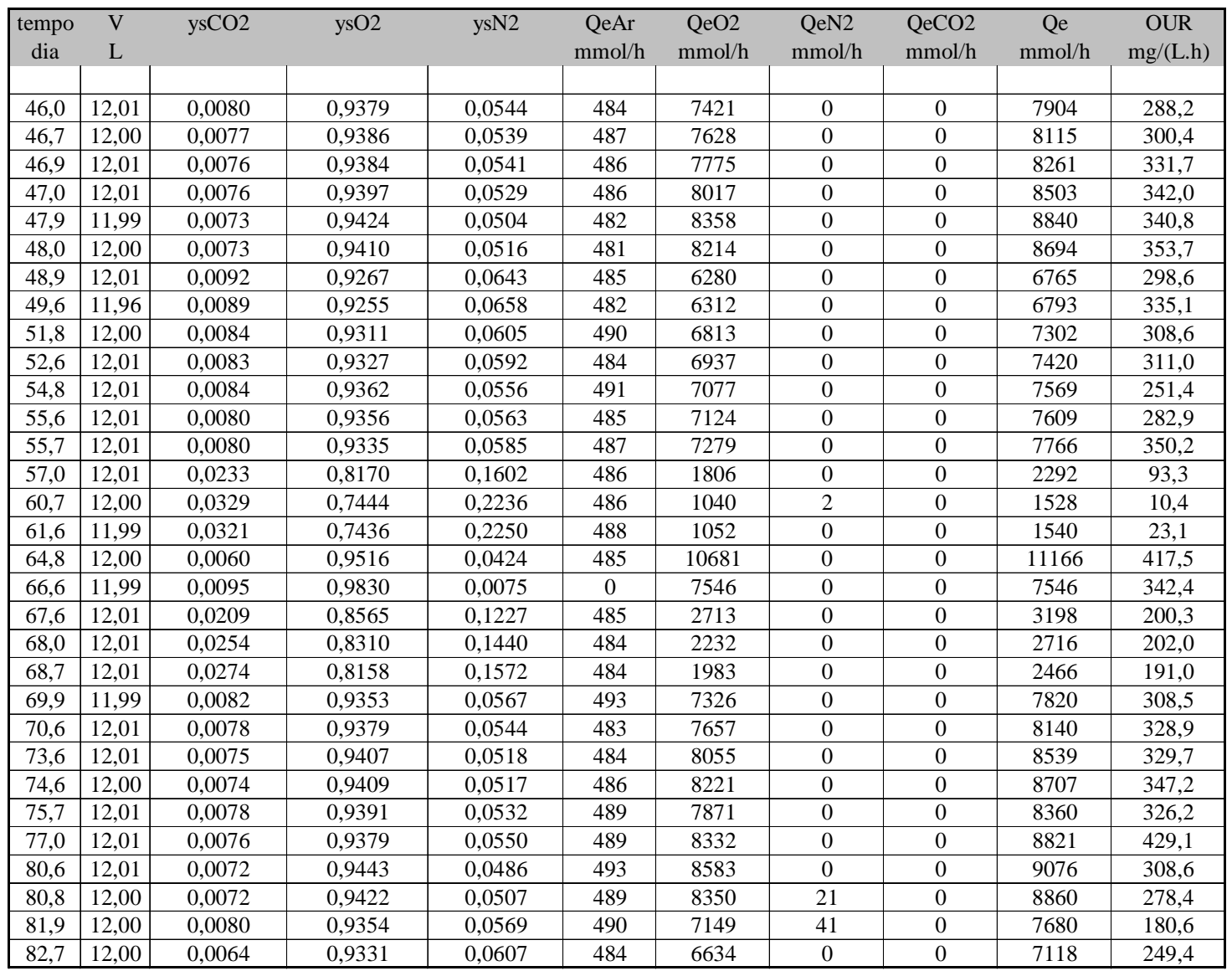

